The 'how to' on incentivising farmers to adapt Fusarium mycotoxin management of wheat

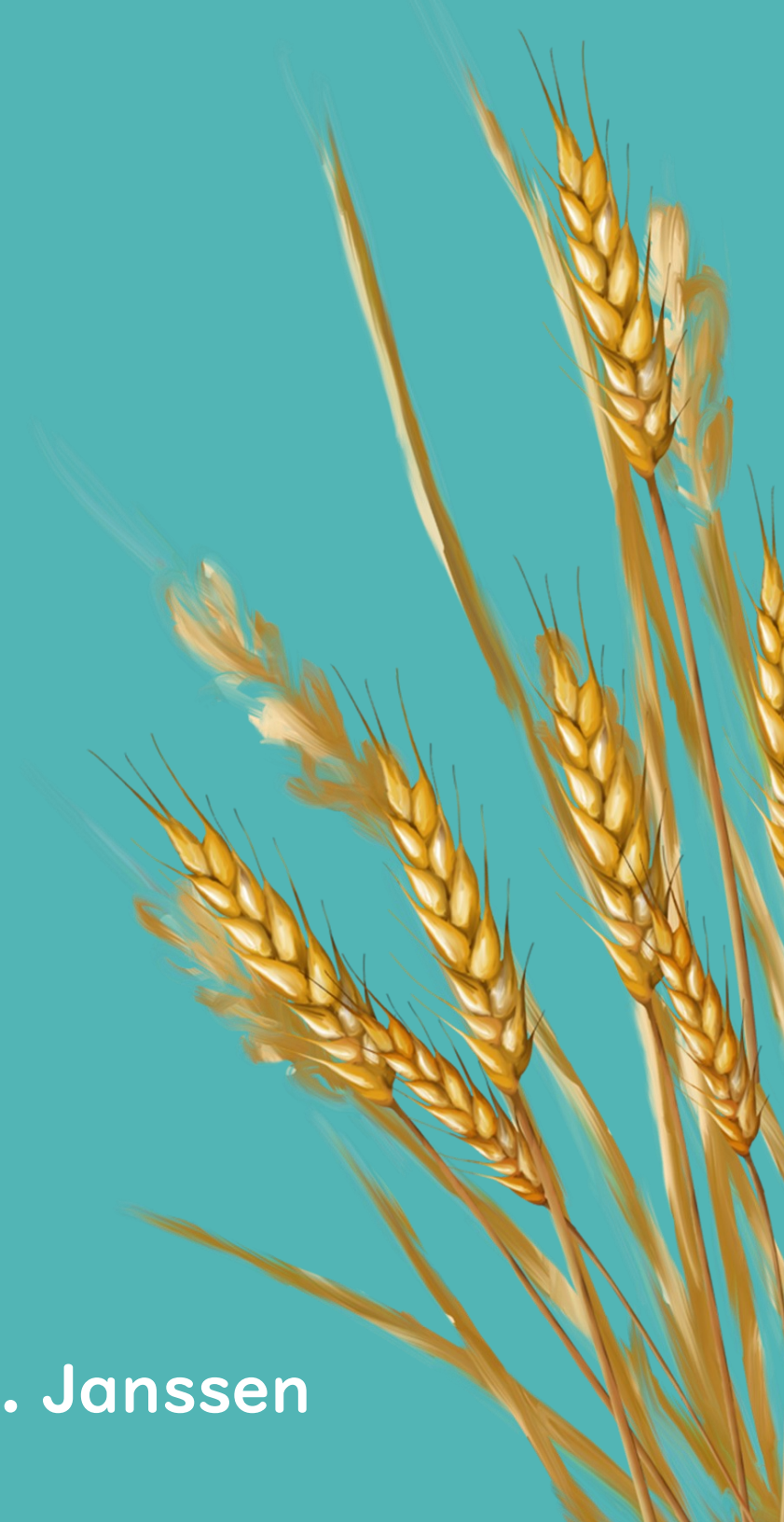

Esmée M. Janssen 


\section{Propositions}

1. Incentive design for reduction of mycotoxins in wheat must account for farm and farmer characteristics.

(this thesis)

2. Reducing Fusarium species mycotoxins in wheat can be both effective and sustainable.

(this thesis)

3. Governmental policy on human health issues must be based on science only.

4. Raising children gender neutral hampers their social and emotional development.

5. The minimum legal drinking age must be raised to 25 years.

6. PhD candidates should get cats, not have babies.

Propositions belonging to the thesis, entitled

“The 'how to' on incentivising farmers to adapt Fusarium mycotoxin management of wheat"

Esmée M. Janssen

Wageningen, 16 December 2020 
The 'how to' on incentivising farmers to adapt Fusarium mycotoxin management of wheat

Esmée M. Janssen 


\section{Thesis committee}

\section{Promotors}

Prof. Dr A.G.J.M. (Alfons) Oude Lansink

Professor of Business Economics

Wageningen University \& Research

Prof. Dr H.J. (Ine) van der Fels-Klerx

Special Professor of Food Safety Economics

Wageningen University \& Research

\section{Co-promotor}

Dr M.C.M. (Monique) Mourits

Associate Professor, Business Economics Group

Wageningen University \& Research

\section{Other members}

Prof Dr C. (Cees) Leeuwis, Wageningen University \& Research

Dr T. (Thomas) Börjesson, Agroväst Livsmedel AB, Skara, Sweden

Dr C.C. (Caroline) de Lauwere, Wageningen University \& Research

Dr A. (Annemarie) Breukers, LTO, Den Haag

This research was conducted under the auspices of the Wageningen School of Social Sciences (WASS). 


\title{
The 'how to' on incentivising farmers to adapt Fusarium mycotoxin management of wheat
}

\author{
Esmée M. Janssen
}

\section{Thesis}

submitted in fulfilment of the requirements for the degree of doctor at Wageningen University

by the authority of the Rector Magnificus,

Prof. Dr A.P.J. Mol, in the presence of the

Thesis Committee appointed by the Academic Board

to be defended in public

on Wednesday 16 December 2020

at 11 a.m. in the Aula. 
Esmée M. Janssen

The 'how to' on incentivising farmers to adapt Fusarium mycotoxin management of wheat 154 pages

PhD thesis, Wageningen University, the Netherlands (2020)

With references, with summary in English and Dutch

ISBN: 978-94-6395-539-3

DOI: https://doi.org/10.18174/530936 


\section{Abstract}

Fusarium spp. infection in wheat can lead to the crop disease Fusarium Head Blight (FHB) and Fusarium damaged kernels (FDK), resulting in reduced wheat yield, loss of quality of the kernels and contamination of kernels with mycotoxins. Whereas FHB is a direct issue for the farmer, the presence of mycotoxins is also a problem downstream the cereal production chain posing health risks for animals and humans. Because mycotoxins are difficult if not impossible to remove further along the chain, agronomic management is mainly focused on reducing initial fungal infection and production of mycotoxins in the field by farmers. The objective of this thesis was to investigate how to incentivise farmers to adapt their agronomic management to reduce FHB and mycotoxin contamination in wheat. First, a literature review was performed to obtain up-to-date knowledge on Fusarium spp. infection, FHB and mycotoxin contamination of wheat and to identify effective agronomic management measures to reduce FHB and mycotoxins. Second, via an online questionnaire, information on farm and farmer characteristics, the pre-harvest measures implemented by the farmers, and farmers' intention to adapt their agronomic management approach under specified incentive mechanisms was collected from wheat farmers in the Netherlands, Italy, Serbia and the United Kingdom. The extent to which Dutch farm and farmer characteristics explained the implementation of preharvest measures was analysed with probit models. Results showed that most farmers applied six or more different measures against Fusarium spp. infection and mycotoxin contamination in wheat and that the use of each pre-harvest measure is related to at least one other measure. The study on intention by Theory of Planned Behaviour showed that forty-six percent of the Dutch farmers had a positive intention to change their management in the next 5 years. Strengthening their beliefs - by demonstrating that a change in management will result in a higher wheat yield quantity and quality and safety (lower mycotoxin levels) - will result in a stronger attitude and, subsequently, a higher intention to change agronomic management. For Dutch farmers, interventions to strengthen these beliefs should preferably go by the most important referents for social norms, which were - in this study - the buyers and the farmer cooperatives. Lastly, incentives that could stimulate European farmers to adapt their agronomic management to reduce FHB and mycotoxins in wheat were identified. Bayesian Network modelling was applied to estimate the probability that farmers would adapt their current management practices under different incentives. The current intention of European wheat farmers to adapt their agronomic approach to reduce Fusarium spp. infection was positive for $51 \%$ of the farmers, although this percentage varied between the four countries. Results showed that most of the farmers would adapt their current management practices under the incentives 'paid extra when wheat contains low levels of mycotoxins' and under the incentive 'wheat is tested for the presence of mycotoxins for free'. Results of this thesis can support policy makers in developing more tailor-made incentives to incentivise different groups of farmers to adapt their FHB and mycotoxin management.

Keywords: mycotoxin, wheat, farmer, agronomic management, Fusarium, intention 


\section{Table of Contents}

Abstract $\quad \mathrm{v}$

List of Tables viii

List of Figures ix

Chapter 1 General Introduction 11

Chapter 2 Fusarium infection and trichothecenes in barley and its comparison 17 with wheat

Chapter $3 \quad$ Pre-harvest measures against Fusarium species infection and $\quad 35$ related mycotoxins implemented by Dutch wheat farmers

Chapter $4 \quad$ Factors underlying Dutch farmers' intentions to adapt their 57 agronomic management to reduce Fusarium species infection in wheat

Chapter 5 Incentives to stimulate European wheat farmers to adapt their Fusarium species mycotoxin management

$\begin{array}{lll}\text { Chapter } 6 \quad \text { General Discussion } & 109\end{array}$

$\begin{array}{ll}\text { References } & 125\end{array}$

$\begin{array}{ll}\text { English Summary } & 140\end{array}$

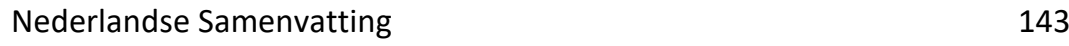

$\begin{array}{ll}\text { Acknowledgements } & 149\end{array}$

$\begin{array}{ll}\text { About the Author } & 150\end{array}$ 


\section{List of Tables}

2.1 Comparison of Fusarium infection and mycotoxins between barley and wheat.. 29

3.1 Uni- and bivariate probit model variables and their descriptive statistics. 43

3.2 Implementation rate of pre-harvest measures against Fusarium spp. infection by 46

3.3 Correlation coefficients between different pre-harvest measures taking into account 48

3.4 Marginal effects of farm and farmer characteristics on the use of pre-harvest 49 measures as determined by univariate probit models.

A.3.1 Selected pre-harvest measures, and their related question and answer format in the 54 questionnaire.

A.3.2 Selected farm and farmer characteristics, and their related question and answer 55 format in the questionnaire.

4.1 Theory of Planned Behaviour (TPB) questionnaire questions and answer formats for intention (INT) and behavioural constructs attitude (ATT), perceived behavioural control (PBC), and social norm (SN).

4.2 Theory of planned behaviour beliefs questionnaire questions and answer formats for attitude (ATT) beliefs, perceived behavioural control (PBC) beliefs, and social norm (SN) beliefs.

4.3 Average score for attitudinal (ATT) beliefs and the percentage of farmers for which the belief is salient $(n=92)$.

4.4 Average score for perceived behavioural control (PBC) beliefs and the percentage of farmers for which the belief is salient $(n=85)$.

4.5 Average score social norm (SN) beliefs and the percentage of farmers for which the 70 belief is salient $(n=83)$.

4.6 Correlation coefficients between the ATT belief score (b) and the ATT construct, and between the four ATT multiplicative composites (uni-bi, uni-uni, bi-uni, bi-bi), and the ATT construct.

4.7 Correlation coefficients between the PBC belief score (b) and the PBC construct, and between the four PBC multiplicative composites (uni-bi, uni-uni, bi-uni, bi-bi), and the PBC construct.

4.8 Correlation coefficients between the SN belief score (b) and the SN construct, and between the four SN multiplicative composites (bi-uni, uni-uni, uni-bi, bi-bi), and the SN construct.

5.1 Question and answer format of the questionnaire for intention.

Question and answer format of the questionnaire for selected incentives.

5.3 Question and answer format of the questionnaire for farm and farmer characteristics, in addition to their defined categories per variable and resulting percentage of farmers per category.

5.4 Conditional probabilities of farm and farmer characteristics of farmers with a decreased (Dec), increased (Inc) or unaltered (Una) intention under the incentives 'paid extra', 'no delivery', 'free test', 'insurance', 'contract'. a

5.5 Probabilities of three selected main farm and farmer characteristics per country of farmers with a decreased (Dec) and increased (Inc) intention under the incentive 'paid extra'.a

A.5.1 Conditional probabilities (\%) of farm and farmer characteristics of farmers with a negative, positive and neutral intention (INT).

A.5.2 Conditional probabilities (\%) of farm and farmer characteristics of farmers with a decreased, increased or unaltered intention under eight incentives. 


\section{List of Figures}

1.1 Outline of the thesis and link between the chapters. 15

3.1 Percentage of farmers per total number of pre-harvest measures taken per farmer. 46

3.2 Percentage of Dutch farmers $(n=103)$ who used (part of) the benchmark approach 51 consisting of fungicide use during flowering, a Fusarium resistant variety, and ploughing or crop rotation.

4.1 Theory of planned behaviour (Ajzen 1991; Francis 2004). 61

4.2 IIntention (INT) of farmers towards adapting their Fusarium spp. management, and 66 their underlying attitude (ATT), perceived behavioural control (PBC), and social norm (SN) (\% negative, neutral, or positive)..

4.3 Regression and correlation coefficients of the TPB analysis. Regression coefficients (black arrows) of attitude (ATT), perceived behaviour control (PBC), and social norm (SN) as independent variables and intention as the dependent variable. Correlation coefficients (grey arrows) between the ATT, PCB and SN beliefs and their respective behavioural construct.

${ }^{1}$ Multiplicative composite of the beliefs reflecting the questionnaire answer scale: uni$\mathrm{bi}=$ unipolar belief score $\times$ bipolar outcome score for ATT and PBC beliefs and bi-uni $=$ bipolar belief score $\times$ bipolar outcome score for $\mathrm{SN}$ referents.

5.1 The percentage of wheat farmers from Italy (IT), the Netherlands (NL), Serbia (RS), and the United Kingdom (UK) and the combination of the four countries (Eur) with a negative, neutral or positive intention to adapt their current agronomic management to reduce Fusarium spp. infection and related mycotoxin contamination.

5.2 The percentage of wheat farmers from Italy (IT), the Netherlands (NL), Serbia (RS), and the United Kingdom (UK) and the combination of the four countries (Eur) who were incentivised (i.e. had an increased intention) to adapt their current agronomic management to reduce Fusarium spp. infection and related mycotoxin contamination.

5.3 Validation of the nine Bayesian Network models showing the correctly predicted dependent variables for the training and test set.

5.4 Directed Acyclic Graph of the Bayesian Network model for intention (INT) representing the probabilities per variable - black arrows indicates a connection between the farm and farmer characteristics and the grey arrows indicate the connection with the conditioned variable INT.

5.5 Directed Acyclic Graph of the Bayesian Network model for intention (INT) for farmers with a positive intention representing the probabilities per variable - black arrows indicates a connection between the farm and farmer characteristics and the grey arrows indicate the connection with the conditioned variable INT.

5.6 Directed Acyclic Graph of the Bayesian Network model for intention (INT) for farmers with a negative intention representing the probabilities per variable - black arrows indicates a connection between the farm and farmer characteristics and the grey arrows indicate the connection with the conditioned variable INT.

5.7 The probability of typical wheat farmers not incentivised by 'paid extra' having an increased intention (are incentivised) under the alternative incentives to adapt their current agronomic management to reduce Fusarium spp. infection and related mycotoxin contamination. (IT= Italy, $\mathrm{NL}=$ the Netherlands, $\mathrm{RS}=$ Serbia, $\mathrm{UK}=$ United Kingdom, Eur $=\mathrm{IT}+\mathrm{NL}+\mathrm{RA}+\mathrm{UK})$.

5.8 The probability of wheat farmers from Italy (IT), the Netherlands (NL), Serbia (RS), and the United Kingdom (UK) and the combination of the four countries (Eur) who did not use the benchmark approach to have an increased intention (are incentivised) under each of the eight incentives.

6.1 Overview of the connections between the variables obtained by the questionnaire and analysed in Chapter 3 (C3), Chapter 4 (C4) and Chapter 5 (C5). 


$$
4
$$




\section{Chapter 1}

General Introduction 


\subsection{Background}

The small-grain cereal wheat is grown in temperate climate regions including Northwest Europe and Canada. Wheat holds the largest area of harvested cereal crops in the EU. Wheat is cultivated on 26 million hectares resulting in a production of 152 million tonnes a year, and is mainly used for feed and food products for further processing, like bread (FAO 2015; FAO 2016).

In wheat, infection with Fusarium spp., a fungus, can lead to the crop disease Fusarium Head Blight (FHB) and Fusarium damaged kernels (FDK), resulting in reduced yield, loss of quality of the kernels and a lower percentage of seed germination (Parry et al. 1995; Tekauz et al. 200o). This can lead to costs related to yield loss and revenue forgone for the farmer (Wilson et al. 2018). Fusarium spp. spores can survive in the soil, crop residues or grain seeds, and reach the spike via wind or water from rain or irrigation (Osborne and Stein 2007; Parry et al. 1995). During warm and moist weather conditions the spores germinate, and the fungus infects the plant. Most Fusarium spp. can produce mycotoxins, fungal secondary metabolites, like zearalenone (ZEA), fumonisins and trichothecenes like deoxynivalenol (DON), T-2 toxin and HT-2 toxin. DON is the most frequently studied mycotoxin in wheat and it is suggested that this toxin may act as virulence factors and increase the aggressiveness of the fungus in small-grain cereals (Bai and Shaner 2004; Boddu et al. 2007; Jansen et al. 2005; Langevin et al. 2004; Maier et al. 2006; Shah et al. 2017). Weather conditions also determine selection of Fusarium spp. (Doohan et al. 2003) and therefore presence of certain Fusarium spp. differ per region and climate conditions (Bakker et al. 2018; Moretti et al. 2019). For example, F. graminearum is the predominant Fusarium spp. in warmer regions, whereas the predominant species in cooler regions are $F$. culmorum and $F$. avenaceum (Champeil et al. 2004). Since not all Fusarium spp. produce the same mycotoxins, the type of mycotoxin present is also climate and weather dependent (Van der Fels-Klerx et al. 2012b).

Mycotoxins can co-occur; for example, the concentrations of DON and ZEA are positively correlated in wheat and barley (Edwards 2009b). The presence of mycotoxins is monitored in raw agricultural commodities, as well as in feed and food, because mycotoxins transfer through processing steps (Kaushik 2015; Nielsen et al. 2014; Oliveira et al. 2012; Oliveira et al. 2013; Urrea et al. 2005). For example, DON is very persistent during processing; it survives many processing steps and is found in multiple endproducts like flour, bread and beer (EFSA, 2013; Varga et al., 2013). In general, DON is found in around $60 \%$ of the food samples tested and ZEA in 8o\% (Eskola et al. 2019).

Some mycotoxins produced by Fusarium spp. can cause adverse health effects in humans and animals upon consumption (Placinta et al. 1999). DON can cause acute and chronic adverse effects on the gastro-intestinal tract, the nervous system, and the immune system in animals and humans (Maresca 2013). T-2/HT-2 toxins are the most potent trichothecenes and exert immunotoxic, haematotoxic, genotoxic and neurotoxic effects (EFSA 2011a). ZEA exerts estrogenic effects (EFSA 2011b). Because of health effects, tolerable daily limits are set for these mycotoxins. DON has a Tolerable Daily Intake (TDI) of $1 \mu \mathrm{g} / \mathrm{kg}$ bw per day (EFSA 2013; JECFA 2010; SCF 2002). The group TDI for the sum of T-2 toxin and HT-2 toxin is $0.02 \mu \mathrm{g} / \mathrm{kg}$ body weight per day (EFSA 2017a) and the 
TDI for ZEA is $0.25 \mu \mathrm{g} / \mathrm{kg}$ bw (EFSA 2011b). Exposure assessments (De Boevre et al. 2013; EFSA 2013; EFSA 2017a; Janssen et al. 2015; Sirot et al. 2013) show that the European human intake of DON is already close to the TDI (JECFA 2010; SCF 2002) for some (sub) populations, like young population groups. In almost all population groups, the main contributor to the total chronic exposure of DON was "bread and rolls" representing between 30.9 and $72.3 \%$ of the total exposure. In a few population groups, the main contributor was either "raw pasta", representing up to $63.8 \%$ of the total exposure, "fine bakery wares", representing up to $43.1 \%$ of the total exposure, or "grain milling products" representing up to $76.9 \%$ of the total exposure. Human chronic dietary exposure to T2/HT-2 toxins may exceed their respective TDI in some sub-populations, in particular young population groups (EFSA 2017a). The exposure to ZEA is mainly through grains and grain milling products, bread and fine bakery wares, which made the largest contribution to the estimated ZEA exposures. However, the exposure is below the TDI in all sub populations (EFSA 2011b).

Legal maximum limits for the presence of mycotoxins in feed and food have been set in Europe and other parts of the world to protect animal and human health (Alim et al. 2016). In the EU, there are legal limits for DON and ZEA in wheat and product derived thereof (EC No 1881/2006 (EC 2006a)) and recommended limits for T-2/HT-2 (2006/576/EC (EC 2006a)). Legislative limits for Fumonisins are only set for maize and maize-based products (EC 2006a). Feed guidance levels for DON, ZEA and Fumonisins are set in EC No 2006/576/EC (EC 2006a); however, often lower limits than the legal maximum limits are used in practices, because of health effects on for example pigs. In the EU, $20 \%$ of materials sampled at source and less than $10 \%$ of food-grade grain samples are contaminated above the regulatory EU and Codex limit (Eskola et al. 2019). Contamination above legal limits results in discharge of batches (waste).

\subsection{Problem statement}

Fusarium spp. infection in wheat can lead to yield losses and a decrease in food quality and safety. FHB and mycotoxin contamination still occurs, implying that the agricultural as well as food and feed industries and consumers remain vulnerable to fungi and subsequently mycotoxin contamination.

Climate and local weather are major influences in Fusarium infection and farmers cope with this risk through their agronomic management (Moretti et al. 2019). Reduction of fungal infection and mycotoxin production can be achieved by applying agronomic management measures like pre-harvest control and preventive measures, such as the use of Fusarium resistant varieties and the application of fungicides (Kabak et al. 2006; Parry et al. 1995; Van der Fels-Klerx et al. 2010; Wegulo et al. 2015). Because mycotoxins are difficult if not impossible to remove further along the chain, agronomic management is mainly focused on reducing initial fungal infection and production of mycotoxins in the field by farmers.

Whereas FHB is a direct issue for the farmer, the presence of mycotoxins is also a problem downstream the cereal production chain posing health risks for animals and humans. Although many studies showed that implementing agronomic management measures can be effective to reduce FHB and mycotoxins, hardly any attention in given to the actual implementation of measures by farmers and opportunities to improve their 
agronomic management. Since effective agronomic management along the supply chain depends on the implementation of agronomic management measures by farmers, it is important to understand the behaviour of farmers regarding their agronomic management. Current literature is lacking on designing (targeted) incentives to incentivise wheat farmers to adapt their agronomic management to reduce FHB and mycotoxins.

\subsection{Objective of the thesis}

The objective of this thesis was to investigate how to incentivise farmers to adapt their agronomic management to reduce Fusarium spp. infection and mycotoxin contamination in wheat. This objective was divided into four sub-objectives:

i. Identify effective agronomic management measures to reduce Fusarium infection and mycotoxin contamination in small-grain cereals by farmers.

ii. Investigate which agronomic management measures Dutch wheat farmers currently apply against Fusarium infection and mycotoxin contamination and to examine which farm and farmer characteristics explain the implementation of these measures.

iii. Explore the intention and underlying behavioural constructs and beliefs of Dutch wheat farmers to adapt their future agronomic management to reduce Fusarium infection and mycotoxin contamination in wheat.

iv. Assess the intention of different types of European wheat farmers to change their agronomic management for prevention and control of Fusarium infection and mycotoxin contamination in wheat under different incentives.

\subsection{Outline of the thesis}

This thesis consists of a general introduction (Chapter 1), followed by four research chapters (Chapters 2-5) each addressing one sub-objective, and ends with a general discussion in which a synthesis of the results is presented (Chapter 6). Figure 1.1 shows the outline of the thesis and link between the chapters.

Chapter 2 presents a literature review to investigate Fusarium spp. infection and identifies effective agronomic management to reduce Fusarium infection and mycotoxin contamination. This chapter shows the choices in agronomic management measures farmers can make.

Chapter 3 identifies which agronomic management measures Dutch wheat farmers currently apply against Fusarium spp. infection and mycotoxin contamination and examines which farm and farmer characteristics explain the implementation of these measures. This chapter investigates whether there is scope for improvement regarding the implementation of agronomic management measures and which farm and farmer types are or are not related to implementation of these measures. For this purpose, Probit models based on survey data of farmers were developed.

Chapter 4 explores the intention and underlying behavioural constructs and beliefs of Dutch wheat farmers to adapt their future agronomic management to reduce FHB and mycotoxins in wheat. Survey data based on the Theory of Planned behaviour (TPB) were 
used to provide insight in the intention of Dutch wheat farmers to adapt their management and shows which beliefs should be used to incentivise a change in their mycotoxin management and through which channels.

Chapter 5 assesses the current intention under different incentives of several types of European wheat farmers from Italy, the Netherlands, Serbia and the United Kingdom to adapt their agronomic management for prevention and control of Fusarium spp. infection and related mycotoxins. Several Bayesian network models were developed to get insight into the relation between farm and farmer characteristics and their altered intention under several incentives.

Chapter 6 discusses the main findings, assesses the data and methods, and provides an outline of the policy and business implications and the main conclusions of this thesis.

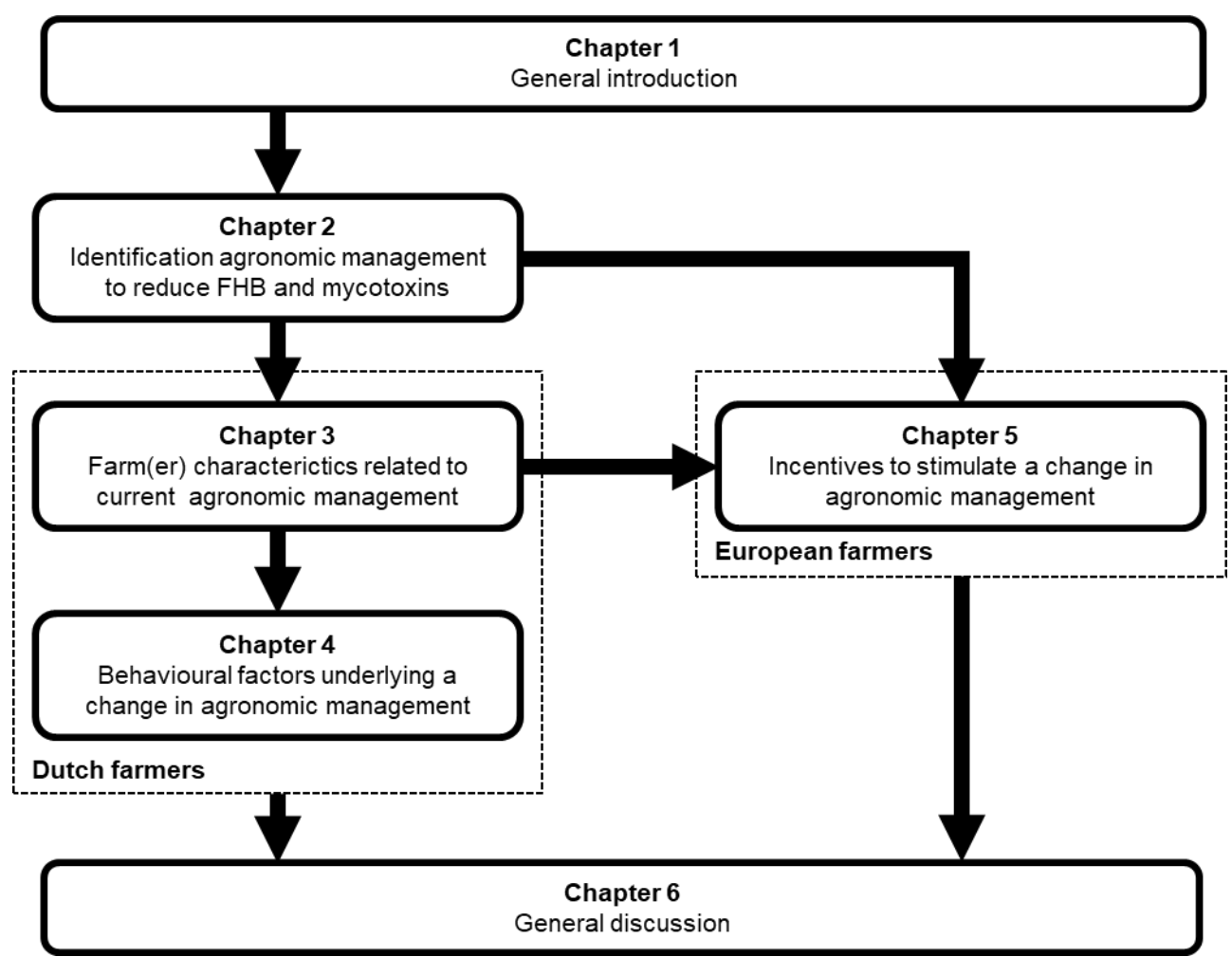

Figure 1.1. Outline of the thesis and link between the chapters. 


\title{
Chapter 2
}

\section{Fusarium infection and trichothecenes in barley and its comparison with wheat}

\author{
E.M. Janssen \\ C. Liu \\ H.J. van der Fels-Klerx
}

This chapter is published as:

Janssen, E. M., Liu, C., \& Van der Fels-Klerx, H. J. (2018). Fusarium infection and trichothecenes in barley and its comparison with wheat. World Mycotoxin Journal, 11(1), 3346. doi:10.3920/WMJ2017.2255 


\section{Abstract}

Barley is a small-grain cereal that can be infected by Fusarium spp. resulting in reduced quality and safety of harvested barley (products). Barley and other small-grain cereals are commonly studied together for Fusarium spp. infection and related mycotoxin contamination, since the infection and its influencing factors are assumed to be the same for all small-grain cereals. Using relevant literature, this study reviewed Fusarium spp. infection and mycotoxin contamination, mainly T-2/HT-2 and deoxynivalenol (DON), in barley specifically. For the first time, review results provide an extensive overview of the influencing factors for Fusarium infection and mycotoxin production in barley, such as weather, agricultural management and processing factors, and includes the comparison of these mechanisms in wheat. Results showed that Fusarium infection in barley is difficult to recognize in the field and mycotoxin levels cannot be estimated based on the symptoms. These factors make it difficult to establish the real severity of Fusarium infection in barley. In addition, most pre-harvest measures to mitigate initial Fusarium infection, such as cultivar use and soil cultivation, are the same for barley and wheat, but due to anatomical differences, some pre-harvest measures have a different effect on Fusarium infection in barley. For example, the effective moment (days after anthesis) of fungicide application in barley and wheat is different. Also, in wheat, there is an additional effect of multiple fungicide applications in reducing FHB and DON concentrations, whereas in barley, no additional effect of multiple application is seen. Hence, care should be taken to use data on one small-grain cereal to draw conclusions for other small-grain cereals. 


\subsection{Introduction}

Barley is the fourth most produced cereal crop worldwide and is grown in temperate climate regions including northwest Europe and Canada. Around 140 million tonnes per year is produced globally, which is mainly used as feed $(70 \%)$ and for beer production (27\%) (FAO 2004; FAO 2016). Infection with Fusarium spp., a fungus, can lead to the crop disease Fusarium Head Blight (FHB) and Fusarium damaged kernels (FDK), resulting in reduced yield, quality of the kernels and the percentage of seed germination (Tekauz et al. 200o). In addition, the presence of Fusarium spp. in barley kernels is related to gushing (Sarlin et al. 2005), the eruptive over foaming of beer upon opening (Christian et al. 2011).

Some Fusarium species produce mycotoxins, secondary metabolites that can cause adverse health effects in humans and animals upon consumption (Placinta et al. 1999). Fusarium mycotoxins include type A trichothecenes such as T-2 toxin and HT-2 toxin, and type B trichothecenes such as deoxynivalenol (DON). T-2/HT-2 toxins are the most potent trichothecenes and exert immunotoxic, genotoxic and neurotoxic effects (EFSA 2011a). DON is the most studied Fusarium mycotoxin in small-grain cereals. It can cause acute and chronic adverse effects on the gastro-intestinal tract, the nervous system, and the immune system in animals and humans (Maresca 2013). Mycotoxins are chemically stable contaminants; they survive many processing steps and are found in multiple endproducts like flour, feed and beer (EFSA 2013; Varga et al. 2013). Human chronic dietary exposure to T-2/HT-2 toxins (EFSA, 2017a) and DON (EFSA, 2017b) may exceed their respective tolerable daily intakes in some sub-populations, in particular young population groups.

The rate of infection and production of mycotoxins by Fusarium spp. in small-grain cereals can be influenced by pre-harvest agronomic measures and other influence factors like weather and post-harvest processing. Although some review papers on infection and these influence factors are available for wheat or small-grain cereals in general (Bai and Shaner 2004; Dweba et al. 2017; Kabak et al. 2006; Kazan et al. 2012; Liu and Ogbonnaya 2015; Parry et al. 1995; Van der Fels-Klerx and Stratakou 2010; Wegulo 2012; Wegulo et al. 2015), no complete overview exists for barley. In addition, several cited reviews draw conclusions for small-grain cereals based on wheat data. It is generally assumed that Fusarium spp. infection and the effect of influence factors on this infection and mycotoxin formation are the same for all small-grain cereals. This literature study aimed to investigate Fusarium infection, its related trichothecene contamination (T-2/HT-2 and DON) and the effect of influence factors like weather, agronomic management and processing in barley specifically, and identify possible differences and similarities with wheat.

\subsection{Material and methods}

An extensive literature review was conducted including scientific papers published up to July 2017. The keywords (Fusarium OR FHB OR mycotoxins OR trichothecenes OR deoxynivalenol OR T-2 OR HT-2) AND (barley OR small-grain cereals) AND (management OR measures) were used to search SCOPUS and PubMed. 


\section{Chapter 2}

The search results were screened for their relevance to the study objectives based on their titles and abstracts. Papers of the relevant records were retrieved and checked based on their full contents. The reference lists of all relevant studies were checked for additional relevant papers (snowballing effect) of which the abstracts were again checked for their relevance to the study objectives.

\subsection{Results}

\subsubsection{Anatomy of barley}

Barley (Hordeum vulgare L.) belongs to the family of grasses and has anatomical similarities and differences with other small-grain cereals such as wheat. Due to anatomical differences the susceptibility between small-grain cereal types can differ (see section 2.3.2).

In small-grain cereal plants, the grain kernels develop in the spike, also called head or ear. This spike consists of multiple spikelets that are connected by a node on the rachis, the main stem. A spikelet consists of one or more florets that can develop to kernels, the actual edible grains. The arrangement of the florets differs between barley types. In barley, three spikelets are connected on a rachis node on alternating sites of the rachis, and each spikelet contains one floret. In six-rowed barley, all three florets are fertile and will develop into kernels. In two-rowed barley, only the middle floret will develop into a kernel (Forster et al. 2007). When viewed from above, six-rowed barley has a ring of six kernels around the rachis whereas two-rowed barley has two kernels on opposite sides of the rachis. During the flowering stage (anthesis) of the plant, anthers extrude from the floret. Barley can be either chasmogamous (open-flowering) or cleistogamous (closed-flowering). Chasmogamous barley has full anther extension whereas cleistogamous barley has no or a limited anther extension (Heta and Hiura 1963; Vivar et al. 1997). In closed-flowering barley, only self-fertilisation occurs (Briggs 1978).

\subsubsection{Infection}

Fusarium spp. spores can survive in the soil, crop residues or grain seeds, and reach the spike via wind or water from rain or irrigation (Osborne and Stein 2007; Parry et al. 1995). During warm and wet conditions the spores germinate and the fungus infects the plant. Mesterházy (1995) summarized the five types of plant resistance to Fusarium spp. infection: I) resistance to initial infection; II) resistance to spread of pathogen; III) resistance to kernel infection; IV) tolerance; and V) resistance to toxins (Miller et al. 1985; Schroeder and Christensen 1963; Snijders 1988). Both type I and II resistance are found in barley, with II as the predominant type (Bai and Shaner 2004).

The fungus can penetrate the rachis and spreads via direct floret-floret contamination. Further contamination via direct floret-floret contact occurs mainly in six-rowed barley because the florets are closer together compared to two-rowed barley (Langevin et al. 2004). In barley, it is possible that only three florets in a spikelet are infected, whereas the neighbouring spikelets are free from infection (Tekauz et al. 20oo). Infection is sometimes restricted to these initially infected florets and does not spread to the adjacent florets (Boddu et al. 2007). Chasmogamous barley is most susceptible to Fusarium spp. infection during anthesis (Oliveira et al. 2012; Yoshida et al. 2007; Yoshida et al. 2012), possibly due to production of fungal growth stimulants (Strange and Smith 1971), whereas cleistogamous barley is most susceptible ten days after anthesis (Yoshida et al. 
2007). Although anthesis mainly occurs while the head is still protected from infection (McCallum and Tekauz 2002), it is observed that barley heads can extrude already fully infected (Osborne and Stein 2007).

\subsubsection{Symptoms}

Fusarium infection can be determined in different ways. On the field, FHB can be determined by visual inspection of the percentage of infected florets (Yoshida et al. 2007), percentage of infected spikelets (Ban and Suenaga 2000; Bérubé et al. 2012; Buerstmayr et al. 2004; Chrpová et al. 2011; Nesvadba et al. 2006; Xue et al. 2006), and percentage of infected kernels in a spikelet (Urrea et al. 2002) or ear (Vančo et al. 2007). These percentages can be used to determine an FHB index (\% incidence * \% severity) (Tekauz et al. 200o). After harvest, FHB can be determined by the percentage of FDK as described by the visual symptom score of the kernels, the presence of fungi or the weight of the kernels.

In infected barley, symptoms are not distinctive, can be hidden, or may be confused with other diseases. Infected barley can be recognized by necrotic patches and bleaching of the florets (Boddu et al. 2007) and discoloured kernels (tan, orange, brown, pink or red) scattered throughout the head. When the bottom of the head is infected, the stem may turn dark brown (Tekauz et al. 200o). Sometimes, fungal mycelium, (orange-pink) spore masses or black spots are visible on the kernels (Canadian Grain Commission 2016). A pink-red colour of the kernels can be caused by production of naphthoquinone pigments by Fusarium spp. (Oliveira et al. 2012). Under extreme stressful conditions for the fungus, it can biosynthesize these pigments (Medentsev et al. 2005). In addition to discolouration of the barley kernels, FDK can also decrease in weight by $20 \%$ compared to healthy kernels (Tekauz et al. 200o). In hulled barley, FDK cannot be distinguished from healthy kernels, because the hull can conceal the damage (Abramson et al. 2004). In addition, symptoms can be confused with those caused by other pathogens (Bérubé et al. 2012); for example discolouration at the basal end of the kernel can also be caused by Helminthosporium sativum and Alternaria alternata (Clear et al. 1996). Overall, these factors make it difficult to establish the real severity of Fusarium infection in barley.

\subsubsection{Mycotoxins}

Most Fusarium spp. are able to produce mycotoxins. It is suggested that these toxins may act as virulence factors and increase the aggressiveness of the fungus in small-grain cereals (Bai and Shaner 2004; Jansen et al. 2005; Langevin et al. 2004). Boddu et al. (2007) showed that a Fusarium strain that produces trichothecenes (DON) and a nontrichothecene producing mutant strain, were both able to infect barley florets without spreading to neighbouring florets. However, the non-trichothecene producing strain resulted in lower disease severity based on the percentage of diseased florets and smaller necrotic patches, less bleaching and lower amount of biomass as compared to the trichothecene producing strain. These results indicate that trichothecene (DON) production is a factor in the pathogenicity and severity of Fusarium infection in barley. However, Langevin et al. (2004) only found differences in pathogenicity of a non- and trichothecene producing strain (DON) in one of the four barley cultivars studied. Jansen et al. (2005) showed that spreading was inhibited by the plant regardless of the presence of DON. 
Fusarium infection can activate the plant defence system (Hofer et al. 2016b) and mycotoxins might play a role in this activation. When DON was applied to one barley floret, it spread to other florets, diluting its concentration (Gardiner et al. 2010). Upon infection with a trichothecene producing strain, gene transcription of plant defence genes increased compared to infection with a non-trichothecene producing strain. One of the plant defence mechanisms is detoxification by glucosylation. Glucosylation of mycotoxins by the plant is thought to be the mechanism behind the presence of the so called "masked" or "modified" mycotoxins. The masked mycotoxin deoxynivalenol-3glucoside $\left(\mathrm{D}_{3} \mathrm{G}\right)$, a plant conjugate of DON, was found when barley was inoculated with DON (Gardiner et al. 2010; Meng-Reiterer et al. 2015). Also, conjugated forms of T-2 and HT-2 were found in barley (Meng-Reiterer et al. 2015). Regarding end-products, high concentrations of $\mathrm{D}_{3} \mathrm{G}$ were found in beer (Varga et al. 2013; Zachariasova et al. 2012).

In Europe between $15 \%$ and $55 \%$ of the barley (products) is contaminated with DON (EFSA 2017b) and between 2\% and 50\% with T-2/HT-2 (EFSA 2011a; EFSA 2017b). Mean DON concentrations are around $484 \mu \mathrm{g} / \mathrm{kg}$ in unprocessed barley, $152 \mu \mathrm{g} / \mathrm{kg}$ in barley

grains for human consumption, 8.4-11.3 $\mu \mathrm{g} / \mathrm{kg}$ in beer, and $187 \mu \mathrm{g} / \mathrm{kg}$ in feed (EFSA 2013; EFSA 2017b; Varga et al. 2013). Mean T-2/HT-2 concentrations are between $22.8 \mu \mathrm{g} / \mathrm{kg}$ in unprocessed barley, 10-13 $\mu \mathrm{g} / \mathrm{kg}$ in barley for human consumption and $0.82-3.3 \mu \mathrm{g} / \mathrm{L}$ in beer (EFSA 2011a; EFSA 2017b). In the EU, Commission Regulation 2006/1881/EC sets maximum levels for DON at $1250 \mu \mathrm{g} / \mathrm{kg}$ in unprocessed cereals and $200-750 \mu \mathrm{g} / \mathrm{kg}$ in cereal (products) for direct human consumption. Commission Recommendations state maximum levels for DON is $8 \mathrm{mg} / \mathrm{kg}$ in cereals and cereal products intended for animal feed $(2006 / 576 / \mathrm{EC})$ and maximum levels of T-2/HT-2 at $250-500 \mu \mathrm{g} / \mathrm{kg}$ in barley products for feed and compound feed, $200 \mu \mathrm{g} / \mathrm{kg}$ in processed barley (including malting barley), $50 \mu \mathrm{g} / \mathrm{kg}$ in barley for direct human consumption and $15-100 \mu \mathrm{g} / \mathrm{kg}$ in barley products for human consumption (2013/165/EU). Regarding exposure to mycotoxins due to barley consumption, barley is a minor contributor to dietary T-2/HT-2 exposure, and its contribution is mainly due to beer consumption of adults (EFSA 2011a; EFSA 2017b). In contrast, barley is not a high contributor to DON exposure (EFSA 2013; EFSA 2017b).

\subsubsection{Correlation between symptoms of Fusarium infection and mycotoxins}

For barley, results for the correlation between disease severity, mycotoxin levels and other symptoms are not consistent. In some studies, a correlation was found between disease severity and the presence of Fusarium spp. (Salas et al. 1999), visually infected kernels (Berger et al. 2014; Legzdina and Buerstmayr 2004), or a reduction in grain weight (Fernandez et al. 2007a). However, other studies could not find such a correlation between disease severity and presence of Fusarium spp. (Nesvadba et al. 2006; Tekauz et al. 2000) or visually infected kernels (Tekauz et al. 2000). In some studies, presence of DON was correlated to the disease severity (Berger et al. 2014; Buerstmayr et al. 2004; Chrpová et al. 2011; Legzdina and Buerstmayr 2004; Salas et al. 1999; Thin et al. 2004), visually infected kernels (Berger et al. 2014; Legzdina and Buerstmayr 2004), a decrease in kernel weight (Chrpová et al. 2011) or presence of Fusarium spp. (Bérubé et al. 2012; Salas et al. 1999; Schöneberg et al. 2016; Tekauz et al. 2000). However, in other studies, no correlation between presence of DON and disease severity (Nesvadba et al. 2006), visually infected kernels (Tekauz et al. 200o), a decrease in kernel weight (Tekauz et al. 2000) or presence of Fusarium spp. (Abramson et al. 1998; Xue et al. 2006) was found. In 
addition, no significant correlation was found between the presence of the Fusarium spp. F. avenaceum, F. equiseti, F. graminearum, F. poae, F. sporotrichioides, and DON content in barley (Abramson et al. 1998; Xue 2013; Xue et al. 2006).

\subsubsection{Influence factors on Fusarium infection and mycotoxin levels Weather}

Weather is one of the most influencing factors on Fusarium infection and the production of mycotoxins in barley (Berger et al. 2014; Bernhoft et al. 2012; Bondalapati et al. 2012; Linkmeyer et al. 2016). Weather conditions determine the germination, growth of the fungi and selection of spp. (Doohan et al. 2003). Germination of the fungus normally occurs with warm and moist weather, depending on the type of Fusarium spp.. Presence of these spp. differ per region and climate conditions. For example, F. graminearum is the predominant Fusarium spp. in warmer regions, whereas the predominant spp. in cooler regions are F. Culmorum and $F$. avenaceum (Champeil et al. 2004). Since not all Fusarium spp. produce the same mycotoxins, the type of mycotoxin present is also climate and weather dependent.

Based on a model with barley samples from North West Europe collected between 19892009, presence of DON in barley was positively correlated with temperature and precipitation in April, probably around ear formation (Van der Fels-Klerx et al. 2012b). Also, T-2/HT-2 production by $F$. sporotrichioides was associated with wet field conditions in summer, probably during ripening, in Canada in 1993 (Abramson et al. 2004). In the Czech Republic, a high incidence of T-2 and HT-2 was associated with relatively low mean temperatures during barley anthesis in May and July in 2008, which are conditions favourable mainly for type A trichothecene producers such as $F$. sporotrichioides and $F$. poae (Malachova et al. 2010).

\section{Barley variety}

Choosing a resistant barley cultivar can be effective to mitigate Fusarium infection and mycotoxin accumulation. Barley cultivars have different susceptibility to Fusarium infection and mycotoxin accumulation (Bérubé et al. 2012; Chrpová et al. 2011; Langevin et al. 2004; Xue 2013; Xue et al. 2006). Susceptible characteristics include six-rowed barley, and open-flowering types and hulled varieties.

A Japanese study with forty-six cultivars, observed higher FHB severity in chasmogamous and six-rowed barley compared to cleistogamous and two-rowed barley from 2001 to 2002 (Yoshida et al. 2005). Also, the number of infected spikelets was higher in wheat than in six-rowed barley (Langevin et al. 2004).

The presence of a hull is another characteristic determining a difference in susceptibility. Most barley cultivars have a hard inedible hull around the kernel (hulled or covered barley), but in some cultivars this hull is loosely attached (hulless barley) and generally falls off during harvest. In the edible parts of both hulled and hulless Korean barley, the highest total mycotoxin content was found in the bran (Hong et al., 2014). Although hulled and hulless barley did not differ in FHB incidence in 18 cultivars in Northern America and 174 cultivars in Austria (Berger et al. 2014; Legzdina and Buerstmayr 2004), the presence of a hull might be related to the extent of trichothecene contamination in barley. DON, 3-acetyldeoxynivalenol and 15-acetyldeoxynivalenol concentrations were 
higher in hulled barley compared to the hulless variant (Legzdina and Buerstmayr 2004), whereas T-2/HT-2 can be up to twice as high in hulless cultivars than hulled cultivars based on data from the Czech Republic in 2005 (Malachova et al. 2010), and not all studies could find a difference for DON (Berger et al. 2014).

\section{Sowing date}

Barley can be sown in spring (spring barley) or the previous autumn/winter (winter barley), and harvested in summer or autumn. Winter barley cultivars needs vernalisation and spring barley cultivars are not always resistant to frost. Spring and winter barley differ in sowing time and susceptibility to Fusarium infection. In 2010, the predominant Fusarium spp. was F. graminearum in winter barley (cv. Campanile and Fridericus) and F. langsethiae in spring barley (cv. Quench) from Germany (Linkmeyer et al. 2016). In Switzerland, F. graminearum incidence and DON content were higher in winter barley (fodder) compared to spring barley (malting) from 2013 and 2014 (Schöneberg et al. 2016). In France, DON levels in malting barley were lower in spring barley compared to winter barley in 2006, but higher 2007 and 2008 (Orlando et al. 2010). T-2/HT-2 levels in France were higher in spring barley compared to winter barley from 2006-2008 (Fournier 2009). Another French study reported higher levels of T-2/HT-2 in winter barley from 20062007 (Barrier-Guillot 2008). The levels of T-2/HT-2 in spring barley were reported to be up to four times higher than those in winter barley in France between 2006 and 2008 (Orlando et al. 2010). A study on European malting barley showed no difference between T-2/ HT-2 levels in 2007, but reported higher T-2/HT-2 in spring barley compared to winter barley in 2008 (Slaiding 2008; Slaiding 2009). In addition, spring barley sown in autumn was less contaminated with T-2/HT-2 compared to spring barley sown in spring. Two potential reasons for these differences are a difference in cultivar susceptibility and difference in co-occurrence of the susceptible time of barley and the infectious time of the Fusarium spp. (Orlando et al. 2010).

\section{Fertilisation}

Fertilisation with nitrogen, applied during sowing or tillage can have a positive effect on growth and yield of barley and wheat grown in Uruguay between 1989-1991 (Baethgen et al. 1995). However, fertilisation can also influence the Fusarium infection and trichothecene production. When barley was grown on high nitrogen soil, the percentage of FDK, presence of F. graminearum and DON levels were higher compared to plants grown on low nitrogen soil in greenhouses (Hofer et al. 2016a; Yang et al. 2010). In contrast, Pageau et al. (2008) found that nitrogen Fertilisation had no significant effect on DON content in barley in Canada from 2002-2005. No studies could be found on the effect of fertilisation on T-2/HT-2 levels.

\section{Lodging}

Lodging, the bending of the stalk or the entire plant, is mainly influenced by plant characteristics and environmental conditions such as soil type, high nitrogen Fertilisation, high sowing density, drought and strong winds with heavy rain (Yoshida et al. 2008b). Two-rowed barley (cv. CI9831) was more resistant to lodging than six-rowed barley (Léger), in Canada and China from 2001-2002 (Thin et al. 2004). Lodging of barley leads to a reduction of the grain yield and quality (Baethgen et al. 1995; Caierão 2006). In addition, lodging increases the moisture content of the plant and can increase Fusarium infection and mycotoxin concentration (Yoshida et al. 2008b). In barley, 
resistance to lodging is associated with lower FHB incidence (Thin et al. 2004). Higher DON concentrations were found after artificial lodging of Norwegian barley samples (Tore and Pemilla) from 1991-1993 (Langseth and Stabbetorp 1996) and natural lodging in Japan from 2002-2006 (Yoshida et al. 2008b). No studies could be found on the effect of lodging on T-2/HT-2 levels in barley.

\section{Fungicide use}

Fungicides can be used to decrease Fusarium infection during cultivation. However, the evidence of effectiveness of fungicide use to reduce Fusarium infection in barley is conflicting. In addition to type and dose of a fungicide, the timing of fungicide application is crucial, because barley is only susceptible during a short period of time.

May et al. (2010) concluded that barley seeds (Excel and Westeck) treated with fungicides improved yield in Canada between 2004-2005. Application of fungicides or herbicides during the vegetation state showed either no effect or an increase of the presence of Fusarium spp. in Norway in 1996 (Henriksen and Elen 2005). This increase might be the result of inhibitory effects of the fungicide on competitor micro-organisms. In addition, during the vegetation state, no effects of fungicide application on DON and T-2/HT-2 concentrations were observed in the Czech Republic between 2005-2008 (Malachova et al. 2010). In some years, the combination of fungicides and barley cultivar resulted in higher DON concentrations or lower T-2/HT-2 concentrations. In Japan between 20052006, applying fungicides on two-rowed cleistogamous barley (cultivar Nishinochikara) in different development stages (before anthesis and up to 30 days after anthesis), showed that application at the beginning of spent anther extrusion (11-12 days after anthesis) was most effective in reducing FHB incidence, FHB severity, and percentage of discoloured kernels, compared to other fungicide application times (Yoshida et al. 2008a). Spraying fungicides on six-rowed chasmogamous barley (cultivar Shunrai) three days after anthesis was more effective compared to later spraying dates. Spraying twice gave no additional effect on FHB and DON concentration comparing to spraying once three days after anthesis in Japan in 2011 (Tateishi et al. 2014).

\section{Biological control}

Biological control, i.e. the application of other micro-organisms to suppress fungal growth or infection, is not well examined in barley. Piriformospora indica used as a biological control agent in barley increased grain weight and decreased root rot (Achatz et al. 2010; Deshmukh and Kogel 2007; Harrach et al. 2013). However, the effect of $P$. indica on FHB or mycotoxin content in barley is not known. In wheat, $P$. indica reduced FHB and DON concentration, and increased grain weight (Rabiey and Shaw 2016). No studies could be found on the effect of biological control on T-2/HT-2 levels in barley.

\section{Soil cultivation}

Fusarium present on plant debris can survive and contaminate the next planted crop. Tillage and ploughing bring the contaminated plant debris deeper in the soil which can avoid contamination of the next crop. In contrast, with minimum tillage and direct drilling, plant residues are not buried and are associated with higher infection of cereals compared to deep ploughing (Imathiu et al. 2013). In Canada, between 1999-2002, incidence of FDK was lower under conventional tillage (seven or more tillage operations) or no tillage compared to minimum tillage (one to six operations) in more than six 


\section{Chapter 2}

cultivars tested (Fernandez et al. 2007b). However, the effectiveness of tillage type on FHB differed between susceptible and more resistant cultivars. For example, lowest disease levels were reached under conventional tillage for susceptible cultivars and under zero tillage under more resistant cultivars (Fernandez et al. 2007b).

Incidence of $F$. graminearum and DON content in barley was higher under minimum tillage compared to ploughing, regardless of previous crop in Switzerland between 2013 and 2014 (Schöneberg et al. 2016). DON contamination in spring barley did not differ significantly between tillage, chisel or direct drilling in the Czech Republic between 2007-2014 (Matušinsky et al. 2016). Orlando et al. (2010) found no effect of tillage (ploughing/non-ploughing) on T-2/HT-2 levels in France in 2006-2008. Although tillage can reduce barley infection, Bérubé et al. (2012) concluded that tillage (mouldboard plough, spring tillage or direct drilling) had minor influence on disease incidence and DON content in three barley cultivars compared to weather and crop rotation in Canada between 2007-2008.

\section{Crop rotation}

With crop rotation, different types of crops will succeed each other in the field, to limit recontamination of crops. For example, sowing Fusarium prone crops after each other increases the chance of recontamination from the soil. In barley, incidence of $F$. graminearum and DON content were higher when barley succeeded maize compared to cereal or pasture in Switzerland between 2013 and 2014 (Schöneberg et al. 2016). DON levels in barley were significantly higher when the previous crop was barley compared with dry pea, soybean, or red clover in Canada from 2002-2005 (Pageau et al. 2008). In barley succeeding barley or wheat, T-2/HT-2 levels were higher compared to barley succeeding maize, beet or other crops in France in 2006-2008 (Orlando et al. 2010). Although Fernandez et al. (2007a) did not find a difference between FHB in barley succeeding a cereal crop, oilseed, pulse or summer fallow, the percentage of FDK was lower when the previous crop was summer fallow compared to the other crops tested, in Canadian barley between 1999-2002.

\section{Harvesting}

Although harvest date is difficult to influence due to weather conditions, a delayed harvest should be avoided. In three barley cultivars (AC Vision, Brucefield, and OAC Baxter), a delayed harvest by two weeks was correlated with the increase of the incidence of total Fusarium and F. sporotrichioides in Canada between 2004-2005 (Xue et al. 2008). Harvesting two weeks before the expected harvest was significantly lowering the presence of total Fusarium and F. sporotrichioides. A change in harvest date could not be statistically correlated to presence of other Fusarium spp. or DON (Xue et al. 2008).

Infected kernels are difficult to be separated from healthy kernels because infected kernels might not have distinguishable symptoms and infected kernels weigh on average $20 \%$ less than healthy kernels, based on a Canadian study with six-rowed malting barley (cv. Excel, Foster, Robust and Stander) (Tekauz et al. 200o). Techniques based on weight to separate FDK at harvest (Salgado et al. 2011) might therefore not be effective in barley compared to wheat where the infected kernel weight decreases up to $50 \%$ (Tekauz et al. 200o). In Canadian barley harvested in 1994, DON accumulated in the outer part of the kernel. Up to $50 \%$ of the initial DON concentration can be lost in hulless barley, because 
the hull is easily removed at harvest (Clear et al. 1997). In addition, commercial dehulling strategies can remove the outer hull as well (Trenholm et al. 1991). No studies could be found on the effect of harvesting on T-2/HT-2 levels in barley.

\section{Processing}

Although mycotoxins can hardly be removed during processing, mycotoxin concentrations can be diluted or accumulated during certain processing steps. Presence of Fusarium fungi and the use of infected kernels during processing can result in a decrease of the quality of the end-product. After harvest, several processing steps like rolling, extruding, cooking and flaking can be applied for feed production (EFSA 2011a). For food consumption, malting and brewing are the most common processing steps. Hong et al. (2014) report that washing or boiling of barley can decrease the DON content by $80 \%$. Although very few other studies are available on effects of barley processing, several studies assess the quality and safety due to Fusarium spp. infection during the malting and brewing process (see also the recent review of Schwarz (2017)).

Barley kernels that are smaller or coloured red are suggested to be related to gushing. These red kernels are an indication of Fusarium infection (Oliveira et al. 2012). Other studies also report a relationship between Fusarium infected kernels and a decrease of malt quality (Nielsen et al. 2014; Oliveira et al. 2013), or a negative relation between Fusarium resistance and malt quality (Urrea et al. 2005). The probability for gushing is reduced by eliminating the red kernels from the batch; however, gushing can still occur because some infected kernels show no symptoms (Christian et al. 2011). Primary gushing is caused by elements in the raw materials and malt, whereas secondary gushing is caused by factors during the production process. Two type of proteins have an influence on the extent of gushing, and both are the result of fungal infection. Hydrophobins are excreted by fungi, and non-specific lipid transfer proteins (ns-LTPs) are produced by the plant upon infection by the fungus (Christian et al. 2011). Barley samples inoculated with $F$. graminearum and $F$. poae had increased proteinase, $\beta$-glucanase and endoxylanase levels compared to the control samples. In malt prepared from infected grain, levels of free amino nitrogen were elevated, and wort $\beta$-glucans levels were reduced. The quality of the malt and wort is negatively affected by these enzymes (Schwarz et al. 2002). DON levels slowly increased during the early stages of malting and were also elevated during the kilning process when the temperature was increased, causing a stress response in the fungi (Oliveira et al. 2012).

When barley is contaminated with mycotoxins, the contamination can also be seen in the beer produced from the barley. For example, when barley is initially contaminated with DON, an increase of DON concentration is seen during malting followed by a slight decrease during brewing. Hazel and Patel (2004) suggest that adding certain products to the brewing process (e.g. maize grits, syrups, wheat) may contribute to the mycotoxin content in the beer. Several studies showed an increase of $\mathrm{D}_{3} \mathrm{G}$ during brewing (Kostelanska et al. 2011; Lancova et al. 2008; Zachariasova et al. 2012). Levels of HT-2 decreased from barley to malt and brewing itself had a minor effect on the HT-2 levels (Lancova et al. 2008). Mycotoxins were transferred to the beer or the germ bud, which is used in the feed industry (Lancova et al. 2008). The technological process of beer brewing might affect the mycotoxin concentration. For example, a positive correlation between the mycotoxin concentration and the alcohol content was reported (Kostelanska et al. 
2009; Papadopoulou-Bouraoui et al. 2004) with non-alcoholic beers showing the lowest contamination (Varga et al. 2013).

\subsubsection{Comparison of Fusarium infection and mycotoxins in barley and wheat}

Barley and wheat are both small-grain cereals used for animal and human consumption, and Fusarium spp. infection results in both a quality and safety loss of these cereals. Similarities and differences of Fusarium spp. infection and mycotoxins in barley and wheat are summarized in Table 2.1.

The main similarities between barley and wheat are (i) the influence factors on Fusarium spp. infection in the pre-harvest stage, such as cultivar use, fungicide use and soil cultivation; and (ii) the contribution of T-2/HT-2 to human exposure, i.e. both barley and wheat contribute to exposure, and current intake levels are above the tolerable daily intake in some (sub) populations. The main differences between barley and wheat in terms of Fusarium infection and mycotoxin accumulation are summarised as following:

i. Barley and wheat are anatomically different which results in differences in susceptibility of the plant to Fusarium infection and disease severity. Barley is more resistant to the spread of the fungal infection within the plant, whereas in wheat, a fast spread of the infection occurs. Therefore, the avoidance of initial infection is more important in wheat than in barley.

ii. Infection determination by visual symptoms are different in barley and wheat. In barley, Fusarium infection hardly shows symptoms, or they can be confused with other diseases, whereas in wheat a Fusarium infection can be apparent in both the field (FHB) and in loose kernels (FDK). This leads to misestimating the presence of Fusarium spp. in barley. Therefore, use visual inspection to decide to take additional measures to prevent further spread of the disease, as is done in practice by wheat farmers, cannot be done by barley farmers. Also, techniques to separate FDK at harvest might not be as effective in barley as in wheat, because in barley FDK are more difficult to distinguish.

iii. The effective moment (days after anthesis) of fungicide application in barley and wheat is different. Also, in wheat, there is an additional effect of multiple fungicide applications in reducing FHB and DON concentrations, whereas in barley, no additional effect of multiple application is seen. In this regard, data on effective fungicide application in wheat, cannot be extrapolated to barley.

iv. Barley and wheat are used for different end-products, which results into differences in mitigation targets and their timing: limiting fungal presence and growth in barley during post-harvest processing to improve product quality, and minimising mycotoxin contamination in wheat during pre-harvest to ensure the product safety. 
Table 2.1. Comparison of Fusarium infection and mycotoxins between barley and wheat.

\begin{tabular}{|c|c|c|}
\hline Barley & Wheat & Reference \\
\hline \multicolumn{3}{|l|}{ Anatomy } \\
\hline $\begin{array}{l}\text { Chasmogamous (open-flowering) } \\
\text { or cleistogamous (closed- } \\
\text { flowering) }\end{array}$ & $\begin{array}{l}\text { Chasmogamous (open- } \\
\text { flowering) }\end{array}$ & $\begin{array}{l}\text { Briggs (1978); Heta and Hiura } \\
\text { (1963); Thomason and Griffey } \\
\text { (2009); Vivar et al. (1997) }\end{array}$ \\
\hline $\begin{array}{l}\text { Florets close together (six-rowed) } \\
\text { or apart (two-rowed) }\end{array}$ & Florets close together & Langevin et al. (2004) \\
\hline \multicolumn{3}{|l|}{ Fusarium infection } \\
\hline Type I resistance more important & $\begin{array}{l}\text { Type II resistance more } \\
\text { important }\end{array}$ & $\begin{array}{l}\text { Bai and Shaner (2004); Jansen et al. } \\
(2005)\end{array}$ \\
\hline $\begin{array}{l}\text { Direct floret-floret (six-rowed) } \\
\text { contamination or limited floret- } \\
\text { floret (two-rowed) }\end{array}$ & $\begin{array}{l}\text { Direct floret-floret } \\
\text { contamination }\end{array}$ & Langevin et al. (2004) \\
\hline $\begin{array}{l}\text { Most susceptible at anthesis } \\
\text { (chasmogamous) or 1o days after } \\
\text { anthesis (cleistogamous) }\end{array}$ & $\begin{array}{l}\text { Most susceptible at } \\
\text { anthesis }\end{array}$ & $\begin{array}{l}\text { Oliveira et al. (2012); Yoshida et al. } \\
\text { (2007); Yoshida et al. (2012) }\end{array}$ \\
\hline $\begin{array}{l}\text { Neighbouring spikelets are free } \\
\text { from infection }\end{array}$ & $\begin{array}{l}\text { Neighbouring spikelets } \\
\text { are often all infected }\end{array}$ & $\begin{array}{l}\text { Boddu et al. (2007); Tekauz et al. } \\
(2000)\end{array}$ \\
\hline \multicolumn{3}{|l|}{ Symptoms } \\
\hline $\begin{array}{l}\text { The affected kernels are scattered } \\
\text { throughout the head }\end{array}$ & $\begin{array}{l}\text { Entire spikelet and } \\
\text { neighbouring spikelets } \\
\text { are affected }\end{array}$ & $\begin{array}{l}\text { Goswami and Kistler (2004); } \\
\text { Tekauz et al. (2000) }\end{array}$ \\
\hline $\begin{array}{l}\text { Discoloured kernels (tan, orange, } \\
\text { brown, pink or red) }\end{array}$ & $\begin{array}{l}\text { FDK smaller, red or } \\
\text { white and shrivelled }\end{array}$ & $\begin{array}{l}\text { Boddu et al. (2006); Canadian Grain } \\
\text { Commission (2016); Goswami and } \\
\text { Kistler (2004); Tekauz et al. (1997) }\end{array}$ \\
\hline FDK weight decrease $20 \%$ & $\begin{array}{l}\text { FDK weight decrease } \\
50 \%\end{array}$ & Tekauz et al. (2000) \\
\hline Hull can cover infection symptoms & No hull & Abramson et al. (2004) \\
\hline $\begin{array}{l}\text { Symptoms can be confused with } \\
\text { other diseases }\end{array}$ & $\begin{array}{l}\text { Clear symptoms for } \\
\text { Fusarium infection }\end{array}$ & $\begin{array}{l}\text { Bérubé et al. (2012); Clear et al. } \\
\text { (1996) }\end{array}$ \\
\hline \multicolumn{3}{|l|}{ Mycotoxins } \\
\hline $\begin{array}{l}\text { Contradicting results if } \\
\text { trichothecenes act as virulence } \\
\text { factor }\end{array}$ & $\begin{array}{l}\text { Trichothecenes act as } \\
\text { virulence factor }\end{array}$ & $\begin{array}{l}\text { Bai and Shaner (2004); Jansen et al. } \\
\text { (2005); Langevin et al. (2004) } \\
\text { Boddu et al. (2007); Langevin et al. } \\
\text { (2004); Maier et al. (2006); Shah et } \\
\text { al. (2017) }\end{array}$ \\
\hline Activation of plant defence system & Idem & $\begin{array}{l}\text { Berthiller et al. (2013); Gardiner et } \\
\text { al. (2010) }\end{array}$ \\
\hline $\begin{array}{l}\text { Plant defence regardless of } \\
\text { mycotoxins }\end{array}$ & $\begin{array}{l}\text { Plant defence inhibited } \\
\text { by mycotoxins }\end{array}$ & Jansen et al. (2005) \\
\hline $\begin{array}{l}\text { Modification of mycotoxins by } \\
\text { barley }\end{array}$ & Idem & $\begin{array}{l}\text { Berthiller et al. (2013); Gardiner et } \\
\text { al. (2010); Meng-Reiterer et al. } \\
\text { (2015) }\end{array}$ \\
\hline Occurrence levels DON lower & $\begin{array}{l}\text { Occurrence levels DON } \\
\text { higher }\end{array}$ & $\begin{array}{l}\text { EFSA (2013); EFSA (2017b); Varga et } \\
\text { al. (2013) }\end{array}$ \\
\hline Occurrence levels T-2/HT-2 higher & $\begin{array}{l}\text { Occurrence levels T- } \\
\text { 2/HT-2 lower }\end{array}$ & EFSA (2011a); EFSA (2017a) \\
\hline $\begin{array}{l}\text { Contribution to DON exposure } \\
\text { limited }\end{array}$ & $\begin{array}{l}\text { High contribution to } \\
\text { DON exposure }\end{array}$ & EFSA (2013); EFSA (2017b) \\
\hline $\begin{array}{l}\text { Contribution to T-2/HT-2 exposure } \\
\text { minor }\end{array}$ & $\begin{array}{l}\text { Contribution to T- } \\
2 / \mathrm{HT}-2 \text { exposure }\end{array}$ & EFSA (2011a); EFSA (2017a) \\
\hline
\end{tabular}


Table 2.1 (continued)

\begin{tabular}{ll}
\hline Barley & Wheat \\
\hline $\begin{array}{ll}\text { Correlation between symptoms } \\
\text { Contradicting results on }\end{array}$ & (Limited) correlation \\
correlation between symptoms & between symptoms
\end{tabular}

Contradicting results on correlation between disease severity and presence of Fusarium spp.

Contradicting results on correlation between presence of DON and disease severity
Significant positive correlation between presence of DON and disease severity

Reference

Abramson et al. (1998); Berger et al. (2014); Bérubé et al. (2012); Chrpová et al. (2011); Fernandez et al.

(2007a); Legzdina and Buerstmayr (2004); Nesvadba et al. (2006); Paul et al. (2005); Paul et al. (2006); Salas et al. (1999); Schöneberg et al. (2016); Tekauz et al. (2000); Xue et al. (2006)

Salas et al. (1999)

Berger et al. (2014); Buerstmayr et al. (2004); Chrpová et al. (2011); Legzdina and Buerstmayr (2004); Nesvadba et al. (2006); Paul et al. (2005); Salas et al. (1999); Thin et al. (2004)

\section{Agronomy and management Presence of DON in barley was positively correlated with temperature and precipitation in April}

Susceptibility differences between barley varieties

Spring and winter barley differ in sowing time, cultivar used, and susceptibility to Fusarium infection

Possible increase of FDK, fungal presence and DON concentration by high nitrogen fertilisation Lodging increases Fusarium infection and mycotoxin concentration

Application of fungicides was most effective in reducing FHB incidence, FHB severity and percentage of discoloured kernels 3 days (chasmogamous barley) or 1112 (cleistogamous barley) days after anthesis
Presence of DON correlated to temperature in April, May, June and September, rainy days during June, and relative humidity during May and June Idem

Inconsistent effects of fertilisation on FHB and mycotoxin levels Idem

\section{Application of} fungicides 4 days after anthesis was most effective to reduce FHB
Van der Fels-Klerx et al. (2012b)

Bai and Shaner (2004); Berger et al. (2014); Bérubé et al. (2012); Chrpová et al. (2011); Langevin et al. (2004); Legzdina and Buerstmayr (2004); Malachova et al. (2010); Xue (2013); Xue et al. (2006) Barrier-Guillot (2008); Fournier (2009); Orlando et al. (2010); Schöneberg et al. (2016); Slaiding (2008); Slaiding (2009)

Hofer et al. (2016a); Pageau et al. (2008); Yang et al. (2010); Yoshida et al. (2008b)

Baethgen et al. (1995); Caierão (2006); Thin et al. (2004); Yoshida et al. (2008b)

Tateishi et al. (2014); Yoshida et al. (2008a) 
Table 2.1 (continued)

\begin{tabular}{|c|c|c|}
\hline Barley & Wheat & Reference \\
\hline \multicolumn{3}{|l|}{ Agronomy and management } \\
\hline $\begin{array}{l}\text { Spraying fungicides twice gave no } \\
\text { additional effect on FHB and DON } \\
\text { concentration }\end{array}$ & $\begin{array}{l}\text { Spraying twice had an } \\
\text { additional effect on } \\
\text { reduction of FHB and } \\
\text { DON concentrations in } \\
\text { wheat }\end{array}$ & Tateishi et al. (2014) \\
\hline $\begin{array}{l}\text { Tillage can reduce Fusarium } \\
\text { infection in barley }\end{array}$ & Idem & $\begin{array}{l}\text { Bérubé et al. (2012); Fernandez et al. } \\
\text { (2007b); Matušinsky et al. (2016); } \\
\text { Orlando et al. (2010); Schöneberg et } \\
\text { al. (2016); Wegulo (2012); Wegulo et } \\
\text { al. (2015) }\end{array}$ \\
\hline $\begin{array}{l}\text { Crop rotation can reduce Fusarium } \\
\text { infection in barley }\end{array}$ & Idem & Wegulo (2012); Wegulo et al. (2015) \\
\hline $\begin{array}{l}\text { Biological control leads to increase } \\
\text { in grain weight, effect on FHB and } \\
\text { mycotoxins unknown }\end{array}$ & $\begin{array}{l}\text { Biological control leads } \\
\text { to increase in grain } \\
\text { weight and decrease } \\
\text { FHB and mycotoxins }\end{array}$ & $\begin{array}{l}\text { Achatz et al. (2010); Deshmukh and } \\
\text { Kogel (2007); Harrach et al. (2013); } \\
\text { Rabiey and Shaw (2016) }\end{array}$ \\
\hline \multicolumn{3}{|l|}{ Harvesting } \\
\hline $\begin{array}{l}\text { Delayed harvest increases presence } \\
\text { fungus, not DON }\end{array}$ & Idem & Xue et al. (2008); Xue et al. (2004) \\
\hline $\begin{array}{l}\text { Separation of FDK based on weight } \\
\text { probably not effective }\end{array}$ & $\begin{array}{l}\text { Separation of FDK } \\
\text { based on weight at } \\
\text { harvest is effective }\end{array}$ & Tekauz et al. (2000) \\
\hline $\begin{array}{l}\text { Loss of DON due to loss of hull in } \\
\text { hulless barley; effective commercial } \\
\text { dehulling }\end{array}$ & $\begin{array}{l}\text { Effective commercial } \\
\text { dehulling }\end{array}$ & $\begin{array}{l}\text { Clear et al. (1997); Trenholm et al. } \\
\text { (1991) }\end{array}$ \\
\hline \multicolumn{3}{|l|}{ Processing } \\
\hline $\begin{array}{l}\text { Main food processes are malting } \\
\text { and brewing }\end{array}$ & $\begin{array}{l}\text { Main food processes } \\
\text { are milling and baking }\end{array}$ & - \\
\hline $\begin{array}{l}\text { Quality issues due to presence } \\
\text { fungus }\end{array}$ & $\begin{array}{l}\text { Presence fungus not an } \\
\text { issue }\end{array}$ & $\begin{array}{l}\text { Nielsen et al. (2014); Oliveira et al. } \\
\text { (2013) }\end{array}$ \\
\hline $\begin{array}{l}\text { Quality issues due to infected } \\
\text { kernels }\end{array}$ & $\begin{array}{l}\text { Contradicting results } \\
\text { on quality issues due to } \\
\text { infected kernels }\end{array}$ & $\begin{array}{l}\text { Dexter et al. (1996); Horvat et al. } \\
\text { (2015); Kreuzberger et al. (2015); } \\
\text { Nielsen et al. (2014); Oliveira et al. } \\
\text { (2012); Oliveira et al. (2013); Prange } \\
\text { et al. (2005) }\end{array}$ \\
\hline $\begin{array}{l}\text { Transfer of mycotoxins through } \\
\text { processing steps }\end{array}$ & Idem & $\begin{array}{l}\text { Kaushik (2015); Nielsen et al. (2014); } \\
\text { Oliveira et al. (2013); Urrea et al. } \\
\text { (2005) }\end{array}$ \\
\hline
\end{tabular}




\subsection{Conclusion}

This is the first study providing an extensive literature review on the influence factors for Fusarium spp. infection and mycotoxin formation in barley, including weather, preharvest and post-harvest factors. It also comprehensively compared these factors and their underlying mechanisms between barley and wheat. The unique anatomy of barley leads to differences regarding its susceptibility and susceptible infection time among cultivars. Fusarium infection in barley is difficult to recognize in the field and mycotoxin levels cannot be estimated based on the symptoms. Overall, these factors make it difficult to establish the real severity of Fusarium infection in barley. Weather influences Fusarium infection and mycotoxin production. Reduction of Fusarium infection and mycotoxin contamination in barley can be achieved by several pre-harvest measures. Although DON concentrations in barley do not contribute much to exposure of human by consumption of barley related food products, barley in beer can be a contributor to T-2/HT-2 exposure. In addition, the presence of Fusarium spp. leads to serious quality issues in beer. Most pre-harvest measures to mitigate initial Fusarium infection are the same for barley and wheat, but due to anatomical differences, some measures (e.g. fungicide application) have a different effect on Fusarium infection. Therefore, in future research (e.g. on biological control) care should be taken to use data on wheat to draw conclusions for barley.

\section{Acknowledgements}

This study has been financed by the Ministry of Economic Affairs in the Netherlands, through the Public Private Cooperation (PPS) project "Prediction of mycotoxins in cereals" (project number AF-TKI-14225) of the Topsector Agri\&Food. The authors acknowledge the involvement of the parties in the project. 


$$
4
$$




\title{
Chapter 3
}

\section{Pre-harvest measures against Fusarium species infection and related mycotoxins implemented by Dutch wheat farmers}

\author{
E.M. Janssen \\ M.C.M. Mourits \\ H.J. van der Fels-Klerx \\ A.G.J.M. Oude Lansink
}

This chapter is published as:

Janssen, E. M., Mourits, M. C. M., van der Fels-Klerx, H. J., \& Oude Lansink, A. G. J. M. (2019).

Pre-harvest measures against Fusarium spp. infection and related mycotoxins implemented

by Dutch wheat farmers. Crop Protection, 122, 9-18. doi:10.1016/j.cropro.2019.04.005 


\section{Abstract}

Fusarium spp. are one of the most widespread mycotoxin-producing fungi in small-grain cereals like wheat. Their rate of infection and production of mycotoxins is mainly influenced by weather and pre-harvest agronomic measures. Consequently, farmers' prevention and control of mycotoxins are imperative since it is difficult to remove mycotoxins further down the cereal supply chain. This study aimed to (i) identify which pre-harvest preventive and control measures Dutch wheat farmers currently apply against Fusarium spp,. infection and mycotoxin contamination and to (ii) examine which farm and farmer characteristics explain the implementation of these measures. Field data on pre-harvest measures, like the selection of resistant varieties, fungicide use, and crop rotation, along with farm and farmer characteristics were collected from Dutch wheat farmers via an online questionnaire. Probit models were applied to examine farm and farmer characteristics that explain the implementation of pre-harvest measures. Results showed that most farmers applied six or more different measures against Fusarium spp. infection and mycotoxin contamination in wheat and that the use of pre-harvest measures is related to at least one other measure. However, results indicated that about $44 \%$ of farmers could become more effective if they implemented a benchmark approach consisting of a combination of fungicide use during flowering, selection of a Fusarium resistant wheat variety, and ploughing or crop rotation. Five out of the ten evaluated farm and farmer characteristics significantly $(p<0.05)$ explained the implementation of at least one of the eight pre-harvest control measures. These five farm and farmer characteristics include wheat as main income crop, the use of a decision support system, the education level of the farmer, the farmer's knowledge about mycotoxins, and the farmer's level of risk aversion. Insight into relevant characteristics can be used by farmer cooperatives, processing industries and government agencies to improve the overall mycotoxin management of wheat farmers. 


\subsection{Introduction}

Mycotoxins are fungal secondary metabolites that can cause adverse effects in humans and animals upon consumption. Mycotoxins occur in various crops like peanut (Arachis hypogaea), maize (Zea mays), and wheat (Triticum spp.), and have significant implications for food and feed safety, food security, and international trade (Dohlman 2003; EFSA 2011a; EFSA 2017b; Unnevehr and Roberts 2002; Wilson et al. 2018; Zain 2011). According to the European Commission (EC), an estimated 5-10\% of crop losses worldwide are caused by mycotoxins (EC 2015), leading to about a 2.4 billion Euro loss in Europe alone (Krska et al. 2016). Many studies have focused on pre-harvest preventive and control measures to reduce fungal infection and limit mycotoxin contamination in food and feed crops (Kabak et al. 2006; Parry et al. 1995; Van der Fels-Klerx et al. 2010; Wegulo et al. 2015). However, mycotoxin contamination still occurs, implying that the agricultural as well as food and feed industries remain vulnerable to fungi and subsequently mycotoxin contamination.

Among the many genera of fungi that can produce mycotoxins, Fusarium spp. are one of the most widespread in small-grain cereals like wheat. Fusarium spp. can affect crops if the seed is contaminated, or if it survives on debris in the soil and/or splashes onto the crop during wet conditions. Once present on the crop, Fusarium spp. can infect the plant and produce mycotoxins like deoxynivalenol (DON), zearalenone and fumonisins. Fusarium spp. infection in wheat leads to Fusarium Head Blight (FHB) which affects crop growth, physically alters kernels, and reduces the quality and safety of the grain (Parry et al. 1995). The rate of infection and production of mycotoxins in wheat by Fusarium spp. is mainly influenced by weather and pre-harvest agronomic measures (EC 2006b).

Use of pre-harvest agronomic control measures by farmers is imperative to help prevent and control mycotoxins because it is difficult to remove mycotoxins further down the cereal supply chain (Kabak et al. 2006). Within the Dutch wheat production system, Fusarium spp., infection and mycotoxin contamination are regularly detected (Franz et al. 2009; Van der Fels-Klerx 2014; Van der Fels-Klerx et al. 2012a); hence, posing a continuous production risk with which farmers need to cope. For example, the percentage of tested wheat fields with DON concentrations above the maximum level of $1,250 \mu \mathrm{g} / \mathrm{kg}$ for unprocessed cereals as set by Commission Regulation 2006/1881/EC (EC 2006c) is on average $11 \%$, and ranged from $0 \%$ to $60 \%$ depending on the year (Franz et al. 2009). Although many studies have assessed the potential effectiveness of pre-harvest measures against Fusarium spp. infection and mycotoxin contamination, few, if any, have considered farmer's implementation. Since effective mycotoxin management along the supply chain depends on the implementation of these measures, it is important to be aware of the factors that can elucidate this implementation. Factors frequently identified as determinants for the implementation of crop management technologies are farm and farmer characteristics (Adesina and Chianu 2002; Tey et al. 2017). Insight into relevant characteristics can be used by farmer cooperatives, processing industries and government agencies to design a targeted approach for farmers to (further) reduce Fusarium spp. infection and mycotoxin contamination.

This study aims to (i) identify which pre-harvest control measures Dutch wheat farmers currently apply against Fusarium spp. infection and mycotoxins and to (ii) examine which farm and farmer characteristics explain the implementation of these measures. 


\subsection{Materials and Methods}

Relevant pre-harvest measures for prevention and control of Fusarium spp. infection and mycotoxin contamination, as well as relevant farm and farmer characteristics relating to the implementation of management technologies, were selected by means of a literature study and expert consultation. Field data on pre-harvest measures and farm and farmer characteristics were subsequently collected from Dutch wheat farmers via an online questionnaire. Descriptive statistics were used to evaluate the implemented sets of measures. Probit models were applied in the context of the farmers' utility maximization framework to identify the farm and farmer characteristics that explain the implementation of pre-harvest measures. The utility maximization framework is based on the assumption that farmers choose measures that provide them with higher utility compared to the non-implemented ones (Adesina and Chianu 2002).

\subsubsection{Selection of pre-harvest measures}

Several pre-harvest measures can be implemented to combat Fusarium spp. infection and mycotoxin contamination in wheat (EC 2006b; Parry et al. 1995; Pirgozliev et al. 2003). From the literature study and expert consultation on potential pre-harvest measures, eight measures were selected for further investigation in this study: (1) decontamination of seeds; (2) crop rotation; (3) ploughing after a grain harvest; (4) lodging resistant cultivar; (5) fungicide use during the entire wheat cultivation period; (6) fungicide use during wheat flowering; (7) resistant cultivar against Fusarium spp.; and (8) biological control. In addition, the combination of fungicide use during flowering, selection of a resistant variety and ploughing or crop rotation were considered as the 'benchmark approach' in this study. The potential use of these measures is subsequently described in this section.

Fusarium spp. can grow systemically in the plant tissues from the seeds (Beccari et al. 2018), so decontaminated seeds are used to avoid initial fungal contamination by infected seeds (Inch and Gilbert 2003). The use of decontaminated seeds was shown to increase the grain yield (May et al. 2010; Sooväli et al. 2017; Xue et al. 2017) and may reduce the likelihood of a Fusarium spp. infection, although studies with contradicting results have been reported (Beccari et al. 2018; Moretti et al. 2014).

Other pre-harvest measures, like crop rotation, ploughing, or the selection of a variety that is resistant to lodging can be applied to combat mycotoxin contamination of crops. Fusarium spp. can survive on debris in the soil, and potentially contaminate and infect the next planted crop when that crop is susceptible to Fusarium, such as wheat, barley, or maize. To avoid this, a crop rotation plan in which two Fusarium susceptible crops (e.g., wheat, barley, or maize) that do not succeed each other should be applied (Edwards 2004; Parry et al. 1995; Shah et al. 2018). Avoiding maize as pre-crop was shown to reduce the DON content by $67 \%$ compared to the DON content in wheat with maize as precrop (Beyer et al. 2006; Obst et al. 2000). Another measure to prevent Fusarium survival is soil cultivation, like deep ploughing after grain harvest, in which Fusarium-infected crop debris is destroyed or buried (Dill-Macky and Jones 200o). Ploughing (deep tillage) has been shown to reduce the DON content by $67 \%$ in wheat (Beyer et al. 2006; Blandino et al. 2012). Also, farmers can choose a wheat variety that is resistant to lodging. Lodging, the bending of the stalk or the entire plant, increases the moisture content of the plant and can increase Fusarium spp. infection and mycotoxin contamination if fungal spores 
are present in the soil. Lodged wheat was reported to have three times the mycotoxin (DON and nivalenol) concentration compared to crops that do not lodge (Yoshida et al. 2008b).

Moreover, fungicide application, particularly during flowering, is an additional preharvest control measure that can be applied. Application of fungicides has been shown to reduce Fusarium spp. infection and mycotoxin production; however, the effect was dependent on the dose, type of fungicide, and application time (D'Angelo et al. 2014; Franz et al. 2009; Ioos et al. 2005; Paul et al. 2008; Yoshida et al. 2012). In wheat, the most effective fungicide application time was reported to be around the flowering stage (D'Angelo et al. 2014). This measure can decrease the DON content by around 50\% compared to non-treated controls (Beyer et al. 2006; Blandino et al. 2012). Hence, fungicide application and fungicide use during flowering were included in the study for further analyses of pre-harvest measures.

Furthermore, the type of wheat variety may play a role in combating Fusarium spp. infection or mycotoxin contamination. There have been inherent differences reported in the susceptibility of wheat varieties to Fusarium spp. infection and mycotoxin accumulation, the selection of a resistant wheat variety is therefore a relevant pre-harvest measure that farmers can apply (Edwards 2004; Kabak et al. 2006; Wegulo et al. 2015). The use of a Fusarium resistant cultivar was shown to decrease DON content by $61-76 \%$ compared to the use of a susceptible cultivar (Beyer et al. 2006; Blandino et al. 2012). Therefore, the selection of a Fusarium resistant wheat variety was also considered as a potential pre-harvest measure to analyse further.

Finally, biological control, like the use of micro-organisms as antagonistic agents or nonchemical fungicides, potentially leads to an increase in grain weight and a decrease of FHB and mycotoxin contamination (see review of Shah et al. (2018)); however, they are not widely used commercially and are considered innovative methods.

The pre-harvest measures described above can be implemented individually or in combination. Combining measures to reduce the contamination of Fusarium spp. and severity of the infection is more effective than isolated approaches, especially when weather or environmental conditions are favourable for fungal infection (Blandino et al. 2017; Edwards 2004; Kabak et al. 2006; McMullen et al. 2012; McMullen et al. 2008; Wegulo et al. 2015). An effective approach in reducing FHB and mycotoxin production in grains by Fusarium spp. is one that combines measures that limit the survival of the fungus in debris, decreases the presence of the fungus on the plant, and reduces the severity of the infection. Blandino et al. (2012) compared the effect on FHB and DON contamination levels using a basic set of measures (direct sowing, selection of a susceptible variety, and no fungicide use) to the effect of using a combination of measures that included ploughing, a Fusarium resistant variety and/or fungicide use during flowering. Compared to the basic set of measures, the combination of a Fusarium resistant variety and fungicide use during flowering reduced DON by $82 \%$; ploughing and fungicide use during flowering reduced DON by $87 \%$; ploughing and a Fusarium resistant variety reduced $\mathrm{DON}$ by $91 \%$; and a combination of all three measures (ploughing, using a Fusarium resistant variety and applying fungicide during flowering) reduced DON by 97\%. These findings concur with McMullen et al. (2008), who showed 
that the use of a Fusarium resistant variety and crop rotation reduced FHB severity by $80 \%$, and a combination of a Fusarium resistant variety, crop rotation and fungicide use during flowering reduced it by $92 \%$. Therefore, the individual and combined effects of pre-harvest measures on farm and farmer characteristics were further analysed during this study. Given the high level of effectiveness in reducing FHB and mycotoxins in grains caused by Fusarium spp., the combination of fungicide use during flowering, selection of a Fusarium resistant variety, and ploughing or crop rotation (Blandino et al. 2012; McMullen et al. 2008) was referred to as the 'benchmark approach' in this study.

\subsubsection{Selection of farm and farmer characteristics}

Fourteen farm and farmer characteristics were assumed to be related to the implementation of pre-harvest measures. These were divided based on those pertaining to the farm (eight) and those to the farmer (six). The eight variables related to the characteristics of the farm were farm size, soil type, organic production, main crop, crop purpose, type of buyer, experience with past Fusarium spp. infections, and the use of a decision support system. The six variables related to characteristics of the farmer were age, gender, education, risk perception, risk aversion, and knowledge of mycotoxins.

Several studies have shown that farm size positively affects implementation decisions (Oude Lansink et al. 2003; Samson et al. 2016). For example, aflatoxin management practices in groundnut have been implemented more on large farms than on small farms (Kumar and Popat 2010). Larger farms benefit from economies of scale as they can reduce their costs per hectare more easily. It was therefore expected that farmers who have a larger farm could take more measures or measures that require a larger scale. Another farm characteristic considered was soil type. Some soil types require different soil cultivation than others and not all soil types have been shown to be suitable for crop rotation (Bürger et al. 2012a; Morris et al. 2010). It was expected that farms with a certain soil type, e.g., heavy clay, would not apply crop rotation. In addition to the effect of soil type, organic crops have been reported to require different crop management practices than conventional crops (Mason and Spaner 2006), because not all pre-harvest measures, like chemical fungicide use, are suitable for organic cultivation. It is therefore likely that on organic farms a different set of measures is taken, e.g., no use of chemical fungicides, as compared to conventional farms. Another characteristic considered besides farm size, soil type, and the organic crop is the main crop on the farm. At some farms, wheat might not be the main income crop; it is included in their crop rotation plan to control pests, diseases, and weeds, and for productive, economic and environmental reasons (Silva et al. 2017). For farmers who grow wheat as their main income crop, it is more important to deliver a product that is of good quality and safe to consume. Farmers with wheat as the main crop were therefore expected to take more or different measures than farmers for which wheat is not their main crop. Moreover, the crop purpose (i.e., for food, feed or seed) is a characteristic that was expected to determine the implementation of preharvest measures. Farmers grow wheat for food consumption, feed or seed production. Wheat used for food has stricter legal mycotoxin limits than wheat used for feed (EC 2006a; EC 2006c; EC 2013). It was therefore hypothesized that farmers growing wheat for food take more or different measures than farmers producing wheat for feed or seed purposes. In addition, the type of buyer was considered a characteristic to be related to the use of pre-harvest measures. Farms that sell their wheat to a collector or directly to a processing facility, probably take different measures because of contractual 
agreements. Furthermore, it was hypothesized that farmers who experienced severe Fusarium spp. infections in the past accumulated more knowledge on (non-)effective pre-harvest measures (Adesina and Chianu 2002) and feel more pressure (Glanz et al. 2008) to take more or other measures than farmers who did not experience an infection. Finally, decision support systems were selected because they can be used to support the decision making progress on the measures to take against Fusarium spp. infection and mycotoxin contamination (Rossi et al. 2007; Rossi et al. 2015; Silva et al. 2017). It has been shown that the use of a decision support system reduces external inputs (i.e., seeds, fungicides, and fertilizers) and costs, maintains or increases crop yield and quality, and keeps mycotoxin contamination below the legal limit (Rossi et al. 2015). It was therefore expected that when a farmer uses a decision support system, independent of other factors like education and knowledge, different sets of measures will be selected.

Since the farmer makes the decision on which pre-harvest measures to implement, specific characteristics of the farmer, like age, gender, and education, were considered to be related to the implementation of pre-harvest measures. Studies have shown that the age of a farmer is negatively related to implementation of new measures (Bagheri et al. 2008; Comer et al. 1999; Oude Lansink et al. 2003) because older farmers were less open to change (Baur et al. 2016); however studies are divided (Aramyan et al. 2007; Burton et al. 1999; Nave et al. 2013). Older farmers also have a shorter planning horizon, as they might exit farming in the near future (Samson et al. 2016), and implement measures that require less investment or labour (Adesina and Chianu 2002) than younger farmers. Older farmers are more likely to have experience with Fusarium spp. infection and were expected to implement a different set of pre-harvest measures than younger farmers. In addition to age, gender has also been found to be a factor in farm adoption studies in the UK, where females were more likely to implement organic techniques (Burton et al. 1999) and in Nigeria, where men were more likely to adopt alley farming technology (Adesina and Chianu 2002). In this study, one of the selected farmer characteristics was, therefore, gender, and it was expected that gender would affect the implementation of measures in the Netherlands as well. Another selected farmer characteristic was education. Farmers with a higher level of education are more likely to implement new technologies (Baur et al. 2016; Comer et al. 1999; Gebrezgabher et al. 2015) and are more open to change (Baur et al. 2016), although there are studies that show insignificant association between education and implementation rate (Burton et al. 1999; Nave et al. 2013). Furthermore, farmer characteristics like risk perception and risk aversion were selected in this study. Risk perception is defined as a combination of the expected severity of an infection and its probability of occurrence (Glanz et al. 2008). As demonstrated by Sok et al. (2016), livestock farmers who had a lower risk perception were less willing to vaccinate against a particular animal disease. Therefore, farmers with high risk perceptions were expected to implement more or different measures to reduce the probability of a Fusarium spp. infection. Also, farmers with a higher risk aversion, i.e., they take less risk than their peer farmers (Meuwissen et al. 2001), were more willing to vaccinate (Sok et al. 2016). Dutch wheat farmers with a higher risk aversion were therefore expected to take more measures. Moreover, farmers who know more about Fusarium spp. infection and mycotoxin contamination, i.e., have more knowledge on the subject, were expected to be able to make a better-informed decision (Breukers et al. 2012), and were expected to take different measures than farmers with less knowledge on this specific subject. 


\subsubsection{Survey}

Data on the selected eight pre-harvest measures and fourteen farm and farmer characteristics were collected from Dutch wheat farmers by means of an online questionnaire. The specific questions and answer format related to these variables are presented in Table A.3.1 and A.3.2. The questions had been incorporated in a broader questionnaire on mycotoxin management that covered related research topics, like the perceived (cost-)effectiveness of pre-harvest measures by farmers. This online questionnaire was pre-tested by three Dutch farmers for consistency and clarity and adapted accordingly. The link to the online questionnaire was distributed via farmers' associations by email and newsletters to Dutch wheat farmers in 2017. In that year, according to the Dutch Central Agency for Statistics (CBS), around 7,50o Dutch farms cultivated wheat on a total area of 120 ,00o ha (CBS 2018). To enhance participation of farmers, they were incentivised by the chance of winning one of ten €25,- gift vouchers. Farmers could give their email address voluntarily for future contact, and all personal information was stored separately from the questionnaire output. The study protocol and consent procedure complied with the Netherlands Code of Conduct for Scientific Practice and were approved by the Social Sciences Ethics Committee of the Wageningen University (CoC number o9131098).

\subsubsection{Data analysis}

Descriptive statistics were used to explore the level of variation among questionnaire responses. Given insufficient variation among the responses for some characteristics (e.g., 98\% of the farmers were male), four of the fourteen originally selected farm and farmer characteristics - soil type, organic production, buyer, and gender - were excluded from further analysis. The final data set included 103 questionnaires of which 75 respondents had completed the questionnaire. The remaining 28 questionnaires had some missing variables for farm and farmer characteristics. For example, 18 missed age and education, 10 missed farm size, 2 missed past infection, 3 missed the main crop, and 1 missed crop purpose. These missing data were captured by regression imputation (Hair 2006). Data were collapsed, or dummies were created to reduce the number of variable states (Table 3.1). Data analysis was done in STATA (StataCorp 2015). Descriptive statistics were also used to calculate the percentage of farmers implementing a certain measure, the total number of pre-harvest measures farmers implemented, and the percentage of farmers that implemented the benchmark approach, i.e. application of fungicides use during flowering, use of a Fusarium resistant variety, and ploughing or crop rotation. 
Table 3.1. Uni- and bivariate probit model variables and their descriptive statistics.

\begin{tabular}{|c|c|c|c|c|c|}
\hline Variable & Model parameter & Mean & $\begin{array}{c}\text { St. } \\
\text { dev. }\end{array}$ & Min & $\operatorname{Max}$ \\
\hline \multicolumn{6}{|l|}{ Farm } \\
\hline Farm size & Numeric in ha & $95 \cdot 3$ & $45 \cdot 5$ & $17 \cdot 5$ & 230 \\
\hline Main crop & Dummy: 1 if wheat is the main crop & 0.15 & 0.36 & o & 1 \\
\hline Wheat purpose & $\begin{array}{l}\text { Dummy: } 1 \text { if wheat produced for } \\
\text { human consumption }\end{array}$ & 0.26 & 0.44 & o & 1 \\
\hline Past infection & $\begin{array}{l}\text { Dummy: } 1 \text { if a Fusarium spp. } \\
\text { infection occurred in the past } 5 \text { years }\end{array}$ & 0.67 & 0.47 & o & 1 \\
\hline $\begin{array}{l}\text { Use of a decision } \\
\text { support system }\end{array}$ & $\begin{array}{l}\text { Dummy: } 1 \text { if a decision support } \\
\text { system is used }\end{array}$ & 0.17 & 0.38 & o & 1 \\
\hline \multicolumn{6}{|l|}{ Farmer } \\
\hline Age & Dummy: 1 if age is over 55 & 0.40 & 0.49 & o & 1 \\
\hline Education & $\begin{array}{l}\text { Dummy: } 1 \text { if farmer followed higher } \\
\text { education }\end{array}$ & 0.54 & 0.50 & o & 1 \\
\hline Risk aversion & $\begin{array}{l}\text { Dummy: } 1 \text { if they take less risk than } \\
\text { peers }\end{array}$ & 0.47 & 0.50 & o & 1 \\
\hline Risk perceptiona & Numeric: score 1-25 & 7.8 & 3.8 & 1 & 25 \\
\hline Knowledge ${ }^{b}$ & Numeric: score o-5 & 3.0 & 1.3 & o & 5 \\
\hline
\end{tabular}

a The scores to sub-questions on susceptibility and severity of an infection (Table A.3.2) were multiplied to obtain a risk perception score (1-25).

b The knowledge score was calculated by the sum of the scores for 5 knowledge statements (Table A.3.2): scored as o (don't know or answered incorrectly) or as 1 (answered correctly). 


\subsubsection{Probit models}

Univariate probit models were employed to evaluate the ten farm and farmer characteristics that explain the implementation of pre-harvest measures (Adesina and Chianu 2002). The theoretical foundation of the univariate probit model assumes that farmers choose a measure if the implementation yields a higher utility than nonimplementation. The implementation of a certain pre-harvest measure is a binary variable; farmers either implement a pre-harvest measure or not. The underlying utility (U) function ranks the preference of the farmer $i$ and is assumed to be the function of farm and farmer characteristics ' $X$ ' (farm size, main crop, age, etc.) with coefficient ' $\beta$ ' and an error term ' $\epsilon$ ' having a zero mean:

$$
\begin{gathered}
U_{i 1}(X)=\beta_{1} X_{i}+\epsilon_{i 1} \text { for implementation of a pre-harvest measure } \\
U_{i 0}(X)=\beta_{0} X_{i}+\epsilon_{i 0} \text { for non-implementation }
\end{gathered}
$$

Farmers implement a certain pre-harvest measure only if $U_{i 1}>U_{i 0}$ (Judge et al. 1982). Thus, for farmer $i$, the probability of implementation is given by:

$$
\begin{gathered}
\mathrm{P}\left(U_{i 1}>U_{i 0}\right)=\mathrm{P}\left(\beta_{1} X_{i}+\epsilon_{i 1}>\beta_{0} X_{i}+\epsilon_{i 0}\right)=\mathrm{P}\left(\epsilon_{i 0}-\epsilon_{i 1}<\beta_{1} X_{i}-\beta_{0} X_{i}\right)=\mathrm{P}\left(\epsilon_{i 1}<\beta X_{i}\right)=\phi \\
\left(\beta X_{i}\right)
\end{gathered}
$$

Where $\phi$ is the cumulative distribution function for the error term $\epsilon$, which is assumed to be normally distributed in a probit model (Greene 1993). Hence, for farmer $i$, the probability of implementing pre-harvest measure $m$ is then given by (Judge et al. 1982):

$$
\phi_{m}\left(\beta X_{i}\right)=\int_{-\infty}^{\beta X_{i}} \frac{1}{\sqrt{2 \pi}} \exp \left(\frac{-t^{2}}{2}\right) d t
$$

This function represents a univariate probit model in which the implementation of only one pre-harvest measure is considered. For each pre-harvest measure, one univariate probit model was run individually with the farm and farmer characteristics as independent variables (Table 3.1). Also, a univariate probit model was run to study the farm and farmer characteristics that are related to the implementation of the benchmark approach. In this analysis, the dependent variable was defined by the implementation of the benchmark approach consisting of fungicide use during flowering AND the use of a Fusarium resistant variety AND ploughing AND/OR crop rotation.

Of all the univariate probit models (9 in total), marginal effects of the variables were calculated to indicate to what extent the (conditional) probability of the outcome variable (implemented pre-harvest measure) will change when the value of an independent variable (farm and farmer characteristic) is changed by one unit, while holding all other variables constant. All univariate probit models were tested for multicollinearity by their variance inflation factor. However, implementing a combination of measures, e.g., the benchmark approach, is shown to be more effective than the implementation of a single measure. Hence, it was expected a priori that the actual use of measures is mutually correlated, i.e., farmers decide on a package of measures rather than a single measure (Bürger et al. 2012a; Bürger et al. 2012b; Loyce et 
al. 2008) ${ }^{1}$. Therefore, to explore to what extent the implementation of a certain measure is interrelated with the selection of another measure, bivariate probit models were run for all combinations of measures ( 28 in total) taking into account the farm and farmer characteristics (Nkamleu and Adesina 2000). The bivariate probit model is a joint model for two binary outcomes, based on the joint probability distribution of two normally distributed dependent variables. If the implementation of measures is correlated, $\rho$ is significant. If $\rho$ is insignificant, two separate univariate probit models will suffice (Greene 1993; Nkamleu and Adesina 2000).

\subsection{Results and Discussion}

It is well known that certain pre-harvest measures can reduce Fusarium spp. infection and mycotoxin contamination (Kabak et al. 2006; Parry et al. 1995; Van der Fels-Klerx et al. 2010; Wegulo et al. 2015). However, to the best of our knowledge, no other study has investigated to what extent pre-harvest measures are actually implemented by farmers and which farm and farmer characteristics explain this implementation. Farmers' participation in this study was voluntary, and farmers who are a priori more involved in Fusarium and mycotoxin management might, therefore, be overrepresented among the respondents.

\subsubsection{Implementation of pre-harvest measures by Dutch farmers}

This study showed that most Dutch farmers already take multiple pre-harvest measures against Fusarium spp. infection and mycotoxin contamination (Figure 3.1). Table 3.2 presents an overview of the implementation rate of the eight pre-harvest measures applied by Dutch wheat farmers, based on the survey results. The pre-harvest measure implemented by most farmers (92\%) was the decontamination of seeds, whereas biological control was implemented by only $20 \%$ of the farmers. The implementation rate of the remaining pre-harvest measures ranged from $65 \%$ to $88 \%$ of the farmers.

Results indicated that farmers generally implemented a combination of measures (Figure 3.1) and as hypothesized, the implementation of pre-harvest measures was mutually correlated (Table 3.2). Of the eight measures included in the questionnaire, thirty-eight different combinations of measures were used during the 2017 growing season, ranging from no measures ( $1 \%$ of the farmers) to the use of all eight measures ( $6 \%$ of the farmers). A combination of seven measures was most commonly applied (Figure 3.1). The use of a Fusarium resistant wheat variety was correlated with the use of fungicides during the whole cultivation period, use of fungicides during flowering, or biological control (Table 3.3). Farmers who did not apply crop rotation were less likely to implement biological control but were more likely to use a lodging resistant wheat variety. The decision to plough after grain harvest and the use of contaminated seeds were positively correlated; however, not dependent on the decision to use any other measure.

\footnotetext{
${ }^{1}$ An application of a multivariate probit model would account for simultaneous choices (Mulwa, 2017; Oude Lansink, 2003; Ward, 2018), by estimating the parameters $\beta$ and the variance covariance matrix of the multivariate normal distribution of the error terms (Cappellari, 2003; Greene, 1993; Judge, 1982). However, in this study, a multivariate approach was technically not feasible because of the relative limited size of the available data set related to the number of variables.
} 


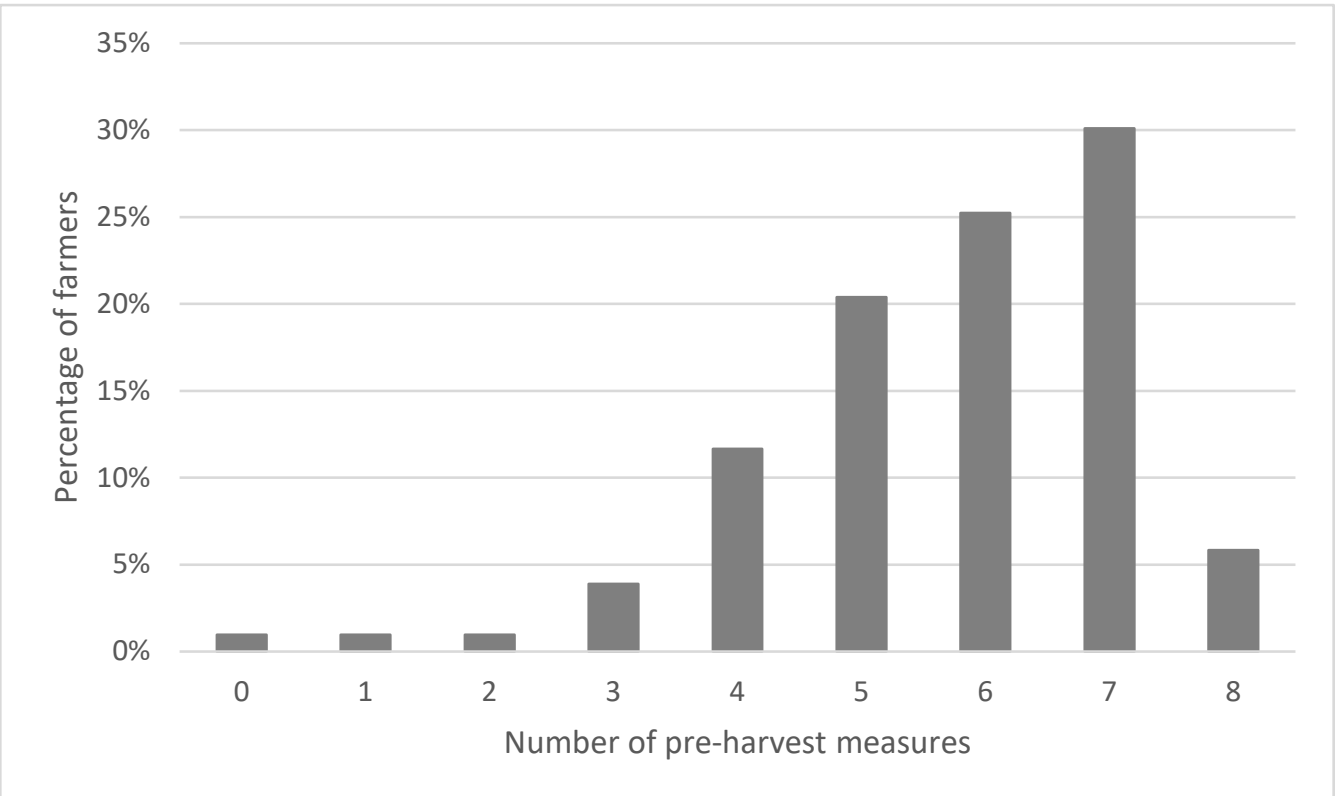

Figure 3.1. Percentage of farmers per total number of pre-harvest measures taken per farmer.

Table 3.2. Implementation rate of pre-harvest measures against Fusarium spp. infection by Dutch wheat farmers.

\begin{tabular}{llll}
\hline Pre-harvest measure & Description & n & \% \\
\hline Decontamination of seeds & Use of decontaminated seeds & 101 & 92 \\
Crop rotation & Crop rotation: no grains as pre-crop & 102 & 73 \\
Ploughing & Ploughing after grain harvest & 101 & 77 \\
Resistant cultivar lodging & Lower the risk of lodging by selection of a wheat & 101 & 88 \\
& variety & & \\
Fungicide use & Fungicide use during the whole cultivation period & 99 & 84 \\
Fungicide use flowering & Fungicide use around flowering & 100 & 65 \\
Resistant cultivar Fusarium & Selection of Fusarium resistant wheat variety & 103 & 85 \\
& (resistance $>$ ) & & \\
Biological control & Biological control & 97 & 20 \\
\hline
\end{tabular}




\subsubsection{Farmer characteristics associated with the implementation of pre- harvest measures}

Farm and farmer characteristics that were significantly related to the implementation of a certain pre-harvest measure were the use of wheat as the main crop, use of a decision support system, farmers' education level, mycotoxin knowledge, and risk aversion of the farmer. Although the selection of farm and farmer characteristics was made based on literature and expert consultation, not all characteristics that were expected to be related to the implementation of measures were statistically significant $(p<0.05)$, like farm size, wheat purpose, age and risk perception. Results showed that no farm and farmer characteristics were related to the use of a lodging resistant wheat variety or the use of decontaminated seeds, probably due to their high implementation rate: $88 \%$ and $92 \%$, respectively (Table 3.2).

Having wheat as the main crop increased the probability to use fungicides during flowering by $36 \%$ and decreased the probability of applying crop rotation (no grain as pre-crop) by $34 \%$. Although a rotation system without grain as a pre-crop is an effective pre-harvest measure against Fusarium spp. infection (Edwards 2004; Parry et al. 1995; Shah et al. 2018), most of the farmers who do not have wheat as the main crop, had potatoes as the main crop, in which a rotation system with wheat is advised. Results of the univariate probit models (Table 3.4) also showed that use of a decision support system increased the probability of the use of fungicides during flowering. Higher educated farmers were $17 \%$ more likely to use Fusarium resistant wheat varieties and $25 \%$ more likely to plough after a grain harvest compared to farmers with lower education levels. Increasing the specific mycotoxin knowledge levels by a point increased the probability of fungicide use by $10 \%$. Farm and farmer characteristics that were associated with the implementation of the benchmark approach (Table 3.4) were the wheat as primary crop, prior experience with Fusarium spp. infections, and education. Farmers with wheat as the main crop, farmers who experienced a severe Fusarium spp. infection in the past five years and farmers who followed higher education had, respectively, an $18 \%, 4 \%$ and $17 \%$ higher probability to implement the benchmark approach. Overall, results showed that significant farm and farmer characteristics differed per pre-harvest measure (Table 3.4). This result concurs with the study by Knowler and Bradshaw (2007) on farmers' adoption of conservation agriculture, which found no universal variables that explain this adoption. This assumes that results of the current study are not easily compared with those of other studies, because relevant characteristics are contextspecific and even differed within this study. However, this study provides valuable insights into relevant farm and farmer characteristics and how it influences the use of pre-harvest control measures, thereby aiding farmer cooperatives, processing industries, and government agencies in improving the overall mycotoxin management of wheat farmers. 


\section{Chapter 3}

Table 3.3. Correlation coefficients between different pre-harvest measures taking into account farm and farmer characteristics, i.e., $\rho$ of bivariate probit models.

\begin{tabular}{|c|c|c|c|c|c|c|c|c|}
\hline & $\begin{array}{l}\text { Decont } \\
\text { aminat } \\
\text { ion of } \\
\text { seeds }\end{array}$ & $\begin{array}{l}\text { Crop } \\
\text { rotatio } \\
\mathrm{n}\end{array}$ & $\begin{array}{l}\text { Plough } \\
\text { ing }\end{array}$ & $\begin{array}{l}\text { Resista } \\
\text { nt } \\
\text { cultiva } \\
\mathrm{r} \\
\text { lodging }\end{array}$ & $\begin{array}{l}\text { Fungici } \\
\text { de use }\end{array}$ & $\begin{array}{l}\text { Fungici } \\
\text { de use } \\
\text { floweri } \\
\text { ng }\end{array}$ & $\begin{array}{l}\text { Resista } \\
\text { nt } \\
\text { cultiva } \\
\mathrm{r} \\
\text { Fusariu } \\
\mathrm{m}\end{array}$ & $\begin{array}{l}\text { Biologi } \\
\text { cal } \\
\text { control }\end{array}$ \\
\hline $\begin{array}{l}\text { Decontami } \\
\text { nation of } \\
\text { seeds }\end{array}$ & & 0.25 & $0.76^{*}$ & 0.31 & 0.37 & 0.43 & -0.37 & 0.11 \\
\hline Crop & 0.25 & & 0.36 & 0.54 & -0.11 & -0.3 & -0.27 & $-0.49^{*}$ \\
\hline $\begin{array}{l}\text { Ploughing } \\
\text { Resistant } \\
\text { cultivar }\end{array}$ & $0.76^{*}$ & 0.36 & & 0.62 & 0.42 & 0.3 & 0.28 & 0.37 \\
\hline $\begin{array}{l}\text { lodging } \\
\text { Fungicide }\end{array}$ & 0.31 & $0.54^{*}$ & 0.62 & & -0.12 & -0.12 & 0.03 & 0.27 \\
\hline $\begin{array}{l}\text { use } \\
\text { Fungicide } \\
\text { use }\end{array}$ & 0.37 & -0.11 & 0.42 & -0.12 & & $0.68^{*}$ & $0.77^{*}$ & 0.14 \\
\hline $\begin{array}{l}\text { flowering } \\
\text { Resistant } \\
\text { cultivar }\end{array}$ & 0.43 & -0.3 & 0.3 & -0.12 & $0.68^{*}$ & & $0.79^{*}$ & 0.17 \\
\hline $\begin{array}{l}\text { Fusarium } \\
\text { Biological }\end{array}$ & -0.37 & -0.27 & 0.28 & 0.03 & $0.77^{*}$ & $0.79^{*}$ & & 0.99 \\
\hline control & $0.99^{*}$ & 0.27 & 0.14 & 0.17 & 0.37 & $-0.49^{*}$ & 0.11 & \\
\hline
\end{tabular}


Pre-harvest measures against Fusarium spp. infection

Table 3.4. Marginal effects of farm and farmer characteristics on the use of pre-harvest measures as determined by univariate probit models.

\begin{tabular}{|c|c|c|c|c|c|c|c|c|c|}
\hline & $\begin{array}{l}\text { Decontami- } \\
\text { nation of } \\
\text { seeds }\end{array}$ & $\begin{array}{l}\text { Crop } \\
\text { rotation }\end{array}$ & Ploughing & $\begin{array}{l}\text { Resistant } \\
\text { cultivar } \\
\text { lodging }\end{array}$ & $\begin{array}{l}\text { Fungicide } \\
\text { use }\end{array}$ & $\begin{array}{l}\text { Fungicide } \\
\text { use } \\
\text { flowering }\end{array}$ & $\begin{array}{l}\text { Resistant } \\
\text { cultivar } \\
\text { Fusarium }\end{array}$ & $\begin{array}{l}\text { Biological } \\
\text { control }\end{array}$ & $\begin{array}{l}\text { Benchmark } \\
\text { approach }\end{array}$ \\
\hline $\begin{array}{l}\text { Total } \\
\text { arable land }\end{array}$ & 0.000 & 0.001 & $-0.002 \dagger$ & 0.000 & 0.001 & -0.001 & 0.001 & 0.000 & 0.001 \\
\hline Main crop & 0.026 & $-0.340^{*}$ & 0.073 & 0.001 & 0.011 & $0.359^{*}$ & 0.019 & 0.025 & $0.182^{*}$ \\
\hline $\begin{array}{l}\text { Wheat } \\
\text { purpose }\end{array}$ & -0.115 & 0.041 & -0.047 & 0.078 & 0.008 & $-0.147 \dagger$ & -0.050 & -0.040 & 0.006 \\
\hline $\begin{array}{l}\text { Past } \\
\text { Fusarium } \\
\text { spp. } \\
\text { infections }\end{array}$ & 0.052 & -0.008 & 0.074 & -0.078 & 0.054 & -0.034 & 0.072 & -0.016 & $0.044^{*}$ \\
\hline $\begin{array}{l}\text { Use of a } \\
\text { decision } \\
\text { support } \\
\text { program }\end{array}$ & -0.108 & 0.143 & -0.158 & -0.081 & -0.050 & $0.306^{*}$ & 0.133 & -0.033 & 0.092 \\
\hline Education & 0.008 & -0.079 & $0.250^{*}$ & 0.036 & 0.007 & -0.034 & $0.174^{*}$ & -0.005 & $0.173^{*}$ \\
\hline $\begin{array}{l}\text { Mycotoxin } \\
\text { knowledge }\end{array}$ & 0.022 & 0.018 & 0.030 & 0.042 & $0.102^{*}$ & -0.005 & 0.031 & 0.012 & 0.058 \\
\hline $\begin{array}{l}\text { Risk } \\
\text { perception }\end{array}$ & 0.014 & -0.008 & -0.007 & 0.001 & $0.020 \dagger$ & $0.019 \dagger$ & 0.008 & $0.020 \dagger$ & -0.181 \\
\hline
\end{tabular}




\subsubsection{Probit models}

This paper employed univariate probit models to identify the farm and farmer characteristics that explain the implementation of pre-harvest measures. The results of the bivariate probit model in this study showed that the choice of some measures was indeed correlated, suggesting a multivariate probit model would have been an appropriate analysis (Cappellari and Jenkins 2003; Greene 1993; Judge et al. 1982; Mulwa et al. 2017; Oude Lansink et al. 2003; Ward et al. 2018). However, due to technical constraints (i.e., high variables to respondents' rate), the multivariate probit model failed to converge. Several sets of three to four measures were selected based on the bivariate probit model results and tested in a multivariate probit model to check whether the univariate results differed from a potential complete multivariate model. The results (significance and direction of the marginal effects of the characteristics) did not differ greatly from those of the univariate model. Therefore, the models in this study were sufficient in providing insights into the important farm and farmer characteristics.

\subsubsection{Benchmark approach}

Although the use of more measures does not necessarily mean a more effective approach (Loyce et al. 2012), research has demonstrated that a combination of measures consisting of a targeted fungicide use during flowering, a Fusarium resistant cultivar, and soil cultivation or crop rotation is highly effective against Fusarium spp. infection and mycotoxin contamination (Blandino et al. 2012; McMullen et al. 2012). This study showed that this specific combination of measures or benchmark approach is implemented by $56 \%$ of the Dutch farmers (Figure 3.2) indicating that about $44 \%$ of the farmers could become more effective in reducing mycotoxins in the field by implementing this benchmark approach.

However, there may be underlying factors for why these farmers did not implement the benchmark approach, like certain farm and farmer characteristics, environmental concerns, and perceived cost-effectiveness of the approach. Results showed that farmers were less likely to implement the benchmark approach if wheat was not their main crop, if they had a lower education level, or if they had not encountered a severe Fusarium spp. infection in the past five years (Table 3.4). Another factor might be the perceived effectiveness and cost-effectiveness of the pre-harvest measures in the benchmark approach. This benchmark approach is effective in reducing Fusarium spp. infection and can be cost-effective depending on the type of measure and external factors like price of wheat, premiums, and discounts (McMullen et al. 2012; Wilson et al. 2018). However, not all farmers of the non-benchmark group perceived the pre-harvest measures of the benchmark approach as effective and cost-effective. A third factor might be the farmers' environmental concerns of pesticide use; one of the benchmark approach pre-harvest measures is fungicide use during flowering, and $20 \%$ of the non-benchmark group did not use fungicides at all. French wheat farmers who were aware of the adverse effects of pesticides and wanted to reduce chemical inputs used fewer pesticides (Nave et al. 2013). Although $44 \%$ of the Dutch farmers could become more effective in reducing Fusarium infection and mycotoxin contamination by implementing the benchmark approach, there are underlying factors that prevent farmers to implement the benchmark approach. 


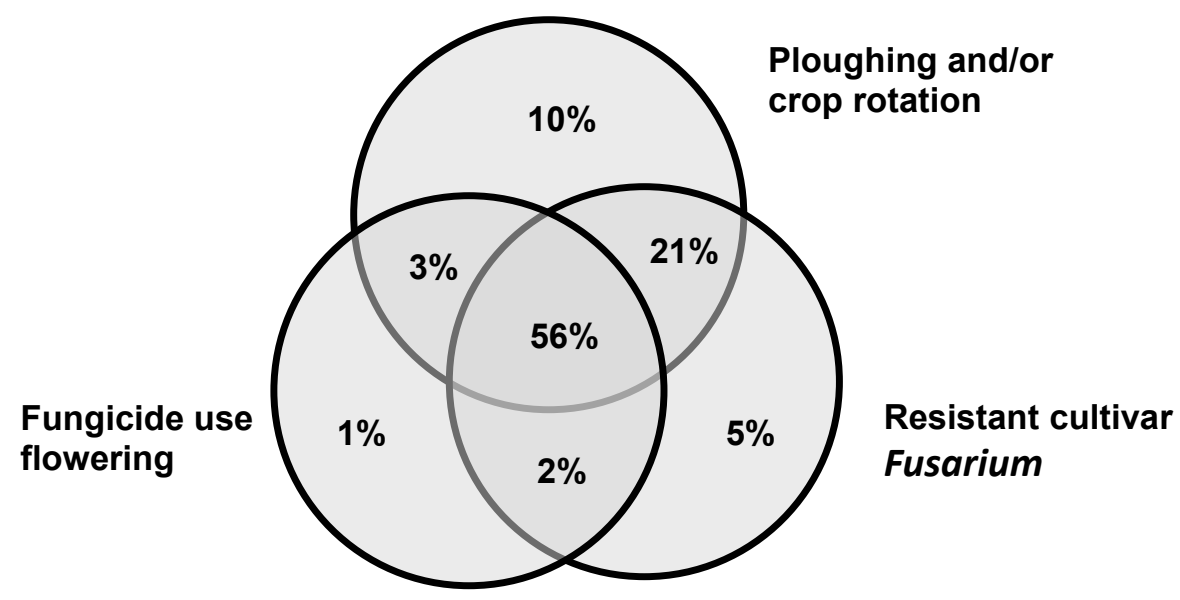

Figure 3.2. Percentage of Dutch farmers ( $n=103$ ) who used (part of) the benchmark approach consisting of fungicide use during flowering, a Fusarium resistant variety, and ploughing or crop rotation.

\subsubsection{Fungicide use}

The flexible use of fungicides during wheat flowering is effective in reducing Fusarium spp. infection (D'Angelo et al. 2014; Ioos et al. 2005; Paul et al. 2008; Yoshida et al. 2012) and is economically more attractive than fungicide use during the whole cultivation period. A reduction of pesticides, including fungicides, is better for the environment and can be cost-effective (EC 2009; Jacquet et al. 2011; Nave et al. 2013). In this study, none of the respondents were organic farmers. Results showed that $15 \%$ of the farmers did not use fungicides at all, $79 \%$ of the farmers used fungicides during the whole cultivation period of which $53 \%$ also used fungicides during flowering. Moreover, $6 \%$ of the farmers used fungicides only during flowering and not during the rest of the cultivation period. Fungicide use during flowering was perceived as an effective measure for $81 \%$ of the farmers and a cost-effective measure for $60 \%$ of the farmers (data not shown). Farmers who are more likely to implement fungicide use during flowering had wheat as the main crop and were more risk-averse. In line with results from Nave et al. (2013), farm and farmer characteristics like farm size, age, and education were not related to the implementation of fungicides (Table 3.4). Fungicide use is an operational management decision, i.e., the choice for the application can be made during the growing season. The correct timing of fungicide application can be difficult to decide since weather conditions that are favourable for Fusarium spp. infection, e.g., humidity and rainfall, often coincide with unfavourable weather conditions for the application of fungicides (D'Angelo et al. 2014). A decision support system can assist with determining the optimal time for applying fungicides. Around $17 \%$ of the Dutch farmers used a decision support system to select measures against Fusarium spp. infection (Table 3.1) and those farmers who used a decision support system were more likely to use fungicides during flowering (Table 3.4). Stimulating farmers to use a decision support system might increase a targeted fungicide use (Nave et al. 2013), improve overall mycotoxin management and reduce overall input costs (McMullen et al. 2012; Rossi et al. 2007; Rossi et al. 2015; Silva et al. 2017). 


\subsubsection{Biological control}

Multiple studies have evaluated new biological measures, not to be confused with organic agriculture, against Fusarium spp. infections, as indicated by the recent review of Shah et al. (2018). Kabak et al. (2006) indicated that biological control measures could be an addition to chemical control. The current study showed that biological control measures were implemented by $5 \%$ of the farmers in the past, whereas $20 \%$ of the farmers implemented biological control in the 2017 growing season (Table 3.2). Out of all the farmers, $25 \%$ perceived biological control as an effective and cost-effective measure (data not shown). According to the expectations, results indicated that older farmers were less likely to implement biological control measures ( $\mathrm{p}<0.10)$ (Table 3.4). In the future, once effective and affordable biological measures are available, an improvement to the current mycotoxin management might be achieved by implementing additional biological control measures.

\subsection{Conclusions}

This study explored the implementation of pre-harvest measures against Fusarium spp. infection and mycotoxin contamination and related farm and farmer characteristics. Most Dutch wheat farmers used at least six mycotoxin pre-harvest measures and their use were mutually correlated. Although many farmers already implemented multiple measures, around half of the farmers could become more effective in reducing mycotoxins in the field by implementing the highly effective benchmark approach consisting of the combination of fungicide use during flowering, selection of a Fusarium resistant variety, and ploughing or crop rotation. Furthermore, future improvements could be made by shifting from fungicide use during the whole cultivation period towards fungicide use during flowering only, and by including biological control. Farm and farmer characteristics that were positively associated with the implementation of individual pre-harvest measures were the use of wheat as the main crop, use of a decision support system, a higher level of education, a higher mycotoxin knowledge level, and a higher risk aversion. Specifically, farmers who do not have wheat as the main income crop should be reached to encourage fungicide use during flowering and to implement the benchmark approach to reduce Fusarium spp. infection. Knowing the effect of these characteristics on the use of pre-harvest measures can help, e.g., farmer cooperatives, processing industries, and government agencies to improve the overall mycotoxin management of Dutch wheat farmers. For example, this could be achieved through training and education to improve the knowledge levels of farmers and recommending the use of a decision support system which might increase better Fusarium and mycotoxin management in wheat, thereby potentially reducing overall costs. 


\section{Acknowledgments}

We gratefully acknowledge the farmers who participated in our survey and the following Dutch organizations that distributed the questionnaire among the farmers: agricultural cooperatives Agrifirm and CZAV, Van Iperen, Dutch Federation of Agriculture and Horticulture (LTO), and Dutch Arable Farming Union (NAV). We thank Jennifer L. Banach (RIKILT) for her critical comments on an earlier version of this paper and improving the English.

\section{Funding}

This study is performed as part of the MyToolbox project, which received funding from the European Union's Horizon 2020 research and innovation programme under grant agreement No. 678012. 


\section{Appendix A.3. Supplementary data}

Table A.3.1. Selected pre-harvest measures, and their related question and answer format in the questionnaire.

\begin{tabular}{|c|c|}
\hline Variable & Question \\
\hline & $\begin{array}{l}\text { Do you expect to use this measure against Fusarium spp. infection in } \\
\text { the coming year? (Yes/No) }\end{array}$ \\
\hline $\begin{array}{l}\text { Decontamination of } \\
\text { seeds }\end{array}$ & Use of decontaminated seeds \\
\hline Crop rotation & Crop rotation: no grains as pre-crop \\
\hline Ploughing & Ploughing after grain harvest \\
\hline $\begin{array}{l}\text { Resistant cultivar } \\
\text { lodging }\end{array}$ & Lower the risk of lodging by selection of a wheat variety \\
\hline Fungicide use & Fungicide use during the whole cultivation period \\
\hline $\begin{array}{l}\text { Fungicide use } \\
\text { flowering }\end{array}$ & Fungicide use around flowering \\
\hline $\begin{array}{l}\text { Resistant cultivar } \\
\text { Fusarium }\end{array}$ & Selection of a Fusarium resistant wheat variety (resistance >7) \\
\hline Biological control & Biological control \\
\hline
\end{tabular}


Table A.3.2. Selected farm and farmer characteristics, and their related question and answer format in the questionnaire.

\begin{tabular}{|c|c|c|}
\hline Variable & Question & Answer format \\
\hline \multicolumn{3}{|l|}{ Farm } \\
\hline Farm size & What is the size of your arable land in hectares? & Size in ha \\
\hline Soil type & $\begin{array}{l}\text { What is the predominant soil type on which you } \\
\text { normally grow wheat? }\end{array}$ & Multiple choice \\
\hline Organic & Do you produce organic wheat? & Yes/no \\
\hline Main crop & What is the most important crop at your arable farm? & Multiple choice \\
\hline Selling & $\begin{array}{l}\text { Do you sell your wheat via a collector/merchant, } \\
\text { directly to a feed or food producer or to others? }\end{array}$ & Multiple choice \\
\hline $\begin{array}{l}\text { Wheat } \\
\text { purpose }\end{array}$ & $\begin{array}{l}\text { Do you grow wheat for human consumption, animal } \\
\text { feed or seed production? }\end{array}$ & Multiple choice \\
\hline Past & How often you think you have had a serious & 6-point scale: \\
\hline infection & Fusarium spp. infection in wheat in the past 5 years? & $<$ never to five times $>$ \\
\hline $\begin{array}{l}\text { Decision } \\
\text { support } \\
\text { system } \\
\text { Farmer }\end{array}$ & $\begin{array}{l}\text { Do you use a decision support system to select } \\
\text { appropriate measures against Fusarium spp. } \\
\text { infection? }\end{array}$ & Yes/no \\
\hline Gender & What is your gender? & Male/Female \\
\hline Age & What is your age? & $\begin{array}{l}\text { Ten-year age } \\
\text { categories }\end{array}$ \\
\hline Education & What is your highest level of education completed? & $\begin{array}{l}\text { Eight educational } \\
\text { categories }\end{array}$ \\
\hline Risk aversion & $\begin{array}{l}\text { Are you willing to take more or less risk regarding } \\
\text { Fusarium spp. infection and mycotoxin } \\
\text { contamination compared to } \\
\text { other farmers in your community? }\end{array}$ & $\begin{array}{l}\text { 5-point scale: } \\
<\text { more to less risk> }\end{array}$ \\
\hline $\begin{array}{l}\text { Risk } \\
\text { perception }\end{array}$ & $\begin{array}{l}\text { Do you expect a serious Fusarium spp. infection in } \\
\text { the coming five years? } \\
\text { What consequences will this have? }\end{array}$ & $\begin{array}{l}\text { 5-point scale: } \\
<\text { never to often> } \\
<\text { no consequences to } \\
\text { significant } \\
\text { consequences }>\end{array}$ \\
\hline Knowledge & $\begin{array}{l}\text { Indicate whether you agree or disagree with the } \\
\text { following statements: } \\
\text { Harvest debris in the soil form a risk for Fusarium } \\
\text { spp. infection } \\
\text { You can recognize a Fusarium spp. infection by black } \\
\text { kernels } \\
\text { Fusarium spp. can also be present in maize and } \\
\text { barley } \\
\text { Fusarium spp. produce mycotoxins like DON } \\
\text { Mycotoxins could be harmful for humans }\end{array}$ & $\begin{array}{l}\text { Agree/Disagree/Don't } \\
\text { know }\end{array}$ \\
\hline
\end{tabular}




\title{
Chapter 4
}

\section{Factors underlying Dutch farmers' intentions to adapt their agronomic management to reduce Fusarium species infection in wheat}

\author{
E.M. Janssen \\ M.C.M. Mourits \\ H.J. van der Fels-Klerx \\ A.G.J.M. Oude Lansink
}

This chapter is published as:

Janssen, E. M., Mourits, M. C. M., van der Fels-Klerx, H. J., \& Oude Lansink, A. G. J. M. (2020).

Factors underlying Dutch farmers' intentions to adapt their agronomic management to

reduce Fusarium species infection in wheat. PLOS ONE, 15, e0237460

doi:10.1371/journal.pone.0237460 


\subsection{Abstract}

Infection of wheat by Fusarium species can lead to Fusarium Head Blight (FHB) and mycotoxin contamination, thereby reducing food quality and food safety, and leading to economic losses. Agronomic management through the implementation of various preharvest measures can reduce the probability of Fusarium spp. infection in the wheat field. To design interventions that could stimulate wheat farmers to (further) improve their agronomic management to reduce $\mathrm{FHB}$, it is key to understand farmers' behaviour towards adapting their management. The aim of this paper was to understand the intention, underlying behavioural constructs, and beliefs of Dutch wheat farmers to adapt their agronomic management to reduce FHB and mycotoxin contamination in wheat, applying the Theory of Planned Behaviour (TPB). Data were collected from 100 Dutch wheat farmers via a questionnaire. The standard TPB analysis was extended with an assessment of the robustness of the belief results to account for the statistical validity of the analysis on TPB beliefs (i.e. to address the so-called expectancy-value muddle). Forty-six percent of the farmers had a positive intention to change their management in the next 5 years. The two behavioural constructs significantly related to this intention were attitude and social norm, whereas association with the perceived behavioural control construct was insignificant indicating that farmers did not perceive any barriers to change their behaviour. Relevant attitudinal beliefs indicated specific attributes of wheat, namely yield, quality and safety (lower mycotoxin contamination). This indicates that strengthening these beliefs - by demonstrating that a change in management will result in a higher yield and quality and lower mycotoxin levels - will result in a stronger attitude and, subsequently, a higher intention to change management. Interventions to strengthen these beliefs should preferably go by the most important referents for social norms, which were the buyers and the farmer cooperatives in this study. 


\subsection{Introduction}

In the Netherlands, wheat is cultivated on around 7,00o farms with an annual total size of 120,00o ha (CBS 2018). During wheat cultivation, Fusarium species can infect the grain, which can lead to Fusarium Head Blight (FHB), decreasing the yield and quality of the wheat produced. Moreover, Fusarium spp. can produce mycotoxins, like deoxynivalenol $(\mathrm{DON})$, zearalenone and nivalenol, which are fungal toxic secondary metabolites that can cause adverse health effects in animals and humans upon consumption of the grain (Parry et al. 1995). Mycotoxin contamination of wheat is regularly reported in the Netherlands (Franz et al. 2009; Liu et al. 2018; Van der Fels-Klerx 2014; Van der Fels-Klerx et al. 2012a) and other countries (EFSA 2017b). Hence, legal maximum limits for the presence of mycotoxins in feed and food have been set in Europe and other parts of the world to protect animal and human health (Alim et al. 2016). Despite these limits, human exposure assessments in Europe have shown that the intake of some mycotoxins is currently above the tolerable daily intake for certain vulnerable groups (EFSA 2017a; EFSA 2017b). The past four years, two large European Union's Horizon 2020 funded research and innovation projects focussed on further reducing mycotoxin contamination in feed and food commodities like wheat (www.mycokey.eu and www.mytoolbox.eu).

Given the difficulty in removing mycotoxins during subsequent processing downstream the wheat supply chain, mycotoxin management is mainly focused on agronomic management at the arable farm (Kabak et al. 2006). Fusarium spp. present on plant debris can survive and contaminate the next planted crop. Various pre-harvest measures can be taken to reduce the probability of Fusarium spp. infection and related mycotoxin contamination, like decontamination of seeds, crop rotation, soil cultivation, selection of a wheat variety resistant to Fusarium spp. infection, and fungicide use (EC 20o6b; Parry et al. 1995; Pirgozliev et al. 2003). Decontaminated seeds are used to avoid initial fungal contamination by infected seeds (Inch and Gilbert, 2003). Tillage and ploughing bring the contaminated plant debris deeper into the soil which can avoid contamination of the next planted crop. In addition, a crop rotation scheme in which Fusarium spp. infection prone crops are not succeeding each other will decrease the chance of recontamination as well. The most effective fungicide application time was reported to be around the wheat flowering stage (Beyer et al. 2006; Blandino et al. 2012; D'Angelo et al. 2014). Additional pre-harvest measures, like novel biological control measures are currently under development and being tested, see reviews of Shah et al. (Shah et al. 2018) and Torres et al. (Torres et al. 2019). An effective way to prevent and control Fusarium spp. infection and mycotoxin contamination in wheat is to use an integrated approach consisting of a combination of effective pre-harvest measures, like the combination of fungicide use during flowering, selection of a Fusarium resistant variety, and ploughing or crop rotation (Blandino et al. 2017; Edwards 2004; Kabak et al. 2006; McMullen et al. 2012; McMullen et al. 2008; Vogelgsang et al. 2019; Wegulo et al. 2015).

Current implementation of pre-harvest measures to reduce FHB and mycotoxin contamination in wheat by Dutch farmers was studied by Janssen et al. (2019). This study showed that most Dutch farmers applied more than six pre-harvest measures against Fusarium spp. infection, while only half of the farmers used an effective integrated approach. This study also showed that $79 \%$ of the farmers used fungicides throughout the whole cultivation period whereas only $6 \%$ of the farmers used fungicides only during 
the flowering stage. In addition, $20 \%$ of the farmers used biological control measures (Janssen et al. 2019).

The optimal mycotoxin management might not fit 'sustainable agriculture' (Rose et al. 2019) in which, for example, conservation tillage is in contrast to the effective mycotoxin reduction approach of (deep) ploughing to burry soil debris to reduce Fusarium spp. infection and the use of fungicides throughout the whole cultivation period. Overall, it is expected that farmers will adapt their agronomic management in the future, for instance, to comply to new regulations, to accommodate environmental policies and/or to become more (cost-)effective. An adaptation in agronomic management to reduce FHB and mycotoxin contamination can entail the future implementation of less, more or different pre-harvest measures. These adaptations could be directed to a more effective integrated approach or a reduction in fungicide use by concentrating its use around the sensitive flowering stage or by adopting biological measures.

To be able to design interventions that adapt agronomic management for Fusarium spp. infection reduction, it is key to understand farmers' behaviour towards agronomic management. A frequently deployed method for understanding farmers' behaviour is the Theory of Planned Behaviour (TPB) with underlying behavioural constructs following from personal beliefs (Ajzen 1991). Knowledge of the underlying constructs and beliefs provides information on how to stimulate this behaviour and can provide targets for setting up incentive mechanisms. Several behavioural studies used the TPB to investigate the intentions, behavioural constructs and beliefs of farmers to manage, for example, grassland (Hyland et al. 2018), pathogen invasions in horticulture (Breukers et al. 2012), diseases in animals (Bruijnis et al. 2013; Jemberu et al. 2015; Sok et al. 2015) or agrienvironmental measures (van Dijk et al. 2016). Although the studies mentioned above give insight into farmers behaviour regarding agronomical measures, sector- and farmspecific differences were found (Breukers et al. 2012; Hyland et al. 2018; van Dijk et al. 2016; Wauters et al. 2010). This makes information on how to stimulate a certain behaviour unique to the target group and the farm and agricultural sector at hand. To date, similar studies have not been performed on agronomic management to reduce FHB and mycotoxins in wheat or other cereal crops. This study aimed to explore the intention and underlying behavioural constructs and beliefs of Dutch wheat farmers to adapt their future agronomic management to reduce FHB and mycotoxins in wheat. A questionnaire was developed based on the TPB and this questionnaire was distributed among a sample of Dutch arable farmers. The relation between the underlying behavioural constructs and intention was analysed, followed by an analysis of the relations between the beliefs and underlying constructs. This latter analysis was extended with an assessment of the robustness of the belief results, because the statistical validity of the standard analysis of the TPB beliefs has been questioned, i.e. the so-called expectancy-value muddle (French and Hankins 2003; Newton et al. 2012; Newton et al. 2014; O'Sullivan et al. 2008).

\subsection{Methods}

\subsubsection{Theory of Planned Behaviour (TPB)}

Intentions are a proximal measure of future behaviour. The stronger the intention is, the more likely the behaviour will be executed in the future. According to the TPB, intentions (INT) can be determined by three behavioural constructs: (i) attitude (ATT), (ii) perceived behavioural control (PBC), and (iii) subjective norm (SN) (Fig. 1). ATT provides 
insight into the positive or negative attitudes towards the behaviour. PBC accounts for factors outside one's control that affect behaviour, and SN accounts for the perceived social pressure. The stronger these behavioural constructs, the stronger an individual's intention to perform the behaviour.

Each of the behavioural constructs follows from personal beliefs (Figure 4.1); beliefs about the likely consequences of the behaviour (ATT beliefs), beliefs about the factors that may stimulate or prevent performance of the behaviour (PBC beliefs), and beliefs about the expectations of others (SN beliefs) (Ajzen 2006). These beliefs help to understand the drivers of farmers' behaviour and provide targets for intervention (Montaño and Kasprzyk 20o8). Targeting ATT beliefs can change a person's attitude towards the behaviour in question, and PBC beliefs provide insight into the actual barriers to perform the behaviour. SN beliefs will indicate the most important people (termed referents) in a person's decision to adapt his/her behaviour, which is useful in understanding the channels that are suited for implementing incentive mechanisms.

Overall, the TPB is a well-known method to gain insight into behaviour and allows for quantitative research by use of data obtained by questionnaires (Ajzen 1991; Hankins et al. 2000). Knowledge of the underlying constructs and beliefs provides information on how to stimulate this behaviour and can provide targets for incentive mechanisms.

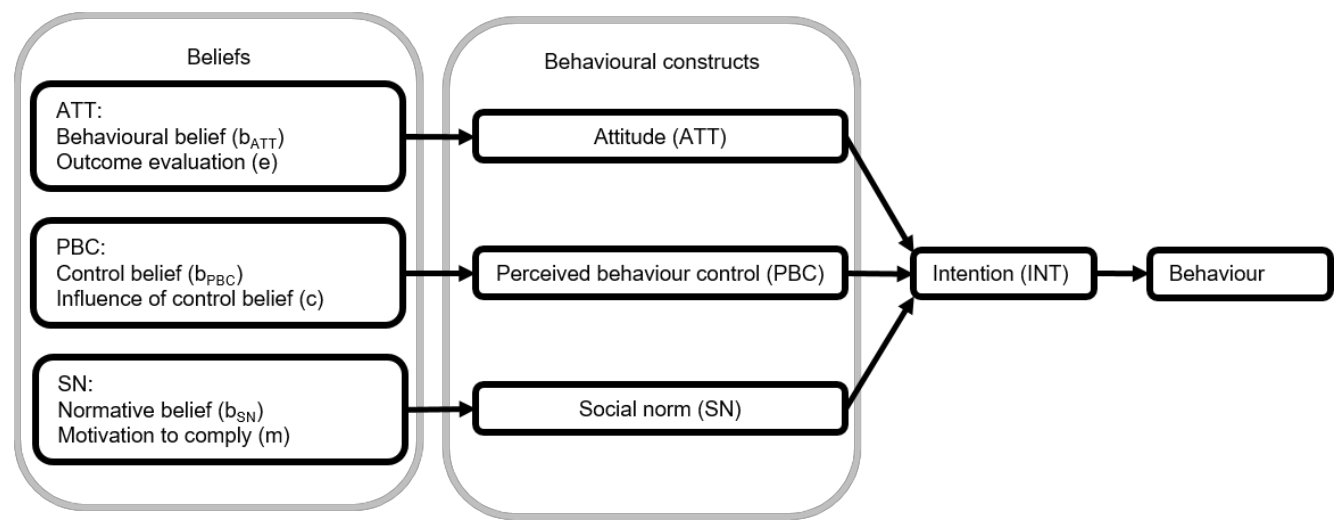

Figure 4.1. Theory of planned behaviour (Ajzen 1991; Francis 2004).

\subsubsection{Survey}

Data on TPB variables, INT, ATT, PBC and SN, and underlying beliefs were collected from 100 Dutch wheat farmers using an online questionnaire in Dutch in 2017. The mean arable land of these farmers was 95.3 ha ranging from 17.5 to 230 ha. Wheat was the main crop for $15 \%$ of the farmers, $26 \%$ produced wheat for food, and $67 \%$ experienced a Fusarium spp. infection in the past five years (Janssen et al. 2019). The questionnaire was developed based on the TPB (Francis 2004) with questions on INT, ATT, PBC and SN, and questions on belief statements. These belief statements were elicitated from commonly held beliefs during ten qualitative face-to-face interviews with farmers and added to the questionnaire. The focus of the questionnaire was on the intention of the following farmers' behaviour: 'to adapt the approach to reduce Fusarium spp. infection in the coming 5 years'. The specific questions and answer formats related to the TPB 
variables in the questionnaire are presented in Tables 4.1 and 4.2. INT, ATT, PBC and SN were measured on a 5-point textual bipolar Likert scale (e.g. strongly disagree somewhat disagree - neither agree nor disagree - somewhat agree - strongly agree). Each belief statement related to ATT, PCB and SN was measured by a belief score (b) and an outcome score; i.e. outcome evaluations (e) for ATT beliefs, the influence of control beliefs (c) for PBC beliefs, and the motivation to comply (m) for SN beliefs. Each answer on the belief statement was measured with a 5-point textual Likert answer scale representing either a unipolar scale (e.g. unlikely - slightly likely - somewhat likely very likely - extremely likely) or a bipolar scale (e.g. very unimportant - moderately unimportant - neutral - moderately important - very important) (Table 4.2).

Questions were part of a more extensive questionnaire that covered related research topics, like farm and farmer characteristics, and implementation of pre-harvest measures (Janssen et al. 2019), (cost-) effectiveness of pre-harvest measures, and incentive mechanisms among European wheat farmers as part of the European Union's Horizon 2020 MyToolbox project (Krska et al. 2016). The questionnaire was pre-tested by three Dutch farmers for clarity and consistency. Their feedback was used to adapt the online questionnaire. The link to the online questionnaire was distributed via farmers' associations by email and newsletters to Dutch wheat farmers. Farmers were incentivised to participate in the survey by offering them the chance of winning one of ten $€ 25$, - gift vouchers. Farmers could give their email address voluntarily for future contact, and all personal information was stored separately from the questionnaire output. The study protocol and consent procedure complied with the Netherlands Code of Conduct for Scientific Practice. It was approved by the Social Sciences Ethics Committee of the Wageningen University (CoC number 09131098). 
Table 4.1. Theory of Planned Behaviour (TPB) questionnaire questions and answer formats for intention (INT) and behavioural constructs attitude (ATT), perceived behavioural control (PBC), and social norm (SN).

\begin{tabular}{|c|c|c|}
\hline TPB & Question & $\begin{array}{l}\text { Possible answer - 5-point } \\
\text { scale }^{\mathrm{a}}\end{array}$ \\
\hline \multirow[t]{3}{*}{ INT } & $\begin{array}{l}\text { I expect to change my approach to reduce Fusarium } \\
\text { infection in the coming } 5 \text { years. }\end{array}$ & $\begin{array}{l}\text { Strongly disagree }<>\text { Strongly } \\
\text { agree }\end{array}$ \\
\hline & $\begin{array}{l}\text { I plan to change my approach to reduce Fusarium } \\
\text { infection in the coming } 5 \text { years. }\end{array}$ & $\begin{array}{l}\text { Strongly disagree }<>\text { Strongly } \\
\text { agree }\end{array}$ \\
\hline & $\begin{array}{l}\text { I want to change my approach to reduce Fusarium } \\
\text { infection in the coming } 5 \text { years. }\end{array}$ & $\begin{array}{l}\text { Strongly disagree }<>\text { Strongly } \\
\text { agree }\end{array}$ \\
\hline \multirow[t]{3}{*}{ ATT } & $\begin{array}{l}\text { Changing my approach to reduce Fusarium } \\
\text { infection is... }\end{array}$ & Harmful <> Beneficial \\
\hline & $\begin{array}{l}\text { Changing my approach to reduce Fusarium } \\
\text { infection is... }\end{array}$ & Necessary <> Unnecessary \\
\hline & $\begin{array}{l}\text { Changing my approach to reduce Fusarium } \\
\text { infection is... }\end{array}$ & Unimportant $<>$ Important \\
\hline \multirow[t]{3}{*}{ PBC } & $\begin{array}{l}\text { I have enough possibilities to change my approach } \\
\text { to reduce Fusarium infection. }\end{array}$ & $\begin{array}{l}\text { Strongly disagree }<>\text { Strongly } \\
\text { agree }\end{array}$ \\
\hline & $\begin{array}{l}\text { I can change my approach to reduce Fusarium } \\
\text { infection if I want to do so. }\end{array}$ & $\begin{array}{l}\text { Strongly disagree }<>\text { Strongly } \\
\text { agree }\end{array}$ \\
\hline & $\begin{array}{l}\text { Changing my approach to reduce Fusarium } \\
\text { infection is up to me and not dependent on other } \\
\text { aspects. }\end{array}$ & $\begin{array}{l}\text { Strongly disagree }<>\text { Strongly } \\
\text { agree }\end{array}$ \\
\hline \multirow[t]{3}{*}{ SN } & $\begin{array}{l}\text { Persons that are dealing with me expect that I } \\
\text { change my approach to reduce Fusarium infection. }\end{array}$ & $\begin{array}{l}\text { Strongly disagree }<>\text { Strongly } \\
\text { agree }\end{array}$ \\
\hline & $\begin{array}{l}\text { I feel social pressure to change my approach to } \\
\text { reduce Fusarium infection. }\end{array}$ & $\begin{array}{l}\text { Strongly disagree }<>\text { Strongly } \\
\text { agree }\end{array}$ \\
\hline & $\begin{array}{l}\text { Persons who are important to me, think that I } \\
\text { should change my approach to reduce Fusarium } \\
\text { infection. }\end{array}$ & $\begin{array}{l}\text { Strongly disagree }<>\text { Strongly } \\
\text { agree }\end{array}$ \\
\hline
\end{tabular}

a The answer formats were text only and reflected a bipolar answer scale $(<>)$. 
Table 4.2. Theory of planned behaviour beliefs questionnaire questions and answer formats for attitude (ATT) beliefs, perceived behavioural control (PBC) beliefs, and social norm (SN) beliefs.

\begin{tabular}{|c|c|c|}
\hline Beliefs & Question & $\begin{array}{l}\text { Possible answer - 5-point } \\
\text { scale }^{\mathrm{a}}\end{array}$ \\
\hline \multirow{6}{*}{$\begin{array}{l}\text { ATT: } \\
\text { behavioural } \\
\text { beliefs }\left(\mathrm{b}_{\mathrm{ATT}}\right)\end{array}$} & $\begin{array}{l}\text { Changing my approach to reduce Fusarium } \\
\text { infection... }\end{array}$ & \\
\hline & ...results in a higher wheat quality & Unlikely >> extremely likely \\
\hline & ...results in a higher wheat yield & Unlikely >> extremely likely \\
\hline & $\begin{array}{l}\text {...results in lower mycotoxin (DON) contamination in } \\
\text { wheat }\end{array}$ & Unlikely >> extremely likely \\
\hline & ...is not cost-effective & Unlikely >> extremely likely \\
\hline & $\begin{array}{l}\text {...is pointless because of the unpredictability of the } \\
\text { weather }\end{array}$ & Unlikely >> extremely likely \\
\hline $\begin{array}{l}\text { ATT: } \\
\text { outcome } \\
\text { evaluation } \\
\text { (e) }\end{array}$ & $\begin{array}{l}\text { Will the <attitudinal statement; e.g. higher wheat } \\
\text { quality, higher wheat yield, etc.> be important in your } \\
\text { decision to change your approach to reduce Fusarium } \\
\text { spp. infection? }\end{array}$ & $\begin{array}{l}\text { Very unimportant }<> \\
\text { Very important }\end{array}$ \\
\hline \multirow{7}{*}{$\begin{array}{l}\text { PBC: control } \\
\text { beliefs (bРC) }\end{array}$} & In order to change my approach... & \\
\hline & $\begin{array}{l}\text {...enough alternative preventive measures are } \\
\text { available }\end{array}$ & Unlikely >> extremely likely \\
\hline & ...enough cost-effective methods are available & Unlikely >> extremely likely \\
\hline & ...I have sufficient knowledge & Unlikely >> extremely likely \\
\hline & $\begin{array}{l}\text {...I have enough possibilities to obtain individual } \\
\text { advice }\end{array}$ & Unlikely >> extremely likely \\
\hline & ...I have sufficient equipment and manpower & Unlikely >> extremely likely \\
\hline & ...I have sufficient financial scope to invest & Unlikely >> extremely likely \\
\hline $\begin{array}{l}\text { PBC: } \\
\text { influence of } \\
\text { control } \\
\text { belief (c) }\end{array}$ & $\begin{array}{l}\text { Do }<P B C \text { statements; e.g. 'the availability of enough } \\
\text { alternative preventive measures', 'having sufficient } \\
\text { knowledge', etc.> make it more difficult (prevent you) } \\
\text { or easier for you (persuade you) to change your } \\
\text { approach? }\end{array}$ & $\begin{array}{l}\text { Extremely more difficult } \\
\text { (prevent) <> Extremely easier } \\
\text { (enable me) }\end{array}$ \\
\hline $\begin{array}{l}\text { SN: } \\
\text { normative } \\
\text { beliefs (bS) }\end{array}$ & $\begin{array}{l}\text { What are the opinions of the following social } \\
\text { referents (e.g. fellow farmers) about you changing } \\
\text { your approach to reduce Fusarium infection? }\end{array}$ & $\begin{array}{l}\text { Strongly oppose }<>\text { Strongly } \\
\text { favour OR not applicable }\end{array}$ \\
\hline
\end{tabular}

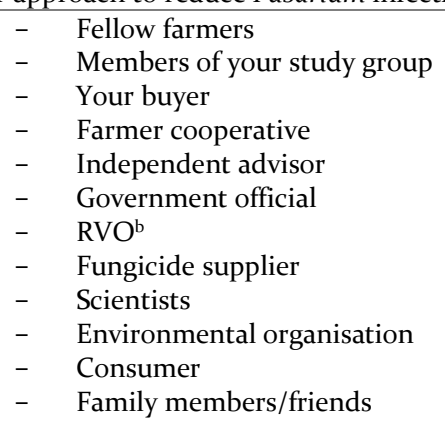

\footnotetext{
SN: $\quad$ Is the opinion of < social referent, e.g. fellow farmers $>$ motivation to comply important in your decision to change your approach to reduce Fusarium infection?

Unimportant >> Extremely important

$(\mathrm{m})$

a The answer formats were text only and reflected a bipolar answer scale $(<>)$ or a unipolar answer scale $(>>)$.

b Rijksdienst voor Ondernemend Nederland (Netherlands Enterprise Agency) is part of the Ministry of Economic Affairs and Climate Policy and works at the instigation of ministries and the European Union, aiming to improve opportunities for entrepreneurs and to strengthen their position (RVO 2018).
} 


\subsubsection{Data analysis \\ Intention and behavioural constructs}

INT and the behavioural constructs ATT, PBC, and SN were each composed of a series of three similar questions (Table 4.1. Theory of Planned Behaviour (TPB) questionnaire questions and answer formats for intention (INT) and behavioural constructs attitude (ATT), perceived behavioural control (PBC), and social norm (SN).) measured on a bipolar textual answer scale which was converted to a numeric score ranging from -2 to 2. For INT, ATT, PBC, and SN, each of their respective answer scores (based on three questions each, see Table 4.1) were measured by Cronbach alpha (Cronbach 1951) to confirm that they were internally consistent $(\mathrm{C} \alpha>0.7)$ and then combined into a single composite score by averaging the scores.

A common approach to study TPB results to understand the relationship between the different behavioural constructs and the intention (INT) of farmers is the use of a linear regression model (Hankins et al. 2000). A censored linear regression model was performed with INT as the dependent variable (which is a left and right censored variable (respectively at $\mathbf{- 2}$ and 2)), and ATT, PBC, and SN as the explanatory variables:

$$
\mathrm{y}(\mathrm{INT})=\beta_{0}+\beta_{1} \times \mathrm{ATT}+\beta_{2} \times \mathrm{PBC}+\beta_{3} \times \mathrm{SN}
$$

In addition to the regression analysis, the percentage of farmers with a negative, neutral, or positive view towards INT, ATT, PBC, and SN were determined. A score below o was labelled 'negative', a score equal to o was 'neutral', and a score above o was 'positive'.

\section{Beliefs}

Beliefs were measured by two composites: (i) the strength of a belief score (b $\mathrm{b}_{\text {ATT }}$, bPBC, or $\mathrm{b}_{\mathrm{SN}}$ ) and (ii) an outcome score (e, c, or $\mathrm{m}$ ) (Table 4.2). It is common to multiply the belief score (expectancy) with the outcome score (Ajzen 1991) - also called the expectancy-value model - to measure a belief, resulting in a multiplicative composite:

$$
\begin{aligned}
\text { ATT belief } & =b_{A T T} \times \mathrm{e} \\
\text { PBC belief } & \left.=b_{P B C} \times \mathrm{c}\right) \\
\text { SN belief } & =b_{S N} \times \mathrm{m}(4)
\end{aligned}
$$

This multiplicative composite of the belief can be used in a regression or correlation analysis to find the beliefs significantly related to their behavioural construct. However, several studies questioned the statistical validity of the expectancy-value model's multiplicative composite, the so-called expectancy-value muddle (French and Hankins 2003; Newton et al. 2012; Newton et al. 2014; O'Sullivan et al. 2008). For example, the size of correlation coefficients between a belief and its construct can vary according to the answer scale, especially when the scale includes zero as in a bipolar answer scale. Also, beliefs calculated as multiplicative composites are difficult to interpret and do not represent what is intended by the TPB (Hankins et al. 200o). A suggested solution is to avoid the use of the multiplicative composites and only use the basic belief score (b) (Newton et al. 2012; Newton et al. 2014; O'Sullivan et al. 2008). 
So, literature is not conclusive on which answer scale to use to calculate the multiplicative composites. Hence, in this study, results from the basic belief score and several multiplicative composites based on different answer scales were compared to the results from the multiplicative composite based on the textual scale used in the questionnaire (Table 4.2), to check the robustness of the results. Therefore, the textual belief- and outcome scores were converted to both a unipolar (1 to 5) and a bipolar answer scale (-2 to 2 ), independent of their textual answer scale. Thus, four different multiplicative composites of the beliefs were calculated: (i) unipolar belief score $x$ unipolar outcome score (uni-uni); (ii) unipolar belief score $\times$ bipolar outcome score (unibi); (iii) bipolar belief score $\times$ unipolar outcome score (bi-uni); (iv) bipolar belief score $\times$ bipolar outcome score (bi-bi). Correlation coefficients were calculated to understand which beliefs underlie the behavioural constructs of Dutch wheat farmers. Per belief, a correlation coefficient was calculated between the belief score (b) and their corresponding behavioural construct (ATT, $\mathrm{PBC}$ or $\mathrm{SN}$ ), and between the four multiplicative composites and their corresponding construct.

\section{Salient beliefs}

In addition to knowing which beliefs underlie the behavioural constructs, the number of farmers with a salient individual belief was determined. If a belief is salient, it means that farmers already hold this belief and that strengthening this belief will result in a stronger behavioural construct. The selection of salient beliefs could be determined by individual respondents or by elicitation of commonly held beliefs among a sample group (Rutter and Bunce 1989). Commonly held beliefs from the elicitation study were classified as salient based on the score of individual farmers for the outcome scores. For ATT beliefs, those farmers were selected who think that the belief is important in their decision, i.e. if the score of outcome evaluation (e) $>0$ when measured on a -2 to 2 scale. Farmers had salient PBC beliefs if they indicated that the belief makes the decision either easier or more difficult, i.e. the influence control $(\mathrm{c}) \neq 0$ on a -2 to 2 scale. Farmers had a salient SN belief if they indicated not applicable (NA) at the belief score (b) question or selected in the motivation to comply question (m) that a referent is important in their decision $(\mathrm{m}>1$ on a 1 to 5 scale).

\subsection{Results}

\subsubsection{Intention}

Most Dutch farmers had a positive $(46 \%)$ or a neutral (33\%) intention to adapt their agronomic management to reduce FHB and mycotoxin contamination in the coming five years (INT), while $21 \%$ of the farmers had a negative intention towards a future adaptation (Fig. 2). Sixty percent of the farmers had a positive ATT towards adapting their agronomic management, while fifteen percent had a negative ATT. About 50\% of the farmers scored positive for PBC. Another 25\% scored negative for PBC. Most farmers $(78 \%)$ did not feel social pressure to adapt; Figure $\mathbf{4 . 2}$ shows that only $9 \%$ scored positively for SN. 


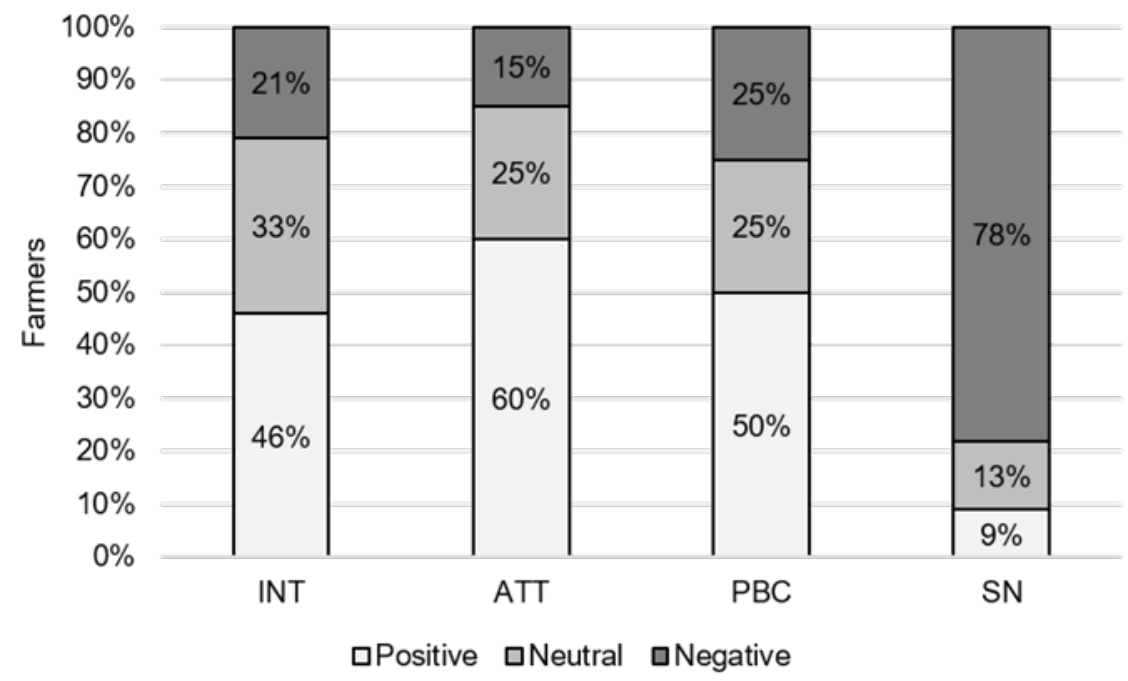

Figure 4.2. Intention (INT) of farmers towards adapting their Fusarium spp. management, and their underlying attitude (ATT), perceived behavioural control (PBC), and social norm (SN) (\% negative, neutral, or positive).

\subsubsection{Explanation of intention by behavioural constructs}

Figure 4.3 shows the results of the censored regression of ATT, PBC, and SN on intention. ATT was related to INT with a positive regression coefficient of 0.42 . SN was related to the intention with a positive coefficient of 0.30 , and PBC was not significantly related to intention.

\subsubsection{Beliefs}

The ATT beliefs with the highest scores were 'higher wheat yield' and 'lower mycotoxin contamination in wheat' (Table 4.3). The belief that was salient for most farmers $(87 \%)$ was 'higher wheat yield'. The PBC beliefs with the highest scores were 'having enough possibilities to obtain individual advice' and 'having sufficient materials and manpower' (Table 4.4). The PBC beliefs salient for most farmers were 'the availability of enough alternative preventive measures' (78\%) and 'the availability of cost-effective measures' (76\%). The referents salient for most farmers were buyers and farmer cooperatives each with $87 \%$, followed by the consumer with $74 \%$ of the farmers (Table $4 \cdot 5$ ). 


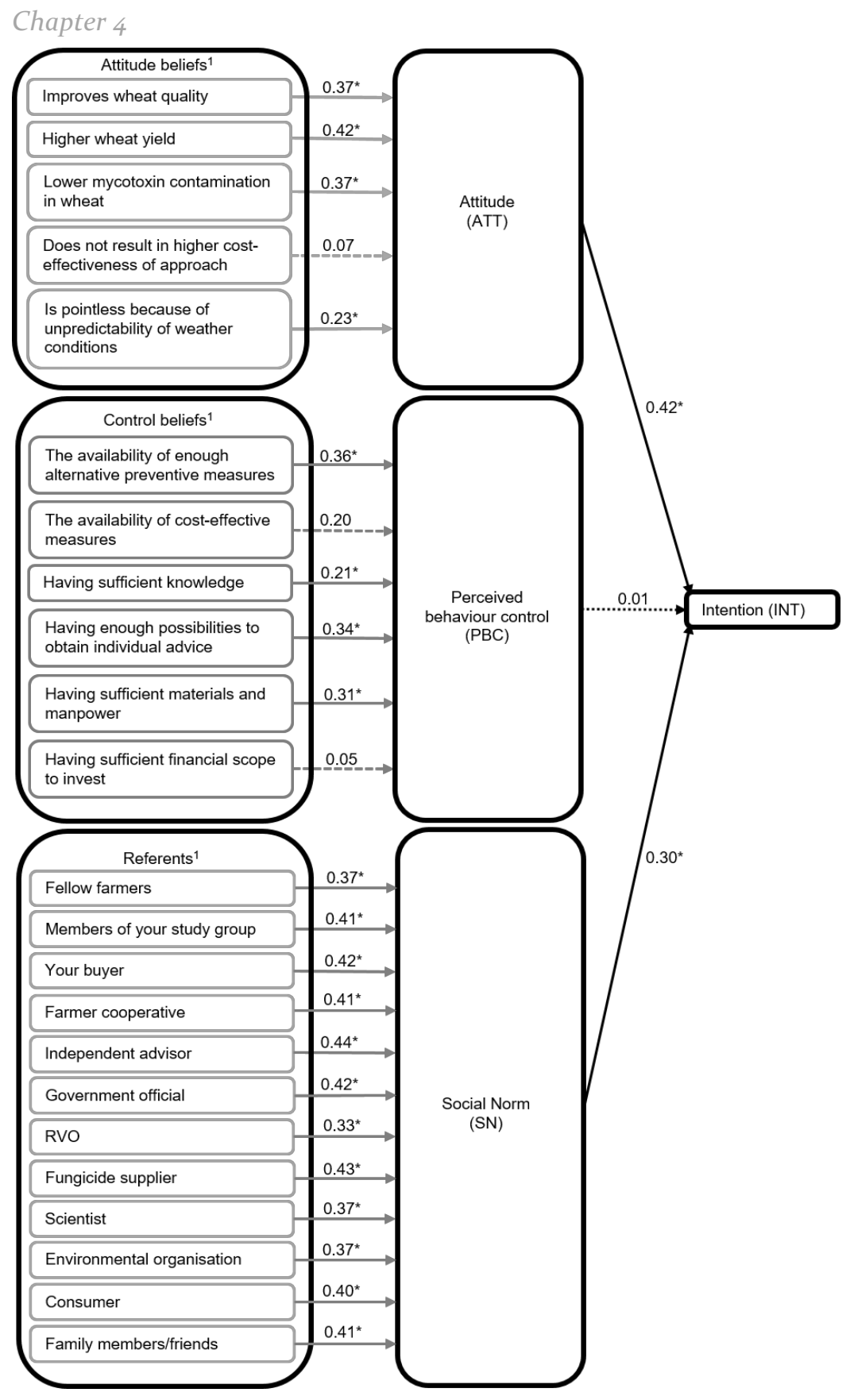

Figure 4.3. Regression and correlation coefficients of the TPB analysis. Regression coefficients (black arrows) of attitude (ATT), perceived behaviour control (PBC), and social norm (SN) as independent variables and intention as the dependent variable. Correlation coefficients (grey arrows) between the ATT, PCB and SN beliefs and their respective behavioural construct. ${ }^{1}$ Multiplicative composite of the beliefs reflecting the questionnaire answer scale: uni-bi = unipolar belief score $\times$ bipolar outcome score for ATT and PBC beliefs and bi-uni = bipolar belief score $\times$ bipolar outcome score for SN referents. 
Table 4.3. Average score for attitudinal (ATT) beliefs and the percentage of farmers for which the belief is salient $(n=92)$.

\begin{tabular}{llllll}
\hline & \multicolumn{2}{l}{$\begin{array}{l}\text { Behavioural beliefs } \\
\text { (b) } \\
\text { Answer scale } \\
{[\mathbf{1} \text { to 5] }}\end{array}$} & $\begin{array}{l}\text { Outcome } \\
\text { evaluations (e) } \\
\text { Answer scale }\end{array}$ & Salient \\
& Mean & Stdev & Mean & Stdev & $\begin{array}{l}\text { \% of } \\
\text { farmers }\end{array}$ \\
\cline { 2 - 6 } & 3.2 & 1.1 & 1.0 & 0.8 & 77 \\
Higher wheat quality & 3.3 & 1.2 & 1.3 & 0.8 & 87 \\
$\begin{array}{l}\text { Higher wheat yield } \\
\text { Lower mycotoxin contamination in } \\
\text { wheat }\end{array}$ & 3.5 & 1.1 & 1.0 & 0.8 & 78 \\
$\begin{array}{l}\text { Does not result in higher cost- } \\
\text { effectiveness of approach }\end{array}$ & 2.8 & 1.1 & 1.1 & 0.9 & 78 \\
$\begin{array}{l}\text { Is pointless because of unpredictability } \\
\text { of weather conditions }\end{array}$ & 3.0 & 1.2 & 0.9 & 0.9 & 65 \\
\hline
\end{tabular}

Table 4.4. Average score for perceived behavioural control (PBC) beliefs and the percentage of farmers for which the belief is salient $(\mathrm{n}=85)$.

\begin{tabular}{|c|c|c|c|c|c|}
\hline & \multicolumn{2}{|c|}{$\begin{array}{l}\text { Control beliefs }(\mathrm{b}) \\
\text { Answer scale } \\
{\left[\begin{array}{lll}1 & \text { to } & 5\end{array}\right]}\end{array}$} & \multicolumn{2}{|c|}{$\begin{array}{l}\text { Influence of } \\
\text { control beliefs } \\
\text { (c) } \\
\text { Answer scale } \\
{\left[\begin{array}{ll}-2 \text { to } 2]\end{array}\right.}\end{array}$} & \multirow{2}{*}{$\begin{array}{l}\text { Salient } \\
\\
\begin{array}{l}\text { \% of } \\
\text { farmers }\end{array}\end{array}$} \\
\hline & Mean & Stdev & Mean & Stdev & \\
\hline $\begin{array}{l}\text { The availability of enough alternative } \\
\text { preventive measures }\end{array}$ & 2.4 & 1.0 & 0.7 & 1.0 & 78 \\
\hline $\begin{array}{l}\text { The availability of cost-effective } \\
\text { measures }\end{array}$ & 2.2 & 0.9 & 0.7 & 1.1 & 76 \\
\hline Having sufficient knowledge & 2.8 & 1.1 & 0.5 & 0.9 & 69 \\
\hline $\begin{array}{l}\text { Having enough possibilities to obtain } \\
\text { individual advice }\end{array}$ & $3 \cdot 5$ & 1.0 & 0.6 & 0.8 & 58 \\
\hline $\begin{array}{l}\text { Having sufficient materials and } \\
\text { manpower }\end{array}$ & 3.5 & 1.0 & 0.5 & 0.7 & 53 \\
\hline $\begin{array}{l}\text { Having sufficient financial scope to } \\
\text { invest }\end{array}$ & 3.1 & 1.1 & 0.6 & 0.9 & 57 \\
\hline
\end{tabular}




\section{Chapter 4}

Table 4.5. Average score social norm (SN) beliefs and the percentage of farmers for which the belief is salient $(n=83)$.

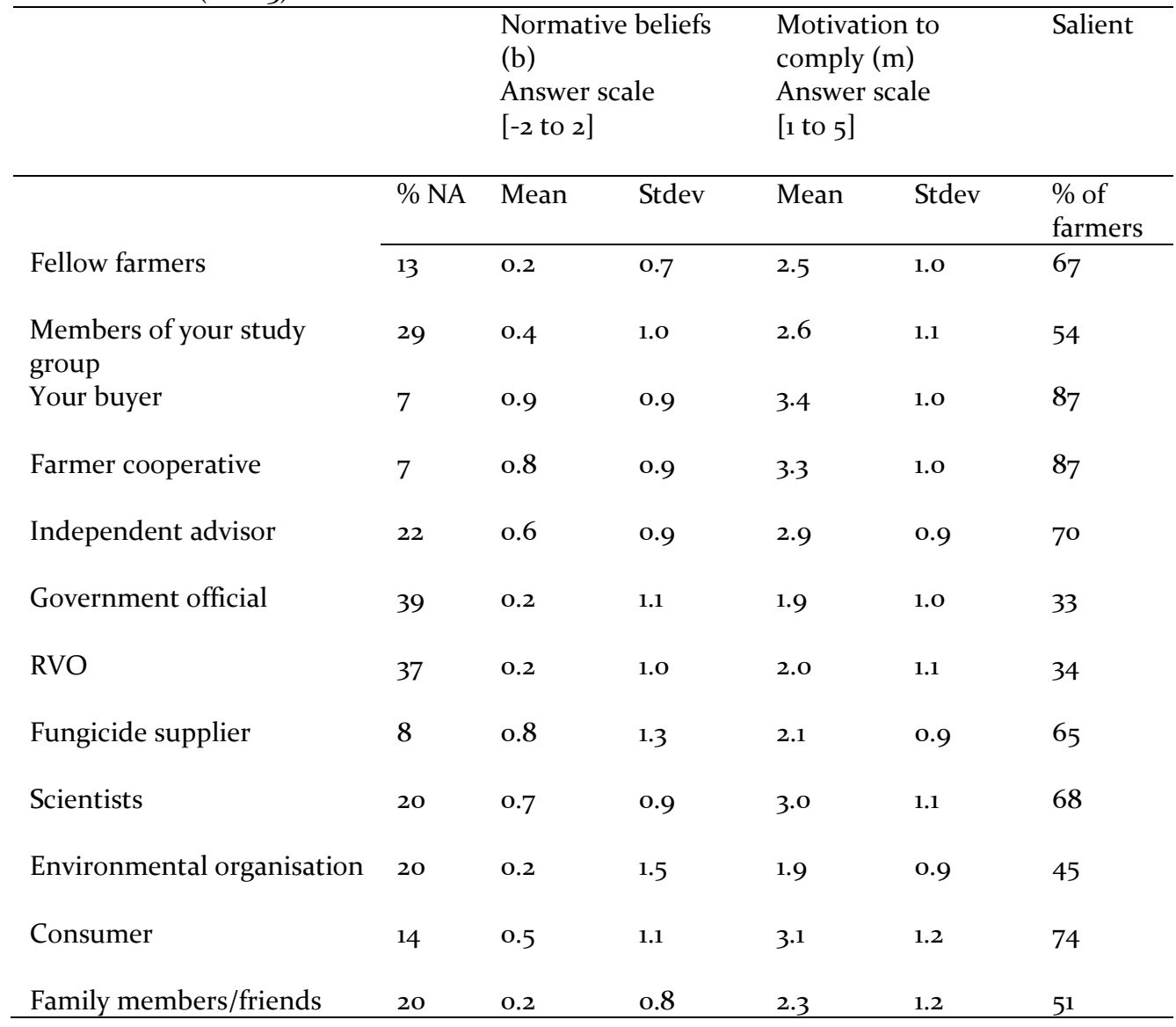




\subsubsection{Correlation between beliefs and behavioural constructs}

Of the five ATT beliefs, three had a positive correlation with ATT. These beliefs are 'higher wheat quality', 'higher wheat yield', and 'lower mycotoxin contamination in wheat' (Table 4.6). The belief 'is pointless because of the unpredictability of weather conditions' was significantly correlated to ATT when scaled according to the questionnaire answer scale, but insignificant when based on the additional four scales (Table 4.6). Four of the six PBC beliefs were significantly related to the PBC construct when scaled according to the answer scale (Table 4.7). However, when taking the other scaling options into account, only three beliefs were important because they were significantly underlying the $\mathrm{PBC}$ in a minimum of four out of the five scaling options. These three beliefs were: (i) 'the availability of enough alternative preventive measures', (ii) 'having enough possibilities to obtain individual advice', and (iii) 'having sufficient materials and manpower'. All referents were significantly related to the SN when measured on the scale reflecting the answer format and when scaled on a uni-uni scale or the basic belief score. When scaled on a uni-bi scale, only four referents were significantly related to the $\mathrm{SN}$, and when scaled on a bi-bi scale, only the buyer was significantly related to the SN (Table 4.8).

Table 4.6. Correlation coefficients between the ATT belief score (b) and the ATT construct, and between the four ATT multiplicative composites (uni-bi, uni-uni, bi-uni, bi-bi), and the ATT construct.

\begin{tabular}{llllll}
\hline ATT belief & $\begin{array}{l}\text { uni } \\
-\mathbf{b i}^{\mathbf{1}}\end{array}$ & $\begin{array}{l}\text { uni- } \\
\mathbf{u n i}^{2}\end{array}$ & $\begin{array}{l}\text { bi- } \\
\text { uni }\end{array}$ & $\begin{array}{l}\text { bi- } \\
\text { bi }\end{array}$ & $\mathbf{b}$ \\
\hline Improves wheat quality & $0.37^{*}$ & $0.47^{*}$ & $0.47^{*}$ & $0.36^{*}$ & $0.49^{*}$ \\
$\begin{array}{l}\text { Higher wheat yield } \\
\text { Lower mycotoxin contamination in wheat }\end{array}$ & $0.42^{*}$ & $0.46^{*}$ & $0.44^{*}$ & $0.45^{*}$ & $0.42^{*}$ \\
$\begin{array}{l}\text { Does not result in higher cost-effectiveness of } \\
\text { approach }\end{array}$ & 0.07 & 0.10 & 0.08 & 0.04 & 0.10 \\
$\begin{array}{l}\text { Is pointless because of unpredictability of weather } \\
\text { conditions }\end{array}$ & $0.23^{*}$ & 0.10 & -0.03 & -0.01 & -0.04 \\
\hline
\end{tabular}

${ }^{*} p<0.05 ;{ }^{1}$ Multiplicative composite of the belief reflecting the questionnaire answer scale: uni-bi $=$ unipolar belief score $\times$ bipolar outcome score; ${ }^{2}$ Other multiplicative composites: uni-uni $=$ unipolar belief score $\times$ unipolar outcome score; bi-uni $=$ bipolar belief score $\times$ bipolar outcome score; bi-bi = bipolar belief score $\times$ bipolar outcome score; $b=$ unipolar belief score. 


\section{Chapter 4}

Table 4.7. Correlation coefficients between the PBC belief score (b) and the PBC construct, and between the four PBC multiplicative composites (uni-bi, uni-uni, bi-uni, bi-bi), and the PBC construct.

\begin{tabular}{lccccc}
\hline PBC belief & $\begin{array}{c}\text { uni- } \\
\mathbf{b i}^{1}\end{array}$ & $\begin{array}{c}\mathbf{u n i}- \\
\mathbf{u n i}^{2}\end{array}$ & $\begin{array}{c}\mathbf{b i}^{-} \\
\mathbf{u n i}\end{array}$ & $\begin{array}{c}\text { bi- } \\
\text { bi }\end{array}$ & b \\
\hline $\begin{array}{l}\text { The availability of enough alternative preventive } \\
\text { measures }\end{array}$ & $0.36^{*}$ & $0.52^{*}$ & $0.51^{*}$ & $0.32^{*}$ & $0.53^{*}$ \\
$\begin{array}{l}\text { The availability of cost-effective measures } \\
\text { Having sufficient knowledge }\end{array}$ & 0.20 & $0.36^{*}$ & $0.32^{*}$ & 0.09 & $0.39^{*}$ \\
$\begin{array}{l}\text { Having enough possibilities to obtain individual } \\
\text { advice }\end{array}$ & $0.21^{*}$ & 0.17 & 0.10 & 0.11 & 0.08 \\
$\begin{array}{l}\text { Having sufficient materials and manpower } \\
\text { Having sufficient financial scope to invest }\end{array}$ & $0.34^{*}$ & $0.28^{*}$ & $0.25^{*}$ & $0.46^{*}$ & 0.14 \\
& 0.05 & 0.06 & 0.14 & $0.26^{*}$ & 0.08 \\
\hline
\end{tabular}

${ }^{*} p<0.05 ;^{1}$ Multiplicative composite of the belief reflecting the questionnaire answer scale: uni-bi $=$ unipolar belief score $\times$ bipolar outcome score ${ }^{2}$ Other multiplicative composites: uni-uni $=$ unipolar belief score $\times$ unipolar outcome score; bi-uni $=$ bipolar belief score $\times$ bipolar outcome score; bi-bi = bipolar belief score $\times$ bipolar outcome score; $b=$ unipolar belief score.

Table 4.8. Correlation coefficients between the SN belief score (b) and the SN construct, and between the four SN multiplicative composites (bi-uni, uni-uni, uni-bi, bi-bi), and the SN construct.

\begin{tabular}{llllll}
\hline SN belief (referent) & $\begin{array}{l}\text { bi- }^{-} \\
\mathbf{u n i}^{\mathbf{1}}\end{array}$ & $\begin{array}{l}\mathbf{u n i}^{-} \\
\mathbf{u n i}^{2}\end{array}$ & $\begin{array}{l}\text { uni- } \\
\text { bi }\end{array}$ & $\begin{array}{l}\text { bi- } \\
\text { bi }\end{array}$ & $\mathbf{b}$ \\
\hline Fellow farmers & $0.37^{*}$ & $0.35^{*}$ & 0.18 & -0.13 & $0.36^{*}$ \\
Members of your study group & $0.41^{*}$ & $0.35^{*}$ & 0.19 & 0.00 & $0.40^{*}$ \\
Your buyer & $0.42^{*}$ & $0.37^{*}$ & $0.24^{*}$ & $0.25^{*}$ & $0.40^{*}$ \\
Farmer cooperative & $0.41^{*}$ & $0.35^{*}$ & 0.21 & 0.21 & $0.41^{*}$ \\
Independent advisor & $0.44^{*}$ & $0.37^{*}$ & 0.19 & 0.10 & $0.40^{*}$ \\
Government official & $0.42^{*}$ & $0.49^{*}$ & $0.33^{*}$ & -0.11 & $0.37^{*}$ \\
RVO & $0.33^{*}$ & $0.45^{*}$ & $0.32^{*}$ & -0.15 & $0.33^{*}$ \\
Fungicide supplier & $0.43^{*}$ & $0.47^{*}$ & $0.28^{*}$ & 0.01 & $0.32^{*}$ \\
Scientists & $0.37^{*}$ & $0.35^{*}$ & 0.24 & 0.12 & $0.34^{*}$ \\
Environmental organisation & $0.37^{*}$ & $0.41^{*}$ & 0.19 & -0.13 & $0.30^{*}$ \\
Consumer & $0.40^{*}$ & $0.34^{*}$ & 0.18 & -0.02 & $0.42^{*}$ \\
Family members/friends & $0.41^{*}$ & $0.34^{*}$ & 0.14 & -0.15 & $0.47^{*}$ \\
\hline
\end{tabular}

${ }^{*} p<0.05 ;{ }^{1}$ Multiplicative composite of the belief reflecting the questionnaire answer scale: bi-uni = bipolar belief score $\times$ bipolar outcome score (reflects the questionnaire answer scale);

${ }^{2}$ Other multiplicative composites: uni-uni $=$ unipolar belief score $\times$ unipolar outcome score; unibi $=$ unipolar belief score $\times$ bipolar outcome score; bi-bi $=$ bipolar belief score $\times$ bipolar outcome score; $\mathrm{b}=$ unipolar belief score. 


\subsection{Discussion}

This study collected and analysed questionnaire data on Dutch farmers' behaviour regarding adaptations in their future agronomic management to reduce FHB and mycotoxins in wheat, by looking into their intentions, the underlying behavioural constructs and beliefs (TPB model). To the best of our knowledge, no study investigated these aspects for agronomic management to reduce FHB and mycotoxins in wheat before. Two related studies showed that the belief 'increase in soil fungi' was negatively related to an attitude to increase soil organic matter in the Netherlands (Hijbeek et al. 2018). And the belief 'Increase risk of fungal diseases' was not a significant driver to adopt incorporation of crop residue in the soil (a well-known measure against Fusarium spp. infection), as surveyed among Italian farmers (Bechini et al. 2015).

Results of this study show that $46 \%$ of the farmers had the intention to adapt their agronomic management to reduce FHB and mycotoxin contamination in wheat, whereas $21 \%$ had no such intention. No difference was found in the current agronomic management between farmers with an intention, a neutral intention, or no intention, i.e. there were no correlations between the number of measures taken and farmer's intention (Spearman's correlation $\mathrm{p}<0.05$ ) and between the implementation of the benchmark approach and farmer's intention (chi-square, $\mathrm{p}<0.05$ ). This is in contrast with Bruijnis et $a l$. who found that farmers with no intention are unable to change because they already implemented multiple measures. Since there is an intention-behaviour gap, not all people with a positive intention will change their behaviour (Fishbein and Yzer 2003). The exact percentage of farmers that will follow through with their positive intention could not be determined, because we performed a cross-sectional rather than a longitudinal study. In general, TPB models explain up to $50 \%$ of the variance for intention and less than that for predicting behaviour (Sutton 1998). Hence, less than $46 \%$ of the wheat farmers with a positive intention are expected to adapt their agronomic management in the future. Reasons for not following through with the actual behaviour are a changed intention or being unable to act on the intentions because of lack of skills or environmental factors (Fishbein and Yzer 2003). Incentive mechanisms should focus on farmers who have no intention to convert them into farmers with an intention, as well as focus on farmers who already have an intention to strengthen this intention and herewith decrease the potential intention-behaviour gap.

According to the TPB, people will have strong intentions if they evaluate the behaviour positively (ATT), if they think that there are no barriers to perform the behaviour (PBC), and if they believe that their social environment (SN) would want them to perform it (Sutton 1998). The relative weights of these behavioural constructs on the intention give targets to achieve behavioural change (Montaño and Kasprzyk 2008). Results show that, in general, farmers $(60 \%)$ think a change in their agronomic management is beneficial (i.e. a positive ATT), an outcome that was also found by Breukers et al. (Breukers et al. 2012). Results of the current study showed that both ATT and SN (social environment) are positively and statistically significantly related to the intention of Dutch wheat farmers to adapt their agronomic management in the coming five years. Interestingly, PBC showed not to be a significant contributor to intention, implying that most farmers feel that they have enough opportunity to change and perceive no barriers to change. Although it was expected that PBC and related control beliefs, like financial scope and 
the availability of alternative pre-harvested measures, are important factors for farmers to determine to adapt their agronomic management in the future, for Dutch wheat farmers regarding Fusarium spp. management, this is not the case. This is in contrast to Breukers et al. who concluded that Dutch horticultural growers were found to be willing to apply risk management measures, and that poor risk management was mainly due to perceived barriers, such as high costs and doubts regarding efficacy of management measures (Breukers et al. 2012).

To be able to stimulate Dutch farmers to adapt their agronomic management in the future, the focus should be on strengthening and changing ATT by targeting significant ATT beliefs, through the most important SN beliefs (social referents). Although the ATT belief statements studied here are specifically elicited from wheat farmers regarding agronomic Fusarium spp. management in the elicitation study, not all these belief statements are relevant. Only the beliefs that are related to their specific behavioural TPB construct are worth focussing on. Results show that important ATT beliefs are closely related because they focus on specific attributes of the grain, namely yield, quality, and safety (lower mycotoxin contamination) and that these beliefs are salient for most $(77-87 \%)$ of the Dutch wheat farmers. If a belief is salient, it means that farmers already hold this belief and that strengthening this belief will result in a stronger behavioural construct. For the remaining farmers, the beliefs are not salient, and the focus should be on converting farmers to believe; however, the ability to change someone's belief is a subjective judgement and cannot always be achieved in practice (Fishbein and Yzer 2003).

The standard method used for measuring beliefs in the TPB by multiplicative composites can lead to statistically uninterpretable results, the so-called 'expectancy-value muddle' (French and Hankins 2003; Newton et al. 2012; Newton et al. 2014; O'Sullivan et al. 2008). The use of a single belief score might be sufficient in determining important beliefs (Hankins et al. 200o). Two studies compared this basic belief score with the multiplicative composites scores in regression models and concluded that the expectancy-value model was appropriate (Elliott et al. 2005) and had only marginally better predictive power (Chan et al. 2015). However, these studies did not test the effect of their multiplicative composites answer scales on the results, as suggested by Hardeman et al. (Hardeman et al. 2013). In the current study, the effect of analysing the questionnaire data with different answer scales was included, to check the robustness of the results based on the standard questionnaire text scale to calculate the beliefs' multiplicative composites. Results showed that the type of applied answer scale affected the statistical significance of the correlation between a belief and its behavioural construct (Tables 4.7-4.9). For example, in all the tested multiplicative composites, three out of five ATT beliefs were significantly correlated to the ATT construct. However, when the belief was scored on a unipolar scale and the evaluation score on a bipolar scale, an additional belief is significantly related to the ATT, suggesting that the answer scale does affect the results. This is further strengthened by the results of PBC beliefs and SN beliefs, which showed that the applied scaling influenced the outcomes and eventually the conclusions that are drawn from the study. Although the conclusions on the significant ATT beliefs are robust to the scaling used, for PBC beliefs and SN beliefs, they are not. Hence, it is important to include scaling effects to show the robustness of the results in future studies. 
Interventions to strengthen or change farmers' beliefs should go via the most important referents, namely the buyers and farmer cooperatives, because they can effectively deliver information and motivate the farmers to act. This observation means that the opinions of these social referents are important in farmers' decision to change their approach. Consequently, if buyers and farmer cooperatives can show farmers that a change in their future agronomic management can improve their wheat quality, yield, and safety (lower mycotoxin contamination), then their belief is strengthened. Accordingly, this may lead to a definite change in agronomic management. Farmer cooperatives can achieve this, for example, by communicating these outcomes to their members through short communications, lectures, or on-farm demonstrations in which the benefits of adapting agronomic management on FHB and mycotoxin contamination are demonstrated on experimental farms.

\subsection{Conclusion}

This study explored the intention, underlying behavioural constructs, and beliefs of Dutch wheat farmers to adapt their agronomic management to reduce $\mathrm{FHB}$ and mycotoxin contamination in wheat in the coming 5 years. Forty-six percent of the Dutch wheat farmers have the intention to adapt their agronomic management. Attitude and social norm underlie the intention of farmers to adapt their management, whereas perceived behavioural control is not a significant contributor to this intention, implying farmers feel that they perceive no barriers to change. The most important underlying beliefs for attitude are 'higher wheat yield', 'higher wheat quality', 'lower mycotoxin contamination', and the most important referents are the buyers and farmer cooperatives. Hence, if buyers and farmer cooperatives can show farmers that a change in their future agronomic management can improve their wheat quality, yield, and safety (lower mycotoxin contamination), then a farmer's belief is strengthened or changed, and this may lead to a definite change in future agronomic management.

\section{Acknowledgements}

We gratefully acknowledge the farmers who participated in our survey and the following Dutch organisations that distributed the questionnaire among the farmers: agricultural cooperatives Agrifirm and CZAV, Van Iperen, Dutch Federation of Agriculture and Horticulture (LTO), and Dutch Arable Farming Union (NAV). We thank J.L. Banach (Wageningen Food Safety Research) for improving the English in an earlier version of the paper.

\section{Funding}

This study is performed as part of the MyToolbox project, which received funding from the European Union's Horizon 2020 research and innovation programme under grant agreement No. 678012 . 


\title{
Chapter 5
}

\section{Incentives to stimulate European wheat farmers to adapt their Fusarium species mycotoxin management}

\author{
E.M. Janssen \\ M.C.M. Mourits \\ H.J. van der Fels-Klerx \\ A.G.J.M. Oude Lansink
}

A modified version of this chapter is submitted for publication as:

Janssen, E. M., Mourits, M. C. M., Oude Lansink, A. G. J. M.\& van der Fels-Klerx, H. J., (2021). Incentives to stimulate European wheat farmers to adapt their Fusarium species mycotoxin management. 


\section{Abstract}

Fusarium species infection in wheat can lead to Fusarium Head Blight (FHB) and contamination with mycotoxins. Farmers manage this infection through the implementation of different pre-harvest control- and preventive measures in their agronomic management. A better understanding of farmers' behaviour towards adapting their agronomic management is needed for designing interventions to reduce mycotoxins in wheat. This study aimed to identify incentives that could stimulate European farmers to adapt their agronomic management to reduce Fusarium spp. infection and related mycotoxins in wheat. The study investigated different incentives through a questionnaire amongst wheat farmers from Italy, the Netherlands, Serbia, and the United Kingdom. Bayesian Network modelling was applied to estimate the probability that farmers would adapt their current management practices under different incentives. The current intention of European wheat farmers to adapt their agronomic approach to reduce Fusarium spp. infection was positive for $51 \%$ of the farmers, although this number varied between the four countries. Results showed that most of the farmers would adapt their current management practices under the incentives 'paid extra when wheat contains low levels of mycotoxins' and under the incentive 'wheat is tested for the presence of mycotoxins for free'. Incentivization of farmers depended on farm and farmer characteristics like country, crop type, size of arable land, soil type, education, and mycotoxin knowledge. Insights into the farm and farmer characteristics related to incentives can help stakeholders in the wheat supply chain, like farmer cooperatives and the government, to design tailor-made incentive plans. 


\subsection{Introduction}

Fusarium species infection in wheat can lead to yield losses and a decrease in food quality and safety, by the development of Fusarium Head Blight (FHB) and contamination of the wheat with mycotoxins, like zearalenones, fumonisins and the trichothecenes deoxynivalenol (DON), nivalenol (NIV), and T-2/HT-2 toxins. Occurrence studies show that Fusarium mycotoxins are regularly found above the European Union (EU) legal limit in wheat and wheat products (EFSA 2011b; EFSA 2017a; EFSA 2017b). Exposure assessments show that the European human intake of Fusarium mycotoxins is close to the tolerable daily intake for animals and some human (sub) populations (De Boevre et al. 2013; EFSA 2013; EFSA 2017a; Janssen et al. 2015; Sirot et al. 2013). Mycotoxins are chemically stable substances and difficult to remove further along the wheat supply chain, implying the high relevance of prevention and control Fusarium spp. infection in the field by agronomic management. However, occurrence of FHB and related toxins in wheat strongly depends on climate and local weather conditions (EC 20o6b; Kharbikar et al. 2015; Kriss et al. 2012). Farmers cope with weather-induced risks by implementing different agronomic management measures to reduce FHB and mycotoxin contamination. One of the most efficient ways to reduce FHB and mycotoxin contamination, especially when weather or environmental conditions are favourable for fungal infection, is the implementation of an integrated agronomic approach of preharvest measures (Blandino et al. 2017; Edwards 2004; Kabak et al. 2006; McMullen et al. 2012; McMullen et al. 2008; Wegulo et al. 2015). For example, by using the combination of a Fusarium spp. resistant wheat variety, using fungicides during flowering and crop rotation and/or ploughing (Blandino et al. 2012; McMullen et al. 2008). Currently, a range of agronomic management measures are implemented by EU farmers to reduce FHB and mycotoxins (Janssen et al. 2019; van der Fels-Klerx et al. 2020; Vogelgsang et al. 2019). However, only $50 \%$ of Dutch farmers used the integrated agronomic approach as described above (Janssen et al. 2019). Also, currently applied mycotoxin management measures might not fit the envisioned changes to food production as foreseen by the European Commission's Green Deal (EC 2019) or 'sustainable agriculture' (Rose et al. 2019). These measures propagate using less pesticides and applying conservation tillage, which contrasts the effective mycotoxin reduction approach of the use of fungicides throughout the whole cultivation period and (deep) ploughing to burry soil debris to reduce Fusarium spp. infection. Furthermore, innovative pre-harvest measures, like novel biological control measures such as biopesticides, are currently under development and being tested, providing additional management opportunities for wheat farmers; see the reviews of Shah et al. (2018) and Torres et al. (2019).

The extent that farmers intend to adapt their agronomic approach to manage FHB and related toxins in the coming years is unknown. Incentive mechanisms, like contracts and extra payments or financial punishments, might help to increase a farmers' intention to adapt their approach (Unnevehr and Roberts 2002). Information on which incentives alter farmers' intention, in addition to information on related farm and farmer characteristics can be valuable when designing (targeted) incentives by stakeholders such as farmer cooperatives and governmental agencies. This study aimed to identify which incentives stimulate European wheat farmers to adapt their agronomic management to prevent and control FHB and mycotoxin contamination in wheat. 


\subsection{Methods}

Incentives, as well as farm and farmer characteristics, were selected based on the results of a literature study and expert consultation. European wheat farmers from four EU countries - Italy (IT), the Netherlands (NL), Serbia (RS), and the United Kingdom (UK) - were questioned to identify which incentives most influenced their intention to adapt their current agronomic management practices. This influence was estimated by an alteration in their intention when no incentives were involved compared to when they were influenced by an incentive, e.g. this can be an increased (incentivised), decreased or unaltered intention. First, descriptive statistics of the questionnaire data were performed to identify (i) the current intention of wheat farmers to adapt their agronomic management and (ii) farmers' altered intention under various incentives. Second, Bayesian Network (BN) modelling was used to evaluate (iii) farm and farmer characteristics related to farmers' altered intention under various incentives and (iv) the altered intention of specific farmer groups. More details are provided in the sections below.

\subsubsection{Selection of variables Intention}

According to the Theory of Planned Behaviour, intentions are a proximal measure of future behaviour, and the stronger the intention, the more likely the behaviour will be executed in the future (Ajzen 1991). The main interest of this study was the current intention of farmers to adapt their agronomic approach to reduce Fusarium spp. infection in the coming five years, and how this intention was altered under certain incentives. An adaptation in agronomic management can entail taking fewer, more, or different pre-harvest management measures.

\section{Incentives}

Incentive mechanisms can be used by stakeholders in the chain to enforce farmers to change their agronomic management. Lefebvre et al. (2014) describes three classes of incentives used in crop protection, namely regulatory instruments, information dissemination measures, and incentive-based instruments. Incentive-based instruments can be classified as rewards and punishments (Lefebvre et al. 2014) and as monetary and in-kind incentives (Peterson and Luthans 2006). In this study, eight incentives relevant to mycotoxin management in wheat were selected covering a range of different types of incentive mechanisms as described above. In this study, two monetary incentives - with either a monetary reward or punishment like premiums and discounts - were evaluated. These were (i) 'paid extra' (getting paid extra when wheat contains low levels of mycotoxins) and (ii) 'paid less' (getting paid less when wheat contains too high levels of mycotoxins). Other incentives offer an in-kind punishment, namely (iii) 'no delivery' (not being allowed to deliver the wheat after harvest because of high mycotoxins levels) or an in-kind reward, namely (iv) 'free test' (a test for mycotoxin presence in the wheat is performed for free) and (v) 'contract' (a multiyear contract with the buyer to deliver wheat for a fixed price). Since the weather is a main influential factor for Fusarium spp. infection and mycotoxin production, the incentive (vi) 'insurance' (taking out insurance for high mycotoxins levels) was also included. The information dissemination measures were covered by the incentive (vii) 'free advice' (getting free advice on agronomic 
management to reduce $\mathrm{FBH}$ ) and the regulatory instruments by the incentive (viii) 'law' (a change in agronomic management is enforced by (inter)national law).

\section{Farm and farmer characteristics}

This section describes the selection of farm and farmer characteristics that are potentially related to farmers' altered intention under various incentives and the altered intention of specific farmer groups. Literature suggests a range of farm and farmer characteristics that are related to agronomic management, a change of management and incentives (Hop et al. 2011; Janssen et al. 2019; Solazzo and Pierangeli 2016; Zhang et al. 2018). Based on the questionnaire used by (Janssen et al. 2019), eighteen farm and farmer characteristics were selected for the analysis in this study, twelve were related to the farm and six related to the farmer. The twelve farm characteristics were country; organic production; arable land size (Kumar and Popat 2010; Oude Lansink et al. 2003; Samson et al. 2016); the percentage of wheat production based on arable land; soil type (Bürger et al. 2012a; Morris et al. 2010); main crop; purpose of wheat production (food, feed, or seed); type of buyer of the wheat; implementation of the benchmark approach to reduce FHB; experience with past Fusarium spp. infections (Adesina and Chianu 2002); the use of a decision support system for FHB and mycotoxin management; and need of a decision support system for FHB and mycotoxin management. The six farmer characteristics were age (Bagheri et al. 2008; Comer et al. 1999; Oude Lansink et al. 2003); gender (Burton et al. 1999); education level (Baur et al. 2016; Comer et al. 1999; Gebrezgabher et al. 2015); risk perception (a combination of the expected severity of an infection and its probability of occurrence (Glanz et al. 2008); risk aversion (i.e. if farmers take less risk than their peer farmers (Meuwissen et al. 2001)); and level of knowledge (Breukers et al. 2012) of mycotoxins.

\subsubsection{Questionnaire}

Data on intention, incentives and characteristics of farmers were collected from wheat farmers in IT, NL, UK, and RS in 2017 using an online questionnaire. The specific questions and answer formats of the variables can be found in Table 5.1, Table 5.2, and Table 5.3. The questions were part of a questionnaire among European wheat farmers who collected information on aspects like farm and farmer characteristics, the preharvest measures implemented by the farmer (Janssen et al. 2019), perceived (cost-) effectiveness of pre-harvest measures, and intention with underlying behavioural constructs based on the Theory of Planned Behaviour of farmers to adapt their agronomic management approach (Janssen et al. 2020). The questionnaire was conducted within the European Union's Horizon 2020 MyToolbox project (Krska et al. 2016). Before implementation, the questionnaire was pre-tested by three Dutch farmers for clarity and consistency. Their feedback was used to improve the online questionnaire. The link to the online questionnaire was distributed via farmers' associations in the four respective countries by email and via online newsletters. The questionnaire was developed in Dutch and translated in the respective languages by native speakers. All personal information was stored separately from the questionnaire output. The study protocol and consent procedure complied with the Netherlands Code of Conduct for Scientific Practice and was approved by the Social Sciences Ethics Committee of the Wageningen University (CoC number 09131098). 


\section{Chapter 5}

Table 5.1. Question and answer format of the questionnaire for intention.

Question $^{\text {a }}$

I expect to change my approach to reduce Fusarium infection in the coming 5 years.

I plan to change my approach to reduce Fusarium infection in the coming 5 years.

I want to change my approach to reduce Fusarium infection in the coming 5 years.

a The answer formats were text-only and reflected a 5-point bipolar Likert scale, ranging from strongly disagree to strongly agree.

Table 5.2. Question and answer format of the questionnaire for selected incentives.

Incentive I want to change my approach to reduce Fusarium infection in the coming 5 years if... ${ }^{a}$

Paid extra ...I get paid extra when my wheat contains low levels of mycotoxins.

Paid less $\quad$...I get paid less when my wheat contains too many mycotoxins.

No delivery ...I am not allowed to deliver my wheat because of high mycotoxins levels.

Free advice $\quad$...I get free agronomy advice in exchange.

Free test $\quad$...I can test my wheat for mycotoxins for free.

Insurance $\quad$...I can take out insurance for high mycotoxins levels.

Contract $\quad$...that is demanded from the buyer where I can enter a multiyear contract stating a fixed wheat price.

Law ...that is required by law.

a The answer formats were text-only and reflected a 5-point bipolar Likert scale, ranging from strongly disagree to strongly agree. 
Table 5.3. Question and answer format of the questionnaire for farm and farmer characteristics, in addition to their defined categories per variable and resulting percentage of farmers per category.

\begin{tabular}{|c|c|c|c|c|}
\hline Variable & Question & $\begin{array}{l}\text { Answer } \\
\text { format }\end{array}$ & Category & $\begin{array}{l}\text { Farmer } \\
(\%)\end{array}$ \\
\hline Country & - & - & $\begin{array}{l}\text { Italy } \\
\text { Netherlands } \\
\text { Serbia } \\
\text { United Kingdom }\end{array}$ & $\begin{array}{l}16 \\
45 \\
29 \\
11\end{array}$ \\
\hline Arable land & $\begin{array}{l}\text { What is the size of your arable land } \\
\text { in hectares? }\end{array}$ & Size in ha & $\begin{array}{l}>100 \\
20-100 \\
<20\end{array}$ & $\begin{array}{l}36 \\
52 \\
12\end{array}$ \\
\hline Wheat area & $\begin{array}{l}\text { What is the approximate number } \\
\text { of hectares of wheat that you } \\
\text { cultivate? }\end{array}$ & Size in ha & $\begin{array}{l}>75 \% \\
25-75 \% \\
<25 \%\end{array}$ & $\begin{array}{l}5 \\
66 \\
29\end{array}$ \\
\hline Soil type & $\begin{array}{l}\text { What is the predominant soil type } \\
\text { on which you normally grow } \\
\text { wheat? }\end{array}$ & $\begin{array}{l}\text { Multiple } \\
\text { choice }\end{array}$ & $\begin{array}{l}\text { Chernozem } \\
\text { Clay } \\
\text { Loam } \\
\text { Loess } \\
\text { Peat } \\
\text { Sand }\end{array}$ & $\begin{array}{l}19 \\
49 \\
12 \\
8 \\
4 \\
8\end{array}$ \\
\hline Organic & Do you produce organic wheat? & Yes/No & - & \\
\hline Main crop & $\begin{array}{l}\text { What is the most important crop } \\
\text { at your arable farm? }\end{array}$ & $\begin{array}{l}\text { Multiple } \\
\text { choice }\end{array}$ & $\begin{array}{l}\text { Maize } \\
\text { Other } \\
\text { Potatoes } \\
\text { Wheat }\end{array}$ & $\begin{array}{l}19 \\
17 \\
36 \\
27\end{array}$ \\
\hline Selling & $\begin{array}{l}\text { Do you sell your wheat via a } \\
\text { collector/merchant, directly to a } \\
\text { feed or food producer or to others? }\end{array}$ & $\begin{array}{l}\text { Multiple } \\
\text { choice }\end{array}$ & $\begin{array}{l}\text { Collector } \\
\text { Other } \\
\text { Producer }\end{array}$ & $\begin{array}{l}83 \\
6 \\
11\end{array}$ \\
\hline $\begin{array}{l}\text { Wheat } \\
\text { purpose }\end{array}$ & $\begin{array}{l}\text { Do you grow wheat for human } \\
\text { consumption, animal feed or seed } \\
\text { production? }\end{array}$ & $\begin{array}{l}\text { Multiple } \\
\text { choice }\end{array}$ & $\begin{array}{l}\text { Food } \\
\text { Feed } \\
\text { Seed }\end{array}$ & $\begin{array}{l}55 \\
41 \\
5\end{array}$ \\
\hline Benchmark & $\begin{array}{l}\text { Do you expect to use this measure } \\
\text { against Fusarium spp. infection in } \\
\text { the coming year? } \\
\text { Selection of a Fusarium resistant } \\
\text { wheat variety. } \\
\text { Fungicide use around flowering. } \\
\text { Ploughing after grain harvest. } \\
\text { Crop rotation: no grains as pre- } \\
\text { crop. }\end{array}$ & Yes/No & $\begin{array}{l}\text { No } \\
\text { Yes }\end{array}$ & $\begin{array}{l}32 \\
68\end{array}$ \\
\hline $\begin{array}{l}\text { Past } \\
\text { infection }\end{array}$ & $\begin{array}{l}\text { How often you think you have had } \\
\text { a serious Fusarium spp. infection } \\
\text { in wheat in the past } 5 \text { years? }\end{array}$ & $\begin{array}{l}\text { 6-point } \\
\text { scale: } \\
<\text { never to } \\
\text { five } \\
\text { times }>\end{array}$ & $\begin{array}{l}\text { No } \\
1 \\
2-5\end{array}$ & $\begin{array}{l}39 \\
36 \\
25\end{array}$ \\
\hline $\begin{array}{l}\text { Decision } \\
\text { support } \\
\text { system - use }\end{array}$ & $\begin{array}{l}\text { Do you use a decision support } \\
\text { system to select appropriate } \\
\text { measures against Fusarium spp. } \\
\text { infection? }\end{array}$ & Yes/No & $\begin{array}{l}\text { No } \\
\text { Yes }\end{array}$ & $\begin{array}{l}73 \\
27\end{array}$ \\
\hline
\end{tabular}


Table 5.3. (continued)

\begin{tabular}{|c|c|c|c|c|}
\hline Variable & Question & $\begin{array}{l}\text { Answer } \\
\text { format }\end{array}$ & Category & $\begin{array}{l}\text { Farmer } \\
(\%)\end{array}$ \\
\hline $\begin{array}{l}\text { Decision } \\
\text { support } \\
\text { system- } \\
\text { need }\end{array}$ & $\begin{array}{l}\text { Are you in need of a supportive } \\
\text { online program that can help you } \\
\text { with a choice for an approach to } \\
\text { control Fusarium infection in } \\
\text { wheat? }\end{array}$ & $\begin{array}{l}\text { 5-point } \\
\text { scale: }<\text { Not } \\
\text { probable to } \\
\text { very } \\
\text { probable> }\end{array}$ & $\begin{array}{l}\text { No } \\
\text { Maybe } \\
\text { Yes }\end{array}$ & $\begin{array}{l}8 \\
34 \\
58\end{array}$ \\
\hline Gender & What is your gender? & $\begin{array}{l}\text { Male/Fema } \\
\text { le }\end{array}$ & - & \\
\hline Age & What is your age? & $\begin{array}{l}\text { Ten-year } \\
\text { age } \\
\text { categories }\end{array}$ & $\begin{array}{l}<35 \\
35-44 \\
45-54 \\
55-64 \\
>64\end{array}$ & $\begin{array}{l}24 \\
17 \\
30 \\
20 \\
10\end{array}$ \\
\hline Education & $\begin{array}{l}\text { What is your highest level of } \\
\text { education completed? }\end{array}$ & $\begin{array}{l}\text { Eight } \\
\text { educational } \\
\text { categories }\end{array}$ & $\begin{array}{l}\text { Primary/ } \\
\text { Secondary } \\
\text { Vocational } \\
\text { University }\end{array}$ & $\begin{array}{l}22 \\
63 \\
16\end{array}$ \\
\hline $\begin{array}{l}\text { Risk } \\
\text { aversion }\end{array}$ & $\begin{array}{l}\text { Are you willing to take more or less } \\
\text { risk regarding Fusarium spp. } \\
\text { infection and mycotoxin } \\
\text { contamination compared to other } \\
\text { farmers in your community? }\end{array}$ & $\begin{array}{l}\text { 5-point } \\
\text { scale: } \\
\text { <more to } \\
\text { less risk> }\end{array}$ & $\begin{array}{l}\text { Yes } \\
\text { No }\end{array}$ & $\begin{array}{l}44 \\
47\end{array}$ \\
\hline $\begin{array}{l}\text { Risk } \\
\text { perception }\end{array}$ & $\begin{array}{l}\text { Do you expect a serious Fusarium } \\
\text { spp. infection in the coming five } \\
\text { years? } \\
\text { What consequences will this have? }\end{array}$ & $\begin{array}{l}\text { 5-point } \\
\text { scale: } \\
\text { <never to } \\
\text { often> } \\
\text { 5-point } \\
\text { scale: <no } \\
\text { consequen } \\
\text { ces to } \\
\text { significant } \\
\text { consequen } \\
\text { ces> }\end{array}$ & $\begin{array}{l}\text { Low } \\
\text { Medium } \\
\text { High }\end{array}$ & $\begin{array}{l}42 \\
45 \\
13\end{array}$ \\
\hline Knowledge & $\begin{array}{l}\text {-Indicate whether you agree or } \\
\text { disagree with the following } \\
\text { statements: } \\
\text {-Harvest debris in the soil forms a } \\
\text { risk for Fusarium spp. infection. } \\
\text {-You can recognise a Fusarium spp. } \\
\text { infection by black kernels. } \\
\text {-Fusarium spp. can also be present } \\
\text { in maize and barley. } \\
\text {-Fusarium spp. produce } \\
\text { mycotoxins like deoxynivalenol } \\
\text { Mycotoxins could be harmful to } \\
\text { humans. }\end{array}$ & $\begin{array}{l}\text { Agree/ } \\
\text { Disagree/ } \\
\text { Do not } \\
\text { know }\end{array}$ & $\begin{array}{l}\text { Low } \\
\text { Medium } \\
\text { High }\end{array}$ & $\begin{array}{l}11 \\
41 \\
48\end{array}$ \\
\hline
\end{tabular}




\subsubsection{Data processing}

Data on the selected variables derived from the questionnaire were processed to be used for further analyses. A total of 332 farmers participated in the study; however, not all farmers finished the questionnaire resulting in missing data. The respondents that missed the dependent variables, namely intention (INT) or the incentives (pINCs), were removed, resulting in a dataset containing 224 respondents. Of these responses, 35 respondents were from IT, 100 from the NL, 65 from RS and 24 from the UK. The variables organic production and gender were removed from the dataset because of insufficient variation among the respondents for these characteristics (e.g., $98 \%$ of the farmers were male) and will therefore yield no results. Of the 224 respondents, 140 (63\%) were complete; the remaining respondents were missing data on at maximum seven out of the eighteen variables. The variables that were missing for most farmers were 'education' (17\%) and 'age' (17\%), which were questions at the end of the questionnaire, as well as 'percentage wheat' (16\%) and 'arable land' (15\%), which were open-ended questions. The variables that were missing for $1 \%$ to $5 \%$ of the respondents were 'main crop'; 'soil type'; 'knowledge'; 'past infection'; and 'crop purpose'.

Numeric data were changed into categories, and categorical data were collapsed to reduce the number of categories per variable (Table 5.3), so a discrete BN model could be applied. The variable farmer's intention (INT) was constructed from respondents data for three related questions (Ajzen 2006; Francis 2004) each measured on a bipolar textual 5-point Likert scale (Table 5.1). For the analysis, this scale was converted into a numerical score ranging from -2 to 2 . The answer scores (based on three questions) were measured by Cronbach alpha (Cronbach, 1951) to confirm that they were internally consistent ( $\alpha \alpha>$ o.7), and then combined into a single composite score (INT) by averaging the three scores. Each primary incentive (INCP) in this study was based on a single question on a bipolar textual 5-point Likert scale in the questionnaire (Table 5.2). This score was also converted to a numerical score ranging from -2 to 2 in the analysis.

A new variable 'INC' was created for each of the eight incentives included in the study based on the primary incentive score in the questionnaire (INCP) and the basis intention score (INT), to indicate a change (increased, decreased or unaltered) in intention. The INC variable state was labelled 'Decreased' when the score of INCP was at least 0.5 point lower than the INT score (INCp-INT $<=-0.5$ ), 'Increased' when the score of INCp was at least 0.5 point higher than the INT score (INCp-INT $>=0.5$ ) and 'Unaltered' when the differences in scores were less than 0.5 point (INCp-INT between [-0.5 , 0.5]). Each INC variable was used for descriptive statistics and as predictor variable in the INC BN models.

The numeric $I N C p$ scores were renamed: a score below zero was labelled 'Negative', a score equal to zero was 'Neutral', and a score above zero was 'Positive', and included as variable in the INC BN models.

Per country, the percentage of farmers with a positive, neutral and negative INT, and the percentage of farmers with an increased intention under the eight incentives (INCs) were calculated.

The classification of the farm and farmer characteristics can be found in Table 5.3. Arable land was measured in hectares (ha) and divided into three categories: small ( $<2 \mathrm{O} \mathrm{ha})$, 


\section{Chapter 5}

medium (20 - $100 \mathrm{ha})$, and large (> $100 \mathrm{ha})$ (EC 2016). The variable 'percentage of wheat production' was created by dividing the continuous variable ha wheat field by the continuous variable ha arable land. The 'percentage of wheat production' was then categorised into small $(<25 \%)$, medium $(25-75 \%)$, and large $(>75 \%)$. Farmers' main crops were divided into four categories: wheat, potatoes, maize, and 'other crops'. The effective integrated agronomic approach consisting of a combination of a Fusarium resistant crop, using fungicides during flowering and crop rotation and/or ploughing (Blandino et al. 2012; McMullen et al. 2008) was referred to as the 'benchmark approach'. This variable was labelled 'yes' when farmers applied the benchmark approach, while it was labelled 'no' otherwise. Five age classes were made; farmers under the age of 35 years were merged into the first class, while those with an age above 65 years into the fifth class. The remaining three classes were defined by 10-year increments between the age of 35 and 65 years. The classification of education varies greatly among countries. In the questionnaire, local names of education were used which were not always directly comparable with one another. Therefore, three broad classes of education were created. The first category 'pri-sec' consisted of primary and secondary education, regardless of the level. The second category 'uni' included university degrees like bachelor and master studies. The remaining educational levels were classified into 'vocational' education. This included, for example, vocational training and trade school. With the variable risk aversion, farmers who answered that they were willing to take less risk than other farmers in their community were classified as risk averse (category 'yes'), the remaining farmers were classified within the category 'no'. Risk perception is defined as a combination of the expected severity of an infection and its probability of occurrence (Glanz et al. 2008). The risk perception score was obtained by the multiplication of the scores to subquestions on susceptibility and severity of infection (1-25), and divided into low $(<7)$, medium $(7<>14)$ and high $(>14)$ risk perception. The knowledge score was calculated by the sum of the scores for five knowledge statements scored as o (does not know or answered incorrectly) or as 1 (answered correctly) and divided into low (<2), medium $(2<>3)$ and high (>3) knowledge. The classification of the other variables was straightforward as presented in Table 5.3.

\subsubsection{Bayesian Network model}

BN modelling (Nielsen and Jensen 2009) is a powerful tool to explore patterns in the data and to model dependencies between variables. BNs are a class of probabilistic models originating from the Bayesian statistics and decision theory combined with graph theory. A BN consists of nodes (e.g. variables like gender) with various states (e.g. male/female) connected by arcs that reflect the dependency between the nodes. Together these form an acyclic directed graph (DAG). A BN shows the relationship between the nodes (variables). It does not show a causal relationship but shows how the variables are statistically related. Conditional probability tables show the probabilistic distribution over the states and can be updated when the state of a node changes. With a scenario analysis, states (e.g. a certain farmer characteristic) of one or multiples nodes can be submitted to the BN model to return the conditional probability tables of the remaining variables (nodes).

\section{BN model development}

Based on the collected questionnaire data, nine Bayesian network models were fitted; one reflecting the relationships between the evaluated variables and the basic intention 
(INT) and one model for each of the eight incentives to reflect the relationships between the evaluated variables and the altered intention given a specific incentive (INC). The nodes represented the farm and farmer characteristics with different states (categories), like 'age' and 'arable land'. Constructing a BN consists of two steps, i.e. (step 1) learning the network structure (i.e. the dependency among the variables of the network) and (step 2) learning the parameters (i.e. quantitative stage that determines the conditional probabilities of each variable, given its parents (Holmes and Jain 20o8). Hence, three different sub-datasets were created for each of the nine developed BN models: one for learning the network structure (training set 1), one for parameter learning (training set 2) and one for model validation (test set). The BN models were constructed and analysed in the software R ( $\mathrm{R}$ Core Team 2019) with packages bnlearn (Scutari 2010) and gRain (Højsgaard 2012). To create training set 1, all records from the entire questionnaire dataset were considered. Incomplete records were imputed with the ExpectationMaximization (EM) algorithm (Friedman) by the structural.em function of the Rpackage bnlearn (Scutari 2010). Subsequently $80 \%$ of this dataset was selected to create training set 1 ( $n=224$ records). To create training set $2,80 \%$ of the original questionnaire data was selected, and incomplete records were removed (training set $2 ; n=112$ records). The remaining $20 \%$ of the original dataset was selected $(n=45)$ for model validation (test set; $\mathrm{n}=45$ records). For each of the nine BN models (one INT and eight INCs), the needed variables were selected from train set 1 , train set 2 and the test set. The INT datasets consisted of INT as dependent/predictor variable and sixteen farm and farmer characteristics variables. The INCs datasets consisted of the specific INC variable (indicating the increased, decreased or unaltered intention) as dependent/predictor variable, the sixteen farm and farmer characteristics, the basic INT and the primary INC variable $(I N C P)$. So, in total, nine predictor variables (one INT and eight INCs) with three datasets each were constructed. The BN models were fitted with the Tree Augmented Naïve (TAN) Bayes algorithm. In line with BN modelling procedure, two types of validation were performed, one with the dataset for parameter learning (training set 2) and one with the test dataset consisting of the $20 \%$ remaining data which were not used in the constructing or training the model. With these data, the dependent variable was predicted (depending on the model, either INT or one of the INCs). A correct prediction was assumed when the predicted state/category with the highest probability was the same as the validation variable state/category. The percentages of correctly predicted dependent variables were calculated to present the model validations.

\section{Farm(er) characteristics related to altered intentions under incentives}

The conditional probability tables returned from the BN model were used to compare the farm and farmer characteristics between farmers with a negative or positive basic intention (INT) and between farmers with a decreased, increased or unaltered intention under incentives (INC).

\section{Targeting specific groups of farmers}

With the developed BN models in place, altered intentions under incentives (INC) of specific groups of farmers can be analysed in more detail by specifying their farm and farmer characteristics and by running a scenario analysis. In this study two scenarios were analysed, focussing on 1) non-incentivised farmers (scenario 1), and 2) farmers not applying the benchmark approach (scenario 2). 
Scenario 1

Farmers who had a decreased intention under one incentive, may have an increased intention under another incentive. With a scenario analysis insight can be obtained in the extent to which these non-incentivised farmers can be incentivised by one of the other incentives. For this purpose, the most promising incentive out of the eight evaluated incentives was selected based on the highest percentage of farmers who were incentivised (i.e. having an increased intention) by this incentive. Based on the BN model results of this most promising incentive, per country the three most discriminating farm or farmer characteristics reflecting farmers with a decreased intention compared to farmers with an increased intention were selected. These characteristics were subsequently used to define the conditions for a scenario run for each of the seven remaining INC BN models, providing the probability of an increased intention for this characterised group of farmers.

\section{Scenario 2}

In the second scenario, the incentivisation of farmers who did not use a benchmark approach was further analysed. The benchmark approach is considered an effective approach to reduce FHB and mycotoxins in wheat, but is not implemented by all farmers yet, therefore promising incentives for this group of farmers to use the benchmark approach were defined. The most promising incentives in altering the intention in this group of farmers were identified for each of the four evaluated countries separately. For this purpose, the specific farmer characteristics of not using the benchmark approach were used to run the BN scenarios to evaluate the probability of an increased intention of this particular group of farmers under each of the eight incentives.

\subsection{Results}

\subsubsection{Intention to adapt the approach}

Overall $50 \%$ of the European wheat farmers indicated to have a positive intention to adapt their Fusarium spp. and mycotoxins approach in the coming five years, ranging from $38 \%$ (UK) to $67 \%$ (RS) per country (Figure 5.1). Twenty-five per cent of the European farmers had a negative intention to adapt their approach ranging from $22 \%$ for NL and RS to $46 \%$ for the UK. 


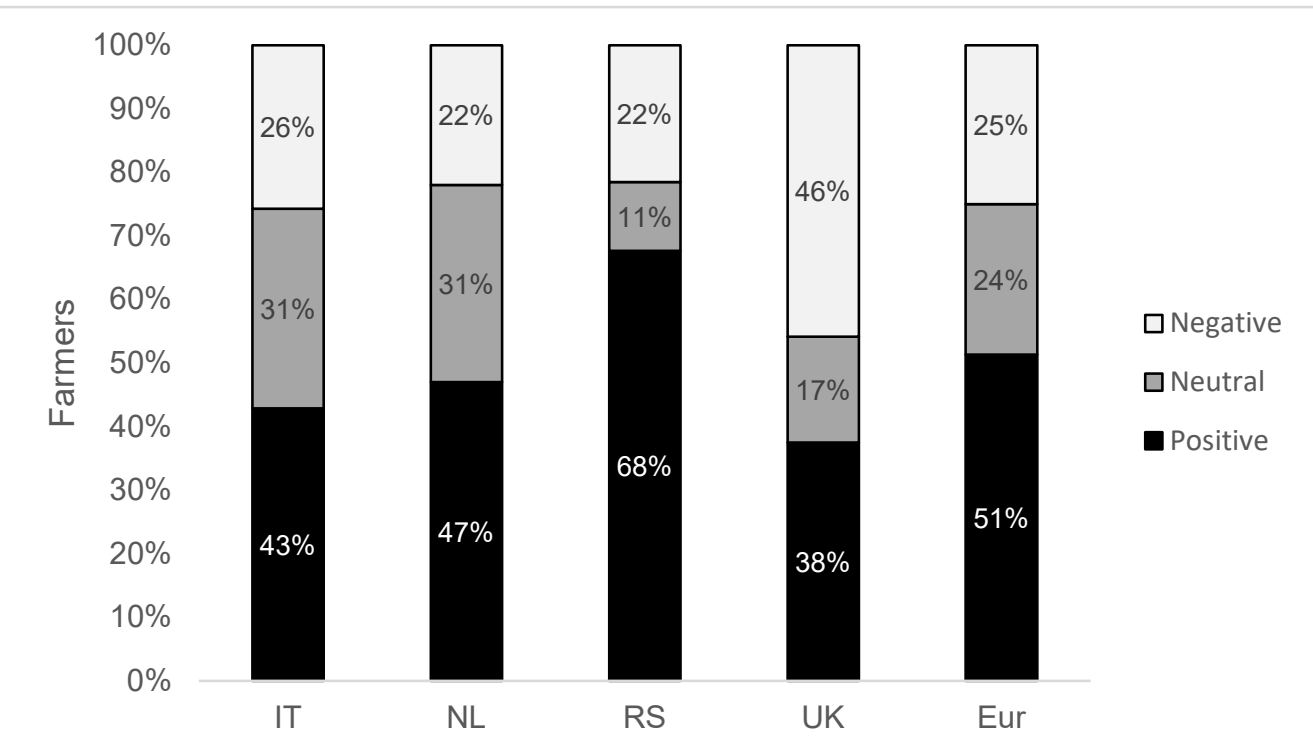

Figure 5.1. The percentage of wheat farmers from Italy (IT), the Netherlands (NL), Serbia (RS), and the United Kingdom (UK) and the combination of the four countries (Eur) with a negative, neutral or positive intention to adapt their current agronomic management to reduce Fusarium spp. infection and related mycotoxin contamination.

\subsubsection{Incentivisation of farmers}

The percentage of farmers who were incentivised to adapt their Fusarium spp. and mycotoxin management approach under the evaluated incentives (reflected by an increased intention) are depicted in Figure 5.2. The percentage of farmers who were incentivised ranged from $27 \%$ for the incentive 'insurance' to $56 \%$ for the incentive 'paid extra'. The incentives that incentivised the highest percentage of farmers were 'paid extra' and 'free test'. These two incentives also had the least variance between the farmers from the four different countries, i.e. the percentages of farmers who were incentivised ranged from $46 \%$ to $63 \%$ for both incentives. In contrast, the farmers who were incentivised under 'paid less' ranged from $38 \%$ (NL) to $75 \%$ (RS) and under 'law' from $30 \%(\mathrm{NL})$ to $71 \%(\mathrm{UK})$.

Per country, the highest percentage of incentivised farmers was as follows: for IT 'paid extra' (63\%) and 'no delivery' (57\%); for NL 'paid extra' (6o\%), 'no delivery'(46\%), and 'free test' ( $46 \%)$; for RS 'free test' (62\%) and 'free advice' (54\%); for the UK 'paid less' (75\%) and 'law' (71\%). 


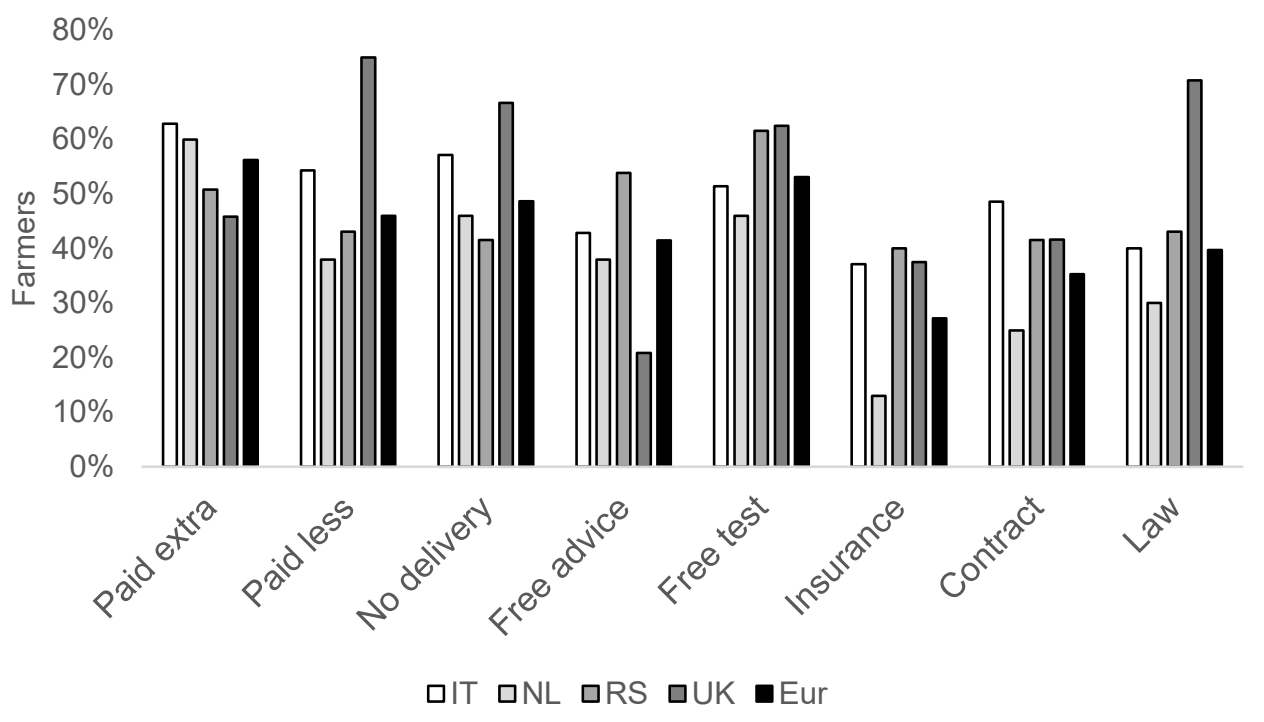

Figure 5.2. The percentage of wheat farmers from Italy (IT), the Netherlands (NL), Serbia (RS), and the United Kingdom (UK) and the combination of the four countries (Eur) who were incentivised (i.e. had an increased intention) to adapt their current agronomic management to reduce Fusarium spp. infection and related mycotoxin contamination.

\subsubsection{Validation of the BN models}

Validation results show that the percentage of correctly predicted responses ranged from $85 \%$ to $97 \%$ for the training set 2 , and from $44 \%$ to $62 \%$ for the test set (Figure 5.3 ).

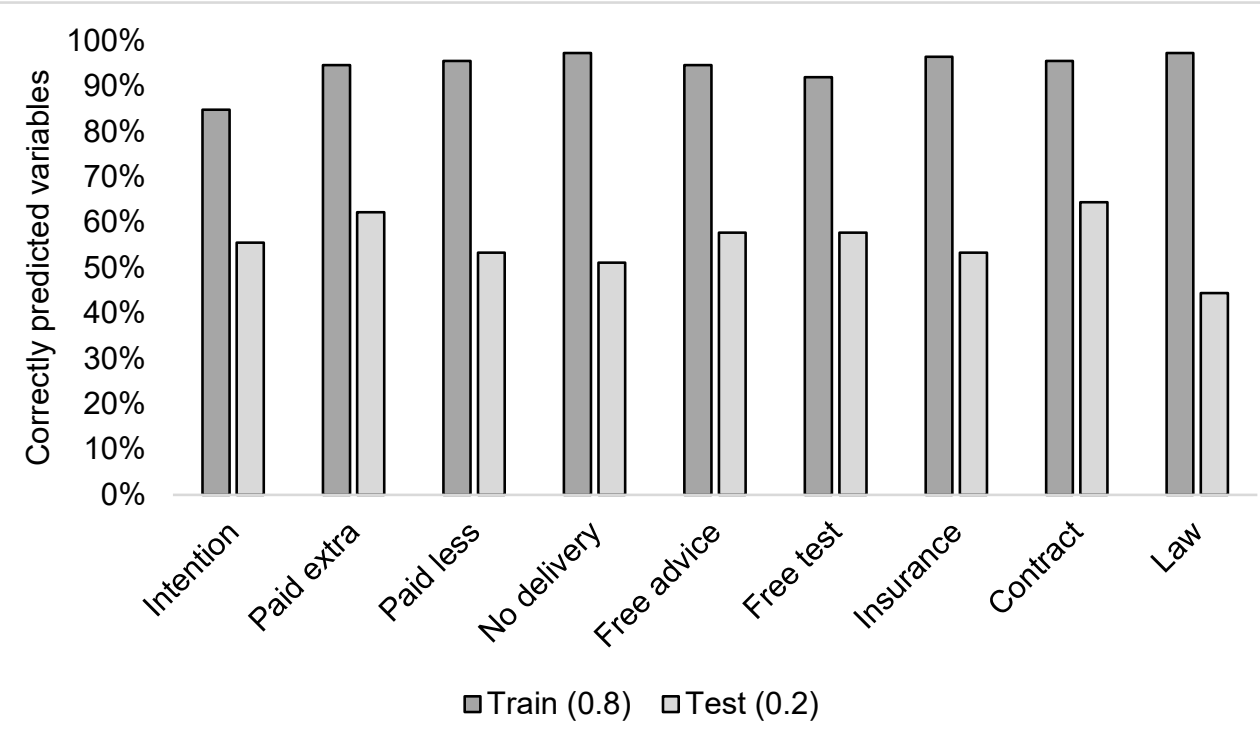

Figure 5.3. Validation of the nine Bayesian Network models showing the correctly predicted dependent variables for the training and test set. 


\subsubsection{Farm and farmer characteristics related to intention (INT)}

Figure 5.4 shows the BN acyclic directed graph (DAG) of the basic intention model with the probabilities per farm and farmer characteristic category. These BN model results show that farmers had a probability of $51 \%$ to have positive basic intention and $25 \%$ to have a negative basic intention to adapt his/her agronomic management. Farmers had a probability of $53 \%$ that to produce wheat for food and $27 \%$ to have wheat as main crop. The probability that farmers have had no severe Fusarium spp. infection in the past was equal to $42 \%$, whereas the probability that they have had more than one infection in the past was $18 \%$ (Figure 5.4). The probability that they used a benchmark approach was 31\%, while the probability that they received vocational education was $18 \%$.

By specifying the DAG by farmer's basic intention category (positive versus negative INT), the conditional probabilities of farm and farmer characteristics of farmers with a positive basic intention (Figure 5.5), and of farmers with a negative basic intention (Figure 5.6) were indicated. For visual interpretation, Figures 5.5 and 5.6 present only the conditional probabilities of the most distinctive farm and farmer characteristics (i.e. indicating a numeric difference in conditional probabilities between farmers with a positive intention and a negative intention of $>30 \%$ ). The complete conditional probability tables of all the farm and farm characteristics can be found in the Appendix (Table A.5.1).

Farmers with a positive intention were most likely to come from the NL (49\%) and RS (37\%) and less likely originating from the UK (11\%) or IT (4\%) (Figure 5.5). Farmers with a negative intention were most likely to come from the NL $(43 \%)$ and the UK $(25 \%)$ and less likely from IT (18\%) and RS (14\%) (Figure 5.6). Wheat was more likely to be the main crop of farmers with a negative intention (39\%); for farmers with a positive intention $21 \%$ had wheat as their main crop. Farmers with a positive or negative intention were most likely to use a benchmark approach. However, the probability level differed, i.e. $75 \%$ for farmers with a positive intention and $54 \%$ for farmers with a negative intention. The probability that a farmer had obtained a university degree was $32 \%$ for farmers with a negative intention, whereas this was only $12 \%$ for farmers with a positive intention. The likelihood that farmers with a positive intention received vocational education was $75 \%$ and for farmers with a negative intention, this was 50\%. 


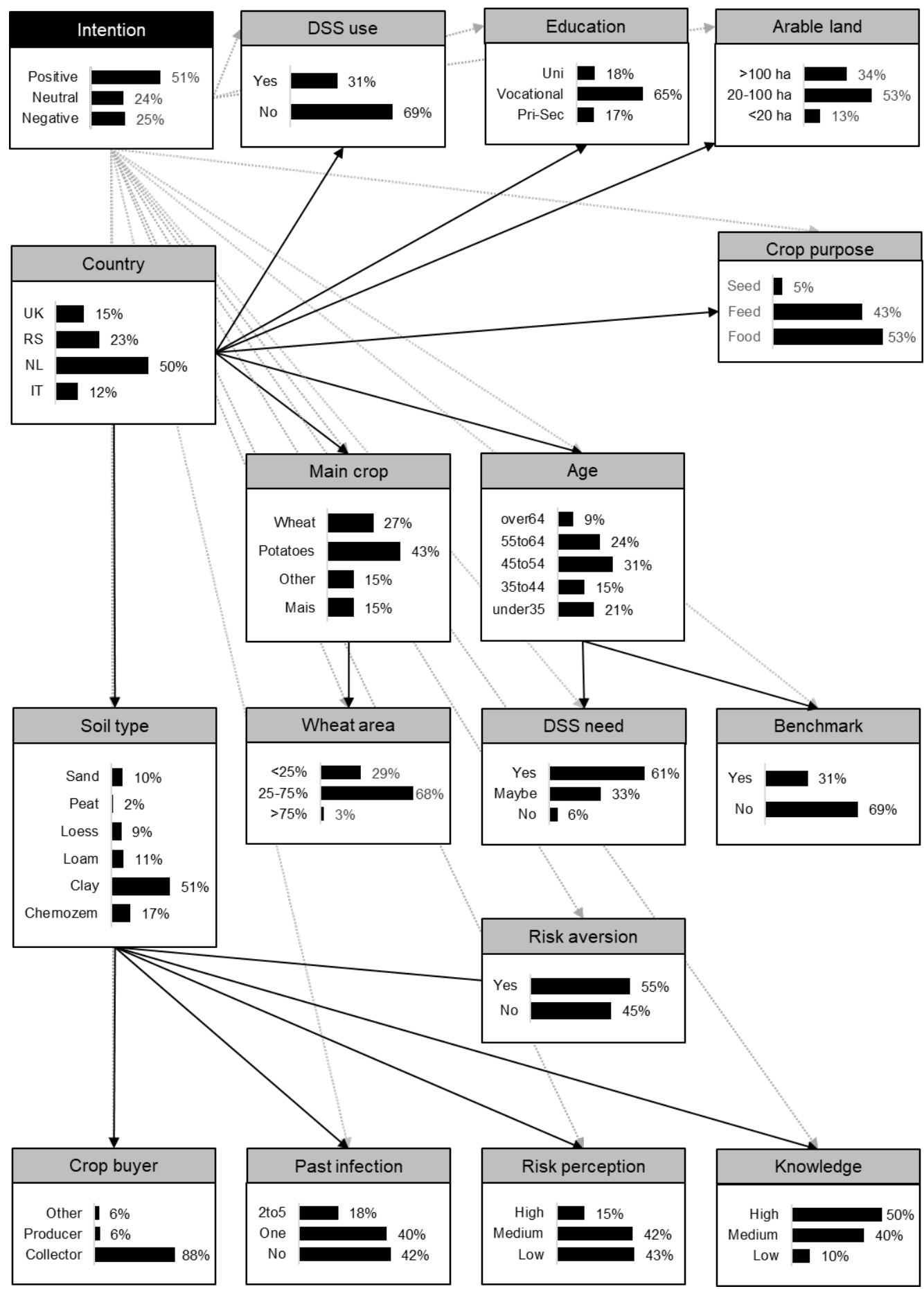

Figure 5.4. Directed Acyclic Graph of the Bayesian Network model for intention (INT) representing the probabilities per variable - black arrows indicates a connection between the farm and farmer characteristics and the grey arrows indicate the connection with the conditioned variable INT. 
Incentives to stimulate European wheat farmers

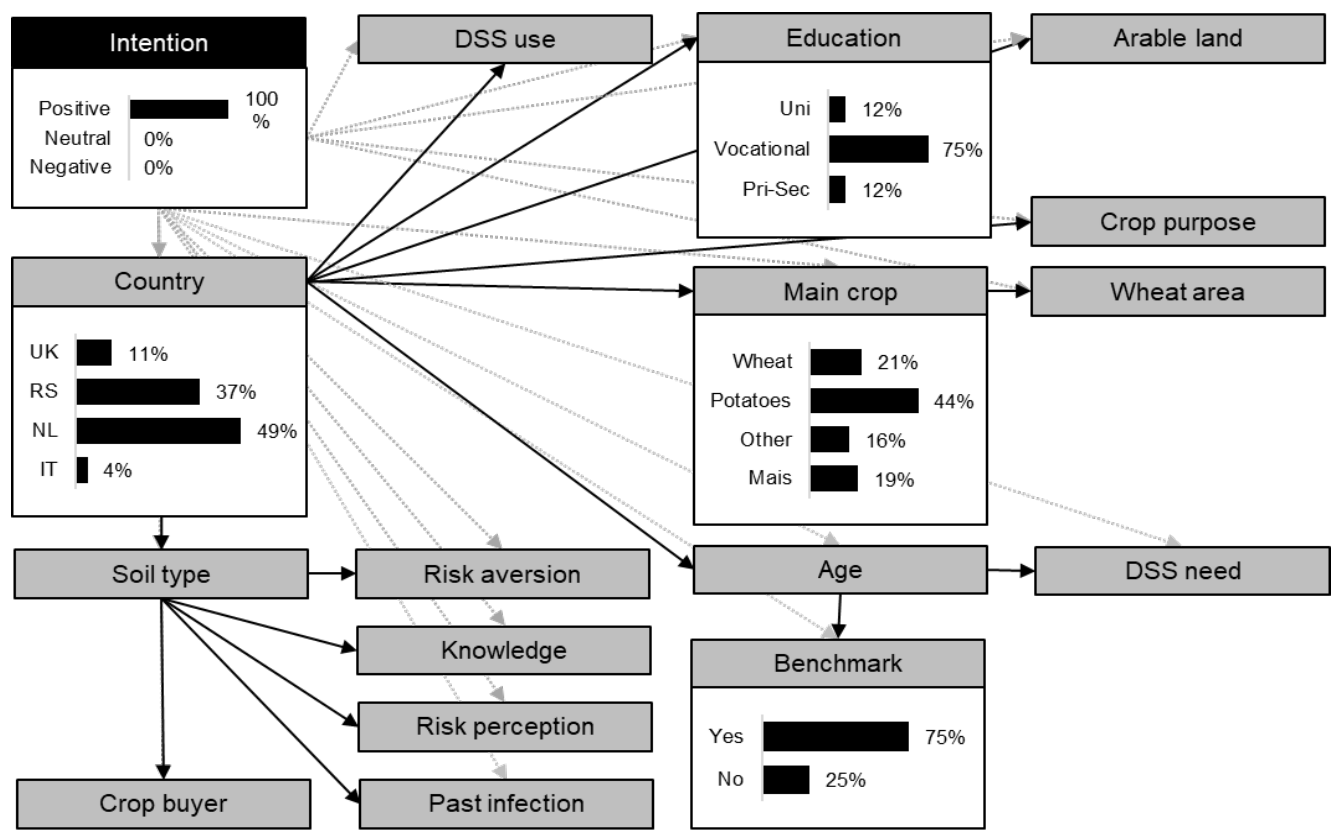

Figure 5.5. Directed Acyclic Graph of the Bayesian Network model for intention (INT) for farmers with a positive intention representing the probabilities per variable - black arrows indicates a connection between the farm and farmer characteristics and the grey arrows indicate the connection with the conditioned variable INT.

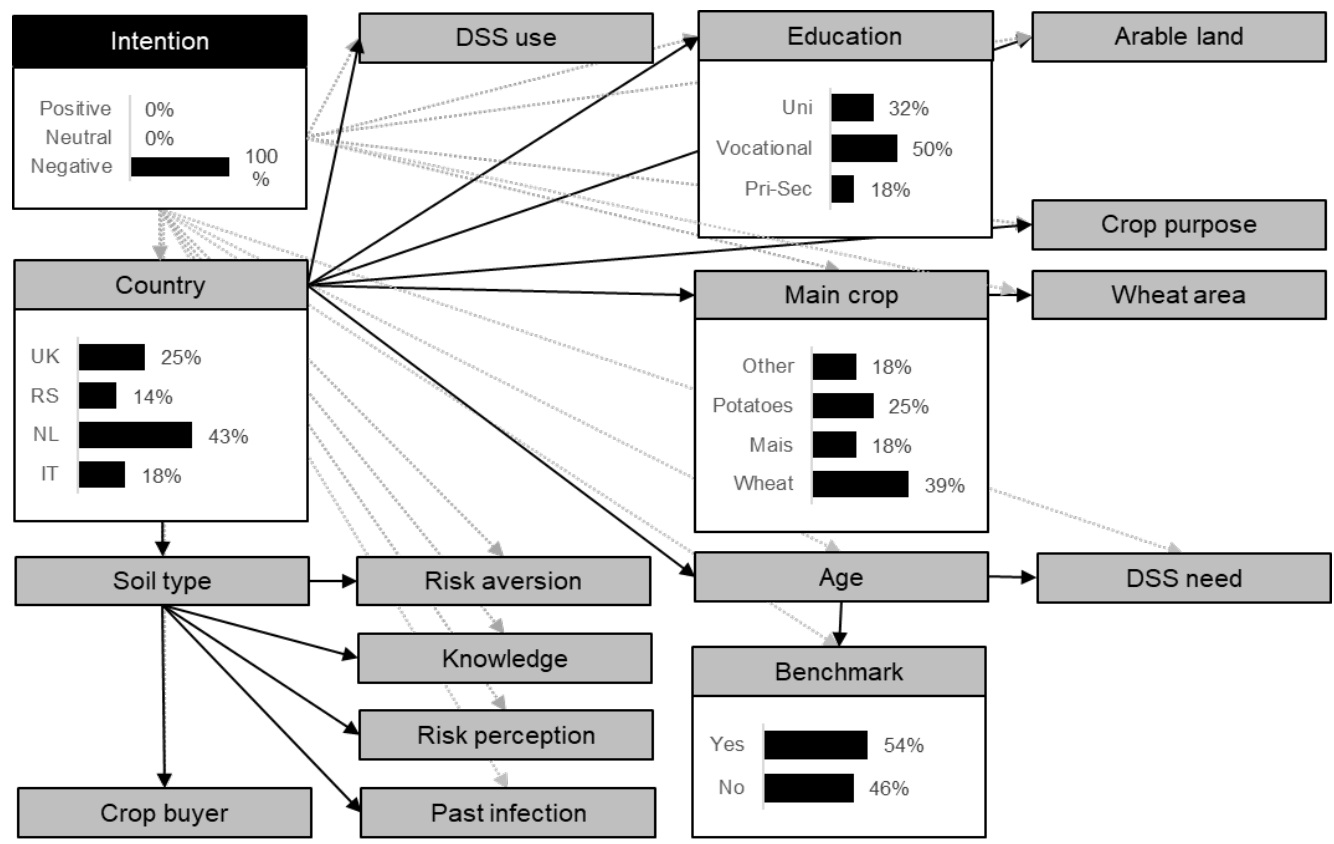

Figure 5.6. Directed Acyclic Graph of the Bayesian Network model for intention (INT) for farmers with a negative intention representing the probabilities per variable - black arrows indicates a connection between the farm and farmer characteristics and the grey arrows indicate the connection with the conditioned variable INT. 


\subsubsection{Farm and farmer characteristics related to incentives (INC)}

The conditional probabilities of each farm and farmer characteristic when a farmer has a decreased, increased or unaltered intention under each incentive mechanism (INC) are shown in the Appendix (Table A.5.2). Table 5.4 shows a selection of the most distinctive results indicating a large numeric difference $(>30 \%)$ in the conditional probabilities of a farm or farmer characteristic category between farmers who were incentivised (i.e. had an increased intention) or not (i.e. had a decreased intention). The results for the incentives 'paid less', 'free test', and 'law' are not shown because the difference between the conditional probabilities of the farmers who were or were not incentivised under these incentives were small.

Table 5.4 shows that farmers with an increased or unaltered intention under incentive 'paid extra' were most likely to originate from the NL ( $56 \%$ and $54 \%$, respectively). Farmers with a decreased intention were most likely to come from RS (33\%) and the UK (33\%). Farmers with an increased or unaltered intention were most likely to have clay as soil type (6o\% and $57 \%$, respectively). Farmers with a decreased intention were most likely to have a large arable farm (61\%). In contrast, farmers with an increased or unaltered intention were most likely to have a medium-sized farm $(61 \%$ and $60 \%$, respectively). In general, under the intention 'paid extra' farmers were more likely to use a benchmark approach, although the probability of using a benchmark approach was higher for farmers with a decreased intention (77\%) and an unaltered intention (82\%) than for farmers with an increased intention (52\%). Farmers with a decreased intention were most likely to be risk-averse $(72 \%)$. This probability was lower for farmers with an unaltered intention $(61 \%)$ or an increased intention $(48 \%)$.

Under the incentive 'no delivery', all farmers (so independent of the INC state of increased, decreased or unaltered intention) were most likely to have received vocational education. However, farmers with increased intention were also likely to have received university education (31\%), whereas farmers with a decreased intention were not likely to have received university education (o\%) (Table 5.4 ).

Farmers with a decreased intention under the incentive 'free test' were most likely to have potatoes as the main crop (68\%) and not maize (o\%). For farmers with an increased intention, the main crop was most likely to be wheat $(35 \%)$ or potatoes $(32 \%)$ while the likelihood to have maize as the main crop was $16 \%$. All farmers under the incentive 'free test' were most likely to have received vocational education; the probabilities were $89 \%$ for farmers with a decreased intention, 53\% for farmers with an increased intention, and $72 \%$ for farmers with an unaltered intention. Farmers with a decreased intention under incentive 'free test' were most likely to originate from NL (73\%).

The likelihood that farmers with a decreased intention under incentive the 'insurance' have potatoes as the main crop was $59 \%$. For farmers with an unaltered intention, this was $39 \%$, while for farmers with an increased intention, this was $11 \%$. Farmers with an increased intention had either wheat $(44 \%)$ or maize $(22 \%)$ as the main crop. The farmers with a decreased or unaltered intention under the incentive 'insurance' were most likely to have received vocational education ( $84 \%$ and $57 \%$, respectively). The likelihood for farmers with an increased intention was the same for each education category (33\% for each of primary/secondary school; vocational; university). Farmers with an increased 
Table 5.4. Conditional probabilities of farm and farmer characteristics of farmers with a decreased (Dec), increased (Inc) or unaltered (Una) intention under the incentives 'paid extra', 'no delivery', 'free test', 'insurance', 'contract'. ${ }^{a}$

\begin{tabular}{|c|c|c|c|c|c|c|c|c|c|c|c|c|c|c|c|c|}
\hline & & Paid & extra & & No d & liver & & Free & & & Insu & ance & & Con & act & \\
\hline & & $\begin{array}{l}\text { Dec } \\
(\%)\end{array}$ & $\begin{array}{l}\text { Inc } \\
(\%)\end{array}$ & $\begin{array}{l}\text { Una } \\
(\%)\end{array}$ & $\begin{array}{l}\text { Dec } \\
(\%)\end{array}$ & $\begin{array}{l}\text { Inc } \\
(\%)\end{array}$ & $\begin{array}{l}\text { Una } \\
(\%)\end{array}$ & $\begin{array}{l}\text { Dec } \\
(\%)\end{array}$ & $\begin{array}{l}\text { Inc } \\
(\%)\end{array}$ & $\begin{array}{l}\text { Una } \\
(\%)\end{array}$ & $\begin{array}{l}\text { Dec } \\
(\%)\end{array}$ & $\begin{array}{l}\text { Inc } \\
(\%)\end{array}$ & $\begin{array}{l}\text { Una } \\
(\%)\end{array}$ & $\begin{array}{l}\text { Dec } \\
(\%)\end{array}$ & $\begin{array}{l}\text { Inc } \\
(\%)\end{array}$ & $\begin{array}{l}\text { Una } \\
(\%)\end{array}$ \\
\hline \multirow[t]{4}{*}{ Country } & IT & 11 & 16 & 3 & & & & 6 & 18 & 6 & 7 & 26 & 7 & & & \\
\hline & NL & 22 & 56 & 54 & & & & 73 & 42 & $5^{0}$ & 66 & 22 & 43 & & & \\
\hline & RS & 33 & 15 & 33 & & & & 11 & 21 & 33 & 14 & 30 & 36 & & & \\
\hline & UK & 33 & 13 & 9 & & & & 11 & 19 & 11 & 12 & 22 & 14 & & & \\
\hline \multirow[t]{4}{*}{ Main crop } & Maize & & & & & & & o & 16 & 22 & 11 & 22 & 18 & 17 & 15 & 13 \\
\hline & Other & & & & & & & 16 & 18 & 11 & 9 & 22 & 21 & 14 & 18 & 13 \\
\hline & Potatoes & & & & & & & 68 & 32 & 47 & 59 & 11 & 39 & 60 & 26 & 45 \\
\hline & Wheat & & & & & & & 16 & 35 & 19 & 21 & 44 & 21 & 9 & 41 & 29 \\
\hline \multirow[t]{3}{*}{ Education } & Pri-Sec & & & & 24 & 13 & 17 & 6 & 23 & 14 & 7 & 33 & 22 & & & \\
\hline & Vocational & & & & 76 & 55 & 70 & 89 & 53 & 72 & 84 & 33 & 57 & & & \\
\hline & Uni & & & & $\mathrm{O}$ & 31 & 13 & 6 & 25 & 14 & 9 & 33 & 22 & & & \\
\hline \multirow[t]{6}{*}{ Soil type } & Chernozem & 28 & 8 & 27 & & & & & & & 14 & 26 & 14 & & & \\
\hline & Clay & 11 & 60 & 57 & & & & & & & 63 & 29 & 50 & & & \\
\hline & Loam & 28 & 10 & 3 & & & & & & & 7 & 15 & 14 & & & \\
\hline & Loess & 17 & 10 & 3 & & & & & & & 5 & 15 & 11 & & & \\
\hline & Peat & o & 2 & 3 & & & & & & & 2 & o & 4 & & & \\
\hline & Sand & 17 & 10 & 6 & & & & & & & 9 & 15 & 7 & & & \\
\hline \multirow[t]{3}{*}{ Arable land } & Large & 61 & 26 & 33 & & & & & & & & & & & & \\
\hline & Medium & 17 & 61 & 60 & & & & & & & & & & & & \\
\hline & Small & 22 & 13 & 6 & & & & & & & & & & & & \\
\hline \multirow[t]{3}{*}{ Know } & Low & & & & & & & & & & 5 & 11 & 18 & & & \\
\hline & Medium & & & & & & & & & & 54 & 15 & 36 & & & \\
\hline & High & & & & & & & & & & 40 & 74 & 46 & & & \\
\hline \multirow[t]{3}{*}{ Crop purpose } & Food & & & & & & & & & & & & & 34 & 64 & 58 \\
\hline & Feed & & & & & & & & & & & & & 63 & 31 & 37 \\
\hline & Seed & & & & & & & & & & & & & 3 & 5 & 6 \\
\hline
\end{tabular}

a The results for the incentives 'paid less', 'free test' and 'law' were not shown because of little differences between the probabilities of farmers with an increased or decreased intention under these incentives, these results are presented in the Appendix (Table A.5.2). 
intention under the incentive 'insurance' were most likely to have a high mycotoxin knowledge level (74\%). In contrast, for farmers with a decreased intention, this probability was $40 \%$; these farmers were more likely to have a medium knowledge score (54\%). Farmers with a decreased intention under incentive 'insurance' were most likely to come from NL (66\%), whereas farmers with an increased intention were most likely to come from RS $(30 \%)$ or IT $(26 \%)$.

Farmers with a decreased intention under the incentive 'contract' were most likely to have potatoes as the main crop (6o\%) and to produce wheat for feed $(63 \%)$, whereas for farmers with an increased intention the main crop was most likely to be wheat (41\%) produced for food (64\%).

\subsubsection{Targeting specific groups of farmers}

A scenario analysis (scenario 1) was conducted to identify an alternative incentive for those farmers who had a decreased intention under the incentive that incentivised the largest percentage of farmers, i.e. the incentive 'paid extra' (Figure 5.2). The three most discriminating farm or farmer characteristics reflecting farmers with a decreased intention compared to farmers who were incentivised by this incentive were selected per country (Table 5.5). For example, IT farmers with a decreased intention under 'paid extra' had the same probability $(49 \%)$ of having a high or a medium wheat area, hence, not indicating a specific difference among these classes. However, farmers who were incentivised (with an increased intention) had an $80 \%$ probability of having a medium wheat area and only a $10 \%$ probability of having a large wheat area, demonstrating a clear distinction in classes. Therefore, the 'high' variable state of the farm characteristic wheat area reflects one of the main characteristic of IT wheat farmers with a decreased intention under the incentive 'paid extra'.

The three main characteristics that distinguished European (Eur) farmers with a decreased intention from incentivised farmers under the incentive 'paid extra' were related to crop purpose, the use of the benchmark approach, and risk-aversion (Table 5.5). Hence, European farmers with a decreased intention were reflected by farmers producing for feed purpose, while implementing the benchmark approach and being risk averse. The main farm and farmer characteristics varied among the four evaluated countries. For Italy, the main characteristics were no past Fusarium spp. infection, growing wheat as the main crop, and having a large wheat area. NL farmers were characterised by having a large size of arable land, being risk-averse, and being in the age group $45-54$. For UK farmers, the three main farm characteristics with a decreased intention under incentive 'paid extra' were: wheat production for food purpose, using the benchmark approach, and being in the age group $55-64$. For RS farmers, these characteristics were having a medium wheat area, received vocational education, and having a low risk perception (Table 5.5).

The above-selected variables were subsequently used to run as a scenario in the INC BN models, providing the probability of obtaining an increased intention in this particular group of farmers under the seven evaluated incentives. Results showed that typical European farmers with a decreased intention under the incentive 'paid extra' (Table A.5.2) had the highest probability to be incentivised under the alternative incentives 'no 
delivery' (55\%), 'free test' (48\%) and 'paid less'(48\%) (Figure 5.7). The best alternative incentives to incentivise Italian farmers with a decreased intention under 'paid extra' were 'free test' (99\%) and 'insurance' (85\%). Corresponding alternative incentives for NL farmers were 'no delivery' (34\%) and 'free advice' (28\%). For RS farmers, these were 'law' (51\%) and 'no delivery (47\%), and for the UK farmers, 'no delivery' (69\%) and 'paid less' (59\%) (Figure 5.7).

Table 5.5. Probabilities of three selected main farm and farmer characteristics per country of farmers with a decreased (Dec) and increased (Inc) intention under the incentive 'paid extra'. ${ }^{a}$

\begin{tabular}{|c|c|c|c|c|c|c|c|c|c|c|c|}
\hline & & IT & & NL & & RS & & UK & & Eur & \\
\hline & & $\begin{array}{l}\text { Dec } \\
(\%)\end{array}$ & $\begin{array}{l}\text { Inc } \\
(\%)\end{array}$ & $\begin{array}{l}\text { Dec } \\
(\%)\end{array}$ & $\begin{array}{l}\text { Inc } \\
(\%)\end{array}$ & $\begin{array}{l}\text { Dec } \\
(\%)\end{array}$ & $\begin{array}{l}\text { Inc } \\
(\%)\end{array}$ & $\begin{array}{l}\text { Dec } \\
(\%)\end{array}$ & $\begin{array}{l}\text { Inc } \\
(\%)\end{array}$ & $\begin{array}{l}\text { Dec } \\
(\%)\end{array}$ & $\begin{array}{l}\text { Inc } \\
(\%)\end{array}$ \\
\hline \multirow[t]{3}{*}{ Arable land } & Large & & & 99 & 18 & & & & & 61 & 26 \\
\hline & Medium & & & 1 & 82 & & & & & 17 & 61 \\
\hline & Small & & & 1 & o & & & & & 22 & 13 \\
\hline \multirow[t]{4}{*}{ Main crop } & Maize & 1 & 30 & & & & & & & & \\
\hline & Other & 1 & 20 & & & & & & & & \\
\hline & Potatoes & 1 & o & & & & & & & & \\
\hline & Wheat & 97 & 50 & & & & & & & & \\
\hline \multirow[t]{3}{*}{ Wheat area } & Large & 49 & 10 & & & o & o & & & & \\
\hline & Medium & 49 & 80 & & & 66 & 33 & & & & \\
\hline & Small & 1 & 10 & & & 33 & 66 & & & & \\
\hline \multirow{3}{*}{$\begin{array}{l}\text { Crop } \\
\text { purpose }\end{array}$} & Feed & & & & & & & o & 37 & & \\
\hline & Food & & & & & & & 99 & 62 & & \\
\hline & Seed & & & & & & & o & o & & \\
\hline \multirow{3}{*}{$\begin{array}{l}\text { Past } \\
\text { infection }\end{array}$} & 2to5 & 1 & 17 & & & & & & & & \\
\hline & No & 78 & 37 & & & & & & & & \\
\hline & One & 21 & 45 & & & & & & & & \\
\hline \multirow[t]{2}{*}{ Benchmark } & No & & & & & & & 19 & 48 & 23 & 48 \\
\hline & Yes & & & & & & & 81 & 52 & 77 & 52 \\
\hline \multirow[t]{5}{*}{ Age } & 35 to 44 & & & 25 & 18 & & & 17 & 13 & & \\
\hline & $45^{\text {to }} 54$ & & & 49 & 18 & & & 17 & 50 & & \\
\hline & $55^{t o 64}$ & & & 25 & 38 & & & 66 & 13 & & \\
\hline & over64 & & & o & 18 & & & o & 13 & & \\
\hline & under35 & & & o & 9 & & & o & 13 & & \\
\hline \multirow[t]{3}{*}{ Education } & Vocational & & & & & 66 & 33 & & & & \\
\hline & Pri-Sec & & & & & 17 & 44 & & & & \\
\hline & Uni & & & & & 17 & 22 & & & & \\
\hline \multirow{2}{*}{$\begin{array}{l}\text { Risk } \\
\text { aversion }\end{array}$} & No & & & 10 & 55 & & & & & 28 & 52 \\
\hline & Yes & & & 90 & 45 & & & & & 72 & 48 \\
\hline \multirow{3}{*}{$\begin{array}{l}\text { Risk } \\
\text { perception }\end{array}$} & High & & & & & 7 & 14 & & & & \\
\hline & Low & & & & & 67 & 36 & & & & \\
\hline & Medium & & & & & 26 & 50 & & & & \\
\hline
\end{tabular}

aThe bold values represent the three selected farm and farmer characteristics to run in the BN models. 


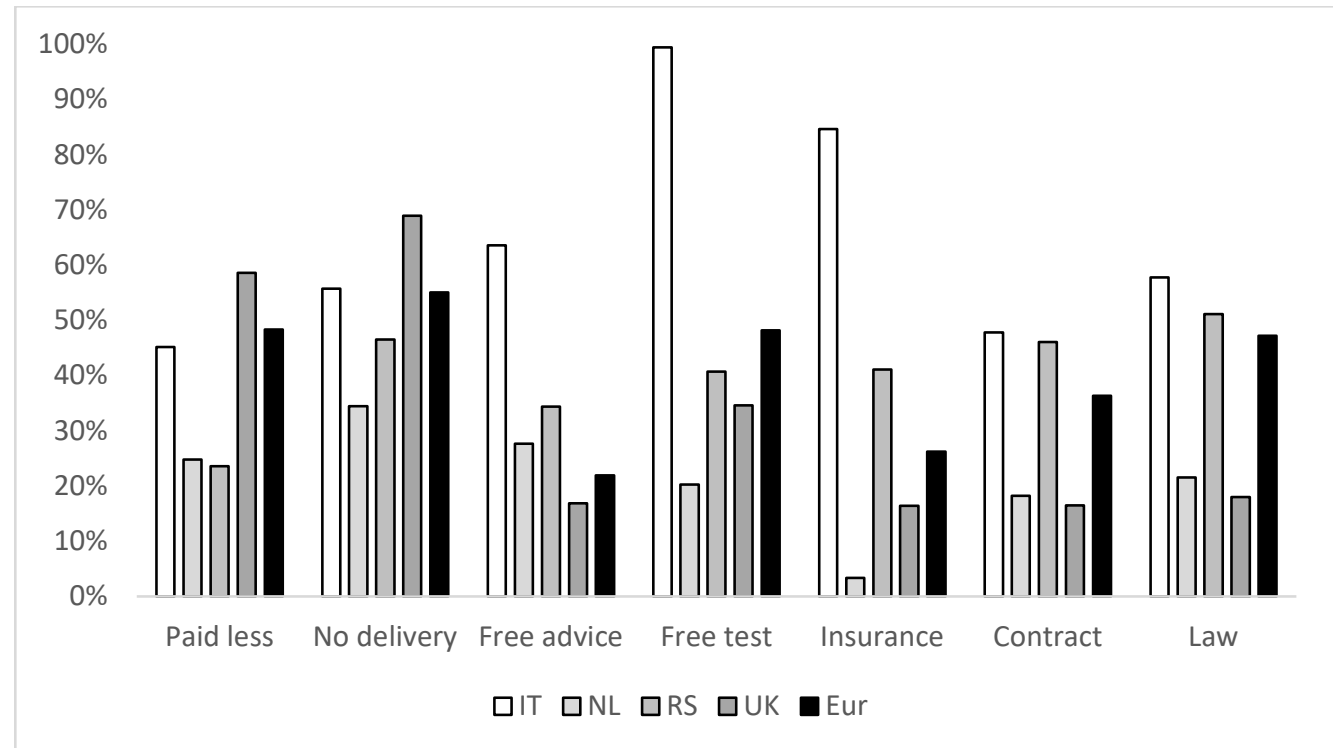

Figure 5.7. The probability of typical wheat farmers not incentivised by 'paid extra' having an increased intention (are incentivised) under the alternative incentives to adapt their current agronomic management to reduce Fusarium spp. infection and related mycotoxin contamination. (IT= Italy, NL = the Netherlands, RS = Serbia , UK = United Kingdom, Eur = IT + NL + RA + UK).

The probability of farmers who did not use the benchmark approach to be incentivised (i.e. had an increased intention) under each incentive is shown in Figure 5.8. These scenario 2 results showed that a European farmer who did not use a benchmark approach had a probability of $74 \%$ to be incentivised under the incentive 'paid extra' and a probability of $56 \%$ to be incentivised under the incentives 'free test' and 'law'. Italian farmers who did not use the benchmark approach had a $91 \%$ probability to be incentivised under the incentive 'paid extra' and a $73 \%$ probability under the incentive 'paid less'. The highest probability for NL farmers to be incentivised was $51 \%$ under 'paid extra' and 44\% under 'no delivery'. For RS farmers, the highest probability to be incentivised was under the incentive 'law' (69\%) and 'no delivery' (61\%). For UK farmers, the highest probability was under the incentives 'paid less' (95\%) and 'contract' (77\%). 


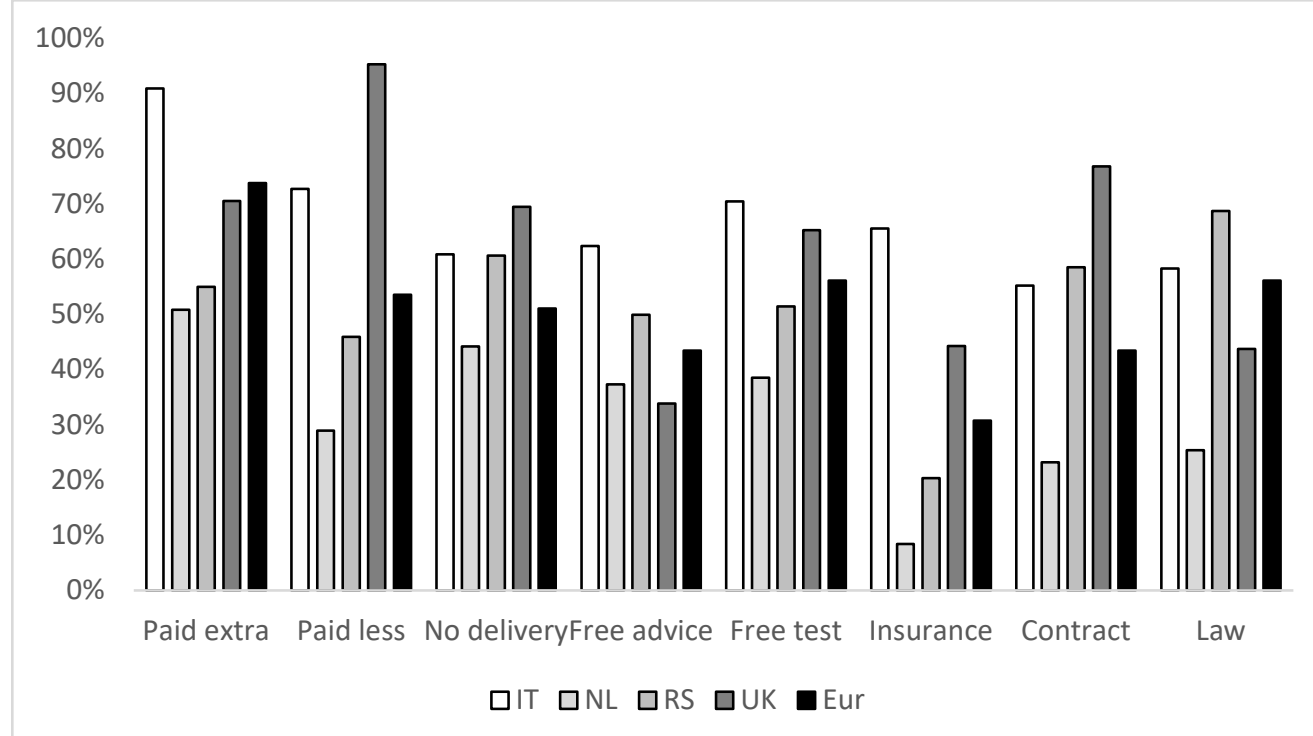

Figure 5.8. The probability of wheat farmers from Italy (IT), the Netherlands (NL), Serbia (RS), and the United Kingdom (UK) and the combination of the four countries (Eur) who did not use the benchmark approach to have an increased intention (are incentivised) under each of the eight incentives.

\subsection{Discussion}

This study collected questionnaire data on wheat farmers' intention regarding adaptations in their future agronomic management to reduce FHB and mycotoxins in wheat, and on farm and farmer characteristics farmers' intention under different incentives and analysed these data with Bayesian Network modelling. Previous studies focused on the relation between farm and farmer characteristics and agronomic management to reduce FHB and mycotoxins in wheat (Janssen et al. 2019), and on the intention of farmers to adapt this agronomic management (Janssen et al. 2020). This study investigated eight different incentives that can incentivise European farmers from Italy, the Netherlands, the United Kingdom and Serbia to adapt their agronomic management for prevention and control of FHB and related mycotoxins in wheat. To date, no other study investigated multiple incentives and various farm and farmer characteristics in detail.

Results of this study showed that 50\% of the European farmers had a positive intention to change their management to reduce FHB and mycotoxin contamination in wheat in the coming five years, ranging from $38 \%$ (UK) to $67 \%(\mathrm{RS})$ per country. On average, $25 \%$ of the European farmers had a negative intention to change their approach, ranging from $22 \%(\mathrm{NL})$ to $46 \%(\mathrm{UK})$. Farmers with a negative intention may be unable to change their approach because they already implemented multiple measures (Bruijnis et al. 2013); however, in this study, farmers with a negative intention were less likely to use a benchmark approach (consisting of using a Fusarium resistant wheat variety, fungicides during flowering and crop rotation or ploughing) compared to the farmers with a positive intention (Figure 5.5 and Figure 5.6). In addition, farmers with a negative 
intention were characterized by having wheat as their main crop and had a likelihood of $32 \%$ to have received university education.

In this study we analysed the incentivization of farmers by their increase in intention (incentivisation) under several incentives, because the stronger the intention is, the more likely the behaviour will be executed in the future (Ajzen 1991). The incentive under which the largest percentage of farmers adapt their FHB and mycotoxin management approach were payments when wheat contains low mycotoxin levels ('paid extra') and testing wheat for presence of mycotoxins for free ('free test').

The benchmark approach, i.e. an effective integrated agronomic approach consisting of a combination of using a Fusarium resistant wheat variety, using fungicides during flowering and crop rotation and/or ploughing (Blandino et al. 2012; McMullen et al. 2008), was used by $68 \%$ of the European farmers. Results imply that there is scope for improvement for the remaining $32 \%$ of the farmers to improve their FHB and mycotoxin management approach. In general, for most of the European wheat farmers who did not use a benchmark approach, the incentives to incentivise an adaptation in their management approach, were 'paid extra', 'free test', and 'law'. However, the 'best' incentive varied per country. For example, the best way to incentivise farmers who do not implement the benchmark approach were 'paid extra' and 'paid less' for Italy; 'paid extra' and 'no delivery' for the Netherlands; 'law' and 'no delivery' for Serbia; and 'paid less' and 'contract' for the United Kingdom. The observed differences in incentives between the four study countries might be related to the differences in wheat producing systems, relationships between the different actors in the chain, or cultural differences. Baur et al. (2016) found differences between countries in North-West Europe regarding their openness to change, i.e. farmers in the Netherlands, Denmark, and Switzerland were less conservative and more open to change than farmers from Austria, Finland, and Germany. Country differences were also found by Fischer et al. (2009), who indicated that the choices of contract type may be highly chain- and country specific; for example, within countries, differences between the cereal, beef and pig meat chain were found. In this study, the likelihood that a farmer was incentivised by the incentive 'contract' was low, ranging from $25 \%$ for NL farmers to $49 \%$ for IT farmers. The responses among countries could have differed because of the different types of contracts with which the farmers are familiar with. In the UK, $53 \%$ of the cereal farmers had a written contract or cross-shareholding arrangements between the farmer and processor (Fischer et al. 2009). Solazzo et al. (2020) found that only $12 \%$ of the Italian durum wheat farmers signed a forwarding contract because they lack trust in contracts and do not want to have constraints. They found that turnover and degree of specialisation in durum wheat production drive the adoption of written contracts. This is in line with the results of the current study, showing that farmers who were incentivised by 'contract' were most likely to have wheat as main crop and produce wheat for food.

Overall, the incentive 'paid extra' seems to be most promising. The exact monetary value needed to incentivise farmers with this incentive was not studied. Implementing the incentive 'paid extra' requires the testing of mycotoxin concentrations in wheat. This testing is paired with extra costs for either the farmer or the stakeholder implementing the incentive (Focker et al. 2019). A change in management can be paired with higher costs for the farmer and, therefore, the risk premium 'paid extra' should be sufficient so 
that farmers will actually change their management under this incentive. See also Dahl and Wilson (2018) who analysed the risk and determined risk premiums necessary to induce farmers to adopt technologies to reduce FHB in wheat. Although with 'paid extra' more farmers can be incentivised to change their management approach compared to the other incentives, it might not be the preferred option for stakeholders, because of budgetary limits. In addition, although farmers indicated a preference for 'paid extra', the incentivisation effect of monetary and in-kind incentives can be similar when evaluated over a longer time span (Peterson and Luthans 2006).

To be able to target the wheat farmers who could not be incentivised by 'paid extra', a BN scenario analysis was run. The typical European farmers who were not incentivised by 'paid extra', were likely to be incentivised by the alternative incentives 'free test', 'no delivery', and 'paid less'. However, the best alternative incentive to 'paid extra' differed per country, i.e. Italian wheat farmers were incentivised by multiple incentives like 'free test' (99\%) and 'insurance' (85\%), the UK farmers by 'no delivery' (69\%) and the Serbian farmers by 'no delivery' ( $55 \%)$. For the Dutch farmers, the highest likelihood for an alternative incentive was only $35 \%$ for 'no delivery'. This implies that Dutch wheat farmers are mainly incentivised by paying them extra when the wheat contains low mycotoxin levels, and they were only limited incentivised by the other seven incentives investigated in this study.

BN modelling was applied to identify the characteristics of farmers and their intention to adapt their agronomic management for reduction of FHB and mycotoxins. One of the strengths of BN modelling is that it can easily consider possible relationships among explaining variables and can handle variables with a skewed distribution. For example, in this study, farms in the Netherlands and Serbia were over-represented in the study sample compared to farms in the United Kingdom and Italy; hence, the distribution of the variable 'country' was skewed but could nevertheless be used in the analysis. Another strength of BN modelling is that it is possible to simulate different scenarios by selecting only a few or even many variable states and determine the probability of other variables, as we have shown for farmers without the benchmark approach (scenario analysis 2). Validation of the BN models was considered acceptable: the percentage of correctly predicted responses ranged from $85 \%$ to $94 \%$ for the training set and $38 \%$ to $67 \%$ for the test set.

With limited budgets, the BN model can be used to select groups of farmers that need to be incentivised to change, like farmers not applying the benchmark approach. The best (or second best) incentives can be selected for these groups, given their specific farm and farmers characteristics. Also, the BN model can give insight into farmer groups with specific farm and farmer characteristics related to an incentive selected by stakeholders. The results of this study provide a starting point for stakeholders to select potential incentives that can stimulate a change in farmers' agronomic management to reduce FHB and mycotoxin contamination. The eight incentives were described in general terms and do not include specific discrimination within the incentives e.g. farmers' intention under different type of contracts. There is extensive literature on the differences in e.g. contracts (Lajili et al. 1997; Wilson and Dahl 2011), insurance (Salazar et al. 2019) and premiums (Dahl and Wilson 2018; Fraser 1997) in wheat and crop production. The inclusion of specific incentive mechanisms was beyond the scope of this study, but the 


\section{Chapter 5}

results of this study provide interesting leads for further, more in-depth investigation. For example, to study the exact premium of the most promising incentive 'paid extra' that is needed to incentivise farmers.

In conclusion, this study showed that, on average, $51 \%$ of the studied European wheat farmers had the intention to change their agronomic approach to reduce Fusarium spp. infection and related mycotoxin contamination. This percentage varied between the four EU countries ranging from $38-67 \%$. Incentives that stimulate most of the farmers were paying farmers extra when wheat contains low levels of mycotoxins and providing tests for the presence of mycotoxins in the harvested wheat for free. The most effective incentive to increase farmers' intention to adapt their management depended on farm and farmer characteristics, like country, crop type, size of arable land, soil type, education, and mycotoxin knowledge. Insights into the farmer characteristics related to incentives can help stakeholders in the wheat supply chain, like farmer cooperatives and the government, to design tailor-made incentive plans.

\section{Acknowledgements}

We gratefully acknowledge the farmers who participated in our questionnaire and the following persons who translated and/or distributed the questionnaire among their network: Ferenc Bagi (University of Novi Sad), Helena Stanko (D.O.O. Agrocentrum Bečej), Simon Edwards (Harper Adams University), John Gilbert (FoodLife International Ltd) and Valentina Manstretta (HORTA). We thank the following organisations for distributing the questionnaire to the farmers: the Dutch agricultural cooperatives Agrifirm and CZAV, Van Iperen, Dutch Federation of Agriculture and Horticulture (LTO), and Dutch Arable Farming Union (NAV), the British AHDB and NFU, the Italian Coldiretti and ANB. We thank J.L. Banach (Wageningen Food Safety Research) for improving the English of the paper.

\section{Funding}

This study is performed as part of the My Toolbox project, which received funding from the European Union's Horizon 2020 research and innovation programme under grant agreement No. 678012 . 


\section{Appendix A.5. Supplementary data}

Table A.5.1. Conditional probabilities (\%) of farm and farmer characteristics of farmers with a negative, positive and neutral intention (INT).

\begin{tabular}{|c|c|c|c|c|}
\hline & & \multicolumn{2}{|l|}{ 'INT' } & \multirow[b]{2}{*}{ Neutral } \\
\hline \multirow{3}{*}{ Country } & \multirow[b]{2}{*}{ IT } & Negative & Positive & \\
\hline & & 0.18 & $4 \%$ & $22 \%$ \\
\hline & NL & $43 \%$ & $49 \%$ & $59 \%$ \\
\hline \multirow{6}{*}{ Soil type } & RS & $14 \%$ & $37 \%$ & $4 \%$ \\
\hline & UK & $25 \%$ & $11 \%$ & $15 \%$ \\
\hline & Chernozem & $11 \%$ & $25 \%$ & $8 \%$ \\
\hline & Clay & $46 \%$ & $49 \%$ & $62 \%$ \\
\hline & Loam & $21 \%$ & $7 \%$ & $8 \%$ \\
\hline & Loess & $11 \%$ & $5 \%$ & $15 \%$ \\
\hline \multirow{5}{*}{ Arable land } & Peat & o\% & $4 \%$ & o\% \\
\hline & Sand & $11 \%$ & $11 \%$ & $8 \%$ \\
\hline & Large & $43 \%$ & $28 \%$ & $37 \%$ \\
\hline & Medium & $50 \%$ & $59 \%$ & $44 \%$ \\
\hline & Small & $7 \%$ & $12 \%$ & $19 \%$ \\
\hline \multirow[t]{3}{*}{ Main crop } & Mais & $18 \%$ & $19 \%$ & $4 \%$ \\
\hline & Other & $18 \%$ & $16 \%$ & $11 \%$ \\
\hline & Potatoes & $25 \%$ & $44 \%$ & $59 \%$ \\
\hline \multirow{4}{*}{ Wheat area } & Wheat & $39 \%$ & $21 \%$ & $26 \%$ \\
\hline & Large & $4 \%$ & $2 \%$ & $4 \%$ \\
\hline & Medium & $64 \%$ & $66 \%$ & $74 \%$ \\
\hline & Small & $32 \%$ & $32 \%$ & $22 \%$ \\
\hline \multirow[t]{2}{*}{ Crop buyer } & Collector & $85 \%$ & $89 \%$ & $88 \%$ \\
\hline & Other & $7 \%$ & $2 \%$ & $11 \%$ \\
\hline \multirow{4}{*}{ Crop purpose } & Producer & $7 \%$ & $9 \%$ & o\% \\
\hline & Feed & $32 \%$ & $46 \%$ & $48 \%$ \\
\hline & Food & $64 \%$ & $49 \%$ & $48 \%$ \\
\hline & Seed & $4 \%$ & $5 \%$ & $4 \%$ \\
\hline \multirow[t]{2}{*}{ Benchmark } & No & $46 \%$ & $25 \%$ & $45 \%$ \\
\hline & Yes & $54 \%$ & $75 \%$ & $55 \%$ \\
\hline \multirow[t]{3}{*}{ Past infection } & 2 to5 & $11 \%$ & $25 \%$ & $11 \%$ \\
\hline & No & $43 \%$ & $37 \%$ & $52 \%$ \\
\hline & One & $46 \%$ & $39 \%$ & $37 \%$ \\
\hline \multirow[t]{2}{*}{ DSS use } & No & $61 \%$ & $75 \%$ & $63 \%$ \\
\hline & Yes & $39 \%$ & $25 \%$ & $37 \%$ \\
\hline \multirow[t]{3}{*}{ DSS need } & Maybe & $43 \%$ & $25 \%$ & $41 \%$ \\
\hline & No & $4 \%$ & $5 \%$ & $8 \%$ \\
\hline & Yes & $53 \%$ & $70 \%$ & $52 \%$ \\
\hline \multirow[t]{5}{*}{ Age } & $35^{\text {to } 44}$ & $14 \%$ & $16 \%$ & $15 \%$ \\
\hline & $45^{\text {to }} 54$ & $32 \%$ & $32 \%$ & $30 \%$ \\
\hline & $55^{t o 6}$ & $28 \%$ & $16 \%$ & $37 \%$ \\
\hline & over64 & $11 \%$ & $11 \%$ & $4 \%$ \\
\hline & under35 & $14 \%$ & $26 \%$ & $15 \%$ \\
\hline \multirow[t]{3}{*}{ Education } & Vocational & $50 \%$ & $75 \%$ & $59 \%$ \\
\hline & Pri-Sec & $18 \%$ & $12 \%$ & $26 \%$ \\
\hline & University & vo.32 & $12 \%$ & $15 \%$ \\
\hline \multirow[t]{3}{*}{ Knowledge } & High & $60 \%$ & $47 \%$ & $44 \%$ \\
\hline & Low & $4 \%$ & $12 \%$ & $11 \%$ \\
\hline & Medium & $36 \%$ & $40 \%$ & $44 \%$ \\
\hline \multirow[t]{3}{*}{ Risk perception } & High & $11 \%$ & $19 \%$ & $11 \%$ \\
\hline & Low & $50 \%$ & $40 \%$ & $41 \%$ \\
\hline & Medium & $39 \%$ & $40 \%$ & $48 \%$ \\
\hline \multirow[t]{2}{*}{ Risk aversion } & No & $36 \%$ & $46 \%$ & $52 \%$ \\
\hline & Yes & $64 \%$ & $54 \%$ & $48 \%$ \\
\hline
\end{tabular}




\section{Chapter 5}

Table A.5.2. Conditional probabilities (\%) of farm and farmer characteristics of farmers with a decreased, increased or unaltered intention under eight incentives.

\begin{tabular}{|c|c|c|c|c|c|c|c|}
\hline & & 'Paid extra' & & & "Paid less' & & \\
\hline \multirow{3}{*}{ Country } & & Decreased & Increased & Unaltered & Decreased & Increased & Unaltered \\
\hline & IT & 11 & 16 & 3 & 13 & 17 & 3 \\
\hline & NL & 22 & 56 & 54 & 53 & 39 & 61 \\
\hline \multirow{6}{*}{ Soil type } & RS & 33 & 15 & 33 & 27 & 15 & 31 \\
\hline & UK & 33 & 13 & 9 & 7 & 28 & 6 \\
\hline & Chernozem & 28 & 8 & 27 & 17 & 13 & 22 \\
\hline & Clay & 11 & 60 & 57 & 46 & 45 & 63 \\
\hline & Loam & 28 & 10 & 3 & 13 & 17 & o \\
\hline & Loess & 17 & 10 & 3 & 10 & 13 & 3 \\
\hline \multirow{5}{*}{ Arable land } & Peat & o & 2 & 3 & o & o & 6 \\
\hline & Sand & 17 & 10 & 6 & 13 & 11 & 6 \\
\hline & Large & 61 & 26 & 33 & 33 & 43 & 22 \\
\hline & Medium & 17 & 61 & 60 & 50 & 41 & 72 \\
\hline & Small & 22 & 13 & 6 & 17 & 15 & 6 \\
\hline \multirow[t]{3}{*}{ Main crop } & Mais & 6 & 3 & o & 4 & 2 & 3 \\
\hline & Other & 72 & 70 & 60 & 73 & 71 & 58 \\
\hline & Potatoes & 22 & 26 & 39 & 23 & 26 & 39 \\
\hline \multirow{4}{*}{ Wheat area } & Wheat & 22 & 13 & 15 & 20 & 11 & 17 \\
\hline & Large & 6 & 13 & 24 & $\mathrm{o}$ & 17 & 25 \\
\hline & Medium & 28 & 47 & 42 & 53 & 35 & 44 \\
\hline & Small & 44 & 26 & 18 & 27 & 37 & 14 \\
\hline \multirow[t]{2}{*}{ Crop buyer } & Collector & 82 & 90 & 87 & 96 & 82 & 88 \\
\hline & Other & 1 & 5 & 9 & o & 7 & 9 \\
\hline \multirow{4}{*}{ Crop purpose } & Producer & 17 & 5 & 3 & 4 & 11 & 3 \\
\hline & Feed & 33 & 41 & 51 & 50 & 37 & 44 \\
\hline & Food & 66 & 52 & 45 & 47 & 59 & 50 \\
\hline & Seed & 1 & 7 & 3 & 4 & 5 & 6 \\
\hline \multirow[t]{2}{*}{ Benchmark } & No & 23 & 48 & 19 & 30 & 46 & 25 \\
\hline & Yes & 77 & 52 & 82 & 70 & 54 & 75 \\
\hline \multirow[t]{3}{*}{ Past infection } & 2 to5 & 12 & 21 & 15 & 14 & 18 & 22 \\
\hline & No & 50 & 39 & 42 & 43 & 43 & 39 \\
\hline & One & 39 & 39 & 42 & 43 & 39 & 39 \\
\hline \multirow[t]{2}{*}{ DSS use } & No & 72 & 65 & 73 & 73 & 56 & 80 \\
\hline & Yes & 28 & 35 & 28 & 27 & 44 & 20 \\
\hline \multirow[t]{2}{*}{ DSS need } & Maybe & 50 & 38 & 15 & 40 & 39 & 20 \\
\hline & No & 6 & 7 & 3 & 10 & 5 & 3 \\
\hline \multirow{5}{*}{ Age } & Yes & 44 & 56 & 81 & 50 & 56 & 77 \\
\hline & $35^{\text {to } 44}$ & 17 & 13 & 18 & 20 & 13 & 14 \\
\hline & $45^{\text {to }} 54$ & 22 & 33 & 33 & 27 & 37 & 28 \\
\hline & 55 to64 & 28 & 26 & 18 & 17 & 28 & 25 \\
\hline & over64 & o & 13 & 6 & 13 & 7 & 8 \\
\hline \multirow{4}{*}{ Education } & under35 & 33 & 15 & 24 & 23 & 15 & 25 \\
\hline & Vocational & 55 & 59 & 81 & 70 & 50 & 80 \\
\hline & Pri-Sec & 17 & 21 & 9 & 17 & 22 & 11 \\
\hline & University & 28 & 20 & 9 & 14 & 28 & 9 \\
\hline \multirow[t]{2}{*}{ Knowledge } & High & 61 & 52 & 39 & 63 & 48 & 42 \\
\hline & Low & 1 & 12 & 12 & 4 & 7 & 20 \\
\hline \multirow{4}{*}{ Risk perception } & Medium & 39 & 36 & 48 & 33 & 46 & 39 \\
\hline & High & 17 & 10 & 24 & 10 & 11 & 25 \\
\hline & Low & 50 & 41 & 42 & 40 & 52 & 33 \\
\hline & Medium & 33 & 49 & 33 & 50 & 37 & 42 \\
\hline Risk aversion & No & 28 & 52 & 40 & 34 & 50 & 47 \\
\hline & Yes & 72 & 48 & 61 & 66 & 50 & 53 \\
\hline INT & Negative & 28 & 33 & 9 & 20 & 39 & 11 \\
\hline & Neutral & 12 & 33 & 15 & 10 & 37 & 20 \\
\hline & Positive & 61 & 34 & 75 & 70 & 24 & 69 \\
\hline INCp & Negative & 50 & 2 & 9 & 66 & o & 9 \\
\hline & Neutral & 44 & 2 & 18 & 30 & 11 & 25 \\
\hline & Positive & 6 & 96 & 72 & 4 & 89 & 66 \\
\hline
\end{tabular}


Table A.5.2. (continued)

\begin{tabular}{|c|c|c|c|c|c|c|c|}
\hline & & \multicolumn{2}{|c|}{ 'No delivery' } & \multicolumn{3}{|c|}{ 'Free advice' } & \multirow[b]{2}{*}{ Unaltered } \\
\hline \multirow{3}{*}{ Country } & & Decreased & Increased & Unaltered & Decreased & Increased & \\
\hline & IT & 3 & 15 & 17 & 8 & 15 & 12 \\
\hline & NL & 64 & 44 & 41 & 58 & 52 & 38 \\
\hline \multirow{6}{*}{ Soil type } & RS & 26 & 19 & 29 & 11 & 25 & 35 \\
\hline & UK & 6 & 22 & 13 & 24 & 8 & 15 \\
\hline & Chernozem & 18 & 19 & 13 & 16 & 15 & 21 \\
\hline & Clay & 58 & 48 & 50 & 50 & 60 & 44 \\
\hline & Loam & 3 & 15 & 13 & 11 & 13 & 9 \\
\hline & Loess & 9 & 9 & 8 & 5 & 10 & 12 \\
\hline \multirow{5}{*}{ Arable land } & Peat & 6 & o & o & 3 & 3 & $\mathrm{o}$ \\
\hline & Sand & 6 & 9 & 17 & 16 & o & 15 \\
\hline & Large & 21 & 41 & 37 & 45 & 23 & 35 \\
\hline & Medium & 70 & 43 & 54 & 52 & 60 & 47 \\
\hline & Small & 9 & 17 & 9 & 3 & 18 & 18 \\
\hline \multirow[t]{4}{*}{ Main crop } & Mais & 15 & 15 & 17 & 5 & 20 & 21 \\
\hline & Other & 3 & 15 & 33 & 16 & 18 & 12 \\
\hline & Potatoes & 61 & 39 & 25 & 52 & 40 & 35 \\
\hline & Wheat & 21 & 31 & 25 & 26 & 23 & 32 \\
\hline \multirow[t]{3}{*}{ Wheat area } & Large & 3 & 2 & 5 & 3 & 5 & o \\
\hline & Medium & 64 & 76 & 54 & 63 & 70 & 70 \\
\hline & Small & 32 & 22 & 42 & 34 & 25 & 29 \\
\hline \multirow[t]{3}{*}{ Crop buyer } & Collector & 91 & 90 & 79 & 86 & 92 & 85 \\
\hline & Other & 3 & 4 & 13 & 3 & 3 & 12 \\
\hline & Producer & 6 & 6 & 9 & 11 & 5 & 3 \\
\hline \multirow[t]{3}{*}{ Crop purpose } & Feed & 47 & 39 & 46 & 52 & 40 & 35 \\
\hline & Food & 50 & 55 & 50 & 42 & 55 & 61 \\
\hline & Seed & 3 & 6 & 5 & 6 & 5 & 3 \\
\hline \multirow[t]{2}{*}{ Benchmark } & No & 30 & 37 & 38 & 27 & 43 & 35 \\
\hline & Yes & 70 & 63 & 62 & 73 & 57 & 65 \\
\hline \multirow[t]{3}{*}{ Past infection } & 2to5 & 21 & 15 & 21 & 19 & 23 & 12 \\
\hline & No & 35 & 44 & 46 & 37 & 37 & 53 \\
\hline & One & 44 & 41 & 33 & 45 & 40 & 35 \\
\hline \multirow[t]{2}{*}{ DSS use } & No & 79 & 63 & 66 & 66 & 62 & 79 \\
\hline & Yes & 21 & 37 & 34 & 34 & 38 & 21 \\
\hline \multirow[t]{3}{*}{ DSS need } & Maybe & 27 & 39 & 29 & 47 & 28 & 24 \\
\hline & No & 9 & 6 & o & 3 & 3 & 12 \\
\hline & Yes & 64 & 55 & 70 & 50 & 70 & 64 \\
\hline Age & $35^{\text {to } 44}$ & 15 & 13 & 21 & 24 & 8 & 15 \\
\hline & $45^{\text {to }} 54$ & 32 & 30 & 33 & 29 & 32 & 32 \\
\hline & $55^{t o 6}$ & 23 & 28 & 17 & 26 & 30 & 15 \\
\hline & over64 & 18 & 7 & o & 3 & 18 & 6 \\
\hline & under35 & 12 & 22 & 29 & 18 & 13 & 32 \\
\hline Education & Vocational & 76 & 55 & 70 & 76 & 57 & 61 \\
\hline & Pri-Sec & 24 & 13 & 17 & 8 & 25 & 18 \\
\hline & University & o & 31 & 13 & 16 & 18 & 21 \\
\hline Knowledge & High & 41 & 57 & 46 & 45 & 47 & 59 \\
\hline & Low & 9 & 8 & 17 & 8 & 10 & 12 \\
\hline & Medium & 50 & 35 & 37 & 47 & 42 & 29 \\
\hline Risk perception & High & 21 & 15 & 9 & 19 & 10 & 18 \\
\hline & Low & 32 & 43 & 58 & 42 & 33 & 56 \\
\hline & Medium & 47 & 43 & 33 & 39 & 57 & 27 \\
\hline Risk aversion & No & 44 & 48 & 38 & 42 & 48 & 44 \\
\hline & Yes & 56 & 52 & 62 & 58 & 52 & 56 \\
\hline INT & Negative & 6 & 41 & 17 & 19 & 35 & 21 \\
\hline & Neutral & 24 & 28 & 17 & 19 & 25 & 29 \\
\hline & Positive & 70 & 31 & 66 & 63 & 40 & 50 \\
\hline INCp & Negative & 79 & o & 13 & 58 & 3 & 15 \\
\hline & Neutral & 18 & 2 & 25 & 37 & 15 & 41 \\
\hline & Positive & 3 & 98 & 62 & 6 & 82 & 44 \\
\hline
\end{tabular}


Table A.5.2. (continued)

\begin{tabular}{|c|c|c|c|c|c|c|c|}
\hline & & 'Free test' & & & 'Insurance' & & \\
\hline \multirow{3}{*}{ Country } & & Decreased & Increased & Unaltered & Decreased & Increased & Unaltered \\
\hline & IT & 6 & 18 & 6 & 7 & 26 & 7 \\
\hline & NL & 73 & 42 & 50 & 66 & 22 & 43 \\
\hline \multirow{6}{*}{ Soil type } & RS & 11 & 21 & 33 & 14 & 30 & 36 \\
\hline & UK & 11 & 19 & 11 & 12 & 22 & 14 \\
\hline & Chernozem & 11 & 14 & 25 & 14 & 26 & 14 \\
\hline & Clay & 68 & 49 & 47 & 63 & 29 & 50 \\
\hline & Loam & 5 & 16 & 6 & 7 & 15 & 14 \\
\hline & Loess & 11 & 9 & 8 & 5 & 15 & 11 \\
\hline \multirow{5}{*}{ Arable land } & Peat & 5 & 2 & o & 2 & o & 4 \\
\hline & Sand & $\mathrm{o}$ & 11 & 14 & 9 & 15 & 7 \\
\hline & Large & 47 & 30 & 33 & 35 & 33 & 32 \\
\hline & Medium & 52 & 53 & 55 & 59 & 37 & 57 \\
\hline & Small & 1 & 18 & 11 & 5 & 30 & 11 \\
\hline \multirow[t]{4}{*}{ Main crop } & Mais & o & 16 & 22 & 11 & 22 & 18 \\
\hline & Other & 16 & 18 & 11 & 9 & 22 & 21 \\
\hline & Potatoes & 68 & 32 & 47 & 59 & 11 & 39 \\
\hline & Wheat & 16 & 35 & 19 & 21 & 44 & 21 \\
\hline \multirow[t]{3}{*}{ Wheat area } & Large & 1 & 5 & o & 2 & 8 & $\mathrm{o}$ \\
\hline & Medium & 73 & 73 & 55 & 68 & 70 & 64 \\
\hline & Small & 26 & 21 & 44 & 30 & 22 & 36 \\
\hline \multirow[t]{3}{*}{ Crop buyer } & Collector & 89 & 89 & 86 & 93 & 85 & 82 \\
\hline & Other & 6 & 4 & 9 & 2 & 8 & 11 \\
\hline & Producer & 6 & 7 & 6 & 5 & 8 & 7 \\
\hline \multirow[t]{3}{*}{ Crop purpose } & Feed & 57 & 37 & 44 & 51 & 33 & 36 \\
\hline & Food & 37 & 59 & 50 & 46 & 66 & 53 \\
\hline & Seed & 6 & 4 & 6 & 4 & o & 11 \\
\hline \multirow[t]{2}{*}{ Benchmark } & No & 22 & 39 & 36 & 26 & 45 & 43 \\
\hline & Yes & 78 & 61 & 64 & 74 & 55 & 57 \\
\hline \multirow[t]{3}{*}{ Past infection } & 2 to 5 & 26 & 19 & 11 & 23 & 19 & 7 \\
\hline & No & 26 & 40 & 53 & 39 & 37 & 53 \\
\hline & One & 47 & 40 & 36 & 39 & 44 & 39 \\
\hline \multirow[t]{2}{*}{ DSS use } & No & 68 & 60 & 83 & 75 & 48 & 75 \\
\hline & Yes & 32 & 40 & 17 & 25 & 52 & 25 \\
\hline \multirow[t]{3}{*}{ DSS need } & Maybe & 42 & 35 & 25 & 30 & 44 & 29 \\
\hline & No & 6 & 7 & 3 & 4 & 11 & 4 \\
\hline & Yes & 52 & 58 & 72 & 66 & 44 & 67 \\
\hline \multirow[t]{5}{*}{ Age } & $35^{\text {to } 44}$ & 16 & 18 & 11 & 21 & 11 & 7 \\
\hline & $45^{\text {to } 54}$ & 42 & 32 & 25 & 26 & 40 & 32 \\
\hline & $55^{t 064}$ & 31 & 21 & 25 & 26 & 19 & 25 \\
\hline & over64 & 6 & 11 & 8 & 9 & 11 & 7 \\
\hline & under35 & 6 & 19 & 30 & 18 & 19 & 28 \\
\hline \multirow[t]{3}{*}{ Education } & Vocational & 89 & 53 & 72 & 84 & 33 & 57 \\
\hline & Pri-Sec & 6 & 23 & 14 & 7 & 33 & 22 \\
\hline & University & 6 & 25 & 14 & 9 & 33 & 22 \\
\hline \multirow[t]{3}{*}{ Knowledge } & High & 42 & 53 & 50 & 40 & 74 & 46 \\
\hline & Low & 6 & 12 & 9 & 5 & 11 & 18 \\
\hline & Medium & 52 & 35 & 42 & 54 & 15 & 36 \\
\hline \multirow[t]{3}{*}{ Risk perception } & High & 21 & 12 & 17 & 16 & 19 & 11 \\
\hline & Low & 52 & 40 & 42 & 40 & 44 & 46 \\
\hline & Medium & 26 & 47 & 42 & 44 & 37 & 43 \\
\hline Risk aversion & No & 47 & 44 & 44 & 42 & 41 & 54 \\
\hline & Yes & 53 & 56 & 56 & 58 & 59 & 46 \\
\hline INT & Negative & 16 & 37 & 11 & 16 & 48 & 22 \\
\hline & Neutral & 16 & 25 & 28 & 21 & 19 & 36 \\
\hline & Positive & 68 & 39 & 61 & 63 & 33 & 43 \\
\hline INCp & Negative & 47 & 2 & 9 & 70 & 8 & 18 \\
\hline & Neutral & 42 & 11 & 39 & 28 & 26 & 46 \\
\hline & Positive & 11 & 87 & 53 & 2 & 66 & 36 \\
\hline
\end{tabular}


Table A.5.2. (continued)

\begin{tabular}{|c|c|c|c|c|c|c|c|}
\hline & & 'Contract' & & & 'Law' & & \\
\hline \multirow{3}{*}{ Country } & & Decreased & Increased & Unaltered & Decreased & Increased & Unaltered \\
\hline & IT & 6 & 18 & 11 & 3 & 17 & 13 \\
\hline & NL & 65 & 38 & 47 & 64 & 37 & 53 \\
\hline \multirow{6}{*}{ Soil type } & RS & 14 & 26 & 29 & 18 & 23 & 30 \\
\hline & UK & 14 & 18 & 13 & 15 & 23 & 4 \\
\hline & Chernozem & 14 & 18 & 18 & 15 & 23 & 10 \\
\hline & Clay & 62 & 43 & 50 & 56 & 44 & 60 \\
\hline & Loam & 9 & 18 & 5 & 12 & 15 & 3 \\
\hline & Loess & 9 & 8 & 11 & 9 & 6 & 13 \\
\hline \multirow{5}{*}{ Arable land } & Peat & o & 3 & 3 & 3 & o & 3 \\
\hline & Sand & 6 & 10 & 13 & 6 & 13 & 10 \\
\hline & Large & 29 & 41 & 32 & 32 & 37 & 30 \\
\hline & Medium & 68 & 38 & 55 & 64 & 46 & 53 \\
\hline & Small & 3 & 21 & 13 & 3 & 17 & 17 \\
\hline \multirow[t]{4}{*}{ Main crop } & Mais & 17 & 15 & 13 & 12 & 17 & 17 \\
\hline & Other & 14 & 18 & 13 & 12 & 17 & 17 \\
\hline & Potatoes & 60 & 26 & 45 & 58 & 31 & 43 \\
\hline & Wheat & 9 & 41 & 29 & 18 & 35 & 23 \\
\hline \multirow[t]{3}{*}{ Wheat area } & Large & o & 5 & 3 & 3 & 2 & 4 \\
\hline & Medium & 68 & 66 & 68 & 64 & 69 & 70 \\
\hline & Small & 31 & 28 & 29 & 32 & 29 & 27 \\
\hline \multirow[t]{3}{*}{ Crop buyer } & Collector & 94 & 89 & 81 & 88 & 91 & 83 \\
\hline & Other & o & 5 & 11 & o & 4 & 14 \\
\hline & Producer & 6 & 5 & 8 & 12 & 4 & 4 \\
\hline \multirow[t]{3}{*}{ Crop purpose } & Feed & 63 & 31 & 37 & 53 & 35 & 43 \\
\hline & Food & 34 & 64 & 58 & 47 & $5^{8}$ & 50 \\
\hline & Seed & 3 & 5 & 6 & o & 6 & 7 \\
\hline \multirow[t]{2}{*}{ Benchmark } & No & 29 & 44 & 32 & 24 & 46 & 30 \\
\hline & Yes & 71 & 56 & 68 & 76 & 54 & 70 \\
\hline \multirow[t]{3}{*}{ Past infection } & 2 to5 & 23 & 16 & 16 & 15 & 19 & 20 \\
\hline & No & 31 & 38 & 55 & 38 & 44 & 43 \\
\hline & One & 46 & 46 & 29 & 47 & 37 & 37 \\
\hline \multirow[t]{2}{*}{ DSS use } & No & 68 & 59 & 79 & 62 & 64 & 83 \\
\hline & Yes & 32 & 41 & 21 & 38 & 36 & 17 \\
\hline \multirow[t]{3}{*}{ DSS need } & Maybe & 40 & 41 & 19 & 27 & 46 & 20 \\
\hline & No & 3 & 3 & 11 & 3 & 6 & 7 \\
\hline & Yes & 57 & 56 & 71 & 70 & 48 & 73 \\
\hline \multirow[t]{5}{*}{ Age } & $35^{\text {to } 44}$ & 23 & 10 & 13 & 21 & 13 & 13 \\
\hline & $45^{\text {to } 54}$ & 26 & 36 & 31 & 35 & 27 & 33 \\
\hline & $55^{\text {to6 }} 4$ & 28 & 23 & 21 & 29 & 23 & 20 \\
\hline & over64 & 9 & 5 & 13 & 9 & 8 & 10 \\
\hline & under35 & 14 & 26 & 21 & 6 & 29 & 23 \\
\hline \multirow[t]{3}{*}{ Education } & Vocational & 74 & 51 & 71 & 64 & 54 & 83 \\
\hline & Pri-Sec & 12 & 23 & 16 & 24 & 15 & 14 \\
\hline & University & 14 & 26 & 13 & 12 & 31 & 4 \\
\hline \multirow[t]{3}{*}{ Knowledge } & High & 51 & 51 & 47 & 44 & 52 & 53 \\
\hline & Low & 9 & 5 & 16 & 6 & 9 & 17 \\
\hline & Medium & 40 & 44 & 37 & 50 & 40 & 30 \\
\hline \multirow[t]{3}{*}{ Risk perception } & High & 17 & 16 & 13 & 18 & 13 & 17 \\
\hline & Low & 43 & 51 & 34 & 32 & 48 & 47 \\
\hline & Medium & 40 & 33 & 52 & 50 & 40 & 37 \\
\hline Risk aversion & No & 43 & 54 & 37 & 44 & 46 & 43 \\
\hline & Yes & 57 & 46 & 63 & 56 & 54 & 57 \\
\hline INT & Negative & 17 & 46 & 11 & 9 & 42 & 17 \\
\hline & Neutral & 26 & 21 & 26 & 21 & 29 & 20 \\
\hline & Positive & 57 & 33 & 63 & 70 & 29 & 63 \\
\hline INCp & Negative & 71 & 8 & 8 & 67 & 2 & 10 \\
\hline & Neutral & 26 & 10 & 42 & 24 & 11 & 37 \\
\hline & Positive & 3 & 82 & 50 & 9 & 87 & 53 \\
\hline
\end{tabular}




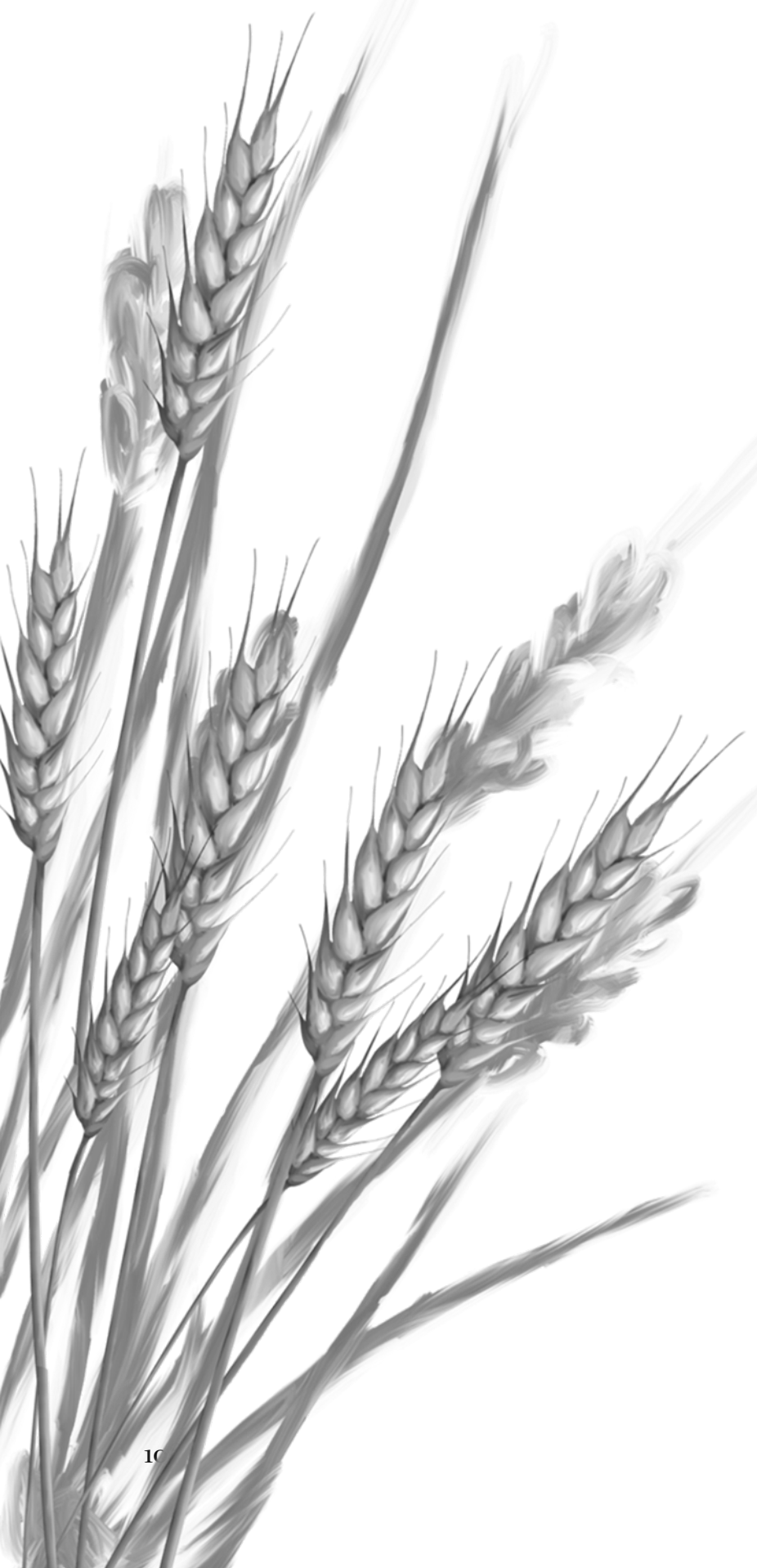




\section{Chapter 6}

General Discussion 


\subsection{Introduction}

Fusarium spp. infection in wheat can lead to the crop disease Fusarium Head Blight (FHB) and Fusarium damaged kernels (FDK), resulting in reduced yield quantity, loss of quality of the kernels and contamination with mycotoxins. Mycotoxin exposure via contaminated feed and food poses health problem to human and animals. Because it is difficult, if not impossible, to remove mycotoxins further along the chain, agronomic management is mainly focused on reducing initial Fusarium spp. infection in the wheat field by farmers. Although many studies showed that implementing agronomic management measures can be effective to reduce FHB and mycotoxins, hardly any attention in given to the actual implementation of measures by farmers and opportunities to improve their agronomic management. Since effective agronomic management along the supply chain also depends on the implementation of agronomic measures by farmers, it is important to understand the behaviour of farmers regarding their agronomic management. Therefore, this thesis aimed to investigate how to incentivise farmers to adapt their agronomic management to reduce FHB and mycotoxin contamination in wheat.

Chapter 2 of this thesis provided a solid base for understanding Fusarium spp. infection and mycotoxin contamination in barley and wheat, and identified effective agronomic management measures to reduce $\mathrm{FHB}$ and mycotoxin contamination. Chapter 3 identified which agronomic management measures Dutch wheat farmers currently apply against FHB and mycotoxin contamination and examined which farm and farmer characteristics explain the implementation of these measures. It showed the scope for improvement regarding the implementation of agronomic management measures for different farmer types. Chapter 4 focussed on the intention of Dutch wheat farmers to adapt their agronomic management to reduce FHB and mycotoxin contamination and studied the underlying behavioural constructs and beliefs using the Theory of Planned Behaviour (TPB). Results showed which beliefs should be used to incentivise a change in farmers' mycotoxin management and via which channels. Chapter 5 assessed eight different incentives that increased the intention of European (NL, UK, IT, RS) farmers' intentions to adapt their agronomic approach, and related these to farm and farmer characteristics.

This concluding chapter synthesises the results of the different chapters (section 2), reflects on the applied research approach and methods (section 3), discusses the possible business and policy implications (section 4), elaborates on the implications for future research (section 5), and ends with the main conclusions of this dissertation (section 6).

\subsection{Synthesis of the results}

In this section the synthesis of the results is given. Figure 6.1 visualises the interrelation between the research chapters as driven by the data obtained by the questionnaires. In Chapter 3, farm and farmer characteristics were related to farmers' current agronomic approach, in Chapter 4, the beliefs and behavioural constructs underlying farmers' intention to alter their management were studied, and in Chapter 5 farm and farmer characteristics were related to various incentives to increase farmers' intention to alter current management. 


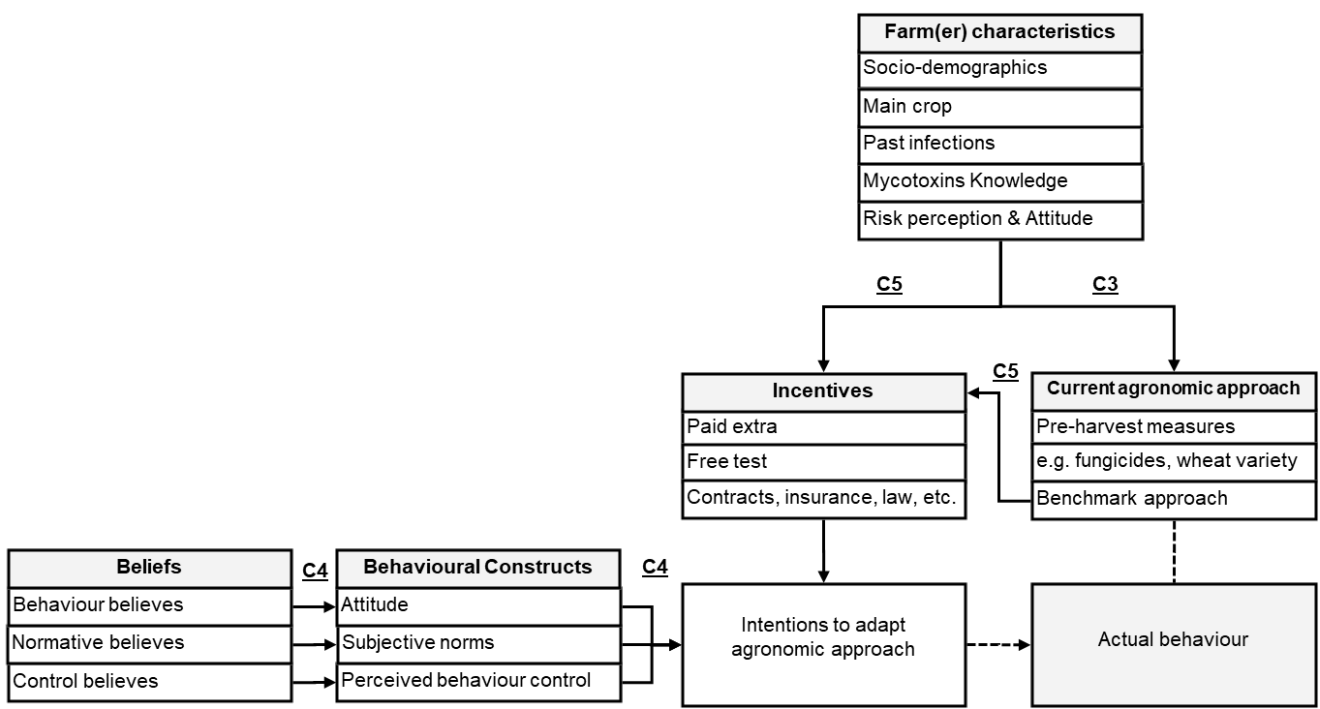

Figure 6.1. Overview of the connections between the variables obtained by the questionnaire and analysed in Chapter $3\left(C_{3}\right)$, Chapter $4\left(C_{4}\right)$ and Chapter $5\left(C_{5}\right)$.

\subsubsection{Opportunities to adapt agronomic management}

Chapter 2 showed that Fusarium spp. infection in wheat can cause FHB and quality issues, like a reduced yield quantity and smaller kernels. In contrast to barley, quality problems due to the presence of the living Fusarium fungus in the end-product is not an issue for wheat; however, Fusarium mycotoxins are transferred through the wheat supply chain, e.g. during different processing steps in milling and baking (Hazel and Patel 2004; Kaushik 2015). Significant correlations between FHB disease severity and DON presence were found (Edwards 2009a; Edwards 2009b; Van der Fels-Klerx and Stratakou 2010), suggesting that reducing Fusarium spp. infection in wheat can increase both quality and safety of the grain. Whereas a reduction in yield quantity and quality is a direct issue for the farmer, the presence of mycotoxins is also a problem for the downstream production chain posing health risks for animals and humans.

Farmers can implement different agronomic management measures to reduce FHB and mycotoxin contamination as shown by literature review in Chapter 2 and 3 . Since weather conditions during cultivation play a major role in Fusarium spp. infection, the effects of agronomic measures on mycotoxins levels are variable and can differ per year. For example, Edwards and Jennings (2018) described the impact of agronomic factors on DON concentrations in wheat in the UK and found that only $5 \%$ of the variance in DON contamination was accounted for by agronomic factors and $59 \%$ by the study year. In addition, (van der Fels-Klerx et al. 2020) showed that in the Netherlands, mostly year and region determined the DON concentration and to a lesser extent agronomic measures such as previous crop and the use of Fusarium spp. resistance cultivars. In contrast, (Vogelgsang et al. 2019) showed that regardless of year, agronomic measures like crop rotation (no maize as pre-crop) and/or ploughing could reduce DON and zearalenone (ZEA) by 78 to $95 \%$. So, the effect of agronomic management measures on the reduction of FHB and mycotoxins is variable. Literature shows that, especially when weather or environmental conditions are favourable for fungal infection, combining 


\section{Chapter 6}

measures to reduce the contamination of Fusarium spp. and severity of the FHB infection is more effective than isolated approaches (Blandino et al. 2017; Edwards 2004; Kabak et al. 2006; McMullen et al. 2012; McMullen et al. 2008; Wegulo et al. 2015). An effective approach in reducing FHB and mycotoxin production in wheat is one that combines measures that limit the survival of the fungus in crop debris, decreases the presence of the fungus on the plant, and reduces the severity of the infection, as shown by the literature study in Chapter 2 and 3. Given the high level of effectiveness in reducing FHB and mycotoxins in wheat caused by Fusarium spp., the combination of the measures fungicide use during flowering, selection of a Fusarium spp. resistant variety, and ploughing or crop rotation (Blandino et al. 2012; McMullen et al. 2008) was identified as the 'benchmark approach' (Chapter 3).

In Chapter 3, eight agronomic measures were selected for further investigation regarding the implementation by farmers based on literature study and expert consultation: (1) decontamination of seeds; (2) crop rotation (no grain as pre-crop); (3) ploughing after a grain harvest; (4) resistant cultivar lodging; (5) fungicide use during the entire wheat cultivation period; (6) fungicide use during wheat flowering; (7) resistant cultivar against Fusarium spp.; and (8) biological control. Results of Chapter 3 showed that most farmers are taking multiple measures that can reduce Fusarium spp. infection and mycotoxin contamination and the so-called benchmark approach is adopted by $56 \%$ of the Dutch farmers. This implies that $44 \%$ of these farmers could become more effective in reducing FHB and mycotoxins by adapting their agronomic management measures. However, specific underlying factors may explain why these farmers did not implement the benchmark approach, like the presence of certain farm and farmer characteristics, environmental concerns, or perceived cost-effectiveness of the approach. Results showed that farmers were less likely to implement the benchmark approach if wheat was not their main crop, if they had a lower education level, and/or if they had not encountered a severe Fusarium spp. infection in the past five years (Chapter 3 ).

The identified effective agronomic management measures to reduce $\mathrm{FHB}$ and mycotoxins (Chapter 2 and 3) and the currently applied measures by Dutch farmers (Chapter 3) might not fit the envisioned changes to food production as foreseen by the European Commission's Green Deal (EC 2019) or 'sustainable agriculture' (Rose et al. 2019). These plans propagate the use of fewer pesticides and conservation tillage, which contrasts the effective mycotoxin reduction approach of (deep) ploughing to burry soil debris (Vogelgsang et al. 2019) and the use of fungicides throughout the whole cultivation period.

Chapter 3 shows that there are opportunities for Dutch wheat farmers to become more environmentally sustainable by making small changes in their agronomic management. These changes can entail the use of novel biological pesticides instead of fungicides (Shah et al. 2018), or using less fungicides by applying the fungicides only in the critical wheat flowering period, and/or applying it locally in the field. Chapter 3 showed that only $20 \%$ of the Dutch wheat farmers used biological measures, $84 \%$ used fungicides during the whole cultivation period, and only $6 \%$ of the farmers used fungicides just during flowering and not during the rest of the cultivation period. This implies opportunities for Dutch wheat farmers to reduce fungicide use by implementing biological control and/or only focussing on fungicides during flowering (Yoshida et al. 
2012), although the effectiveness of type and concentration of the fungicide must be taken into account (Ioos et al. 2005; Paul et al. 2008).

So, in practice there is opportunity for farmers to improve their agronomic management to reduce FHB and mycotoxin contamination, and at the same time become more environmentally sustainable. However, it depends on the intention of the farmer whether he/she will make an actual change in agronomic management. Intentions are a proximal measure of future behaviour. The stronger the intention is, the more likely the behaviour will be executed in the future (Ajzen 1991). Chapter 5 showed that overall, $25 \%$ of the European farmers from Italy, the Netherlands, Serbia and the United Kingdom indicated to have a negative intention to adapt their approach in the coming five years, ranging from $21 \%$ for NL to $46 \%$ for the UK. Fifty percent of the farmers had a positive intention ranging from $38 \%$ (UK) to $67 \%$ (RS) per country (Chapter 5 ). Since there is an intention-behaviour gap, not all farmers with a positive intention will actually change their behaviour (Fishbein and Yzer 2003). The exact percentage of farmers with a positive intention that will follow through with the actual behaviour could not be determined in this study, because we performed a cross-sectional rather than a longitudinal study. Since intentions are a proximal measure for future behaviour, it is important to understand what underlies farmers' intention and how this intention can be increased, to subsequently increase farmers adaptation of agronomic management. Therefore, in the next section the underlying behavioural constructs and beliefs to understand this intention were assessed and incentives that can increase this intention which can be implemented by stakeholders were identified.

\subsubsection{Incentivisation to adapt management}

According to the results in this thesis, a change in farmers' intention can be achieved by targeting their attitude towards an adaptation in agronomic management and not by targeting potential barriers that prevent farmers to adapt their management (Chapter 4 and 5 and MyToolBox (2019)). Chapter 4 showed that the underlying behavioural construct perceived behaviour control, which account for factors outside one's control, was not related to this intention of Dutch wheat farmers, implying that these farmers have enough opportunities to change and perceive no barriers to change. This finding is confirmed by results from the MyToolbox project for farmers from Austria, Italy, the United Kingdom and Serbia (MyToolBox 2019). In addition, the belief that it is not costeffective to adapt the FHB and mycotoxin management approach was not related to the attitude of Dutch (Chapter 4) or other studied European farmers (MyToolBox 2019). This is in contrast to Breukers et al. (2012) who found that Dutch horticultural growers were willing to apply risk management measures, and that poor risk management was mainly due to perceived barriers, such as high costs and doubts regarding efficacy of management measures. Also, results (Chapter 4) showed that among the Dutch farmers, the belief 'it is pointless to change the FHB and mycotoxin management because of the unpredictability of weather conditions' was only weakly associated with farmers' attitude. This implies that unpredictability of the weather does not play a role in the farmers' intention to adapt their management. This is in contrast with our a priori expectations, because weather has a major influence on Fusarium spp. infection (Chapter 2). Beliefs that were significantly related to the attitude of Dutch farmers to adapt their agronomic approach to reduce FHB and mycotoxins indicated specific attributes of wheat, namely yield quantity, quality and safety (lower mycotoxin contamination) 


\section{Chapter 6}

(Chapter 4). This is in contrast to the findings of (Hijbeek et al. 2018) showing that the belief 'increase in soil fungi' was negatively related to an attitude to increase soil organic matter in the Netherlands and (Bechini et al. 2015) showing that the belief 'increase risk of fungal diseases' was not a significant driver to adopt incorporation of crop residues in the soil (a well-known measure against Fusarium spp. infection) by Italian farmers. In the MyToolbox project, no attitudinal beliefs that were significantly related to the attitude of Italian farmers to adapt their agronomic approach to reduce FHB and mycotoxins could be identified (MyToolBox 2019). These results indicate country and sector specific differences in beliefs related to the behaviour of farmers.

Whereas results from the MyToolbox project showed that only attitude was significantly related to the intention to adapt the agronomic approach of farmers from IT, UK and RS (MyToolBox 2019), social norm was related to the intention of Dutch farmers, implying that Dutch farmers include the opinion of others in the decision to adapt their approach or not. This difference might be due to cultural differences (Baur et al. 2016). To incentivise an adaptation in agronomic management of Dutch farmers, e.g. interventions to strengthen attitudinal beliefs, should preferably go via the most important referents for social norms, which were the buyers and the farmer cooperatives (Chapter 4). Strengthening these beliefs - by demonstrating that a change in management will result in a higher yield quantity and quality and lower mycotoxin levels - will result in a stronger attitude and, subsequently, a higher intention to change management.

In addition to targeting beliefs and attitude related to the intention of farmers, incentives can be used to increase the intention of farmers to adapt their agronomic approach to reduce FHB and mycotoxins in wheat. Results of Chapter 5 showed that the incentives to increase their intention to adapt their approach for most of the European farmers were paid extra when wheat contains low levels of mycotoxins and testing the wheat for the presence of mycotoxins for free.

Whereas a reduction in yield quantity and quality is a direct issue for the farmer, the presence of mycotoxins is also a problem for the downstream production chain posing health risks for animals and humans. Farmers might need to be incentivised to change their management approach to become more effective in reducing mycotoxins in the wheat supply chain by implementing the benchmark approach or becoming more environmentally sustainable. One of the ways that farmers can improve their agronomic management is to use fungicides during flowering, which is the most effective timing against Fusarium spp. infection (Yoshida et al. 2008a). The use of a decision support system can assist with determining the optimal time for applying fungicides and, indeed, Chapter 3 results showed that Dutch farmers who used a decision support system were more likely to use fungicides during flowering. Stimulating farmers to use a decision support system might increase a targeted fungicide use (Nave et al. 2013), improve overall FHB and mycotoxin management and reduce overall input costs (McMullen et al. 2012; Rossi et al. 2007; Rossi et al. 2015; Silva et al. 2017). However, Chapter 5 results showed that under the incentive 'free advice' only $37 \%$ of the farmers had an increased intention. This implies that although a decision support system can assist in reducing fungicide application by switching to fungicide use during flowering (rather than during the entire wheat cultivation period), free advice to farmers, e.g. from advisors or by using a decision support system, is not an incentive that can stimulate Dutch wheat farmers to adapt their 
agronomic management approach. Chapter 5 showed that Dutch farmers without the benchmark approach could best be stimulated by the incentives 'paid extra' and 'no delivery' although not with a high probability, namely $51 \%$ and $44 \%$, respectively.

When looking at incentives to increase Dutch farmers' intention, results of Chapter 5 showed that Dutch farmers are not sensitive to most investigated incentives. Despite that only around half of the Dutch farmers could be incentivised by the incentives 'paid extra', 'no delivery' and 'free test', these are considered the best incentives. In addition, there is not really a 'best' alternative for the farmers who are not incentivised by the external incentive 'paid extra'. The best alternative was 'no delivery' but the related probability that a farmer was incentivised by this incentive was only $34 \%$. This indicates that there is a group of Dutch farmers that is not sensitive to any of the incentives investigated. It might be possible that Dutch farmers are less stimulated by external incentives (Chapter 5 ) and are more intrinsically motivated by their attitude towards a change in management as shown in Chapter 4.

\subsubsection{Heterogeneity among wheat farmers}

In this thesis we assessed farm and farmer characteristics to explain the implementation of pre-harvest measures and intention of farmers to reduce FHB and mycotoxins in wheat. No universal farmer characteristics were found, because significant farmer characteristics differed per pre-harvest measure (Chapter 3) and per incentive (Chapter 5). This is in line with (Knowler and Bradshaw 2007) who studied farmers' adoption of conservation agriculture. In addition, other studies also found sector- and farm-specific differences (Breukers et al. 2012; Hyland et al. 2018; van Dijk et al. 2016; Wauters et al. 2010) (Chapter 4). These results stress the point that research outcomes on farmers are very specific and results are difficult to extrapolate to other (scientific) fields, agricultural sectors and farmer types. In addition, this makes information on how to stimulate a certain behaviour unique to the target group and the farm and agricultural sector at hand. Therefore, it is important to take the heterogeneity of farmers into account when designing incentives. To date, similar studies have not been performed on agronomic management to reduce FHB and mycotoxins in wheat or other cereal crops and this thesis contributes by providing insight into the heterogeneity among wheat farmers. Results will support policy makers in developing more tailor-made incentives to incentivise different groups of farmers to adapt their FHB and mycotoxin management.

Although no universal farm or farmer characteristics could be determined, farmers with wheat as main crop or farmers who produce wheat for food showed to be different compared to the other farmers. Dutch farmers with wheat as main crop were more likely to implement the benchmark approach and were less likely to implement crop rotation (Chapter 3). These farmers seem to form a particular group who produce mainly wheat, and not many other crops in their rotation plan, with the aim to sell the wheat for food production. European farmers with an increased intention under the incentives 'free test', 'insurance' and 'contract' are most likely to have wheat as main crop compared to farmers with a decreased intention (Chapter 5). It is not surprising that they can be incentivised by the incentives 'free test', 'insurance' and 'contract', because they depend on low mycotoxins levels to comply to the requirements for food-grade wheat. In addition, Italian farmers with a decreased intention under 'paid extra' were likely to have wheat as main crop (Chapter 5 ). 
Risk factors were expected to play a role in farmers' agronomic management decisions, because adapting an agronomic approach as well as not implementing agronomic measures both entails risks. Farmers with a high risk perception, i.e. a combination of expected severity of an infection and its probability of occurrence (Glanz et al. 2008) and farmers who are risk averse, were expected to implement more measures (precautionary principle). A change in management can also be accompanied with risks (Lefebvre et al. 2014). We investigated whether farm and farmer characteristics like past Fusarium spp. infections, risk aversion and risk perception were related to the implementation of preharvest measures (Chapter 3 ) in addition to the relation to being sensitive to different incentives (Chapter 5). Results showed that farmers who have had a severe Fusarium spp. infection in wheat in the past 5 years were more likely to implement the benchmark approach (Chapter 3). Risk perception was not significantly related to their agronomic management (Chapter 3 ). Dutch risk averse farmers were more likely to use fungicides during flowering (Chapter 3). Also, risk averse Dutch farmers were not incentivised by the incentive 'paid extra', in addition to Italian farmers who did not have a past infection in last 5 years and Serbian farmers with a low risk perception.

\subsection{Reflection on data and methods}

\subsubsection{Data}

For this study, an online questionnaire was developed and distributed among farmers from the Netherlands, Italy, Austria, Serbia and the United Kingdom. This questionnaire was extensive and covered aspects like farm and farmer characteristics, implementation of pre-harvest measures, perceived (cost)-effectiveness of pre-harvest measures, intention to adapt agronomic management and underlying behavioural constructs and beliefs, and incentive mechanisms. The number of responses to the questionnaire was low, in particular in Austria. Only eight Austrian farmers completed the questionnaire, which was not enough to conduct a proper data analysis for this country; for this reason, responses from Austria were excluded from the analysis. Responses from the other countries included 24 responses from the UK, 35 from Italy, 65 from Serbia and around 100 from the Netherlands. To put in perspective, around 7,500 of wheat farms were registered in the Netherlands in 2017 (CBS 2018). The small sample of respondents from the five European countries might not be representative for all wheat farmers in Europe. In addition, the small sample size limited the use of some statistical data analysis techniques, like the multivariate probit model in Chapter 3, which failed to converge. An option was to merge the datasets of the different countries to create a larger data set. However, due to the variation in farm and farmer characteristics between countries, this was considered not an option for the analysis in Chapter 3 and Chapter 4 . The Bayesian Network model could handle variation in data, so in Chapter 5 , the datasets were merged.

The questionnaire contained closed questions to provide consistency among the different countries and to make it easier for farmers to answer. This can result in a loss of information; for example, age was asked in ten-year age categories and not as a numeric value. In addition, data obtained by the questionnaire are static information, i.e. measured at one point in time, and we have no insight in variations or evolution over the years. van der Fels-Klerx et al. (2020) showed that the use of fungicides during wheat flowering and the choice of wheat cultivar varied widely between years in the Netherlands. In Chapter 3 and 5, these two pre-harvest measures were used to determine 
whether the farmers used a benchmark approach, meaning that the use of a benchmark approach can vary over the years. This implies that the strength of the evaluated associations between the farm and farmer characteristics and the implementation of agronomic management measures (Chapter 3 ) might vary over the years as well.

A major limitation of the questionnaire was that it took farmers a lot of time to fill out, resulting in missing data, like the missing variables of respondents. There are several ways to deal with missing data (Hair 2006), for example, pair-wise deletion of respondents with missing variables, the removal of variables with missing data, and imputation of missing data. In this thesis a combination of these options was used to deal with missing data. The advantage of using complete data, is that real data is used. The disadvantage is that many records might need to be deleted resulting in a dataset too small for analysis, as was the case in our studies if we would have used this method in Chapter 3 and Chapter 4. The advantage of data imputation is that all given information can be used, so information is not removed; however, missing variables are estimated rather than measured. For Chapter 3 and Chapter 5, variables with many missing data points were removed, like gender and organic farming. In Chapter 3 linear regression was used to estimate the missing data. For Chapter 5 , first the respondents' complete data on all the dependent variables were selected and, next, the independent variables were imputed by Bayesian Network modelling. In Chapter 4, only the complete records per sub-question were used, resulting in a slightly different set of farmer respondents per research question, depending on the missing data per respondent. These different approaches to handle missing data resulted in slightly different datasets per research chapter. The experiences with these missing data techniques give insight into the (dis)advantages of handling missing data. In hindsight, the preferred option would have been to impute the raw dataset containing all variables of respondents of all countries with Bayesian Network modelling. This way, there is optimal use of available information, because all variables will be used to estimate missing data. Next, for each research chapter, a subset of the data can be selected from the main dataset for further analysis related to a specific research question. Afterwards, depending on the type of analyses per chapter, variables with low variation or many missing data points can be removed. Such an approach would have given more consistency in quantitative results across the chapters. For example, results of Chapter 4 showed that $21 \%$ of the Dutch farmers had a negative intention, whereas in Chapter 5 this is $22 \%$, because of the use of a slightly different dataset. In addition, it would have been more time efficient.

\subsubsection{Models}

In Chapter 3, univariate probit models were employed to evaluate the relation between ten farm and farmer characteristics and the implementation of pre-harvest measures. For this purpose, data needed to be collapsed or dummies created to reduce the number of variable states, resulting in a loss of information. For all univariate probit models (9 in total), marginal effects of the variables were calculated to indicate to what extent the (conditional) probability of the outcome variable (implemented pre-harvest measure) would change when the value of an independent variable (farm and farmer characteristic) is changed by one unit, while holding all other variables constant. It was expected a priori that the actual use of measures is mutually correlated, i.e., farmers decide on a package of measures rather than a single measure (Bürger et al. 2012a; Bürger et al. 2012b; Loyce et al. 2008) and that therefore a multivariate probit model would have 


\section{Chapter 6}

been the choice (Cappellari and Jenkins 2003; Greene 1993; Judge et al. 1982; Mulwa et al. 2017; Oude Lansink et al. 2003; Ward et al. 2018). Chapter 3 results showed indeed a correlation between the use of agronomic measures to reduce FHB and mycotoxins in wheat. However, due to technical constraints (i.e. many variables in contrast to a low number of respondents), the multivariate probit model failed to converge. Instead, several sets of three to four measures were selected based on the bivariate probit model results, and tested in a multivariate probit model to check whether the univariate results differed from a potential complete multivariate model. The results (significance and direction of the marginal effects of the characteristics) did not differ greatly from those of the univariate model. Therefore, the results of the univariate models were considered robust.

In Chapter 4, the TPB was used to reflect the intention and underlying behavioural constructs of farmers to adapt their agronomic approach to reduce $F H B$ and mycotoxins in wheat. Although other behavioural models exist, e.g. the Health Belief Model (Rosenstock 1974), the TBP was selected because it includes the social norm. This variable was considered important to determine if farmers were sensitive to external opinions and via which channels incentives were best implemented. The TBP is therefore deemed an appropriate model for our study purpose. In addition, the TPB is used in comparable behavioural studies used to investigate the intentions, behavioural constructs and beliefs of farmers to manage, for example, grassland (Hyland et al. 2018), pathogen invasions in horticulture (Breukers et al. 2012), diseases in animals (Bruijnis et al. 2013; Jemberu et al. 2015; Sok et al. 2015) or agri-environmental measures (Bagheri et al. 2019; Bechini et al. 2015; Hijbeek et al. 2018; van Dijk et al. 2016; Wauters et al. 2010). The disadvantage of the TPB is that many additional questions were needed, and these extended the questionnaire to such an extent that we believe this was the reason that many farmers did not complete the entire questionnaire. In addition, although properly designed (Ajzen 2006; Francis 2004), the TBP questions were considered vague and sometimes difficult to interpret by the farmers. Since focusing on the behaviour regarding the implementation of one agronomic measure was too specific for our aim and focusing on three or more pre-harvest measures made the questionnaire too extensive to complete for a farmer, we decided to focus on adapting agronomic management' in general. We realised this behaviour is general formulated, a change in agronomic management can entail, taking less, more, or different pre-harvest measures, the advantage is that the results of the study in Chapter 4 are now interpretable for different adaptations in agronomic management for the reduction of FHB and mycotoxins in wheat.

The standard method used for measuring beliefs in the TPB by multiplicative composites can lead to statistically uninterpretable results, the so-called 'expectancy-value muddle' (French and Hankins 2003; Newton et al. 2012; Newton et al. 2014; O'Sullivan et al. 2008). The use of a single belief score might be sufficient in determining important beliefs (Hankins et al. 200o). Two studies compared this basic belief score with the multiplicative composites scores using linear regression models and concluded that the expectancy-value model was appropriate (Elliott et al. 2005) with only a marginally better predictive power (Chan et al. 2015). However, these studies did not test the effect of their multiplicative composites answer scales on the results, as suggested by Hardeman et al. (2013). In Chapter 4, the effect of analysing the questionnaire data with different answer 
scales was investigated, to check the robustness of the results based on the standard questionnaire text scale to calculate the beliefs' multiplicative composites. Results showed that the type of applied answer scale affected the statistical significance of the correlation between a belief and its behavioural construct. Hence, it is important to include scaling effects to show the robustness of the results in future studies.

Chapter 5 developed nine Bayesian Network models. Bayesian Network modelling (Nielsen and Jensen 2009) is a powerful tool to explore patterns in the data and to model dependencies between variables. Bayesian Network models are a class of probabilistic models originating from the Bayesian statistics and decision theory combined with graph theory. Bayesian Network modelling was applied to identify characteristics of farmers with a certain intention for a behavioural change under an incentive. Validation of the Bayesian Network models showed that the percentage of correctly predicted responses ranged from $85 \%$ to $94 \%$ for the train set and from $38 \%$ to $67 \%$ for the test set. Since the predictor variable (basic intention or an incentive) consists of three categories, model predictions above $33 \%$ were considered acceptable. One of the advantages of Bayesian Network modelling is that it can easily consider possible relationships among explanatory variables as well as variables with an uneven distribution among variable categories, like in our dataset, the country of the farm, with farms in the Netherlands and Serbia being more represented than farms in the United Kingdom and Italy. Another strength of Bayesian Network modelling is that it is possible to simulate different scenarios by selecting only a few or even many variable states and determine the probability of other variables, as we have shown for farmers without the benchmark approach.

\subsection{Business and policy implications}

Food safety is the responsibility of every actor in the chain. The reduction of mycotoxins in wheat goes together with the improvement of yield quantity and quality of the grain since Fusarium spp. infection needs to be reduced to lower the toxin levels. Farmers can contribute to food safety by taking an effective integrated approach to reduce Fusarium spp. infection in wheat (Chapter 2), e.g. the benchmark approach (Chapter 3) consisting of a combination of fungicide use during flowering, the use of a Fusarium resistant variety, and ploughing or crop rotation (Blandino et al. 2012; McMullen et al. 2008). Chapter 3 showed the opportunities for Dutch wheat farmers to become more effective in the reduction of FHB and mycotoxins in wheat. However, to what extent an adaptation in agronomic management by farmers results in a reduction in exposure by animals and humans and how such an adaptation could be cost-effective for the farmer was beyond the scope of this thesis.

The Bayesian Network model developed in Chapter 5 can be used to select effective incentives for specific groups of farmers and can be used to select specific groups of farmers that can be stimulated by a known incentive. For example, the group of UK farmers who do not yet apply a benchmark approach is best incentivised when they get paid less when their wheat contains too much mycotoxins. The incentive 'contract' is best implemented to incentivise farmers who have wheat as the main crop and produce wheat for food, and not with farmers that produce wheat for feed and have potatoes as the main crop. 


\section{Chapter 6}

Results of Chapter 5 showed that the incentive 'Law' (a change in agronomic management is required by law) was overall not very effective in incentivizing farmers, except for specific farmers groups, like UK farmers. This implies that the role of legislation by governmental agencies is limited. However, to implement the incentives under which most farmers were incentivised, namely 'paid extra', 'no delivery' and 'free test', wheat needs to be tested for mycotoxins. Here, the government can play a role by providing free tests for mycotoxins in grains.

Results in Chapter 5 showed major differences between countries and specific farmer groups. Farmers from Italy, Serbia or the United Kingdom can be incentivised via several external incentives such as 'paid extra' and 'no delivery' for Italian farmers, 'free test' and 'free advice' for Serbian farmers, and 'paid less' and 'law' for farmers from the United Kingdom (Chapter 5). These differences between countries imply that an overarching European intervention approach is not useful and that national programs will be more effective in incentivizing wheat farmers, although these national programs need to be further dedicated to farm and farmer characteristics.

The results of this thesis imply that several aspects should be considered when designing interventions to incentivise a change in Dutch farmers' agronomic management. First, the current implementation of agronomic management measures differs per farm (Chapter 3); therefore, an adaptation of agronomic management is different for each farmer. For some pre-harvest measures, the implementation is related to farm and farmer characteristics, as shown in the case of Dutch wheat farmers (Chapter 3). For example, results of Chapter 3 showed that farmers who do not have wheat as main crop were less likely to implement the benchmark approach and are therefore a target group to incentivise change. Second, not all farmers have an intention to adapt their agronomic management approach (Chapter 4 and Chapter 5). Third, Dutch farmers are difficult to incentivise with external incentives; however, incentives like 'paid extra', 'free test' and 'no delivery' were found to be the most effective in incentivising farmers to adapt their agronomic approach (Chapter 5). Fourth, in the Netherlands, interventions should be focussed on improvement of farmers' attitude towards an adaptation in their agronomic management, by e.g. changing attitudinal beliefs of farmers related to a positive view on the advantages of an adaptation of agronomic management on wheat yield quantity, quality and safety (Chapter 4). Fifth, Dutch wheat farmers are not limited by perceived behavioural control (Chapter 4), implying that they have enough opportunities to change and perceive no barriers to change their agronomic approach. Increasing opportunities by providing more (cost)-effective agronomic measures, might therefore not be effective to change farmers' intention. Sixth, Dutch farmers take the opinion of others into account when taking decisions regarding FHB and mycotoxin management (Chapter 4). They can be best incentivised via farmer cooperatives and buyers and to lesser extent by independent advisors or scientists, depending on the individual farmer (Chapter 4). In addition, the role of a government official is expected to be low (Chapter 4).

\subsection{Future Research}

To what extent an adaptation in agronomic management to reduce FHB and mycotoxins by farmers results in a reduction in mycotoxin exposure by animals and humans was beyond the scope of this thesis. This thesis did not address the question if adaptations in 
agronomic management are cost-effective for the individual farmer and, if not, what should change to make them cost-effective. The impact of agronomic management measures on wheat yield and mycotoxin concentration can be derived from literature (see Chapter 2 and 3). Since Fusarium spp. infection in wheat and its influence on yield loss and mycotoxin concentrations are subject to yearly variation, in addition to the influence of agronomic measures, and to account for the variation in the effectiveness of a measure, a crop growth model linked with a Fusarium-toxin model can be used (Van Ittersum et al. 2003). Distributions of yield and DON contamination can be calculated with Monte Carlo simulations. Monetary values could then be assigned to the revenues from wheat production while accounting for the impact of Fusarium spp. infection on the wheat quantity and quality, and for the costs for implementation of pre-harvest measures.

The model described above can be extended to include the effects of climate change on the effectiveness and cost-benefits of agronomic management measures to reduce FHB and mycotoxins in wheat. As discussed in Chapter 2 and 3, literature shows that several pre-harvest measures are effective and an integrated management approach is most effective, but climate and weather conditions play a major role in Fusarium spp. infection and mycotoxin contamination of the grain (Moretti et al. 2019). Local climate conditions determine the selection of Fusarium spp. (Doohan et al. 2003) and therefore the Fusarium community present in the wheat field varies per region and climatic conditions (Bakker et al. 2018; Moretti et al. 2019) (Champeil et al. 2004) as well as the concentration of mycotoxins produced by these Fusarium spp. (Van der Fels-Klerx et al. 2012b). Changes mediated by climate change will impact FHB infection and mycotoxins in cereals (Moretti et al. 2019; Scala et al. 2016; Shang et al. 2018; van derFels-Klerx et al. 2013; Vaughan et al. 2016). It will be needed interesting to develop a model that estimates the effectiveness of an adaptation in agronomic management to reduce $\mathrm{FHB}$ and mycotoxins in grans in a changing climate.

In addition, currently applied mycotoxin management measures as well as the measures in the benchmark approach might not fit the envisioned changes to food production in an environmentally sustainably way, such as advocated in the EC Green Deal (EC 2019). It contrasts the effective mycotoxin reduction approach of e.g. (deep) ploughing to burry soil debris and fungicide use to reduce Fusarium spp. infection in wheat. Environmentally sustainable measures like crop rotation already are available and novel biological measures are being developed and tested (Shah et al. 2018), providing opportunities to adapt agronomic management in a sustainable way. Future research can entail the further development and assessment of an effective environmentally sustainable agronomic management approach to reduce FHB and mycotoxins, the willingness of farmers to adopt this sustainable approach, in addition to specific ways to incentivise farmers to apply sustainable agronomics for the reduction of FHB and mycotoxins in wheat. Results of this thesis can help stakeholders in the chain to incentivise farmers to adapt their agronomic management approach. However, the main variable to assess if farmers wanted to change, was their intention. Although intention is a proxy for future behaviour (Ajzen 1991), there is an intention-behaviour gap, i.e. not all farmers with a positive intention will change their behaviour (Fishbein and Yzer 2003). The exact percentage of farmers that will follow through with their positive intention could not be determined in this thesis, because a cross-sectional rather than a 
longitudinal study was performed. Future research employing a longitudinal approach can entail the assessment of the intention-behaviour gap for wheat farmers and the role of incentives to decrease this gap.

This thesis (Chapter 5 ) showed the successful use of Bayesian Network modelling in the analysis of survey data. Results also showed that farmers are heterogeneous and incentivisation should be tailor-made. Unfortunately, not all the results of the different farmer types could be shown due to space restraints. Therefore, access to a dynamic online model can help stakeholders to select appropriate incentives. The models developed in Chapter 5 can be extended to include other survey data or economic variables to provide extended support for tailor-made incentives design by stakeholders.

\subsection{Main conclusions}

- Although local weather and region play a major role in Fusarium spp. infection, preharvest agronomic management measures can reduce FHB and mycotoxin contamination in wheat (Chapters 2 and 3 ).

- Most Dutch wheat farmers used at least six pre-harvest agronomic management measures simultaneously to reduce Fusarium spp. infection and mycotoxins in wheat, and $56 \%$ of the farmers used an effective set of measures (benchmark approach) (Chapter 3 ).

- Farmers who are not using the effective benchmark approach for the reduction of Fusarium spp. infection and mycotoxin contamination in wheat (Chapter 3 ) can be incentivised to adapt their agronomic management by the incentives 'paid extra when wheat contains low levels of mycotoxins' (Italian and Dutch farmers), 'paid less when wheat contains high levels of mycotoxins' (United Kingdom), and 'when required by law' (Serbia) (Chapter 5).

- The farm and farmer characteristics 'wheat as main crop', 'the use of a decision support system', 'the education level of the farmer', 'farmers' knowledge of about mycotoxins' and 'farmer's level of risk aversion' explained the implementation of one or more agronomic management measures for reduction of Fusarium spp. infection and mycotoxins in wheat in the Netherlands (Chapter 3).

- Farmers with wheat as main crop are more likely to implement the benchmark approach and are more likely to be incentivised to adapt their agronomic management approach to reduce Fusarium spp. infection and mycotoxins in wheat under the incentives 'free mycotoxin testing', 'insurance for high mycotoxins levels' and 'a multiyear contract with the buyer to deliver wheat for a fixed price' compared to farmers with another main crop (Chapters 3 and 5 ).

- The current intention of European wheat farmers to change their agronomic approach for FHB and mycotoxins reduction is positive for $43 \%$ of Italian farmers, $46 \%$ for Dutch farmers, $68 \%$ for Serbian farmers and $38 \%$ for farmers from the United Kingdom (Chapters 4 and 5).

- Dutch wheat farmers' intention can be increased by strengthening their attitude via attitudinal beliefs - by demonstrating that a change in management will result in a higher yield quantity and quality and lower mycotoxin levels - disseminated through their most important referents, namely their buyer or farmer cooperative, or by the incentives 'paid extra' and 'no delivery', but not by targeting their perceived behavioural control (Chapters 4 and 5). 
References 
Abramson D, Clear RM, Usleber E, Gessler R, Nowicki TW, Märtlbauer E (1998) Fusarium species and 8-ketotrichothecene mycotoxins in Manitoba barley Cereal Chemistry 75:137-141

Abramson D, McCallum B, Tekauz A, Smith DM (2004) HT-2 and T-2 toxins in barley inoculated with Fusarium sporotrichioides Canadian Journal of Plant Science 84:1189-1192

Achatz B, Kogel K-H, Franken P, Waller F (2010) Piriformospora indica mycorrhization increases grain yield by accelerating early development of barley plants Plant Signaling \& Behavior 5:1685-1687 doi:10.4161/psb.5.12.14112

Adesina AA, Chianu J (2002) Determinants of farmers' adoption and adaptation of alley farming technology in Nigeria Agroforestry Systems 55:99-112 doi:10.1023/a:1020556132073

Ajzen I (1991) The theory of planned behavior Organizational Behavior and Human Decision Processes 50:179211 doi:10.1016/0749-5978(91)90020-T

Ajzen I (2006) Constructing a theory of planned behavior questionnaire

Alim M, Iqbal SZ, Selamat J, Ariño A (2016) Regulations for Food Toxins. In: Food Safety: Basic Concepts, Recent Issues, and Future Challenges. Springer International Publishing, Cham, pp 33-39. doi:10.1007/978-3-319-39253-0_2

Aramyan LH, Oude Lansink AGJM, Verstegen JAAM (2007) Factors underlying the investment decision in energy-saving systems in Dutch horticulture Agricultural Systems 94:520-527 doi:10.1016/j.agsy.2007.01.005

Baethgen WE, Christianson CB, Lamothe AG (1995) Nitrogen fertilizer effects on growth, grain yield, and yield components of malting barley Field Crops Research 43:87-99 doi:10.1016/0378-429o(95)ooo34-n

Bagheri A, Bondori A, Allahyari MS, Damalas CA (2019) Modeling farmers' intention to use pesticides: An expanded version of the theory of planned behavior Journal of Environmental Management 248 doi:10.1016/j.jenvman.2019.109291

Bagheri A, Shabanali Fami H, Rezvanfar A, Asadi A, Yazdani S (2008) Perceptions of paddy farmers towards sustainable agricultural technologies: Case of haraz catchments area in Mazandaran province of Iran American Journal of Applied Sciences 5:1384-1391 doi:10.3844/ajassp.2008.1384.1391

Bai G, Shaner G (2004) Management and resistance in wheat and barley to fusarium head blight vol 42. doi:10.1146/annurev.phyto.42.040803.140340

Bakker MG et al. (2018) Fusarium mycotoxins: a trans-disciplinary overview Canadian Journal of Plant Pathology 40:161-171 doi:10.1080/07060661.2018.1433720

Ban T, Suenaga K (200o) Genetic analysis of resistance to Fusarium head blight caused by Fusarium graminearum in Chinese wheat cultivar Sumai 3 and the Japanese cultivar Saikai 165 Euphytica 113:87-99 doi:10.1023/a:1003951509797

Barrier-Guillot B T-2 and HT-2 in cereals in France. In: 5th EC Fusarium Toxin Forum, Brussels, Belgium, 10-11 January 20082008.

Baur I, Dobricki M, Lips M (2016) The basic motivational drivers of northern and central European farmers Journal of Rural Studies 46:93-101 doi:10.1016/j.jrurstud.2016.06.001

Beccari G et al. (2018) Development of three Fusarium crown rot causal agents and systemic translocation of deoxynivalenol following stem base infection of soft wheat Plant Pathology 67:1055-1065 doi:10.1111/ppa.12821

Bechini L, Costamagna C, Zavattaro L, Grignani C, Bijttebier J, Ruysschaert G (2015) Barriers and drivers towards the incorporation of crop residue in the soil. Analysis of Italian farmers' opinion with the theory of planned behaviour Italian Journal of Agronomy 10:178-184 doi:10.4081/ija.2015.663

Berger $\mathrm{G}$ et al. (2014) Characterization of fusarium head blight resistance and deoxynivalenol accumulation in hulled and hulless winter barley Plant Disease 98:599-606 doi:10.1094/pdis-05-13-0479-re

Bernhoft A, Torp M, Clasen PE, Løes AK, Kristoffersen AB (2012) Influence of agronomic and climatic factors on Fusarium infestation and mycotoxin contamination of cereals in Norway Food Additives \& Contaminants: Part A 29:1129-1140 doi:10.108o/19440049.2012.672476

Berthiller F et al. (2013) Masked mycotoxins: A review Molecular Nutrition and Food Research 57:165-186 doi:10.1002/mnfr.201100764

Bérubé ME, Vanasse A, Rioux S, Bourget N, Dion Y, Tremblay G (2012) Effect of glyphosate on fusarium head blight in wheat and barley under different soil tillages Plant Disease 96:338-344 doi:10.1094/pdis-0411-0297

Beyer M, Klix MB, Klink H, Verreet JA (2006) Quantifying the effects of previous crop, tillage, cultivar and triazole fungicides on the deoxynivalenol content of wheat grain - A review Journal of Plant Diseases and Protection 113:241-246 doi:10.1007/bfo3356188

Blandino M, Haidukowski M, Pascale M, Plizzari L, Scudellari D, Reyneri A (2012) Integrated strategies for the control of Fusarium head blight and deoxynivalenol contamination in winter wheat Field Crops Research 133:139-149 doi:10.1016/j.fcr.2012.04.004 
Blandino M, Scarpino V, Sulyok M, Krska R, Reyneri A (2017) Effect of agronomic programmes with different susceptibility to deoxynivalenol risk on emerging contamination in winter wheat European Journal of Agronomy 85:12-24 doi:10.1016/j.eja.2017.01.001

Boddu J, Cho S, Kruger WM, Muehlbauer GJ (2006) Transcriptome analysis of the barley-Fusarium graminearum interaction Molecular Plant-Microbe Interactions 19:407-417 doi:10.1094/mpmi-190407

Boddu J, Cho S, Muehlbauer GJ (2007) Transcriptome Analysis of Trichothecene-Induced Gene Expression in Barley Molecular Plant-Microbe Interactions 20:1364-1375 doi:10.1094/mpmi-20-11-1364

Bondalapati KD, Stein JM, Neate SM, Halley SH, Osborne LE, Hollingsworth CR (2012) Development of weather-based predictive models for Fusarium head blight and deoxynivalenol accumulation for spring malting barley Plant Disease 96:673-68o doi:10.1094/pdis-05-11-0389

Breukers A, van Asseldonk M, Bremmer J, Beekman V (2012) Understanding growers' decisions to manage invasive pathogens at the farm level Phytopathology 102:609-619 doi:10.1094/phyto-06-11-0178

Briggs DE (1978) Barley. Chapman \& Hall,

Bruijnis M, Hogeveen H, Garforth C, Stassen E (2013) Dairy farmers' attitudes and intentions towards improving dairy cow foot health Livestock Science 155:103-113 doi:10.1016/j.livsci.2013.04.005

Buerstmayr H, Legzdina L, Steiner B, Lemmens M (2004) Variation for resistance to Fusarium head blight in spring barley Euphytica 137:279-29o doi:10.1023/B:EUPH.0oooo40440.99352.b9

Bürger J, de Mol F, Gerowitt B (2012a) Influence of cropping system factors on pesticide use intensity - A multivariate analysis of on-farm data in North East Germany European Journal of Agronomy 40:5463 doi:10.1016/j.eja.2012.02.008

Bürger J, Günther A, De Mol F, Gerowitt B (2012b) Analysing the influence of crop management on pesticide use intensity while controlling for external sources of variability with Linear Mixed Effects Models Agricultural Systems 111:13-22 doi:10.1016/j.agsy.2012.05.002

Burton M, Rigby D, Young T (1999) Analysis of the determinants of adoption of organic horticultural techniques in the UK Journal of Agricultural Economics 50:47-63 doi:10.1111/j.14779552.1999.tboo794.x

Caierão E (2006) Effect of induced lodging on grain yield and quality of brewing barley Crop Breeding and Applied Biotechnology 6:215-221

Canadian Grain Commission (2016) Identifying wheat and barley seed affected by fusarium head blight. www.grainscanada.gc.ca/guides-guides/identification/fusarium/iwbfm-mibof-eng.htm. Accessed June 2016

Cappellari L, Jenkins SP (2003) Multivariate probit regression using simulated maximum likelihood Stata Journal 3:278-294

CBS (2018) Centraal Bureau voor de Statistiek; Activiteiten van biologische landbouwbedrijven. Den Haag/Heerlen

Champeil A, Doré T, Fourbet JF (2004) Fusarium head blight: Epidemiological origin of the effects of cultural practices on head blight attacks and the production of mycotoxins by Fusarium in wheat grains Plant Science 166:1389-1415 doi:10.1016/j.plantsci.2004.02.004

Chan DKC, Hardcastle S, Dimmock JA, Lentillon-Kaestner V, Donovan RJ, Burgin M, Hagger MS (2015) Modal salient belief and social cognitive variables of anti-doping behaviors in sport: Examining an extended model of the theory of planned behavior Psychology of Sport and Exercise 16:164-174 doi:10.1016/j.psychsport.2014.03.002

Christian M, Titze J, Ilberg V, Jacob F (2011) Novel perspectives in gushing analysis: A review Journal of the Institute of Brewing 117:295-313

Chrpová J, Šíp V, Štočková L, Stemberková L, Tvarůžek L (2011) Resistance to Fusarium head blight in spring barley Czech Journal of Genetics and Plant Breeding 47:58-63

Clear RM, Patrick SK, Nowicki T, Gaba D, Edney M, Babb JC (1997) The effect of hull removal and pearling on Fusarium species and trichothecenes in hulless barley Canadian Journal of Plant Science 77:161-166

Clear RM, Patrick SK, Platford RG, Desjardins M (1996) Occurrence and distribution of Fusarium species in barley and oat seed from Manitoba in 1993 and 1994 Canadian Journal of Plant Pathology 18:409-414

Comer S, Ekanem E, Muhammad S, Singh SP, Tegegne F (1999) Sustainable and conventional farmers: A comparison of socio-economic characteristics, attitude, and beliefs Journal of Sustainable Agriculture 15:29-45 doi:10.1300/Jo64v15no1_04

Cronbach LJ (1951) Coefficient alpha and the internal structure of tests Psychometrika 16:297-334 doi:10.1007/bfo2310555

D’Angelo DL, Bradley CA, Ames KA, Willyerd KT, Madden LV, Paul PA (2014) Efficacy of fungicide applications during and after anthesis against Fusarium head blight and deoxynivalenol in soft red winter wheat Plant Disease 98:1387-1397 doi:10.1094/pdis-01-14-oo91-re 
Dahl B, Wilson WW (2018) Risk premiums due to Fusarium Head Blight (FHB) in wheat and barley Agricultural Systems 162:145-153 doi:10.1016/j.agsy.2018.01.025

De Boevre M et al. (2013) Human exposure to mycotoxins and their masked forms through cereal-based foods in Belgium Toxicology Letters 218:281-292 doi:10.1016/j.toxlet.2013.02.016

Deshmukh SD, Kogel KH (2007) Piriformospora indica protects barley from root rot caused by Fusarium graminearum Journal of Plant Diseases and Protection 114:263-268

Dexter JE, Clear RM, Preston KR (1996) Fusarium head blight: Effect on the milling and baking of some canadian wheats Cereal Chemistry 73:695-701

Dill-Macky R, Jones RK (2000) The effect of previous crop residues and tillage on Fusarium head blight of wheat Plant Disease 84:71-76

Dohlman E (2003) Mycotoxin Hazards and Regulations Impacts on Food and Animal Feed Crop Trade. International Trade and Food Safety.

Doohan FM, Brennan J, Cooke BM (2003) Influence of climatic factors on Fusarium species pathogenic to cereals European Journal of Plant Pathology 109:755-768 doi:10.1023/a:1026090626994

Dweba CC, Figlan S, Shimelis HA, Motaung TE, Sydenham S, Mwadzingeni L, Tsilo TJ (2017) Fusarium head blight of wheat: Pathogenesis and control strategies Crop Protection 91:114-122 doi:10.1016/j.cropro.2016.10.002

EC (2006a) Commission Recommendation of 17 August 2006 on the presence of deoxynivalenol, zearalenone, ochratoxin A, T-2 and HT-2 and fumonisins in products intended for animal feeding.

EC (2006b) Commission Recommendation of 17 August 2006 on the prevention and reduction of Fusarium toxins in cereals and cereal products (2006/583/EC). Official Journal of the European Union,

EC (2006c) Commission Regulation (EC) No 1881/2006 of 19 December 2006 setting maximum levels for certain contaminants in foodstuffs.

EC (2009) Directive 2009/128/EC of the European Parliament and of the Council of 21 October 2009 establishing a framework for Community action to achieve the sustainable use of pesticides.

EC (2013) Commission Recommendation of 27 March 2013 on the presence of T-2 and HT-2 toxin in cereals and cereal products.

EC (2015) European Commission Decision C (2015) 2453: Horizon 2020 Work Programme 2014-2015: Food Security, Sustainable Agriculture and Forestry, Marine and Maritime and Inland Water Research and Bioeconomy (revised)

EC (2016) Agriculture, forestry and fishery statistics 2016 edition Statistical Books Eurostat doi:10.2785/917017

EC (2019) Communication from the commission to the European parliament, the European council, the council, the European economic and social committee and the committee of the regions: The European Green Deal COM/2019/640 final

Edwards SG (2004) Influence of agricultural practices on Fusarium infection of cereals and subsequent contamination of grain by trichothecene mycotoxins Toxicology Letters 153:29-35 doi:10.1016/j.toxlet.2004.04.022

Edwards SG (2009a) Fusarium mycotoxin content of UK organic and conventional barley Food Additives and Contaminants - Part A Chemistry, Analysis, Control, Exposure and Risk Assessment 26:1185-119o doi:10.1080/02652030902919418

Edwards SG (2009b) Fusarium mycotoxin content of UK organic and conventional wheat Food Additives and Contaminants - Part A Chemistry, Analysis, Control, Exposure and Risk Assessment 26:496-506 doi:10.1080/02652030802530679

EFSA (2011a) Scientific Opinion on the risks for animal and public health related to the presence of T-2 and HT-2 toxin in food and feed EFSA Journal 9:2481-n/a doi:10.2903/j.efsa.2011.2481

EFSA (2011b) Scientific Opinion on the risks for public health related to the presence of zearalenone in food EFSA Journal 9:2197 doi:10.2903/j.efsa.2011.2197

EFSA (2013) Deoxynivalenol in food and feed: occurrence and exposure EFSA Journal 2013;11(10):3379 doi:10.2903/j.efsa.2013.3379

EFSA (2017a) Human and animal dietary exposure to T-2 and HT-2 toxin EFSA Journal 15:e04972-n/a doi:10.2903/j.efsa.2017.4972

EFSA (2017b) Risks to human and animal health related to the presence of deoxynivalenol and its acetylated and modified forms in food and feed EFSA Journal 15:eo4718-n/a doi:10.2903/j.efsa.2017.4718

Elliott MA, Armitage CJ, Baughan CJ (2005) Exploring the beliefs underpinning drivers' intentions to comply with speed limits Transportation Research Part F: Traffic Psychology and Behaviour 8:459-479 doi:10.1016/j.trf.2005.08.002

Eskola M, Kos G, Elliott CT, Hajšlová J, Mayar S, Krska R (2019) Worldwide contamination of food-crops with mycotoxins: Validity of the widely cited 'FAO estimate' of $25 \%$ Critical Reviews in Food Science and Nutrition:1-17 doi:10.1080/10408398.2019.1658570 
FAO (2004) BARLEY: Post-Harvest Operations.

FAO (2015) Statistics Division. http://faostat3.fao.org/. Accessed 30 March 2016

FAO (2016) Crop statistics.

Fernandez MR, Zentner RP, DePauw RM, Gehl D, Stevenson FC (2007a) Impacts of crop production factors on common root rot of barley in Eastern Saskatchewan Crop Science 47:1585-1595 doi:10.2135/cropsci2006.09.0606

Fernandez MR, Zentner RP, DePauw RM, Gehl D, Stevenson FC (2007b) Impacts of crop production factors on fusarium head blight in barley in Eastern Saskatchewan Crop Science 47:1574-1584 doi:10.2135/cropsci2006.09.0596

Fischer $C$ et al. (2009) Factors influencing contractual choice and sustainable relationships in European agrifood supply chains European Review of Agricultural Economics 36:541-569 doi:10.1093/erae/jbpo41

Fishbein M, Yzer MC (2003) Using Theory to Design Effective Health Behavior Interventions Communication Theory 13:164-183 doi:10.1111/j.1468-2885.2003.tboo287.x

Focker M, van der Fels-Klerx HJ, Oude Lansink AGJM (2019) Cost-Effective Sampling and Analysis for Mycotoxins in a Cereal Batch Risk Analysis 39:926-939 doi:10.1111/risa.13201

Forster BP, Franckowiak JD, Lundqvist U, Lyon J, Pitkethly I, Thomas WTB (2007) The Barley Phytomer Annals of Botany 100:725-733 doi:10.1093/aob/mcm183

Fournier R Fusariotoxins on malting barley from field to end products and by-products. In: 6th EC Fusarium Toxin Forum, Brussels, Belgium, 9-10 February 20092009.

Francis J, Eccles, M. P., Johnston, M., Walker, A. E., Grimshaw, J. M., Foy, R., Kaner, E. F. S., Smith, L. \& Bonetti, D. (2004) Constructing questionnaires based on the theory of planned behaviour: A manual for health services researchers

Franz E, Boou K, Van Der Fels-Klerx I (2009) Prediction of deoxynivalenol content in Dutch winter wheat Journal of Food Protection 72:2170-2177 doi:10.4315/0362-028x-72.10.2170

Fraser R (1997) Seasonal variability, land values and willingness-to-pay for a forward wheat contract with protein premiums and discounts Australian Journal of Agricultural and Resource Economics 41:139155 doi:10.1111/1467-8489.00007

French DP, Hankins M (2003) The expectancy-value muddle in the theory of planned behaviour - and some proposed solutions British Journal of Health Psychology 8:37-55 doi:10.1348/135910703762879192

Friedman $\mathrm{N}$ Learning belief networks in the presence of missing values and hidden variables. In.

Gardiner SA, Boddu J, Berthiller E, Hametner C, Stupar RM, Adam G, Muehlbauer GJ (2010) Transcriptome analysis of the barley-deoxynivalenol interaction: Evidence for a role of glutathione in deoxynivalenol detoxification Molecular Plant-Microbe Interactions 23:962-976 doi:10.1094/mpmi23-7-0962

Gebrezgabher SA, Meuwissen MPM, Kruseman G, Lakner D, Oude Lansink AGJM (2015) Factors influencing adoption of manure separation technology in the Netherlands Journal of Environmental Management 150:1-8 doi:10.1016/j.jenvman.2014.10.029

Glanz K, Rimer BK, Viswanath K (2008) Health Behavior and Health Education: Theory, Research, and Practice. John Wiley \& Sons,

Goswami RS, Kistler HC (2004) Heading for disaster: Fusarium graminearum on cereal crops Molecular Plant Pathology 5:515-525 doi:10.1111/j.1364-3703.2004.00252.x

Greene WH (1993) Econometric Analysis. Second edn. Macmillan Publishing Company,

Hair JF, Jr. (2006) Multivariate data analysis. Pearson Education, Upper Saddle River, N.J. :

Hankins M, French D, Horne R (200o) Statistical guidelines for studies of the theory of reasoned action and the theory of planned behaviour Psychology and Health 15:151-161 doi:10.1080/08870440008400297

Hardeman W, Prevost AT, Parker RA, Sutton S (2013) Constructing multiplicative measures of beliefs in the theory of planned behaviour British Journal of Health Psychology 18:122-138 doi:10.1111/j.20448287.2012.02095.X

Harrach BD, Baltruschat H, Barna B, Fodor J, Kogel KH (2013) The mutualistic fungus piriformospora indica protects barley roots from a loss of antioxidant capacity caused by the necrotrophic pathogen fusarium culmorum Molecular Plant-Microbe Interactions 26:599-605 doi:10.1094/mpmi-o9-12o216-r

Hazel CM, Patel S (2004) Influence of processing on trichothecene levels Toxicology Letters 153:51-59 doi:10.1016/j.toxlet.2004.04.040

Henriksen B, Elen O (2005) Natural Fusarium grain infection level in wheat, barley and oat after early application of fungicides and herbicides Journal of Phytopathology 153:214-220 doi:10.1111/j.14390434.2005.00955.x

Heta H, Hiura U (1963) Varietal differences in resistance to head blight, Gibberella zeae (Schw.) Petch. Studies on the disease-resistance in barley. XIII Nogaku Kenkyu 49:177-187 
Hijbeek R, Pronk AA, van Ittersum MK, ten Berge HFM, Bijttebier J, Verhagen A (2018) What drives farmers to increase soil organic matter? Insights from the Netherlands Soil Use and Management 34:85-100 doi:10.1111/sum.12401

Hofer K, Barmeier G, Schmidhalter U, Habler K, Rychlik M, Hückelhoven R, Hess M (2016a) Effect of nitrogen Fertilisation on Fusarium head blight in spring barley Crop Protection 88:18-27 doi:10.1016/j.cropro.2016.05.007

Hofer K, Geißinger C, König C, Gastl M, Hückelhoven R, Heß M, Coleman AD (2016b) Influence of Fusarium isolates on the expression of barley genes related to plant defense and malting quality Journal of Cereal Science 69:17-24 doi:10.1016/j.jcs.2016.02.005

Højsgaard S (2012) Graphical Independence Networks with the gRain Package for R Journal of Statistical Software 1 doi:10.18637/jss.vo46.i1o

Holmes D, Jain L (2008) Innovations in Bayesian Networks: Theory and Applications vol 156. Springer. doi:10.1007/978-3-540-85066-3

Hong SM, Kwon OK, Choi DS, Kim JH, Choi GH, Cho NJ (2014) Diminution of mycotoxins from Fusarium sp. in barley and wheat through post-harvest processing methods Journal of the Korean Society for Applied Biological Chemistry 57:297-299 doi:10.1007/s13765-014-4016-1

Hop GE, Velthuis AGJ, Frankena K (2011) Assessing Dutch farmers' incentives to join a voluntary Johne's Disease programme NJAS - Wageningen Journal of Life Sciences 58:57-64 doi:10.1016/j.njas.2011.03.001

Horvat D, Spanic V, Dvojkovic K, Simic G, Magdic D, Nevistic A (2015) The influence of Fusarium infection on wheat (Triticum aestivum L.) proteins distribution and baking quality Cereal Research Communications 43:61-71 doi:10.1556/crc.2014.0023

Hyland JJ, Heanue K, McKillop J, Micha E (2018) Factors influencing dairy farmers' adoption of best management grazing practices Land Use Policy 78:562-571 doi:10.1016/j.landusepol.2018.07.006

Imathiu SM, Edwards SG, Ray RV, Back MA (2013) Fusarium langsethiae - a HT-2 and T-2 Toxins Producer that Needs More Attention Journal of Phytopathology 161:1-10 doi:10.1111/jph.12036

Inch SA, Gilbert J (2003) Survival of Gibberella zeae in Fusarium-damaged wheat kernels Plant Disease 87:282287 doi:10.1094/pdis.2003.87.3.282

Ioos R, Belhadj A, Menez M, Faure A (2005) The effects of fungicides on Fusarium spp. and Microdochium nivale and their associated trichothecene mycotoxins in French naturally-infected cereal grains Crop Protection 24:894-902 doi:10.1016/j.cropro.2005.01.014

Jacquet F, Butault JP, Guichard L (2011) An economic analysis of the possibility of reducing pesticides in French field crops Ecological Economics 70:1638-1648 doi:10.1016/j.ecolecon.2011.04.003

Jansen C, Von Wettstein D, Schäfer W, Kogel KH, Felk A, Maier FJ (2005) Infection pattern in barley and wheat spikes inoculated with wild-type and trichodiene synthase gene disrupted Fusarium graminearum Proceedings of the National Academy of Sciences of the United States of America 102:16892-16897 doi:10.1073/pnas.0508467102

Janssen EM, Mourits MCM, van der Fels-Klerx HJ, Lansink AGJMO (2020) Factors underlying Dutch farmers' intentions to adapt their agronomic management to reduce Fusarium species infection in wheat.

Janssen EM, Mourits MCM, van der Fels-Klerx HJ, Oude Lansink AGJM (2019) Pre-harvest measures against Fusarium spp. infection and related mycotoxins implemented by Dutch wheat farmers Crop Protection 122:9-18 doi:10.1016/j.cropro.2019.04.005

Janssen EM, Sprong RC, Wester PW, De Boevre M, Mengelers MJB (2015) Risk assessment of chronic dietary exposure to the conjugated mycotoxin deoxynivalenol-3- $\beta$-glucoside in the Dutch population World Mycotoxin Journal 8:561-572 doi:10.3920/wmj2014.1876

JECFA (2010) Evaluation of certain contaminants in food: seventy-second report of the Joint FAO/WHO Expert Committee on Food Additives. .

Jemberu WT, Mourits MCM, Hogeveen H (2015) Farmers' intentions to implement foot and mouth disease control measures in Ethiopia PLoS ONE 10 doi:10.1371/journal.pone.0138363

Judge GG, Hill RC, Griffiths W, Lutkepohl H, Lee TC (1982) Introduction to the Theory and Practice of Econometrics. John Wiley \& Sons.

Kabak B, Dobson ADW, Var I (2006) Strategies to prevent mycotoxin contamination of food and animal feed: A review Critical Reviews in Food Science and Nutrition 46:593-619 doi:10.1080/10408390500436185

Kaushik G (2015) Effect of processing on mycotoxin content in grains Crit Rev Food Sci Nutr 55:1672-1683 doi:10.1080/10408398.2012.701254

Kazan K, Gardiner DM, Manners JM (2012) On the trail of a cereal killer: Recent advances in Fusarium graminearum pathogenomics and host resistance Molecular Plant Pathology 13:399-413 doi:10.1111/j.1364-3703.2011.00762.x

Kharbikar LL, Dickin ET, Edwards SG (2015) Impact of post-anthesis rainfall, fungicide and harvesting time on the concentration of deoxynivalenol and zearalenone in wheat Food Additives and Contaminants - 
Part A Chemistry, Analysis, Control, Exposure and Risk Assessment 32:2075-2085 doi:10.1080/19440049.2015.1084652

Knowler D, Bradshaw B (2007) Farmers' adoption of conservation agriculture: A review and synthesis of recent research Food Policy 32:25-48 doi:10.1016/j.foodpol.2006.01.003

Kostelanska M, Dzuman Z, Malachova A, Capouchova I, Prokinova E, Skerikova A, Hajslova J (2011) Effects of milling and baking technologies on levels of deoxynivalenol and its masked form deoxynivalenol-3glucoside Journal of Agricultural and Food Chemistry 59:9303-9312 doi:10.1021/jf202428f

Kostelanska M et al. (2009) Occurrence of deoxynivalenol and its major conjugate, deoxynivalenol-3- glucoside, in beer and some brewing intermediates Journal of Agricultural and Food Chemistry 57:3187-3194 doi:10.1021/jf8o3749u

Kreuzberger M, Limsuwan S, Eggert K, Karlovsky P, Pawelzik E (2015) Impact of Fusarium spp. infection of bread wheat (Triticum aestivum L.) on composition and quality of flour in association with EU maximum level for deoxynivalenol Journal of Applied Botany and Food Quality 88:177-185 doi:10.5073/jabfq.2015.088.025

Kriss AB et al. (2012) Quantification of the relationship between the environment and Fusarium head blight, Fusarium pathogen density, and mycotoxins in winter wheat in Europe European Journal of Plant Pathology 133:975-993 doi:10.1007/s10658-012-9968-6

Krska R et al. (2016) Safe food and feed through an integrated toolbox for mycotoxin management: the MyToolBox approach World Mycotoxin Journal 9:487-495 doi:10.3920/wmj2016.2136

Kumar GDS, Popat MN (2010) Factors influencing the adoption of aflatoxin management practices in groundnut (Arachis hypogaea L.) International Journal of Pest Management 56:165-171 doi:10.108o/09670870903268346

Lajili K, Barry PJ, Sonka ST, Mahoney JT (1997) Farmers' preferences for crop contracts Journal of Agricultural and Resource Economics 22:264-280

Lancova K, Hajslova J, Poustka J, Krplova A, Zachariasova M, Dostalek P, Sachambula L (2008) Transfer of Fusarium mycotoxins and 'masked' deoxynivalenol (deoxynivalenol-3-glucoside) from field barley through malt to beer Food Additives and Contaminants - Part A Chemistry, Analysis, Control, Exposure and Risk Assessment 25:732-744 doi:10.1080/02652030701779625

Langevin F, Eudes F, Comeau A (2004) Effect of trichothecenes produced by Fusarium graminearum during Fusarium head blight development in six cereal species European Journal of Plant Pathology 110:735746 doi:10.1023/B:EJPP.0oooo41568.31778.ad

Langseth W, Stabbetorp H (1996) The effect of lodging and time of harvest on deoxynivalenol contamination in barley and oats Journal of Phytopathology 144:241-245

Lefebvre M, Langrell SRH, Gomez-y-Paloma S (2014) Incentives and policies for integrated pest management in Europe: a review Agronomy for Sustainable Development 35:27-45 doi:10.1007/s13593-014-0237-2

Legzdina L, Buerstmayr H (2004) Comparison of infection with Fusarium head blight and accumulation of mycotoxins in grain of hulless and covered barley Journal of Cereal Science 40:61-67 doi:10.1016/j.jcs.2004.03.002

Linkmeyer A, Hofer K, Rychlik M, Herz M, Hausladen H, Hückelhoven R, Hess M (2016) Influence of inoculum and climatic factors on the severity of Fusarium head blight in German spring and winter barley Food Additives and Contaminants - Part A Chemistry, Analysis, Control, Exposure and Risk Assessment 33:489-499 doi:10.1080/19440049.2015.1133932

Liu C, Manstretta V, Rossi V, Van Der Fels-Klerx HJ (2018) Comparison of three modelling approaches for predicting deoxynivalenol contamination in winter wheat Toxins 10, 1-15 doi:10.339o/toxins10070267

Liu C, Ogbonnaya FC (2015) Resistance to Fusarium crown rot in wheat and barley: A review Plant Breeding 134:365-372 doi:10.1111/pbr.12274

Loyce $C$ et al. (2008) Interaction between cultivar and crop management effects on winter wheat diseases, lodging, and yield Crop Protection 27:1131-1142 doi:10.1016/j.cropro.2008.02.001

Loyce $C$ et al. (2012) Growing winter wheat cultivars under different management intensities in France: A multicriteria assessment based on economic, energetic and environmental indicators Field Crops Research 125:167-178 doi:10.1016/j.fcr.2011.08.007

Maier FJ et al. (2006) Involvement of trichothecenes in fusarioses of wheat, barley and maize evaluated by gene disruption of the trichodiene synthase (Tri5) gene in three field isolates of different chemotype and virulence Molecular Plant Pathology 7:449-461 doi:10.1111/j.1364-3703.2006.00351.x

Malachova A, Cerkal R, Ehrenbergerova J, Dzuman Z, Vaculova K, Hajslova J (2010) Fusarium mycotoxins in various barley cultivars and their transfer into malt Journal of the Science of Food and Agriculture 90:2495-2505 doi:10.1002/jsfa.4112

Maresca M (2013) From the gut to the brain: Journey and pathophysiological effects of the food-associated trichothecene mycotoxin deoxynivalenol Toxins 5:784-820 doi:10.3390/toxins5040784 
Mason HE, Spaner D (2006) Competitive ability of wheat in conventional and organic management systems: A review of the literature Canadian Journal of Plant Science 86:333-343 doi:10.4141/po5-051

Matušinsky P, Váňová M, Tvaružek L, Polišenská I, Janeček M, Smutný V (2016) Soil management technologies and mycotoxin contamination of wheat and barley grain Cereal Research Communications 44:320329 doi:10.1556/0806.44.2016.021

May WE, Fernandez MR, Lafond GP (2010) Effect of fungicidal seed treatments on the emergence, development, and grain yield of Fusarium graminearum-infected wheat and barley seed under field conditions Canadian Journal of Plant Science 90:893-904 doi:10.4141/cjpso9173

McCallum BD, Tekauz A (2002) Influence of inoculation method and growth stage on fusarium head blight in barley Canadian Journal of Plant Pathology 24:77-8o doi:10.108o/o7060660109506976

McMullen M, Bergstrom G, De Wolf E, Dill-Macky R, Hershman D, Shaner G, Van Sanford D (2012) A unified effort to fight an enemy of wheat and barley: Fusarium head blight Plant Disease 96:1712-1728 doi:10.1094/pdis-03-12-0291-fe

McMullen M, Halley S, Schatz B, Meyer S, Jordahl J, Ransom J (2008) Integrated strategies for fusarium head blight management in the United States Cereal Research Communications 36:563-568 doi:10.1556/CRC.36.2008.Suppl.B.45

Medentsev AG, Arinbasarova AY, Akimenko VK (2005) Biosynthesis of naphthoquinone pigments by fungi of the genus Fusarium Applied Biochemistry and Microbiology 41:503-507 doi:10.1007/s10438-005-00918

Meng-Reiterer J et al. (2015) Tracing the metabolism of HT-2 toxin and T-2 toxin in barley by isotope-assisted untargeted screening and quantitative LC-HRMS analysis Analytical and Bioanalytical Chemistry doi:10.1007/soo216-015-8975-9

Mesterházy A (1995) Types and components of resistance to Fusarium head blight of wheat Plant Breeding 114:377-386 doi:10.1111/j.1439-0523.1995.tboo816.x

Meuwissen MPM, Huirne RBM, Hardaker JB (2001) Risk and risk management: an empirical analysis of Dutch livestock farmers Livestock Production Science 69:43-53 doi:10.1016/So301-6226(oo)oo247-5

Miller JD, Young JC, Sampson DR (1985) Deoxynivalenol and Fusarium head blight resistance in spring cereals Journal of Phytopathology 113:359-367

Montaño DE, Kasprzyk D (2008) Theory of reasoned action, theory of planned behavior, and the integrated behavioral model. In: Health behavior and health education: Theory, research, and practice, 4 th ed. Jossey-Bass, San Francisco, CA, US, pp 67-96

Moretti A, Panzarini G, Somma S, Campagna C, Ravaglia S, Logrieco AF, Solfrizzo M (2014) Systemic growth of F. graminearum in wheat plants and related accumulation of deoxynivalenol Toxins 6:1308-1324 doi:10.3390/toxins6041308

Moretti A, Pascale M, Logrieco AF (2019) Mycotoxin risks under a climate change scenario in Europe Trends in Food Science and Technology 84:38-40 doi:10.1016/j.tifs.2018.03.008

Morris NL, Miller PCH, Orson JH, Froud-Williams RJ (2010) The adoption of non-inversion tillage systems in the United Kingdom and the agronomic impact on soil, crops and the environment-A review Soil and Tillage Research 108:1-15 doi:10.1016/j.still.2010.03.004

Mulwa C, Marenya P, Rahut DB, Kassie M (2017) Response to climate risks among smallholder farmers in Malawi: A multivariate probit assessment of the role of information, household demographics, and farm characteristics Climate Risk Management 16:208-221 doi:10.1016/j.crm.2017.01.002

MyToolBox (2019) Deliverable 4.5: Report covering socio-economic impact of MyToolBox including recommendations for incentives.

Nave S, Jacquet F, Jeuffroy MH (2013) Why wheat farmers could reduce chemical inputs: Evidence from social, economic, and agronomic analysis Agronomy for Sustainable Development 33:795-807 doi:10.1007/s13593-013-0144-y

Nesvadba Z, Vyhnánek T, Ježišková I, Tvarůžek L, Špunarová M, Špunar J (2006) Evaluation of spring barley genotypes with different susceptibility to Fusarium head blight using molecular markers Plant, Soil and Environment 52:485-491

Newton JD, Ewing MT, Burney S, Hay M (2012) Resolving the theory of planned behaviour's 'expectancy-value muddle' using dimensional salience Psychology and Health 27:588-602 doi:10.108o/o8870446.2011.611244

Newton JD, Newton FJ, Ewing MT (2014) The dimensional salience solution to the expectancy-value muddle: An extension Psychology and Health 29:1458-1475 doi:10.108o/o8870446.2014.950657

Nielsen LK, Cook DJ, Edwards SG, Ray RV (2014) The prevalence and impact of Fusarium head blight pathogens and mycotoxins on malting barley quality in UK International Journal of Food Microbiology 179:3849 doi:10.1016/j.ijfoodmicro.2014.03.023

Nielsen TD, Jensen FV (2009) Bayesian networks and decision graphs. Springer Science \& Business Media, 
Nkamleu GB, Adesina AA (200o) Determinants of chemical input use in peri-urban lowland systems: Bivariate probit analysis in Cameroon Agricultural Systems 63:111-121 doi:10.1016/so3o8-521x(99)ooo74-8

O'Sullivan B, McGee H, Keegan O (2008) Comparing solutions to the 'expectancy-value muddle' in the theory of planned behaviour British Journal of Health Psychology 13:789-802 doi:10.1348/135910708x278306

Obst A, Lepschy J, Beck R, Bauer G, Bechtel A (2000) The risk of toxins by Fusarium graminearum in wheat Interactions between weather and agronomic factors Mycotoxin research 16:16-20 doi:10.1007/bfo2942972

Oliveira PM, Mauch A, Jacob F, Waters DM, Arendt EK (2012) Fundamental study on the influence of Fusarium infection on quality and ultrastructure of barley malt International Journal of Food Microbiology 156:32-43 doi:10.1016/j.ijfoodmicro.2012.02.019

Oliveira PM, Waters DM, Arendt EK (2013) The impact of Fusarium culmorum infection on the protein fractions of raw barley and malted grains Applied Microbiology and Biotechnology 97:2053-2065 doi:10.1007/soo253-013-4696-1

Orlando B, Barrier-Guillot B, Gourdain E, Maumené C (2010) Identification of agronomic factors that influence the levels of T-2 and HT-2 toxins in barley grown in France World Mycotoxin Journal 3:169-174 doi:10.3920/wmj2009.1191

Osborne LE, Stein JM (2007) Epidemiology of Fusarium head blight on small-grain cereals International Journal of Food Microbiology 119:103-108 doi:10.1016/j.ijfoodmicro.2007.07.032

Oude Lansink A, van den Berg M, Huirne R (2003) Analysis of strategic planning of Dutch pig farmers using a multivariate probit model Agricultural Systems 78:73-84 doi:10.1016/So3o8-521X(03)ooo34-9

Pageau D, Lafond J, Lajeunesse J, Savard ME (2008) Effect of preceding crop and nitrogen Fertilisation on the deoxynivalenol contents of barley Canadian Journal of Plant Pathology 30:397-403 doi:10.108o/07060660809507537

Papadopoulou-Bouraoui A, Vrabcheva T, Valzacchi S, Stroka J, Anklam E (2004) Screening survey of deoxynivalenol in beer from the European market by an enzyme-linked immunosorbent assay Food Additives and Contaminants 21:607-617 doi:10.108o/02652030410001677745

Parry DW, Jenkinson P, McLeod L (1995) Fusarium ear blight (scab) in small grain cereals-a review Plant Pathology 44:207-238 doi:10.1111/j.1365-3059.1995.tbo2773.x

Paul PA, Lipps PE, Hershman DE, McMullen MP, Draper MA, Madden LV (2008) Efficacy of triazole-based fungicides for Fusarium head blight and deoxynivalenol control in wheat: A multivariate metaanalysis Phytopathology 98:999-1011 doi:10.1094/phyto-98-9-0999

Paul PA, Lipps PE, Madden LV (2005) Relationship between visual estimates of Fusarium head blight intensity and deoxynivalenol accumulation in harvested wheat grain: A meta-analysis Phytopathology 95:1225-1236 doi:10.1094/phyto-95-1225

Paul PA, Lipps PE, Madden LV (2006) Meta-analysis of regression coefficients for the relationship between fusarium head blight and deoxynivalenol content of wheat Phytopathology 96:951-961 doi:10.1094/phyto-96-0951

Peterson SJ, Luthans F (2006) The impact of financial and nonfinancial incentives on business-unit outcomes over time Journal of Applied Psychology 91:156-165 doi:10.1037/o021-9010.91.1.156

Pirgozliev SR, Edwards SG, Hare MC, Jenkinson P (2003) Strategies for the control of Fusarium head blight in cereals European Journal of Plant Pathology 109:731-742 doi:10.1023/a:1026034509247

Placinta CM, D'Mello JPF, MacDonald AMC (1999) A review of worldwide contamination of cereal grains and animal feed with Fusarium mycotoxins Animal Feed Science and Technology 78:21-37 doi:10.1016/s0377-8401(98)00278-8

Prange A, Birzele B, Krämer J, Meier A, Modrow H, Köhler P (2005) Fusarium-inoculated wheat: deoxynivalenol contents and baking quality in relation to infection time Food Control 16:739-745 doi:10.1016/j.foodcont.2004.06.013

R Core Team (2019) R: A language and environment for statistical computing. R Foundation for Statistical Computing, Vienna, Austria.

Rabiey M, Shaw MW (2016) Piriformospora indica reduces fusarium head blight disease severity and mycotoxin DON contamination in wheat under UK weather conditions Plant Pathology 65:940-952 doi:10.1111/ppa.12483

Rose DC et al. (2019) Integrated farm management for sustainable agriculture: Lessons for knowledge exchange and policy Land Use Policy 81:834-842 doi:10.1016/j.landusepol.2018.11.0o1

Rosenstock IM (1974) Historical Origins of the Health Belief Model Health Education \& Behavior 2:328-335 doi:10.1177/109019817400200403

Rossi V, Giosuè S, Terzi V, Scudellari D (2007) A decision support system for Fusarium head blight on small grain cereals EPPO Bulletin 37:359-367 doi:10.1111/j.1365-2338.2007.01138.x 
Rossi V, Manstretta V, Ruggeri M (2015) A multicomponent decision support system to manage Fusarium head blight and mycotoxins in durum wheat World Mycotoxin Journal 8:629-640 doi:10.3920/wmj2015.1881

Rutter DR, Bunce DJ (1989) The theory of reasoned action of Fishbein and Ajzen: A test of Towriss's amended procedure for measuring beliefs British Journal of Social Psychology 28:39-46 doi:10.1111/j.20448309.1989.tboo844.x

RVO (2018) The Netherlands Enterprise Agency. english.rvo.nl. 2018

Salas B, Steffenson BJ, Casper HH, Tacke B, Prom LK, Fetch Jr TG, Schwarz PB (1999) Fusarium species pathogenic to barley and their associated mycotoxins Plant Disease 83:667-674

Salazar C, Jaime M, Pinto C, Acuña A (2019) Interaction between crop insurance and technology adoption decisions: The case of wheat farmers in Chile Australian Journal of Agricultural and Resource Economics 63:593-619 doi:10.1111/1467-8489.12307

Salgado JD, Wallhead M, Madden LV, Paul PA (2011) Grain Harvesting Strategies to Minimize Grain Quality Losses Due to Fusarium Head Blight in Wheat Plant Disease 95:1448-1457 doi:10.1094/pdis-04-110309

Samson GS, Gardebroek C, Jongeneel RA (2016) Explaining production expansion decisions of Dutch dairy farmers NJAS - Wageningen Journal of Life Sciences 76:87-98 doi:10.1016/j.njas.2015.11.007

Sarlin T, Laitila A, Pekkarinen A, Haikara A (2005) Effects of three Fusarium species on the quality of barley and malt Journal of the American Society of Brewing Chemists 63:43-49 doi:10.1094/asbcj-63-0043

Scala V et al. (2016) Climate, soil management, and cultivar affect Fusarium head blight incidence and deoxynivalenol accumulation in durum wheat of Southern Italy Frontiers in Microbiology 7 doi:10.3389/fmicb.2016.01014

SCF (2002) Opinion of the Scientific Committee on Food (SCF) on Fusarium toxins. Part 6: Group evaluation of T-2 toxin, HT-2 toxin, nivalenol and deoxynivalenol, adopted on 26 February 2002. $\mathrm{SCF} / \mathrm{CS} / \mathrm{CNTM} / \mathrm{MYC} / 27$ Final.

Schöneberg T et al. (2016) Fusarium and mycotoxin spectra in Swiss barley are affected by various cropping techniques Food Additives and Contaminants - Part A Chemistry, Analysis, Control, Exposure and Risk Assessment 33:1608-1619 doi:10.1080/19440049.2016.1219071

Schroeder HW, Christensen JJ (1963) Factors affecting resistance of wheat to scab caused by Gibberella zeae Phytopathology 53:831-838

Schwarz PB (2017) Fusarium head blight and deoxynivalenol in malting and brewing: successes and future challenges Tropical Plant Pathology 42:153-164 doi:10.1007/s40858-017-0146-4

Schwarz PB, Jones BL, Steffenson BJ (2002) Enzymes associated with Fusarium infection of barley Journal of the American Society of Brewing Chemists 6o:130-134

Scutari M (2010) Learning Bayesian Networks with the bnlearn R Package Journal of Statistical Software 1 doi:10.18637/jss.v035.io3

Shah L et al. (2018) Integrated control of Fusarium head blight and deoxynivalenol mycotoxin in wheat Plant Pathology 67:532-548 doi:10.1111/ppa.12785

Shah L, Ali A, Zhu Y, Wang S, Si H, Ma C (2017) Wheat defense response to Fusarium head blight and possibilities of its improvement Physiological and Molecular Plant Pathology 98:9-17 doi:10.1016/j.pmpp.2017.01.004

Shang S, Shang Z, Yu J, Zhang X, Wu J, Jiang D (2018) Impacts of climate change on fusarium head blight in winter wheat Fresenius Environmental Bulletin 27:3906-3913

Silva JV, Reidsma P, van Ittersum MK (2017) Yield gaps in Dutch arable farming systems: Analysis at crop and crop rotation level Agricultural Systems 158:78-92 doi:10.1016/j.agsy.2017.06.005

Sirot V, Fremy JM, Leblanc JC (2013) Dietary exposure to mycotoxins and health risk assessment in the second French total diet study Food and Chemical Toxicology 52:1-11 doi:10.1016/j.fct.2012.10.036

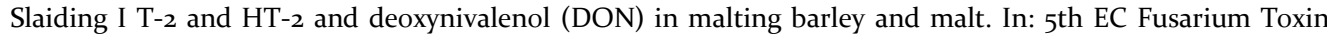
Forum, Brussels, Belgium, 10-11 January 20082008.

Slaiding I T-2 and HT-2 and deoxynivalenol (DON) in malting barley and malt. In: Proceedings of the 6th EC Fusarium Toxin Forum, Brussels, Belgium, 9-10 February 20092009.

Snijders CHHA (1988) Factors of resistance to Fusarium culmorum in wheat Cereal Breeding Related to Integrated Cereal Production Proc Conf of Cereal Sect:149-153

Sok J, Hogeveen H, Elbers ARW, Oude Lansink AGJM (2015) Farmers' beliefs and voluntary vaccination schemes: Bluetongue in Dutch dairy cattle Food Policy 57:40-49 doi:10.1016/j.foodpol.2015.09.0o6

Sok J, Hogeveen H, Elbers ARW, Oude Lansink AGJM (2016) Perceived risk and personality traits explaining heterogeneity in Dutch dairy farmers' beliefs about vaccination against Bluetongue Journal of Risk Research:1-17 doi:10.108o/13669877.2016.1223162 
Solazzo R, Petriccione G, Perito MA (2020) The contractual relationships in the Italian durum wheat chain: Empirical survey evidence New Medit 19:101-111 doi:10.30682/nm2002g

Solazzo R, Pierangeli F (2016) How does greening affect farm behaviour? Trade-off between commitments and sanctions in the Northern Italy Agricultural Systems 149:88-98 doi:10.1016/j.agsy.2016.07.013

Sooväli P, Koppel M, Kangor T (2017) Effectiveness of seed treatment against Fusarium spp. and cochliobolus sativus of spring barley in different conditions Agronomy Research 15:280-287

StataCorp (2015) Stata Statistical Software: Release 14. College Station, TX: StataCorp LP

Strange RN, Smith H (1971) A fungal growth stimulant in anthers which predisposes wheat to attack by Fusarium graminearum Physiological Plant Pathology 1:141-144,IN145,145-150 doi:10.1016/00484059(71)90023-3

Sutton S (1998) Predicting and explaining intentions and behavior: How well are we doing? Journal of Applied Social Psychology 28:1317-1338 doi:10.1111/j.1559-1816.1998.tbo1679.x

Tateishi H, Miyake T, Mori M, Sakuma Y, Saishoji T (2014) Effect of application timing of metconazole on Fusarium head blight development and mycotoxin contamination in wheat and barley Journal of Pesticide Science 39:1-6 doi:10.1584/jpestics.D12-077

Tekauz A, Gilbert J, Abramson D (1997) Reaction to Fusarium head blight of spring wheats based on symptoms, fusarium spp. and mycotoxins Cereal Research Communications 25:821-822

Tekauz A, McCallum B, Gilbert J (200o) Fusarium head blight of barley in western Canada Canadian Journal of Plant Pathology 22:9-16

Tey YS et al. (2017) Factors influencing the adoption of sustainable agricultural practices in developing countries: A review Environmental Engineering and Management Journal 16:337-349

Thin MC, Vigier B, Qiu QS, Martin RA, Keh MH, Savard M (2004) Barley traits associated with resistance to fusarium head blight and deoxynivalenol accumulation Phytopathology 94:1145-1150

Thomason WE, Griffey CA (2009) Understanding Pre-harvest Sprouting of Wheat.

Torres AM et al. (2019) Fusarium head blight and mycotoxins in wheat: Prevention and control strategies across the food chain World Mycotoxin Journal 12:333-355 doi:10.3920/WMJ2019.2438

Trenholm HL, Charmley LL, Prelusky DB, Warner RM (1991) Two physical methods for the decontamination of four cereals contaminated with deoxynivalenol and zearalenone Journal of agricultural and food chemistry 39:356-360

Unnevehr L, Roberts T (2002) Food safety incentives in a changing world food system Food Control 13:73-76 doi:10.1016/So956-7135(o1)oo10o-1

Urrea CA, Horsley RD, Steffenson BJ, Schwarz PB (2002) Heritability of Fusarium head blight resistance and deoxynivalenol accumulation from barley accession CIho 4196 Crop Science 42:1404-1408

Urrea CA, Horsley RD, Steffenson BJ, Schwarz PB (2005) Agronomic characteristics, malt quality, and disease resistance of barley germplasm lines with partial fusarium head blight resistance Crop Science 45:1235-1240 doi:10.2135/cropsci2003.0608

Van der Fels-Klerx HJ (2014) Evaluation of performance of predictive models for deoxynivalenol in wheat Risk Analysis 34:380-39o doi:10.1111/risa.12103

Van der Fels-Klerx HJ, Burgers SLGE, Booij CJH (2010) Descriptive modelling to predict deoxynivalenol in winter wheat in the Netherlands Food Additives \& Contaminants: Part A 27:636-643 doi:10.1080/19440040903571762

Van der Fels-Klerx HJ et al. (2012a) Occurrence of Fusarium head blight species and Fusarium mycotoxins in winter wheat in the Netherlands in 2009 Food Additives and Contaminants - Part A Chemistry, Analysis, Control, Exposure and Risk Assessment 29:1716-1726 doi:10.108o/19440049.2012.685891

van der Fels-Klerx HJ, Focker M, de Rijk T, Liu C (2020) Mycotoxins in wheat cultivated in the Netherlands: field survey results of one decade $(2009-2018)$. Unpublished work

Van der Fels-Klerx HJ, Klemsdal S, Hietaniemi V, Lindblad M, Ioannou-Kakouri E, Van Asselt ED (2012b) Mycotoxin contamination of cereal grain commodities in relation to climate in North West Europe Food Additives and Contaminants - Part A Chemistry, Analysis, Control, Exposure and Risk Assessment 29:1581-1592 doi:10.1080/19440049.2012.689996

Van der Fels-Klerx HJ, Stratakou I (2010) T-2 toxin and HT-2 toxin in grain and grain-based commodities in Europe: Occurrence, factors affecting occurrence, co-occurrence and toxicological effects World Mycotoxin Journal 3:349-367 doi:10.3920/wmj2010.1237

van derFels-Klerx HJ, van Asselt ED, Madsen MS, Olesen JE (2013) Impact of Climate Change Effects on Contamination of Cereal Grains with Deoxynivalenol PLoS ONE 8 doi:10.1371/journal.pone.0073602

van Dijk WFA, Lokhorst AM, Berendse F, de Snoo GR (2016) Factors underlying farmers' intentions to perform unsubsidised agri-environmental measures Land Use Policy 59:207-216 doi:10.1016/j.landusepol.2016.09.003 


\section{References}

Van Ittersum MK, Leffelaar PA, Van Keulen H, Kropff MJ, Bastiaans L, Goudriaan J (2003) On approaches and applications of the Wageningen crop models European Journal of Agronomy 18:201-234 doi:10.1016/S1161-0301(02)oo106-5

Vančo B, Šliková S, Šudyova V, Šrobárová A (2007) Response to Fusarium culmorum inoculation in barley Biologia 62:56-61 doi:10.2478/s11756-007-0o11-x

Varga E, Malachova A, Schwartz H, Krska R, Berthiller F (2013) Survey of deoxynivalenol and its conjugates deoxynivalenol-3-glucoside and 3-acetyl-deoxynivalenol in 374 beer samples Food Additives and Contaminants - Part A Chemistry, Analysis, Control, Exposure and Risk Assessment 30:137-146 doi:10.1080/19440049.2012.726745

Vaughan M, Backhouse D, Del Ponte EM (2016) Climate change impacts on the ecology of Fusarium graminearum species complex and susceptibility of wheat to Fusarium head blight: A review World Mycotoxin Journal 9:685-700 doi:10.3920/WMJ2016.2053

Vivar HE, Gilchrist L, Hayes P, Zongzhen L, Steffenson B, Franco J, Henry M (1997) Head scab resistant barley for malting and food Cereal Research Communications 25:693-697

Vogelgsang S et al. (2019) An eight-year survey of wheat shows distinctive effects of cropping factors on different Fusarium species and associated mycotoxins European Journal of Agronomy 105:62-77 doi:10.1016/j.eja.2019.01.002

Ward PS, Bell AR, Droppelmann K, Benton TG (2018) Early adoption of conservation agriculture practices: Understanding partial compliance in programs with multiple adoption decisions Land Use Policy 70:27-37 doi:10.1016/j.landusepol.2017.10.001

Wauters E, Bielders C, Poesen J, Govers G, Mathijs E (2010) Adoption of soil conservation practices in Belgium: An examination of the theory of planned behaviour in the agri-environmental domain Land Use Policy 27:86-94 doi:10.1016/j.landusepol.2009.02.009

Wegulo SN (2012) Factors influencing deoxynivalenol accumulation in small grain cereals Toxins 4:1157-1180 doi:10.339o/toxins4111157

Wegulo SN, Baenziger PS, Hernandez Nopsa J, Bockus WW, Hallen-Adams H (2015) Management of Fusarium head blight of wheat and barley Crop Protection 73:100-107 doi:10.1016/j.cropro.2015.02.025

Wilson W, Dahl B, Nganje W (2018) Economic costs of Fusarium head blight, scab and deoxynivalenol World Mycotoxin Journal:1-12 doi:10.3920/wmj2017.2204

Wilson WW, Dahl BL (2011) Grain contracting strategies: The case of durum wheat Agribusiness 27:344-359 doi:10.1002/agr.20270

Xue A (2013) Effect of harvest date on barley grain contamination with Fusarium spp. and deoxynivalenol in northeastern Ontario Phytoprotection 93:1-7 doi:10.7202/1015205ar

Xue A, Rowsell J, Chen Y (2008) Effect of harvesting time on grain contamination with Fusarium Spp. and deoxynivalenol in barley Cereal Research Communications 36:549-551 doi:10.1556/CRC.36.2008.Suppl.B.43

Xue AG, Frégeau-Reid J, Rowsell J, Babcock C, Hoekstra GJ, Sparry E (2004) Effect of harvesting time on incidence of seed-borne Fusarium spp. in spring wheat in eastern Ontario Canadian Journal of Plant Science 84:757-763 doi:10.4141/po3-206

Xue AG, Guo W, Chen Y, Siddiqui I, Marchand G, Liu J, Ren C (2017) Effect of seed treatment with novel strains of Trichoderma spp. on establishment and yield of spring wheat Crop Protection 96:97-102 doi:10.1016/j.cropro.2017.02.003

Xue AG, Keh MH, Butler G, Vigier BJ, Babcock C (2006) Pathogenicity of Fusarium species causing head blight in barley Phytoprotection 87:55-61

Yang F et al. (2010) Investigation of the effect of nitrogen on severity of Fusarium Head Blight in barley Journal of Proteomics 73:743-752 doi:10.1016/j.jprot.2009.10.010

Yoshida M, Kawada N, Nakajima T (2007) Effect of infection timing on fusarium head blight and mycotoxin accumulation in open- and closed-flowering barley Phytopathology 97:1054-1062 doi:10.1094/phyto97-9-1054

Yoshida M, Kawada N, Tohnooka T (2005) Effect of row type, flowering type and several other spike characters on resistance to Fusarium head blight in barley Euphytica 141:217-227 doi:10.1007/s10681-005-7008-8

Yoshida M, Nakajima T, Arai M, Suzuki F, Tomimura K (2008a) Effect of the timing of fungicide application on Fusarium head blight and mycotoxin accumulation in closed-flowering barley Plant Disease 92:11641170 doi:10.1094/pdis-92-8-1164

Yoshida M, Nakajima T, Tomimura K, Suzuki F, Arai M, Miyasaka A (2012) Effect of the timing of fungicide application on Fusarium head blight and mycotoxin contamination in wheat Plant Disease 96:845851 doi:10.1094/pdis-10-11-0819 
Yoshida M, Nakajima T, Tonooka T (20o8b) Effect of nitrogen application at anthesis on Fusarium head blight and mycotoxin accumulation in breadmaking wheat in the western part of Japan Journal of General Plant Pathology 74:355-363 doi:10.1007/s10327-008-0109-1

Zachariasova M, Vaclavikova M, Lacina O, Vaclavik L, Hajslova J (2012) Deoxynivalenol oligoglycosides: New "masked" fusarium toxins occurring in malt, beer, and breadstuff Journal of Agricultural and Food Chemistry 60:9280-9291 doi:10.1021/jf302069z

Zain ME (2011) Impact of mycotoxins on humans and animals Journal of Saudi Chemical Society 15:129-144 doi:10.1016/j.jscs.2010.06.006

Zhang H, Potts SG, Breeze T, Bailey A (2018) European farmers' incentives to promote natural pest control service in arable fields Land Use Policy 78:682-69o doi:10.1016/j.landusepol.2018.07.017 


\section{Summaries}

English Summary

Nederlandse Samenvatting 


\section{English Summary}

Fusarium spp. infection in wheat can lead to the crop disease Fusarium Head Blight (FHB) and Fusarium damaged kernels (FDK), resulting in reduced wheat yield, loss of quality of the kernels and contamination with mycotoxins. Despite the many prevention and control efforts, FHB and mycotoxin contamination still occur. Mycotoxins are a problem for human and animal health due to exposure via food and feed consumption. Because it is difficult, if not impossible, to remove mycotoxins further along the wheat supply chain, agronomic management is mainly focused on reducing initial Fusarium spp. infection in the field by farmers. Although many studies showed that implementing agronomic management measures can be effective, hardly any attention is given to the actual implementation of measures by farmers and possible opportunities to improve agronomic management. Since effective mycotoxins management along the supply chain largely depends on the implementation of agronomic management measures by farmers, it is important to understand the behaviour of farmers regarding their agronomic management.

The objective of this thesis was to investigate how to incentivise farmers to adapt their agronomic management to reduce Fusarium spp infection and mycotoxin contamination in wheat. This objective was divided into the following four sub-objectives:

i) To identify effective agronomic management measures to reduce Fusarium spp. infection and mycotoxin contamination in small-grain cereals by farmers.

ii) To investigate which agronomic management measures Dutch wheat farmers currently apply against Fusarium spp. infection and mycotoxin contamination and to examine which farm and farmer characteristics explain the implementation of these measures.

iii) To explore the intention and underlying behavioural constructs and beliefs of Dutch wheat farmers to adapt their future agronomic management to reduce Fusarium spp. infection and mycotoxin contamination in wheat.

iv) To assess the intention of different types of European wheat farmers to change their agronomic management for prevention and control of Fusarium spp. infection and mycotoxin contamination in wheat under different incentives.

Chapter 2 presents a literature review to investigate Fusarium spp. infection in smallgrain cereals, barley and wheat. It provides a solid base to understand Fusarium spp. infection, FHB and mycotoxin contamination. It identifies effective agronomic management measures to reduce FHB and mycotoxins.

Chapter 3 identifies which agronomic management measures Dutch wheat farmers currently apply against FHB and mycotoxins and examines which farm and farmer characteristics explain the implementation of these measures. Field data on pre-harvest measures, like the selection of resistant wheat cultivars, the use of fungicides, and crop rotation, along with farm and farmer characteristics were collected from Dutch wheat farmers via an online questionnaire. Probit models were applied to examine farm and farmer characteristics that explain the implementation of pre-harvest agronomic measures. Results showed that most farmers applied six or more different measures against Fusarium spp. infection and mycotoxin contamination in wheat and that the use of each pre-harvest measure is related to at least one other measure. However, results 
also indicated that about $44 \%$ of farmers could further improve their agronomic management to reduce Fusarium spp. infection and mycotoxin contamination if they implemented a benchmark approach consisting of a combination of fungicide use during flowering, the selection of a Fusarium resistant wheat variety, and ploughing or crop rotation. Five of the ten evaluated farm and farmer characteristics significantly $(p<0.05)$ explained the implementation of at least one of the eight pre-harvest agronomic prevention and control measures. These five farm and farmer characteristics included: having wheat as main income crop, the use of a decision support system, the education level of the farmer, the farmer's knowledge about mycotoxins, and the farmer's level of risk aversion.

Chapter 4 explores the intention and underlying behavioural constructs and beliefs of Dutch wheat farmers to adapt their future agronomic management to reduce FHB and mycotoxins in wheat, applying the Theory of Planned Behaviour (TPB). Data were collected from 100 Dutch wheat farmers via an online questionnaire. The standard TPB analysis was extended with an assessment of the robustness of the belief results to account for the statistical validity of the analysis on TPB beliefs (i.e. to address the socalled expectancy-value muddle). Forty-six percent of the farmers had a positive intention to change their management in the next 5 years. The two behavioural constructs significantly related to this intention were attitude and social norm, whereas association with the perceived behavioural control construct was insignificant, indicating that farmers did not perceive any barriers to change their behaviour. Relevant attitudinal beliefs indicated specific attributes of wheat, namely wheat quality and safety aspects (lower mycotoxin contamination). This indicates that strengthening these beliefs - by demonstrating that a change in management will result in a higher wheat yield quantity and quality and safety (lower mycotoxin levels) - will result in a stronger attitude and, subsequently, a higher intention to change agronomic management. Interventions to strengthen these beliefs should preferably go by the most important referents for social norms, which were the buyers and the farmer cooperatives in this study.

Chapter 5 identifies incentives that could stimulate European farmers to adapt their agronomic management to reduce FHB and mycotoxins in wheat. Several Bayesian network models were developed to get insight into the relation between farm and farmer characteristics and the increase in intention under several incentives. The study investigated different incentives through an online questionnaire amongst wheat farmers from Italy, the Netherlands, Serbia, and the United Kingdom. Bayesian Network modelling was applied to estimate the probability that farmers would adapt their current management practices under different incentives. The current intention of European wheat farmers to adapt their agronomic approach to reduce Fusarium spp. infection was positive for $51 \%$ of the farmers, although this percentage varied between the four countries. Results showed that most of the farmers would adapt their current management practices under the incentives 'paid extra when wheat contains low levels of mycotoxins' and under the incentive 'wheat is tested for the presence of mycotoxins for free'. Incentivization of farmers depended on farm and farmer characteristics like country, crop type, size of arable land, soil type, education, and mycotoxin knowledge. 
Chapter 6 provides a synthesis of the results by focussing on opportunities to adapt agronomic management, incentivisation of farmers to adapt their agronomic management and, heterogeneity among wheat farmers. In addition, a reflection on the methods is given, followed by a section on business and policy implications, and future research ideas.

The main conclusions of this thesis are summarized as follows:

- Although local weather and region play a major role in Fusarium spp. infection, preharvest agronomic management measures can reduce FHB and mycotoxin contamination in wheat (Chapters 2 and 3 ).

- Most Dutch wheat farmers used at least six pre-harvest agronomic management measures simultaneously to reduce Fusarium spp. infection and mycotoxins in wheat, and $56 \%$ of the farmers used an effective set of measures (benchmark approach) (Chapter 3).

- Farmers who are not using the effective benchmark approach for the reduction of Fusarium spp. infection and mycotoxin contamination in wheat (Chapter 3) can be incentivised to adapt their agronomic management by the incentives 'paid extra when wheat contains low levels of mycotoxins' (Italian and Dutch farmers), 'paid less when wheat contains high levels of mycotoxins' (United Kingdom), and 'when required by law' (Serbia) (Chapter 5).

- The farm and farmer characteristics 'wheat as main crop', 'the use of a decision support system', 'the education level of the farmer', 'farmers' knowledge of mycotoxins' and 'farmer's level of risk aversion' explained the implementation of one or more agronomic management measures for reduction of Fusarium spp. infection and mycotoxins in wheat in the Netherlands (Chapter 3).

- Farmers with wheat as main crop are more likely to implement the benchmark approach and are more likely to be incentivised to adapt their agronomic management approach to reduce Fusarium spp. infection and mycotoxins in wheat under the incentives 'free mycotoxin testing', 'insurance for high mycotoxins levels' and 'a multiyear contract with the buyer to deliver wheat for a fixed price' compared to farmers with another main crop (Chapters 3 and 5 ).

- The current intention of European wheat farmers to change their agronomic approach for FHB and mycotoxins reduction is positive for $43 \%$ of Italian farmers, $46 \%$ for Dutch farmers, $68 \%$ for Serbian farmers and $38 \%$ for farmers from the United Kingdom (Chapters 4 and 5).

- Dutch wheat farmers' intention can be increased by strengthening their attitude via attitudinal beliefs - by demonstrating that a change in management will result in a higher yield quantity and quality and lower mycotoxin levels - disseminated through their most important referents, namely their buyer or farmer cooperative, or by the incentives 'paid extra' and 'no delivery', but not by targeting their perceived behavioural control (Chapters 4 and 5 ). 


\section{Nederlandse Samenvatting}

Fusarium spp. infectie in tarwe kan leiden tot de gewasziekte aarfusarium, wat resulteert in beschadigde tarwekorrels, verminderde tarweopbrengst, kwaliteitsverlies en contaminatie met mycotoxines. Ondanks de vele inspanningen op het gebied van preventie en bestrijding, komt FHB en mycotoxinecontaminatie nog steeds voor. Mycotoxines vormen een probleem voor de gezondheid van mens en dier door blootstelling via voedsel en diervoeding. Omdat het moeilijk, zo niet onmogelijk, is om mycotoxines verderop in de tarweketen te verwijderen, is agronomisch management voornamelijk gericht op het verminderen van de initiële Fusarium spp. infectie in het veld. Hoewel veel onderzoeken hebben aangetoond dat het implementeren van agronomische managementmaatregelen effectief kunnen zijn, is er nauwelijks aandacht besteed aan de daadwerkelijke implementatie ervan door telers. Aangezien effectief mycotoxine management in de keten grotendeels afhangt van de implementatie van agronomische managementmaatregelen door tarwetelers, is het belangrijk om hun gedrag met betrekking tot hun agronomisch management te begrijpen. Het doel van dit proefschrift was om te onderzoeken hoe telers gestimuleerd kunnen worden om hun agronomisch management aan te passen om infectie door Fusarium spp. en mycotoxinecontaminatie in tarwe te verminderen. Deze doelstelling was onderverdeeld in de volgende vier subdoelstellingen:

i) Identificeren van effectieve agronomische maatregelen die telers kunnen nemen om Fusarium spp. infectie en mycotoxines in granen te verminderen.

ii) Onderzoeken welke agronomische maatregelen Nederlandse tarwetelers momenteel nemen tegen Fusarium spp. infectie en mycotoxinecontaminatie en welke karakteristieken van de teler de implementatie van deze maatregelen verklaren.

iii) Onderzoeken van de intentie en daaraan gerelateerde gedragsconstructen en overtuigingen van Nederlandse tarwetelers omtrent het aanpassen van hun toekomstige agronomische management om Fusarium spp. infectie en mycotoxines in tarwe te verminderen.

iv) Analyseren van het effect van verscheidene stimuleringsmaatregelen op de intentie van verschillende type Europese tarwetelers omtrent het aanpassen van hun agronomisch management ter vermindering van Fusarium spp. infectie en mycotoxine contaminatie.

Hoofdstuk 2 is een literatuuroverzicht over Fusarium spp. infectie in granen, zoals gerst en tarwe. Het biedt een solide basis om Fusarium spp. infectie, FHB en mycotoxinecontaminatie te begrijpen. Verschillende effectieve agronomische maatregelen om FHB en mycotoxines te verminderen worden beschreven. Hoofdstuk 3 identificeert welke agronomische maatregelen Nederlandse tarwetelers momenteel toepassen tegen FHB en mycotoxines en gaat na welke karakteristieken van de teler en zijn bedrijf de implementatie van deze maatregelen verklaren. Praktijkgegevens over de toegepaste maatregelen vóór de oogst, zoals de selectie van resistente tarwerassen, het gebruik van fungiciden en vruchtwisseling, zijn samen met informatie omtrent deze karakteristieken verzameld via een online vragenlijst. Om te kunnen verklaren welke karakteristieken de implementatie van agronomische maatregelen verklaren, zijn op de verkregen enquête data Probit modellen toegepast. De 
resultaten toonden aan dat de meeste tarwetelers zes of meer verschillende maatregelen tegen Fusarium spp. infectie en mycotoxinecontaminatie in tarwe namen en dat het gebruik van elke maatregel verband hield met ten minste één andere maatregel. De resultaten gaven echter ook aan dat ongeveer $44 \%$ van de telers hun agronomisch management verder zou kunnen verbeteren om Fusarium spp. infectie en mycotoxinecontaminatie te verminderen als ze een benchmarkbenadering zouden implementeren (bestaande uit een combinatie van fungicidegebruik tijdens de bloei, de selectie van een Fusarium-resistente tarwevariëteit en het toepassen van ploegen of vruchtwisseling). Vijf van de tien geëvalueerde karakteristieken verklaarde significant ( $\mathrm{p}$ $<0,05)$ de implementatie van ten minste één van de acht agronomische preventie- en controlemaatregelen. Deze vijf karakteristieken omvatten: tarwe als belangrijkste inkomensgewas, het gebruik van een beslissingsondersteunend systeem, het opleidingsniveau van de teler, de kennis van de teler over mycotoxines en de mate van risicoaversie van de teler.

Hoofdstuk 4 onderzoekt met de Theory of Planned Behaviour (TPB) de intentie en onderliggende gedragsconstructen en overtuigingen van Nederlandse tarwetelers omtrent het aanpassen van hun toekomstige agronomische management om FHB en mycotoxines in tarwe te verminderen. Via een online vragenlijst zijn gegevens verzameld van 100 Nederlandse tarwetelers. De standaard TPB-analyse werd uitgebreid met een beoordeling van de robuustheid van de resultaten om de statistische validiteit van de analyse op TPB-overtuigingen te verklaren (gericht op de zogenaamde verwachtingwaarde-controversie). Zesenveertig procent van de telers had een positieve intentie om in de komende vijf jaar van management te veranderen. De twee gedragsconstructen die significant verband hielden met deze intentie waren attitude en sociale norm, terwijl de associatie met het waargenomen gedragscontroleconstruct onbeduidend was, wat aangeeft dat telers geen belemmeringen zagen om hun gedrag te veranderen. Relevante attitudes duidden op specifieke eigenschappen van tarwe, namelijk tarwekwaliteit en veiligheidsaspecten (lagere mycotoxine contaminatie). Dit geeft aan dat het versterken van deze overtuigingen - door aan te tonen dat een verandering in het management zal resulteren in een hogere tarweopbrengst, kwantiteit en kwaliteit dan wel lagere mycotoxine niveaus - zal resulteren in een sterkere attitude en vervolgens een grotere intentie om het agronomisch management te veranderen. Interventies om deze opvattingen te versterken dienen bij voorkeur te gaan via de belangrijkste referenties voor sociale normen, namelijk de kopers en de telerscoöperaties.

Hoofdstuk 5 identificeert stimuleringsmaatregelen die Europese telers zouden kunnen aanzetten om hun agronomisch management aan te passen ter vermindering van FHB en mycotoxines in tarwe. Verschillende Bayesiaanse netwerkmodellen zijn ontwikkeld om inzicht te krijgen in de relatie tussen bedrijf- en telerkarakteristieken en de toename van de intentie bij verschillende stimuleringsmaatregelen. Deze studie onderzocht verschillende stimuleringsmaatregelen via een online vragenlijst onder tarwetelers uit Italië, Nederland, Servië en het Verenigd Koninkrijk. Met de ontwikkelde Bayesiaanse netwerkmodellen is ingeschat wat de kans zou zijn dat telers hun huidige managementpraktijken zouden aanpassen. De huidige intentie van Europese tarwetelers om hun agronomische aanpak te wijzigen om Fusarium spp. te verminderen, was positief voor $51 \%$ van de telers, al varieerde dit percentage tussen de vier landen. De resultaten toonden aan dat de meeste telers hun huidige maatregelen zouden aanpassen bij de 
stimuleringsmaatregelen 'extra betaald worden wanneer tarwe een laag mycotoxinegehalte bevat' en bij de stimuleringsmaatregelen 'tarwe wordt gratis getest op de aanwezigheid van mycotoxines'. De mate van stimulering van telers was afhankelijk van de karakteristieken van de bedrijf en de teler, zoals land, gewastype, grootte van bouwland, bodemtype, opleiding en kennis over mycotoxines.

Hoofdstuk 6 geeft een synthese van de resultaten met een focus op mogelijkheden om agronomisch management aan te passen, de stimulering van telers om hun agronomisch management aan te passen en heterogeniteit onder tarwetelers. Daarnaast wordt een reflectie op de toegepaste methoden gegeven, gevolgd door een paragraaf over praktijken beleidsimplicaties en ideeën over toekomstig onderzoek. De belangrijkste conclusies van dit proefschrift worden als volgt samengevat:

- Hoewel het lokale weer en de regio een grote rol spelen bij het optreden van Fusarium spp. infectie, kunnen agronomische managementmaatregelen FHB- en mycotoxinecontaminatie in tarwe verminderen (Hoofdstukken 2 en 3 ).

- De meeste Nederlandse tarwetelers gebruikten ten minste zes agronomische managementmaatregelen tegelijkertijd om Fusarium spp. infectie en mycotoxines in tarwe te verminderen, en $56 \%$ van de telers gebruikte een effectieve set van maatregelen (benchmark benadering) (Hoofdstuk 3 ).

- Telers die geen gebruik maken van de effectieve benchmark maatregelen voor de vermindering van Fusarium spp. infectie en mycotoxinecontaminatie in tarwe (Hoofdstuk 3) kunnen worden gestimuleerd om hun agronomisch management aan te passen bij de stimuleringsmaatregelen 'extra betaald worden wanneer tarwe lage concentraties mycotoxines bevat' (Italiaanse en Nederlandse telers), 'minder betaald worden wanneer tarwe hoge concentraties mycotoxines bevat' (Verenigd Koninkrijk) en 'indien wettelijk vereist' (Servië) (Hoofdstuk 5).

- De karakteristieken van de bedrijf en teler zoals 'tarwe als hoofdgewas', 'het gebruik van een beslissingsondersteunend systeem', 'het opleidingsniveau van de teler', 'kennis van telers over mycotoxines' en 'risicoaversie van de teler' verklaarden de implementatie van een of meer agronomische managementmaatregelen ter vermindering van Fusarium spp. infectie en mycotoxines in tarwe in Nederland (Hoofdstuk 3).

- Telers met tarwe als hoofdgewas passen de benchmarkmaatregelen eerder toe en worden eerder gestimuleerd om hun agronomische managementaanpak aan te passen om Fusarium spp. infectie en mycotoxines in tarwe te verminderen bij de stimuleringsmaatregelen 'gratis mycotoxines testen', 'verzekering voor hoge mycotoxineniveaus' en 'een meerjarig contract met de koper om tarwe te leveren voor een vaste prijs' dan telers met een ander hoofdgewas (Hoofdstukken 3 en 5 ).

- De huidige intentie van Europese tarwetelers om hun agronomische aanpak voor FHB en mycotoxine vermindering te veranderen is positief voor $43 \%$ van de Italiaanse telers, $46 \%$ voor Nederlandse telers, $68 \%$ voor Servische telers en $38 \%$ voor telers uit het Verenigd Koninkrijk (Hoofdstuk 4 en 5).

- De intentie van Nederlandse tarwetelers kan worden vergroot door hun attitude te versterken via attitudeovertuigingen - door aan te tonen dat een verandering in management zal resulteren in een hogere opbrengst, kwantiteit en kwaliteit dan wel lagere mycotoxineniveaus - via hun belangrijkste referenten, namelijk hun afnemers of coöperatie, of bij de stimuleringsmaatregelen 'extra betaald' en 'geen levering' (Hoofdstuk 4 en 5 ). 
Acknowledgements

About the Author Education certificate 


\section{Acknowledgements}

"I sometimes find, and I am sure you know the feeling, that I simply have too many thoughts and memories crammed into my mind."

$\sim$ J.K. Rowling, Harry Potter and the Goblet of Fire

In this section, I tried to distil these thoughts and memories to be able to write down a thank you to everyone who contributed directly and indirectly to the making of this thesis.

First, I would like to thank Alfons Oude Lansink, Ine van der Fels-Klerx and Monique Mourits for giving me the opportunity to obtain my $\mathrm{PhD}$ in the Business Economics Group. Without you, these acknowledgements would never have been written. Thank you for your constructive feedback and inspiring meetings. A special thanks to Monique, as a daily supervisor you were definitely always available. I appreciate that I was always welcome to come talk to you about work or personal life. Also, a sort of thank you for your itchy questions which sometimes frustrated me, but always improved the work in the end.

I would like to thank the BEC colleagues for the fun outings, lunch walks, BBQs, coffee breaks, and (international) sweets and treats. To all my (former) office mates in 6048: thank you for the work discussions and personal conversations. Nurul and Dikky, I greatly enjoyed being your paranymph, it was an honour.

Dear Jamal and Jen, I am happy that you are my paranymphs and that I am yours. Jamal, it was great having you as an office buddy with all the talks about anything. Jen, thank you for all the walking in-depth discussions and proofreading my papers.

I want to thank my (extended) family and friends for being there for me no matter what. For the endless talks, walks and teas. You know what you did for me and I appreciate it. Uke \& Tori, thank you for bringing happiness in my life with your unlimited cuddles and funny behaviour, and for inspiring my cat proposition. A special thanks to my brother Roman, Marjolijn and Koen for being there at my best and worst, always.

Tom, my partner (not-in-crime), thank you for making home feel like home. Colin, you won't remember any of this, but it will be cool (will they use this word in the future?) for you to read it later: Thank you for being in my life.

I want to dedicate this PhD thesis to my parents. Mama and Papa, your unconditional love and support got me here. Thank you for being proud of me, even though I do not always feel it myself.

The past years were turbulent times. I am grateful to have you, my family and friends, in my life and appreciate all of you for your support. 


\section{About the Author}

\section{Curriculum Vitae}

Esmée M. Janssen was born on 11 November 1987 in the Netherlands. After completing high school, she obtained a BSc in Biology at the Utrecht University in 2009. After a gap year working in a toxicology lab and travels abroad, she obtained a MSc in Toxicology \& Environmental Health (Utrecht University) in 2012 and a MSc in Food Safety (Wageningen University) in 2014. During her studies, she worked on several research projects including studying the effect of dioxins in in vitro models, heat resistant spore forming bacteria in the food chain, a dietary risk assessment of masked mycotoxins and performed an internship with subjects as process related toxins and ingredient risk assessments. After her studies Esmée worked as a Junior Researcher Food Safety at RIKILT (currently Wageningen Food Safety Research) on 'Literature research and data collection on hazards in the food chain', co-authoring four papers. In 2016, Esmée started as a $\mathrm{PhD}$ candidate within the Horizon 2020 project MyToolbox: 'the smart way to tackle mycotoxins', at the research group Business Economics (WUR), resulting in three peerreviewed scientific papers. During this time, she also joined the YoungWUR board as chair and member (2016-2018). 


\section{List of publications}

\section{Publications in this thesis}

Janssen, E. M., Mourits, M. C. M., van der Fels-Klerx, H. J., \& Oude Lansink, A. G. J. M. (2020). Factors underlying Dutch farmers' intentions to adapt their agronomic management to reduce Fusarium species infection in wheat. PLOS ONE, 15, e023746o. doi:10.1371/journal.pone.0237460

Janssen, E. M., Mourits, M. C. M., van der Fels-Klerx, H. J., \& Oude Lansink, A. G. J. M. (2019). Pre-harvest measures against Fusarium spp. infection and related mycotoxins implemented by Dutch wheat farmers. Crop Protection, 122, 9-18. doi:10.1016/j.cropro.2019.04.005

Janssen, E. M., Liu, C., \& Van der Fels-Klerx, H. J. (2018). Fusarium infection and trichothecenes in barley and its comparison with wheat. World Mycotoxin Journal, 11(1), 33-46. doi:10.3920/WM]2017.2255

\section{Other scientific publications}

Bouzembrak, Y., Camenzuli, L., Janssen, E., \& van der Fels-Klerx, H. J. (2018). Application of Bayesian Networks in the development of herbs and spices sampling monitoring system. Food Control, 83, 38-44.

doi:10.1016/j.foodcont.2017.04.019

Marvin, H. J. P., Janssen, E. M., Bouzembrak, Y., Hendriksen, P. J. M., \& Staats, M. (2017). Big data in food safety: An overview. Critical Reviews in Food Science and Nutrition, 57(11), 2286-2295. doi:10.1080/10408398.2016.1257481

Marvin, H. J. P., Bouzembrak, Y., Janssen, E. M., van der Zande, M., Murphy, F., Sheehan, B., ... Bouwmeester, H. (2017). Application of Bayesian networks for hazard ranking of nanomaterials to support human health risk assessment. Nanotoxicology, 11(1), 123-133. doi:10.1080/17435390.2016.1278481

Marvin, H. J. P., Bouzembrak, Y., Janssen, E. M., van der Fels-Klerx, H. J., van Asselt, E. D., \& Kleter, G. A. (2016). A holistic approach to food safety risks: Food fraud as an example. Food Research International, 89, 463-470. doi:10.1016/i.foodres.2016.08.028

Janssen, E. M., Sprong, R. C., Wester, P. W., De Boevre, M., \& Mengelers, M. J. B. (2015). Risk assessment of chronic dietary exposure to the conjugated mycotoxin deoxynivalenol-3 $\beta$-glucoside in the Dutch population. World Mycotoxin Journal, 8(5), 561-572. doi:10.3920/WMJ2014.1876 
Esmée M. Janssen

Wageningen School of Social Sciences (WASS)

Completed Training and Supervision Plan

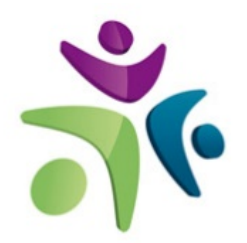

Wageningen School

of Social Sciences

\begin{tabular}{|c|c|c|c|}
\hline Name of the learning activity & Department/Institute & Year & ECTS* \\
\hline \multicolumn{4}{|l|}{ A) Project related competences } \\
\hline Writing Research proposal & BEC, WUR & 2016 & 6 \\
\hline $\begin{array}{l}\text { 'EU wheat farmers' intentions to improve } \\
\text { their mycotoxin management' }\end{array}$ & $\begin{array}{l}\text { First Mycokey International } \\
\text { Conference, Ghent, Belgium }\end{array}$ & 2017 & 1 \\
\hline $\begin{array}{l}\text { 'Farm(er) characteristics driving the } \\
\text { adoption of pre-harvest mycotoxin } \\
\text { management measure' }\end{array}$ & $\begin{array}{l}\text { The World Mycotoxin Forum 10th } \\
\text { Conference, Amsterdam, the } \\
\text { Netherlands }\end{array}$ & 2018 & 1 \\
\hline $\begin{array}{l}\text { 'Pre-harvest mycotoxin management and } \\
\text { associated farm(er) characteristics in the } \\
\text { Netherlands' }\end{array}$ & $\begin{array}{l}\text { WASS PhD Day, Wageningen, the } \\
\text { Netherlands }\end{array}$ & 2018 & 1 \\
\hline $\begin{array}{l}\text { 'Exploration of questionnaire data on } \\
\text { European wheat farmers' mycotoxin }\end{array}$ & $\begin{array}{l}\text { European Association of } \\
\text { Agricultural Economists (EAAE) }\end{array}$ & 2019 & 1 \\
\hline $\begin{array}{l}\text { management by Bayesian Network } \\
\text { modelling' }\end{array}$ & Seminar 168, Uppsala, Sweden & & \\
\hline
\end{tabular}

\section{B) General research related competences}

Introduction course

Advanced Agricultural Business

Economics (BEC-30306)

Risk Analysis and Risk Management in

Agriculture

Questionnaire Design for Social Surveys

$\mathrm{R}$ for Statistical Analysis

Scientific Writing

Efficient Writing Strategies

Reviewing scientific paper

PhD Discussion group
Data Management Planning

$\begin{array}{lll}\text { WASS, WUR } & 2016 & 1 \\ \text { WGS, WUR } & 2016 & 0.4 \\ \text { BEC, WUR } & 2016 & 6 \\ \text { WUR } & 2017 & 2 \\ & & \\ \text { Coursera } & 2016 & 1.5 \\ \begin{array}{l}\text { UU Summer School, Utrecht, the } \\ \text { Netherlands }\end{array} & 2016 & 1.5 \\ \begin{array}{l}\text { WGS, WUR } \\ \text { WGS, WUR }\end{array} & 2016 & 1.8 \\ \text { International Journal of } & 2018 & 1.3 \\ \text { Agronomy } & 2018 & 1 \\ \text { BEC, WUR } & & \\ & 2016 . & 4 \\ & 2020 & \end{array}$

C) Career related competences/personal development

YoungWUR board
Competence Assessment
Project and Time Management
Critical thinking and argumentation
Effective behaviour in your professional
surroundings
Teaching Food Safety Economics

WUR

2016. 4

2018

WGS, WUR

$2017 \quad 0.3$

WGS, WUR

$2017 \quad 1.5$

WGS, WUR $\quad 2018 \quad 0.3$

WGS, WUR $\quad 2018 \quad 1.3$

WUR

2018, 2

Total 39.9

*One credit according to ECTS is on average equivalent to 28 hours of study load 
The work presented in this dissertation was conducted within the framework of the MyToolbox project, a European Union's Horizon 2020 research and innovation programme project under grant agreement No. 678012. Funding was also received from the Ministry of Economic Affairs in the Netherlands, through the Public Private Cooperation (PPS) project "Prediction of mycotoxins in cereals" (project number AFTKI-14225) of the Topsector Agri\&Food. In addition, the Business Economics Group of Wageningen University \& Research contributed to the funding of this dissertation.

Layout and cover: Esmée M. Janssen

Printing: ProefschriftMaken || www.proefschriftmaken.nl 
